This report has been reproduced directly from the best available copy.

Available to DOE and DOE contractors from the Cffice of Scientific and Technical Information, P.O. Box 62, Oak Ridge, TN 37831; prices available from (615) 576-8401, FTS $626-8401$.

Available to the public from the National Technicill Information Service, U.S. Department of Commerce, 5285 Port Royal Rd., Sprisigfield, VA 22161.

This report was prepared as an account of work sponsored by an agency of the United States Government. Neither the United States Goveinment nor any agency thereot, nor any of their employees, makes any warranty, express or implied, or assumes any legal liability or responsibility for the accuracy, completeness, or usefulness of any information, apparatus, product, or process disclosed, or represents that its use would not infringe privately owned rights. Reference herein to any specific commercial product, process, or service by trade name, tradernark, manulacturer, or otherwise, does not necessarily constitute or imply its endorsement, recommendation, or favoring by the United States Government or any agency thereot. The views and opinions of authors expressed herein do not necessarily state or reflect those of the United States Government or any agency thereor. 


\title{
GUIDANCE MANUAL FOR CONDUCTING TECHNOLOGY DEMONSTRATION ACTIVITIES
}

\author{
Robert L. Jolley \\ Michael I. Morris \\ Suman P. N. Singh
}

Date Published - December 1991

Prepared for

Office of Environmental Restoration and Waste Management

(EW 201030 1)

(EW 405020 0)

Prepared by the

OAK RIDGE NATIONAL LABORATORY

Oak Ridge, Tennessee 37831 managed by

MIARTIN MARIETTA ENERGY SYSTEMS, INC.

for the

U.S. DEPA.RTMENT OF ENERGY

under contract DE-AC05-84OR21400 


\section{CONTENTS}

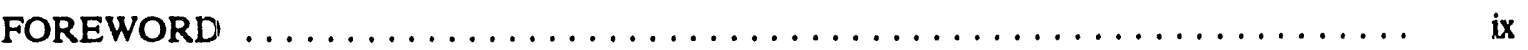

PREFACE AND ACKNOWLEDGMENTS $\ldots \ldots \ldots \ldots \ldots \ldots \ldots \ldots \ldots \ldots \ldots \ldots$

LIST OF ACRONYMS $\ldots \ldots \ldots \ldots \ldots \ldots \ldots \ldots \ldots \ldots \ldots \ldots \ldots \ldots \ldots \ldots \ldots \ldots \ldots \ldots$

EXECUTIVE SUMMARY $\ldots \ldots \ldots \ldots \ldots \ldots \ldots \ldots \ldots \ldots \ldots \ldots \ldots \ldots \ldots \ldots \ldots$

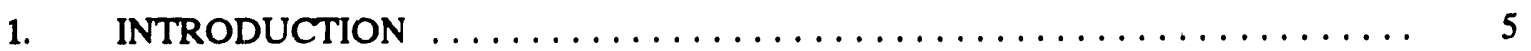

1.1 PURPOSE OF MANUAL $\ldots \ldots \ldots \ldots \ldots \ldots \ldots \ldots \ldots \ldots \ldots$

1.2 REDEMONSTRATION ACTIVITIES $\ldots \ldots \ldots \ldots \ldots \ldots \ldots \ldots . \ldots \ldots$

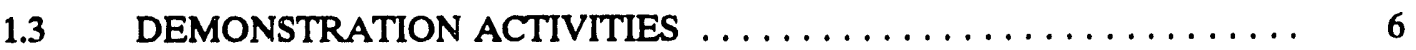

1.4 LOGIC FLOW DIAGRAM $\ldots \ldots \ldots \ldots \ldots \ldots \ldots \ldots \ldots \ldots \ldots$

$1.5 \quad$ SPECIAL CONSIDERATIONS $\ldots \ldots \ldots \ldots \ldots \ldots \ldots \ldots \ldots \ldots$

2. REDEMONSTRATION-PHASE ACTIVITIES $\ldots \ldots \ldots \ldots \ldots \ldots \ldots \ldots \ldots$

2.1 IDENTIFY PROBLEM AREA OR NEED (DOE AND/OR ENERGY SYSTEMS STAFF RESPONSIBLE) . . . . . . . . . . . . 19

2.2 SELECT A PRINCIPAL INVESTIGATOR (DOE AND/OR

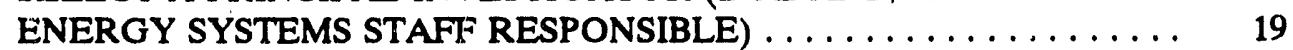

2.3 DEFINE PRINCIPAL INVESTIGATOR RESPONSIBILITIES ....... 20

2.4 SELECT A REDEMONSTRATION MANAGEMENT TEAM (PI RESPONSIBLE FOR SELECTION WITH APPROPRIATE

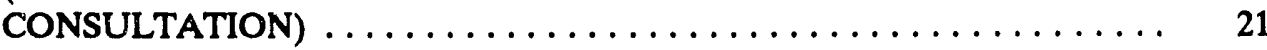

2.5 CHARACTERIZE AND QUANTIFY PROBLEM AREA OR NEED (PI AND REDEMONSTRATION MANAGEMENT TEAM RESPONSIBLE) $\ldots \ldots \ldots \ldots \ldots \ldots \ldots \ldots \ldots$

2.6 IDENTIFY POSSIBLE SOLUTIONS TO PROBLEM AREAS OR NEEDS (PI AND REDEMONSTRATION MANAGEMENI' TEAM RESPONSIBLE) $\ldots \ldots \ldots \ldots \ldots \ldots \ldots \ldots \ldots$

2.7 DEVELOP REDEMONSTRATION LABORATORY BENCHSCALE OR TREATABILITY STUDIES PROPOSAL IF DETERMINED NECESSARY IN SECT. 2.6, ITEM 5 (PI AND REDEMONSTRATION MANAGEMENT TEAM RESPONSIBLE). LABORATORY BENCH-SCALE OR TREATABILITY STUDIES WILL BE INCLUDED IN THE DEMONSTRATION PROPOSAL AS OUTLINED IN SECT. 2.8, ITEM $11 \ldots \ldots \ldots \ldots \ldots \ldots \ldots \ldots \ldots \ldots$

2.8 PREPARE DEMONSTRATION PROPOSAL IF DETERMINED NECESSARY IN SECT. 2.6, ITEM 6 (PI AND REDEMONSTRATION MANAGEMENT TEAM OR THE PM,

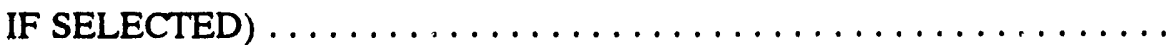


2.9 FACILITATE FINANCIAL ACTIONS AFTER FUNDING APPROVAL (PI OR PM, IF SELECTED, RESPONSIBLE) . . . . . . . 26

2.10 CONTRACT WITH PRIVATE VENDOR, AS DETERMINED IN SECT. 2.9, ITEM 9 (PI AND REDEMONSTRATION MANAGEMENT TEAM OR PM, IF SELECTED,

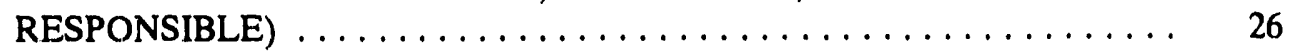

3. ORGANIZATION FOR DEMONSTRATION MANAGEMENT . . . . . . . . . 29

3.1 PROJECT MANAGER (SELECTED BY ENERGY SYSTEMS

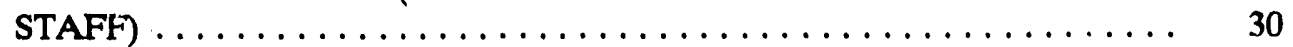

3.2 PROJECT MANAGER RESPONSIBILITIES ................. 30

3.3 DEMONSTRATION MANAGEMENT TEAM (GENERALLY SELECTED BY PM WITH INPUT FROM DOE AND ENERGY

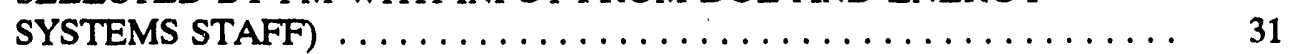

3.4 DEMONSTRATION MANAGEMENT TEAM RESPONSIBILITIES $\ldots \ldots \ldots \ldots \ldots \ldots \ldots \ldots \ldots \ldots \ldots \ldots \ldots \ldots, \ldots \ldots \ldots$ DOE AND ENERGY SYSTEMS MANAGEMENT OVERSIGHT TEAM .

4. MANAGEMENT STEPS LEADING TO DEMONSTRATION

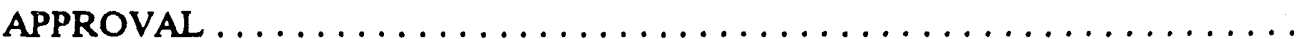

4.1 SCHEDULE AND CONDUCT INITIAL ORGANIZATION

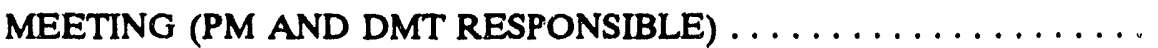

4.2 PREPARE PROJECT DESCRIPTION AND OBTAIN APPROVAL (PM AND DMT RESPONSIBLE). SEE APPENDIX C FOR EXAMPLE PROJECT $\ldots \ldots \ldots \ldots \ldots \ldots \ldots \ldots \ldots \ldots \ldots \ldots, 38$

4.3 PREPARE PROJECT PLAN (PM AND DMT RESPONSIBLE) . . . . . 40

4.4 PREPARE PROJECT DEMONSTRATION COST AND SCHEJULE (PM RESPONSIBLE) $\ldots \ldots \ldots \ldots \ldots \ldots \ldots \ldots \ldots$

4.5 ENSURE COMPLIANCE WITH SITE SECURITY REQUIREMENTS AND COMPLIANCE WITH CLASSIFICATION REQUIREMENTS. (PM AND DMT COORDINATE WITH SITE SECURITY

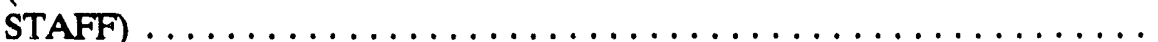
ENSURE COMPLIANCE WITH SITE WASTE MANAGEMENT REQUIREMENTS (PM AND DMT COORDINATE, WITH SITE ENVIRONMENTAL COORDINATOR AS CONSULTANT) $\ldots \ldots \ldots \ldots$ ENSURE DEMONSTRATION REGULATORY COMPLLANCE (PM AND DMT COORDINATE, WITH SITE ENVIRONMENTAL COORDINATOR, SITE ENVIRONMENTAL PROTECTION OFFICERS, AND SITE RCRA COMPLIANCE STAFF AS CONSULTANTS). SEE ALSO SECTS. 4.8 AND 4.9 
4.8 OBTAIN NECESSARY STATE/EPA RESEARCH, DEVELOPMENT AND DEMONSTRATION PERMITS OR TREATABILITY STUDIES EXCLUSIONS (PM AND DMT COORDINATE, WITH SITE RCRA COMPLIANCE STAFF AND PERMITTING SPECIALISTS AS CONSULTANTS) $\ldots \ldots \ldots \ldots \ldots \ldots \ldots$

4.9 ENSURE COMPLIANCE WITH NEPA REQUIREMENT (PM AND DMT RESPONSIBLE FOR COORDINATING WITH SITE NEPA COORDINATOR). THE PREPARATION OF NEPA DOCUMENTATION IS CONSIDERED IN MORE DETAIL IN APPENDIX F

4.10 ENSURE MEETING OF SITE ENVIRONMENTAL

REQUIREMENTS (PM AND DMT RESPONSIBLE, WITH SITE ENVIRONMENTAL COORDINATOR AS CONSULTANT)

4.11 ENSURE SAFE DEMONSTRATION OPERATIONS (PM AND DMT RESPONSIBLE FOR COORDINATION WITH SITE INDUSTRIAL SAFETY STAFF) $\ldots \ldots \ldots \ldots \ldots \ldots \ldots \ldots$

4.12 ENSURE COMPLIANCE WITH OSHA AND SITE INDUSTRIAL HYGIENE STANDARDS (PM AND DMT RESPONSIBLE, WITH SITE INDUSTRLAL HYGIENE STAFF AS

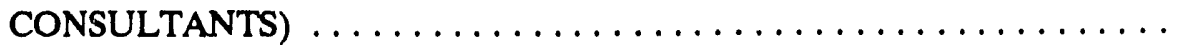

4.13 ENSURE COMPLIANCE WITH HEAL,TH PHYSICS REQUIREMENTS (PM AND DMT TO COORDINATE WITH SITE HEALTH PHYSICS STAFF) $\ldots \ldots \ldots \ldots \ldots \ldots \ldots \ldots \ldots$

4.14 EVALUATE ES\&H STANDARDS OF VENDOR SITES AS NECESSARY (PM AND DMT WITH CWMD AND ENVIRONMENTAL AND SAFETY ACTIVITIES STAFF) ........

4.15 ENSURE COMPLIANCE WITH ENGINEERING POLICIES AND PROCEDURES (PM AND DMT RESPONSIBLE, WITH SITE ENGINEERING STAFF AS CONSULTANTS) $\ldots \ldots \ldots \ldots \ldots \ldots$

4.16 ACCOMPLISH PROCUREMENT ACTIVITIES AS NEEDED (PM AND DMT RESPONSIBLE THROUGH ENERGY SYSTEMS PROCUREMENT/PURCHASING STAFF) $\ldots \ldots \ldots \ldots \ldots \ldots \ldots$

4.17 PREPARE AND ENSURE COMPLIANCE WITH DEMONSTRATION QUALITY ASSURANCE PLAN (PM AND DMT RESPONSIBLE, WITH SITE QA STAFF AS CONSULTANTS) $\ldots \ldots \ldots \ldots \ldots \ldots$

4.18 DEVELOP AND MAINTAIN A RECORD AND DOCUMENTATION FILE (PM AND DMT RESPONSIBLE, WITH SITE QA STAFF

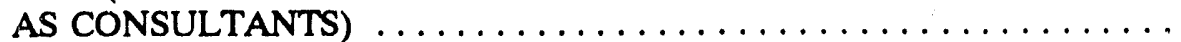

4.19 PERFORM NECESSARY SITE AND/OR WASTE CHARACTERIZATIONS (PM AND DMT' RESPONSIBLE, WITH SITE MANAGEMENT, ANALYTICAL, AND STATISTICAL STAFF AS CONSULTANTS) 
4.20 COORDINATE SITE PREPARATION FOR DEMONSTRATION (PM AND DMT TEAM RESPONSIBLE, ASSISTED BY SITE ENVIRONMENTAL COORDINATOR AND PLANT AND EQUIPMENT STAFF) $\ldots \ldots \ldots \ldots \ldots \ldots \ldots \ldots \ldots \ldots \ldots \ldots, 60$

4.21 CONTROL ACCESS TO DEMONSTRATION SITE (PM AND DMT RESPONSIBLE) $\ldots \ldots \ldots \ldots \ldots \ldots \ldots \ldots \ldots \ldots \ldots \ldots \ldots, 61$

4.22 DEVELOP AND COORDINATE PUBLIC RELATIONS (PR) ACTIVITIES AS NEEDED (PM AND DMT RESPONSIBLE THROUGH ENERGY SYSTEMS PR DEPARTMENT) $\ldots \ldots \ldots \ldots \ldots 61$

4.23 SCHEDULE AND COORDINATE DEMONSTRATION REVIEWS, SENIOR MANAGEMENT READINESS REVIEWS, AND APPROVAL MEETINGS (PM AND DMT RESPONSIBLE)

5. MANAGEMENT STEPS FOR THE CONDUCT OF DEMONSTRATION

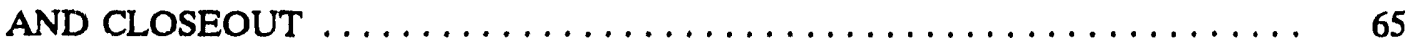

5.1 DEMONSTRATION SETUP (PM AND DMT RESPONSIBLE) ...... 65

5.2 ENSURE DEMONSTRATION READINESS (PM AND

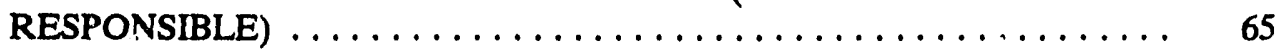

5.3 OPERATE DEMONSTRATION AND COLLECT DATA (PM AND DMT RESPONSIBLE) $\ldots \ldots \ldots \ldots \ldots \ldots \ldots \ldots \ldots \ldots \ldots, 66$

5.4 CLOSEOUT OF DEMONSTRATION (PM AND DMT

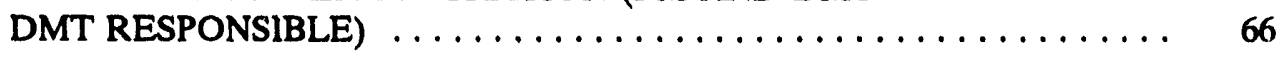

5.5 ANALYZE PROCESS AND OPERATIONS DATA (PM AND DMT RESPONSIBLE) $\ldots \ldots \ldots \ldots \ldots \ldots \ldots \ldots \ldots \ldots \ldots \ldots \ldots . \ldots \ldots$

5.6 PREPARE DEMONSTRATION REPORTS (PM AND DMT RESPONSIBLE)

Appendix A. REQUIREMENTS FOR RESEARCHERS INITIATING TREATABILITY STUDIES ON HAZARDOUS WASTES DEFINED UNDER THE RESOURCE CONSERVATION AND RECOVERY

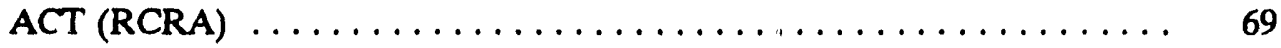

Appendix B. PROCUREMENT OF VENDOR CONTRACT $\ldots \ldots \ldots \ldots \ldots \ldots \ldots \quad 73$

Appendix C. EXAMPLE OF PROJECT DESCRIPTION .............. 75

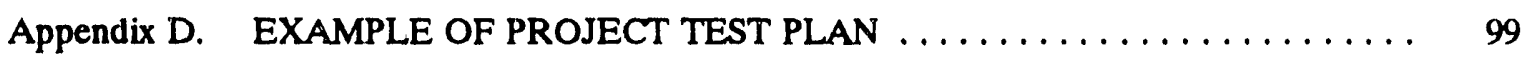

Appendix E. EXAMPLE OF WASTE MANAGEMENT PLAN . . . . . . . . . . 159

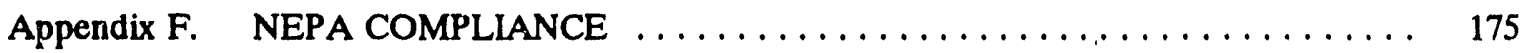

Appendix G. MARTIN MARIETTA ENERGY SYSTEMS, INC., OFF-SITE FACILITIES CONDUCTING TREATABILITY STUDIES

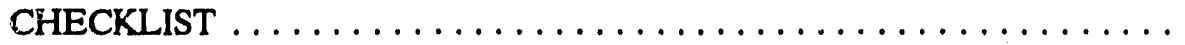


Appendix H. ENVIRONMENTAL REVIEW SUMMARY $\ldots \ldots \ldots \ldots \ldots \ldots \ldots$

Appendix I. EXAMPLE OF SAFETY ASSESSMENT . . . . . . . . . . . . . 189

Appendix J. EXAMPLE OF HEALTH AND SAFETY PLAN $\ldots \ldots \ldots \ldots \ldots \ldots .211$

Appendix K EXAMPLE OF QUALITY ASSURANCE/QUALITY

CONTROL PLAN $\ldots \ldots \ldots \ldots \ldots \ldots \ldots \ldots \ldots \ldots \ldots \ldots \ldots \ldots \ldots$

Appendix L. EXAMPLE OF READINESS REVIEW PLAN $\ldots \ldots \ldots \ldots \ldots \ldots \ldots$ 


\section{FOREWORD}




\section{FOREWORD}

The conduct of successful technology demonstrations is essential to achieving the objectives established by the U. S. Department of Energy (DOE) for the remediation of contaminated sites and the management of waste generated from past, present, and future operations. It is equally essential that these technology demonstrations be conducted in a manner that is strictly adherent to pertinent regulatory requirements and policies and with full recognition of the liabilities associated with access to hazardous waste sites. Thorough planning is, therefore, paramount to the successful conduct of a technology demonstration; the identification of all requirements, be they technical, financial, or legal, is a necessary component of a sound technology demonstration plan.

In recognition of the importance of detailed planning with regard to both the demonstration of emerging technologies and their eventual implementation, the Office of Waste Research and Development Programs and the Enviionmental Restoration Division at Martin Marietta Energy Systems, Inc., have teamed to produce this "Guidance Manual for Conducting Technology Demonstration Activities." The purpose of this manual is to provide personnel who are planning and/or conducting technical demonstrations with a guide that describes the actions necessary to plan, implement, and conclude a technical demonstration in a manner that will maximize the benefits. Thu document can also serve as a useful resource to supporting organizations that are likewise essential to the successful conduct of technology demonstrations by providing them with information on the scope of the requirements that must be met.

If the innovative technologies that are sorely needed to effectively and econoinically achieve the DOE objectives are to be implemented, proper planning, execution, and reporting of the associated demonstrations are essential not only for performance assessment but also to satisfy regulatory acceptance requirements. This manual will help ensure that this happens.

A. P. Malinauskas, Director Waste Research and Development Programs
David W. Swindle, Director Technical Integration

Environmental Restoration Division 


\section{PREFACE AND ACKNOWLEDGMENTS}

This document is intended to be a "living" document, thus suggesting this flexible looseleaf-notebook format. It will be updated with increasing experience and must be modified in accordance with current regulations and work practices. Candidate changes and contributions by users are invited and will improve the efficacy of this guidanze manual.

The impetus to use demonstrations for the evaluation of waste technologies stems from the insightful DOE/OR leadership of Bill Bibb and Bill Adams with the able assistance of Bob Sleeman and Mike Jugan. Subsequently, the need for and use of technology demonstrations in the waste management and environmental restoration areas have received increasing national attention.

This demonstration guidance manual is based upon the experience of several Energy Systems employees in addition to those of the authors. Because this manual is the result of collective experience, we may inadvertently err in not listing individuals who have made important contributions. We hope such oversights, if any, are minimal. Especially noteworthy are the contributions of John Kennerly and Paul Hollenbeck, who, under the tutelage of Richard Genung, pioneered in waste technology demonstration management; Allen Croff for budgetary and management guidance; Helen Braunstein for NEPA compliance guidance; Nancy Dailey for RCRA treatability studies guidance; Lance Mezga for Energy Systems offsite facilities checklist and environmental review forms; and Bill Brooke for QA/QC guidance.

Energy Systems sponsors for this guidance manual were Dave Swindle, Environmental Restoration Division, and Tony Malinauskas, Waste Research and Development Program. Important critical reviews were completed by Jack Watson, Phil McGinnis, Waldo Golliher, Lynn Jones, Davis Milan, Larry Long, Jim Bradbury, Tommy Bowers, C. H. "Pete" Peterson, J. M. Eaton, and Mike Stiefel. Waldo Golliher's critical review was especially insightful and important with respect to operational reviews and management procedures.

The importance of typing, editing, and secretarial assistance can not be overemphasized. We are deeply appreciative of the efforts of Janice Woodard, Debbie Brown, Linda Ficlds, and John Nunn for preparing this manual for publication and Donna Reichle for invaluable editing assistance. 


\section{LIST OF ACRONYMS}

AcDM

ADS

ALARA

CWMD

CXD

D\&D

DMT

DOD

DOE

EA

EAM

EIS

Energy Systems

EPA

ER

ERD

ES\&H

FONSI

FSAR

GDP

HQ

NEPA

NPDES

ORNL

OR

ORP

OSHA

OTD
Activities Description Memorandum

Activity Data Sheet

As Low as Reasonably Achievable

Central Waste Management Division

Categorical Exclusion Determination

Decontamination and Decommissioning

Demonstration Management Team

Department of Defense

Department of Energy

Environmental Assessment

Environmental ALARA Memorandum

Environmental Impact Statement

Martin Marietta Energy Systems, Inc.

Environmental Protection Agency

Environmental Restoration

Environmental Restoration Division

Environmental, Safety, and Health

Finding of No Significant Impact

Final Safety Assessment Report

Gaseous Diffusion Plant

Headquarters

National Environmental Policy Act

National Pollutant Discharge Elimination System

Oak Ridge National Laboratory

Oak Ridge Field Office

Operational Readiness Process

Occupational Safeguard Health Administration

Office of Technology Development 
PI

PM

PR

QA

QC

R\&D

RCRA

RD\&D

RDDT\&E

RFP

ROD

RRB

SARA

sow

TDHE

TTP

WM

WR\&D
Principal Investigator

Project Manager

Public Relations

Quality Assurance

Quality Control

Research and Development

Resource Conservation and Recovery Act

Research, Development, and Demonstration

Research, Development, Demonstration, Testing and Evaluation

Request for Proposal

Record of Decision

Readiness Review Board

Superfund Amendments and Reauthorization Act of 1986

Statement of Work

Tennessee Department of Health and Environment

Technical Task Plan

Waste Management

Waste Research and Development 


\section{EXECUTTVE SUMMARY}

This demonstration guidance manual has been prepared to assist Martin Marietta Energy Systems, Inc. (Energy Systems), staff in conducting demonstrations. It is prepared in checklist style to facilitate its use and assumes that Energy Systems personnel have project management responsibility. In andition to a detailed step-by-step listing of procedural considerations, a general checklist, logic flow diagram, and several examples of necessary plans are included to assist the user in developing an understanding of the many complex activities required to manage technology demonstrations.

Demonstrations are pilot-scale or field-scale applications of often innovative technologies to determine the commercial viability of the technologies to perform the $\mathrm{i}_{\mathrm{i}}$ - designed function. Demonstrations are generally conducted on well-defined problems for winich cxisting technologies or processes are less than satisfactory in terms of effectiveness, cost, and/or regulatory compliance. Critically important issues in demonstration management include, but are not limited to, such factors as communications with line and matrix management and with the U. S. Department of Energy (DOE) and Energy Systems staff responsible for management oversight, budgetary and schedule requirements, regulatory compliance, and safety.

Although this document assumes that all predemonstration activities related to the project have been completed and that the necessary funds and initial approvals for the demonstration have been secured before commencement of demonstration activities, guidance on accomplishing the predemonstration activities is given in Sect. 2. Predemonstration activities would include, but not be limited to, identification of the need for the demonstration, commitment of necessary funds and resources, and definition of the objective, scope, and goals of the demonstration.

Guidance for conducting demonstration activities is presented in Sect. 3, Organization for Demonstration Management; Sect. 4, Management Steps Leading to Demonstration Approval; and Sect. 5, Management Steps for the Conduct of Demonstrations and Closeouts. Appendices include detailed discussions of the requirements for treatability studies under the Resource Conservation and Recovery Act (RCRA), National Environmental Policy Act (NEPA) compliance, and procurement of vendor contracts. The appendices also include 
examples of a project description, project plan, vaste management plan, quality assurance/quality control plan, an environmental review, a safety assessment, and a checklist for offsite facilities conducting ireatability studies.

The demonstration Project Manager (PM) is responsible for organization, setup, conduction, and closeout of the demonstration. The PM may be assisted by a demonstration management team (DMT). Management complexity dictates the use of the team concept for demonstration management. The PM must have the assistance of many specialists to ensure regulatory compliance along with safe and cost-effective demonstration operation. Therefore, the DMT concept involves specialists on an as-needed (ad hoc) basis to ensure authoritative and appropriate action (e.g., regulatory compliance, permitting, quality assurance, procurement, legal, environmental, safety, operations). Management oversight consists of demonstration readiness reviews, operation approval by the management oversight tean, and final demonstration approval by the DOE Site Manager and the appropriate DOE/Oak Ridge Operatious (ORO) Program Manager or representative. Thus, senior management involvement consists of two tiers or levels of management: (1) oversight to ensure demonstration operational readiness and (2) approval to permit the demonstration operation. It is Energy Systems policy (GP-24) to conduct formal operational readiness processes (ORP), including focused readiness reviews, to ensure that a given activity is ready to proceed to the next increment of work by identifying and minimizing the risks associated with mission success. It is the responsibility of the PM to ensure that the ORP is considered and the decision basis documented for startup of significant, new, or modified, activities including technology demonstration. The ORP applies to all Energy Systems facilities, operations, processes, systems, construction efforts, and projects. ORP is a management tool that establishes and verifies the status and degree of readiness of an activity to start up or to proceed with the next phase of 'work. ORP complements other quality assurance (QA), environmental safety and health $(E S \& H)$, engineering, and management policies and procedures.

Demonstrations include a complex array of activities, some of which will occur sequentially, but many of which most likely will take place at the same time. Most of the parallel activities occur at the front end; th.se consist principally of securing necessary permits, ensuring regulatory compliance [e.g., an Environmental Protection Agency (EPA) environmental assessment must be conducted, and supporting NEPA documentation must be 
prepared], meeting site ES\&H standards, and obtaining Energy Systems and DOE approvals. After approval, the actual conduct and completion of the demonstration consist of a series of sequential management steps.

A comprehensive Project Plan, including budget and task schedule, is the principal tool used by the PM to properly conduct the demonstration. This includes compliance with all applicable federal, state, and local regulations, DOE orders, and Encrgy Systems policies and procedures. The Project Plan is expected to provide the basis for coordination of all parties involved directly in performing the demonstration and keep those informed who have an interest in how the demonstration is proceeding. The budget and schedule are used to track progress on the project. 


\section{GUIDANCE MANUAL FOR CONDUCTING TECHNOLOGY DEMONSTRATION ACTIVITIES}

Robert L. Jolley, Michael I. Morris, Suman P. N. Singh

\section{INTRODUCTION}

\subsection{PURPOSE OF MANUAL}

This demonsiration guidance manual has been prepared to assist Martin Marietta Energy Systems, Inc. (Energy Systems), staff in conducting demonstrations. It is prepared in checklist style to facilitate its use and assumes that Energy Systems personnel have project management responsibility. (See General Checklist.)

\subsection{PREDEMONSTRATION ACTTVTTIES}

Predemonstration activities would inclute, but not be limited to, the following:

1. identification of the need for the demonstration;

2. commitment of necessary funds and resources; and

3. definition of the objective, scope, and the goals of the demonstration.

Predemonstration activities are generally conducted by a Principal Investigator (PI), who may later, after the need for a demonstration is determined, be selected as the demonstration Project Manager (PM). Guidance or accomplishing the predemonstration activities is given in Sect. 2. The PM would be responsible for the following important predemonstration activities: preparation of the demonstration proposal, coordination of the funding activities, and development of contracts, if required (Sects. 2.8-2.11).

This document assurnes that all predemonstration activities related to the project have been completed and that the necessary funds and initial approvals for the demonstration have been secured before commencement of demonstration activities (Sects. 3-5). 


\subsection{DEMONSTRATION ACTIVTTIES}

Demonstrations are pilot-scale or field-scale applications of often innovative technologies to determine the commercial viability of the technologies to perform their designed function. Demonstrations are generally conducted on well-defined problems for which existing technologies or processes are less than satisfactory in terms of effectiveness, cost, and/or regulatory compliance.

By their very nature, demonstrations are more complex than research \& development (R\&D) activities but less complex than full-scale implementation, in terms not only of engineering scale but also in terms of support logistics, management, organization, and regulatory compliance. Demonstration complexity can be a function of many factors, such as size, location, equipment, and waste stream. Critically important issues in demonstration management include, but are not limited to, such factors as communications with line and matrix management and with U. S. Department of Energy (DOE) and Energy Systems staff responsible for management oversight, budgetary and schedule requirements, regulatory compliance, and safety.

Demonstration Team. The PM is responsible for organization, setup, conduction, and closeout of the demonstration. The PM may be assisted by a demonstration management team (DMT). Management complexity dictates the use of the team concept for demonstration management. The PM must have the assistance of many specialists to ensure regulatory compliance along with safe and cost-effective demonstration operation. Therefore, the DMT concept involves specialists on an as-needed (ad hoc) basis to ensure authoritative and appropriate action (e.g., regulatory compliance, permitting, quality assurance, procurement, legal, environmental, safety, operations).

Demonstration Objectives. Because a demonstration is a means of testing or evaluating an often innovative technology, equipment, or methodology, it consequently may or may not achieve set treatment goals. Nevertheless, if performed according to reasonable statistical experimental designs, and if the conclusions reached are statistically valid, a demonstration will achieve its objective (i.e., evaluation of the process, equipment, or technology). A demonstration is not R\&D. However, preliminary R\&D at the bench scale (e.g., treatability studies) may be necessary to scope demonstration efforts and may, in certain circumstances, be considered an integral part of the total demonstration package. 
Demonstration Categories. Although this document pertains to DOE demonstrations managed by Energy Systems staff and located on DOE sites or on vendor sites (i.e., off-site), other categories of demonstrations also exist. For example, demonstrations may be categorized according to the performer or technology owner, the demonstration site, and funding source. Demonstration performers or technology owners may include Energy Systems, federal agencies [e.g., Department of Defense (DOD)], universities, private vendors [in response to a Request for Proposal (RFP)], or any combination thereof. Demonstration sites may include DOE or other federal agency sites, university or research institute sites, and private vendor sites. Funding sources may include governmental, academic, Energy Systems, and private vendor sources. Consequently, many possible permutations and combinations of this three-dimensional matrix may occur. However, the basic principles for conducting all demonstrations are essentially the same.

Demonstration Sites. The demonstration site is the location where the demonstration is performed. It may or may not correspond to the waste generation site.

\subsection{LOGIC FLOW DIAGRAM}

A simplified logic flow diagram for conducting technology demonstrations is given in Fig. 1.

\subsection{SPECIAL CONSIDERATIONS}

Because of Energy Systems' contractual relationship with DOE, mention is made of special factors that must be considered in technology demonstration activities.

Technology demonstrations involving classified waste streams and classified waste burials at inactive sites would be considered on a case-by-case basis. Specific consideration must be given and approvals obtained before classified materials may be involved in technology demonstrations. Wastes and materials are generally classified in accordance with national security requirements and should be dealt with accordingly.

Equipment involved in technology demonstrations can not be released from demonstration sites until it is released by appropriate management staff after inspection by the site's health physics and industrial hygiene staffs. 
ORNL DWG 91A-106

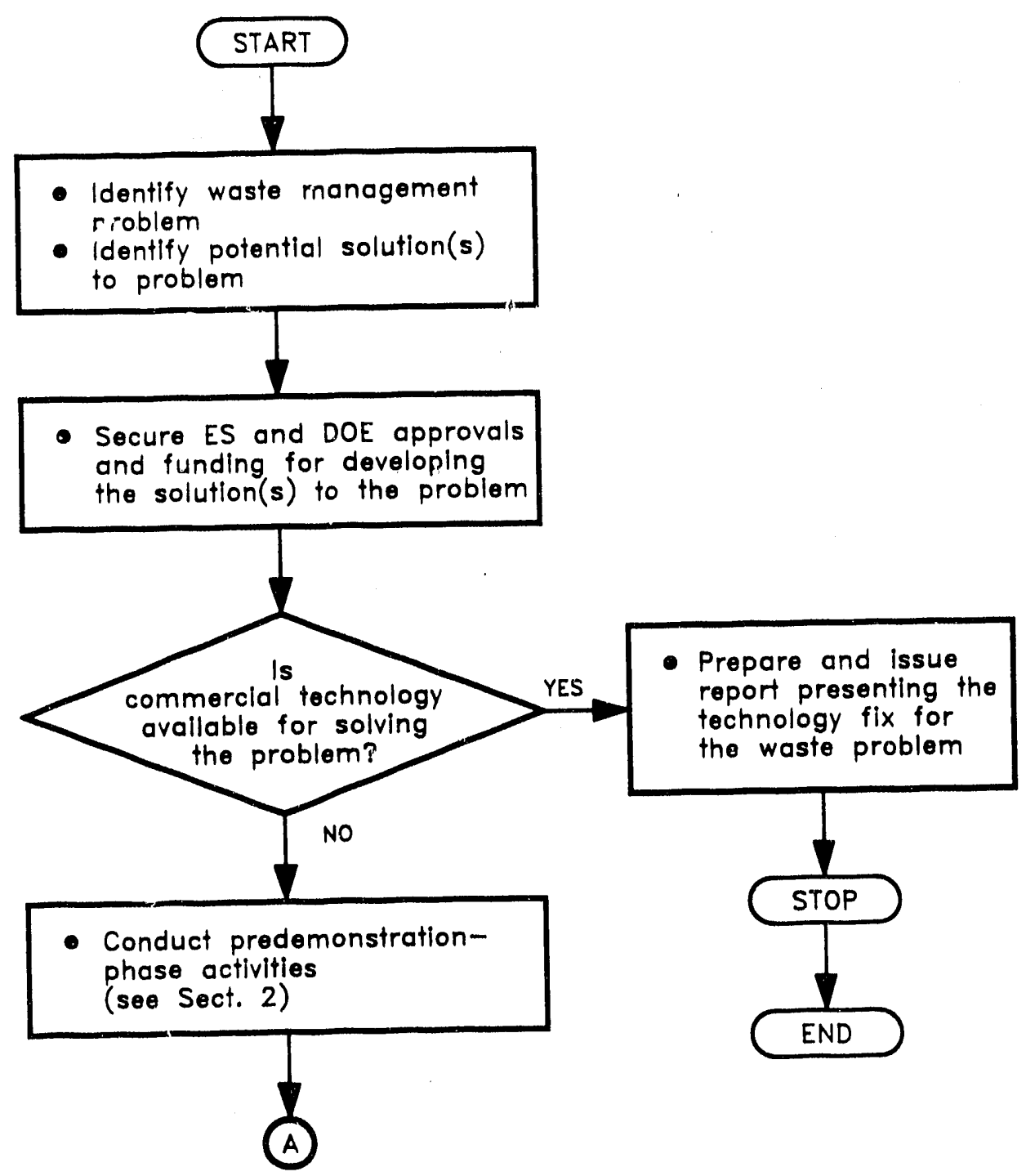

Fig. 1. Simplified logic flow diagram for conducting technology demonstrations. 


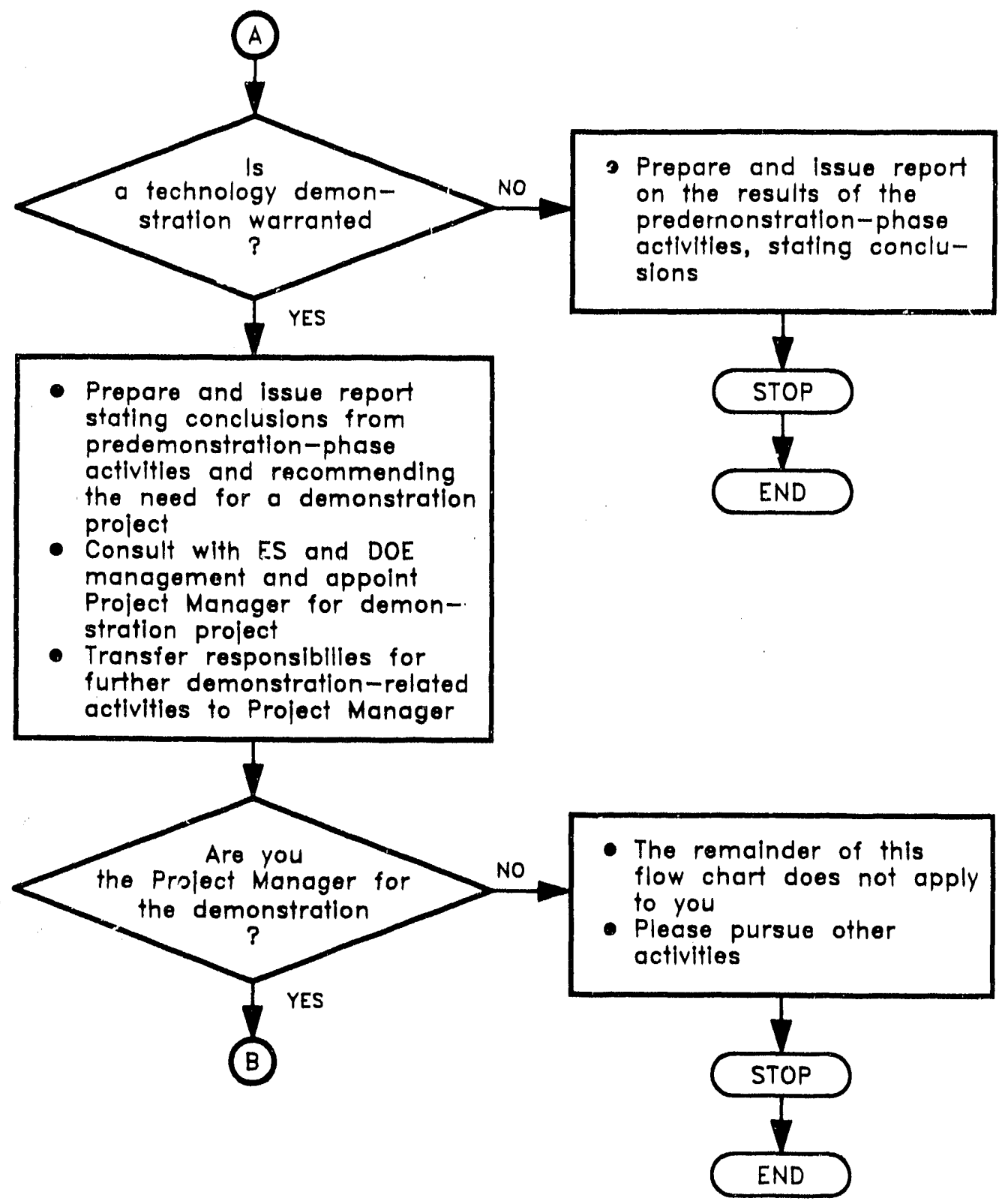

Fig. 1. (continued)

Fig. 1. (continued) 


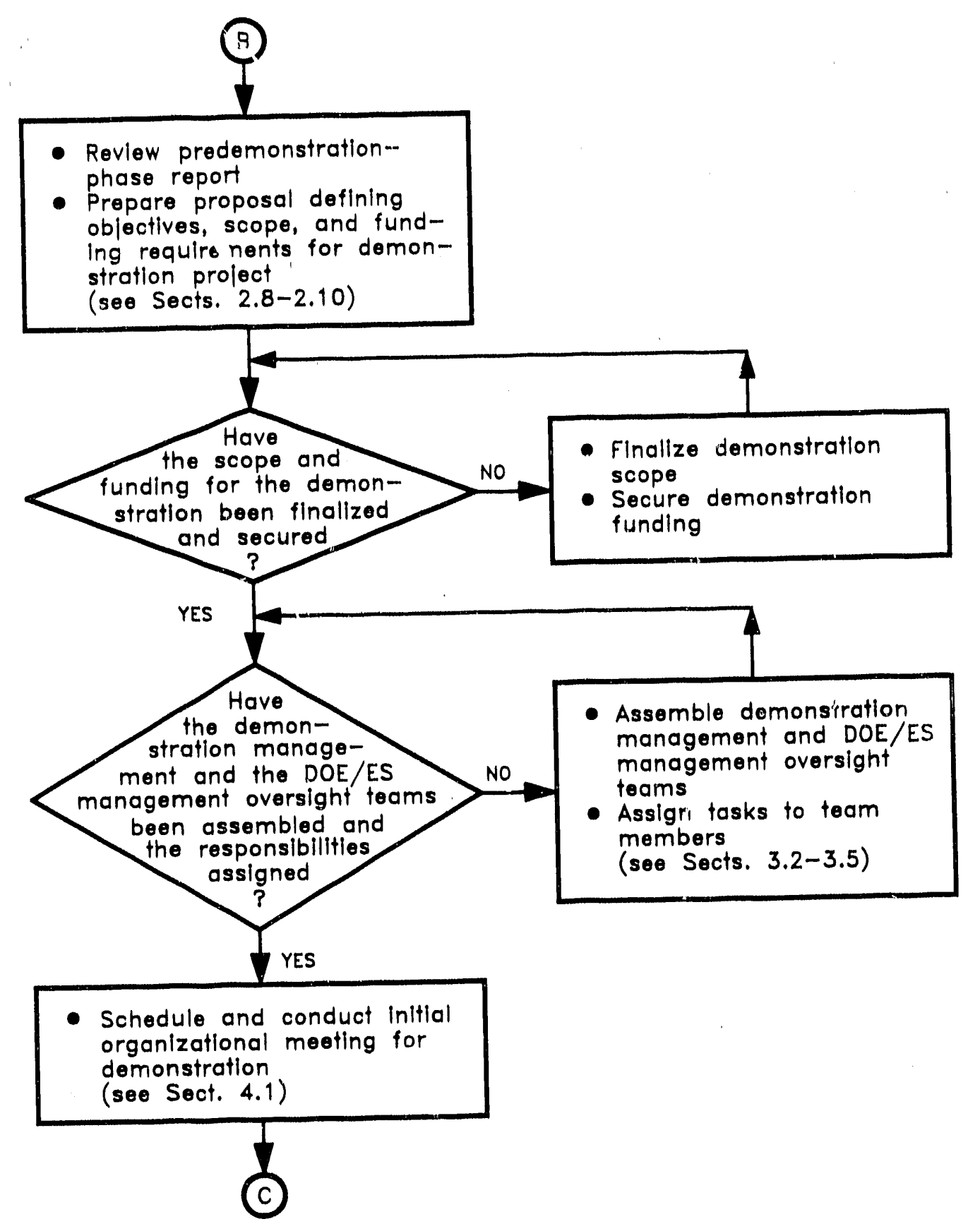

Fig. 1. (continued) 
ORNL DWG 91A-109
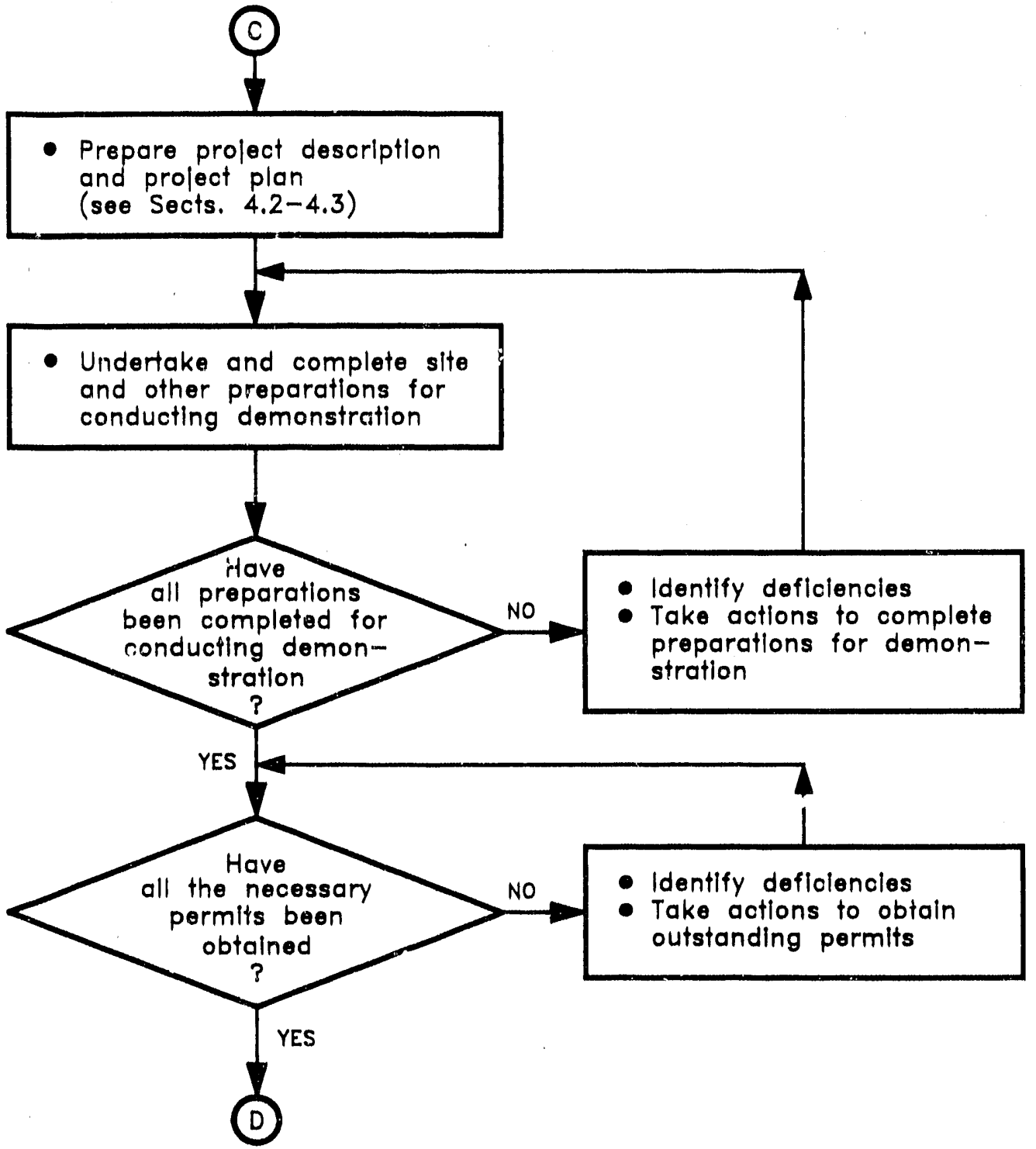

Fig. 1. (continued) 
ORNL DWG $91 A-110$

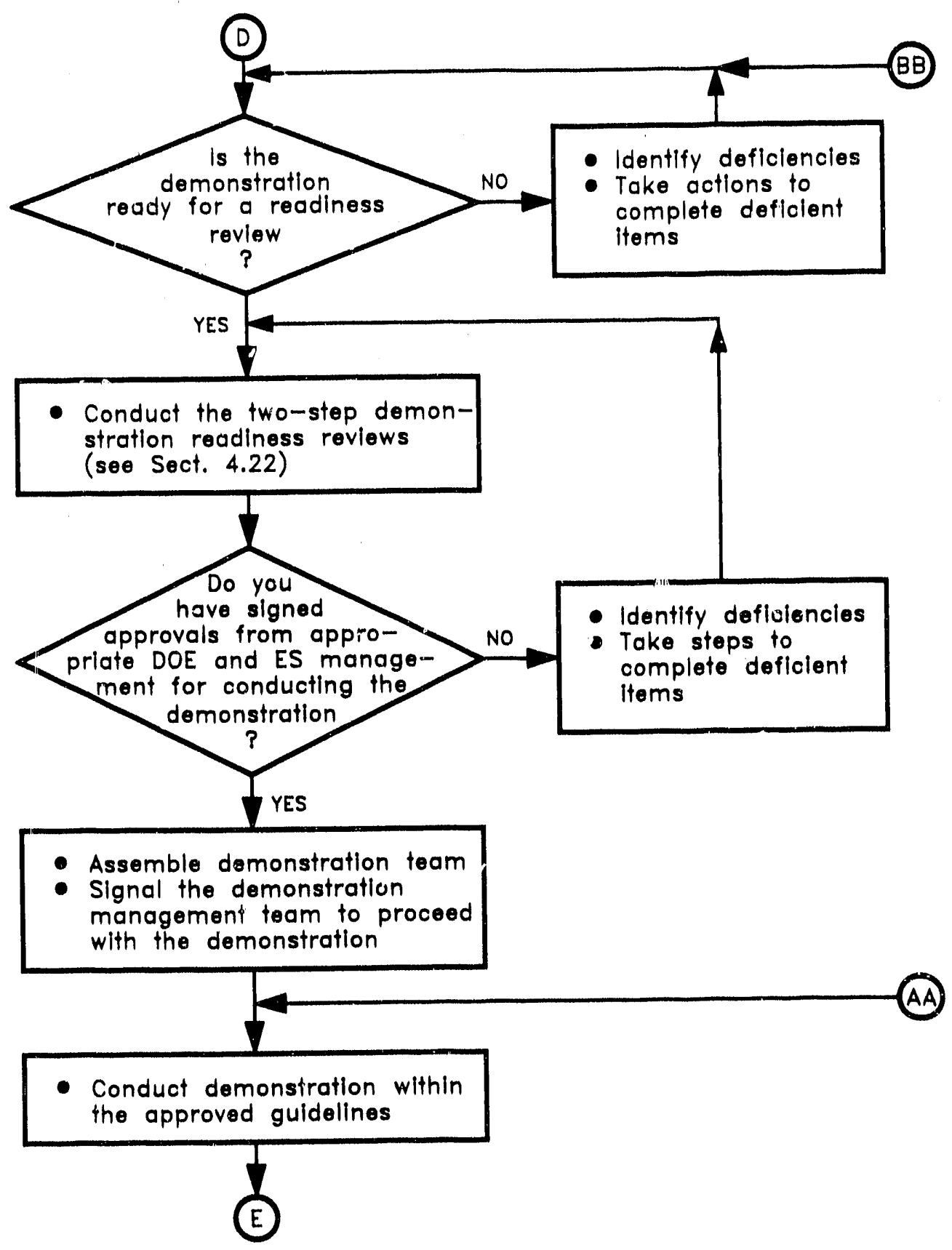

Fig. 1. (continued) 
ORNL DWO 91A-111

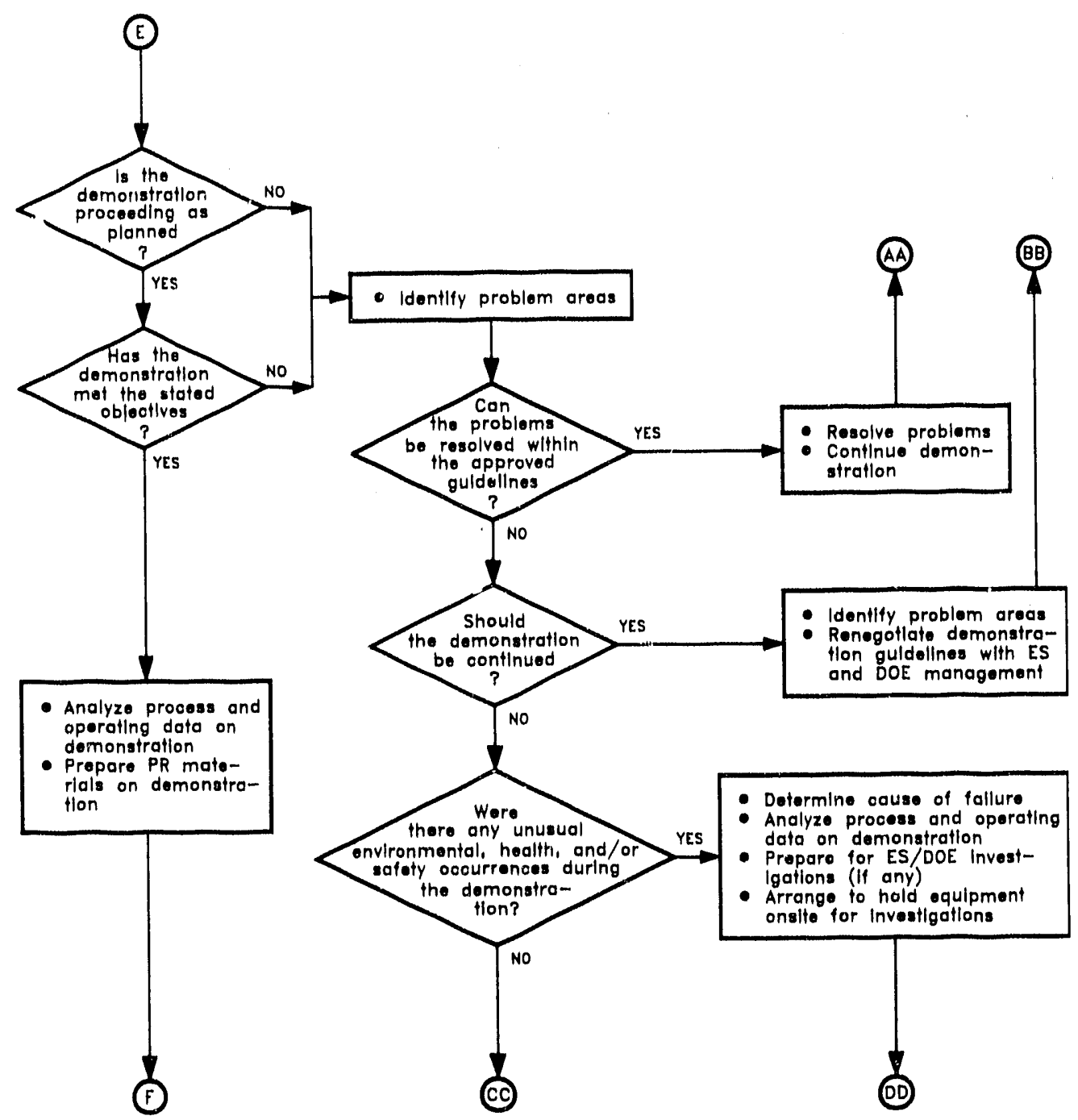

Fig. 1. (continued) 


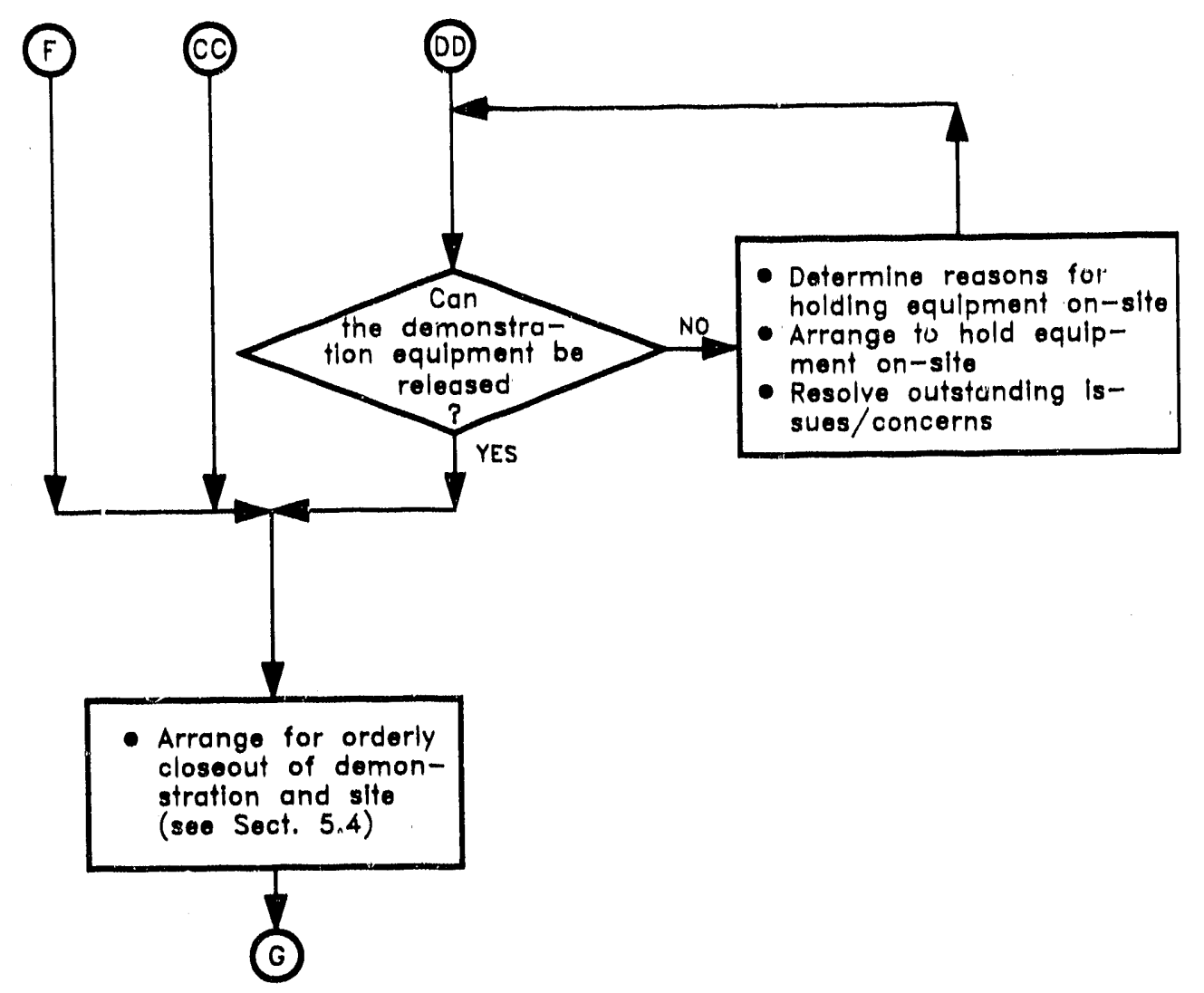

Fig. 1. (continued) 


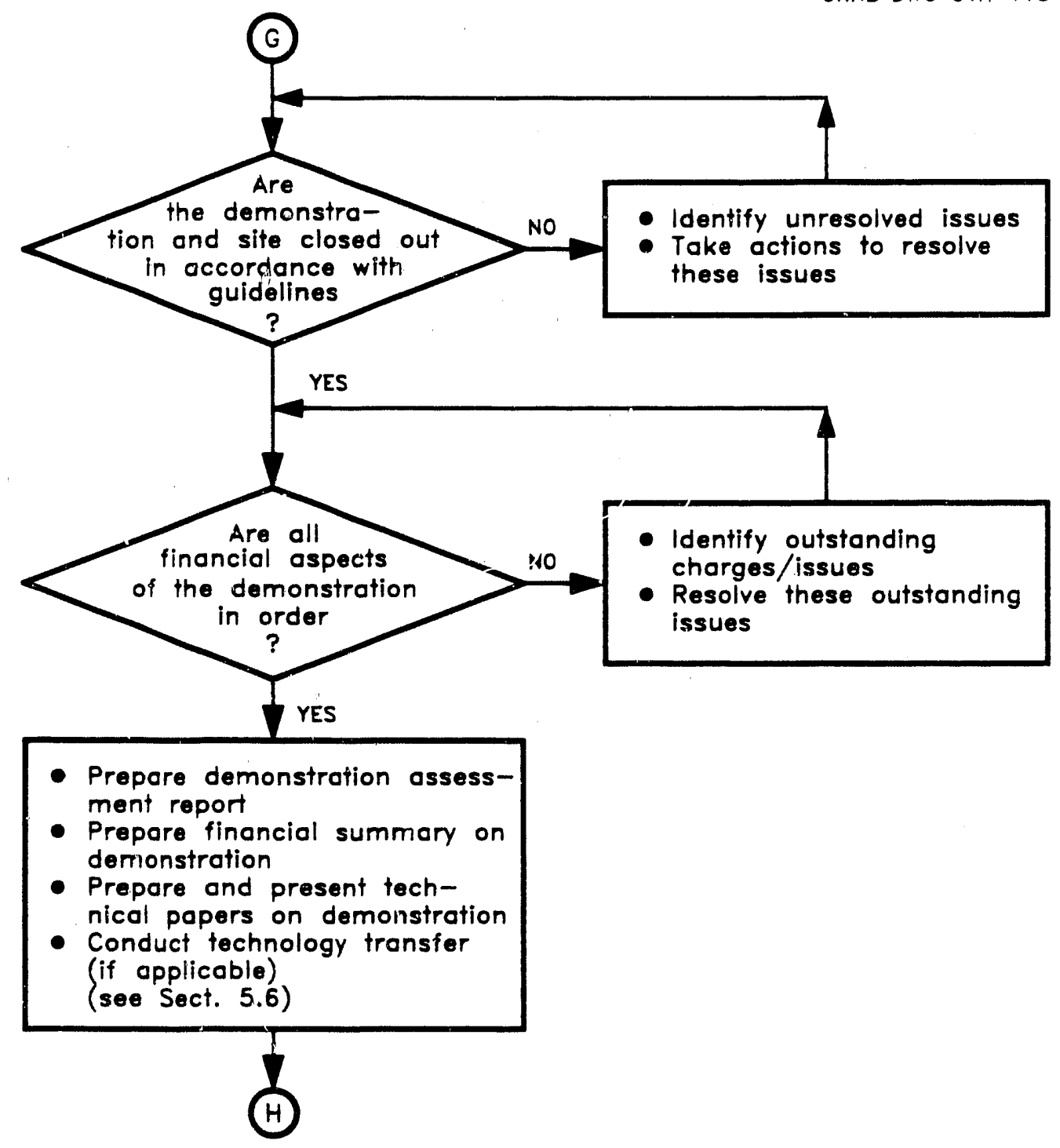

Fig. 1. (continued) 
ORNL DWG 91A-114

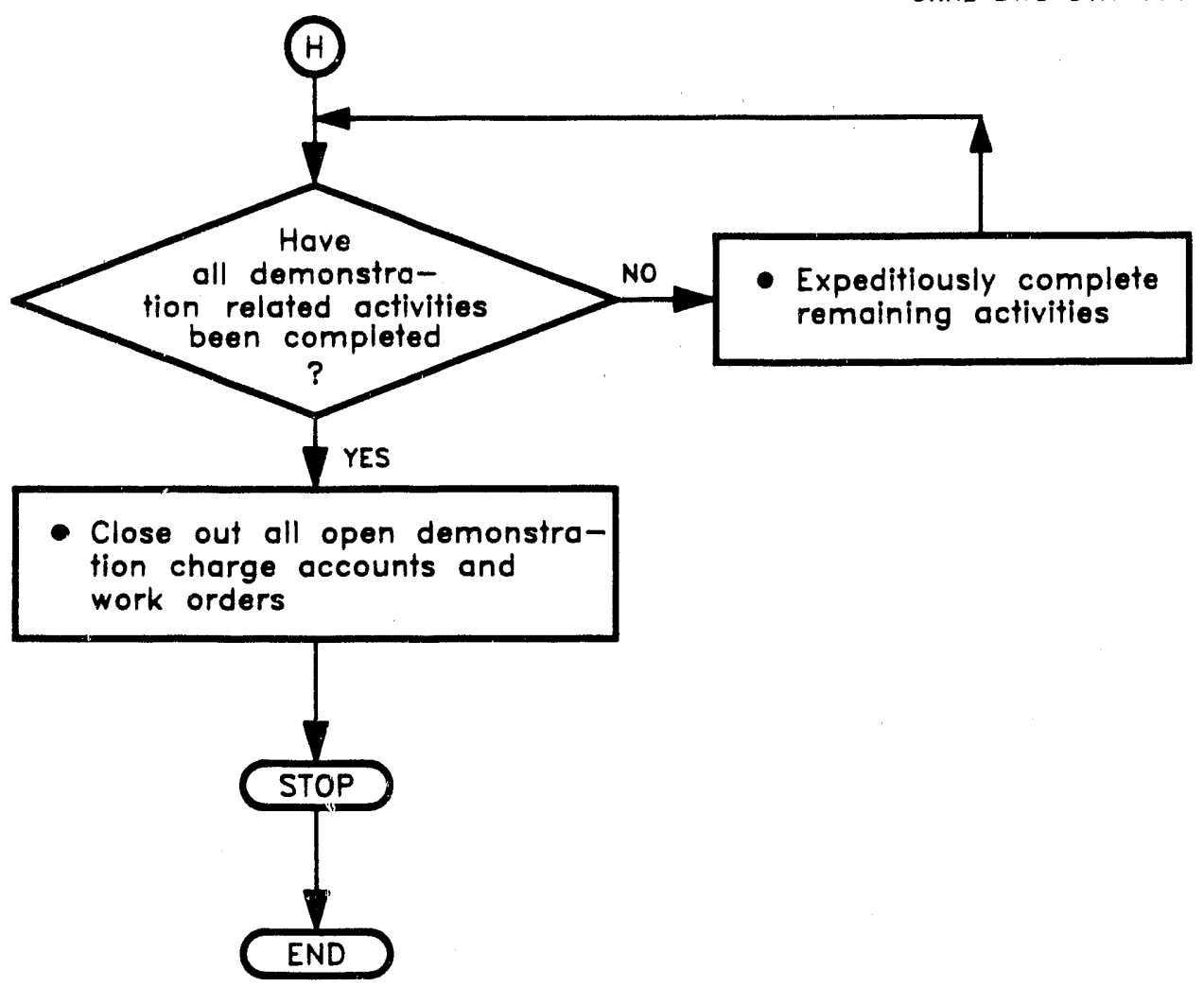

Fig. 1. (concluded) 
The treatment and disposal of secondary wastes generated during technology demonstrations must be included appropriately in the planning process.

Technology demonstrations conducted at sites that are either scheduled for interim corrective measures or are in the process of active remediation must comply with the specific regulatory requirements for the site. Consequently, specific approvals for the demonstrations may be required from the regulatory bodies [e.g., Environmental Protection Agency (EPA) and state regulatory bodies)] in addition to Energy Systems and DOE/Oak Ridge Operations (ORO) approvals.

Demonstrations conducted by private vendors require specific contractual consideration for liability as well as rules and regulations for conducting the demonstration. In general, issues of legal liability need to be considered on a case-by-case basis with the liability issues defined in the contract. 


\section{PREDEMONSTRATION-PHASE ACTTVITIES}

\section{IDENTIFY PROBLEM AREA OR NEED (DOE AND/OR ENERGY SYSTEMS STAFF RESPONSIBLE)}

Waste management problem areas are usually identified in response to a regulatory compliance or of a perceived environmental, health, and safety issue. The problem area may be specific to a particular waste or site or generic and national in scope. The problem identification may occur at any management level and may include, but not be limited to, the following entities:

1. Energy Systems site problem area or need;
(a) DOE Site Manager
(b) Energy Systems management

(1) Site waste management and environmental restoration staff

(2) Central Waste Management Division (CWMD) and Environmental Restoration Division (ERD) staff

2. DOE/OR problem area or need;

3. national (e.g., DOE/HQ, EPA, DOD) problem area or need;

4. other customer with problem areas or needs; and

5. Energy Systems division, program, or group staff.

\section{SELECT A PRINCIPAL INVESTIGATOR (DOE AND/OR ENERGY SYSTEMS STAFF RESPONSIBLE)}

After the problem identification, a PI is selected by the sponsoring Energy Systems division management and the Waste R\&D (WR\&D) program. The PI typically is the person who researches the need and proposes the technical approach to solve the need. The PI is responsible for problem definition and the predemonstration phase. The PI may enlist the support of a predemonstration management team that reports to him/her for its assignment in this activity. Generally, the PI is selected by Energy Systems line management after consultation with other Energy Systems division and program matrix management staff. The 
PI may be selected as the demonsiration Program Manager after the need for a demonstration is determined.

\subsection{DEFINE PRINCIPAL INVESTIGATOR RESPONSIBILITIES}

The PI has the principal responsibilities for defining the problem area and completing the predemonstration phase. The PI's responsibilities include:

1. Scope problem area or need. No extensive project work is to be started without securing the necessary DOE/OR and Energy Systems approvals and appropriate funding.

2. Obtain input from or communicate with DOE.
(a) DOE/OR Manager
(b) DOE/OR WM or ER representatives
(c) DOE Site Manager

3. Obtain inpur from Energy Systems management.
(a) Site Environmental Coordinator
(b) Site representatives
(c) Division, program, or group
(d) WR\&D Demonstration Coordinator

4. Initiate project and accomplish predemonstration phase.

5. Initiate NEPA determination requirements.

6. Select and coordinate predemonstration management team activities on an ad hoc basis.

7. Develop communications with DOE Site Manager; DOE/OR representatives; Energy Systems management oversight staff, line management, and matrix or program management; WR\&D Program Demonstration Coordinator; and Site Demonstration Manager, Environmental Coordinator, Waste Manager, ER Manager and line and matrix or program management.

8. Obtain necessary DOE and Energy Systems approvals.

9. Comply with budget constraints.

10. Meet deliverables schedule. 
11. Ensure compliance with regulations (e.g., permits and compliance therewith; waste treatment, storage, or disposal; safety).

12. Use good management practices.

13. To assist him/her in this activity, the PI may select and use a predemonstration management team.

\section{SELECT A PREDEMONSTRATION MANAGEMENT TEAM (PI RESPONSIBLE FOR SELECTION WITH APPROPRIATE CONSULTATION)}

The PI may select a predemonstration management team to assist in problem definition and accomplishment of the predemonstration phase. The composition of the team will vary depending upon the nature and complexity of the predemonstration effort. For example, if the predemonstration phase includes development of an RFP and a subsequent contract with a private vendor, Procurement/Purchasing staff members will form an important component of the team. Similarly, if bench-scale or treatability studies are necessary, the appropriate scientists and engineers will become important members of the team. Team members may include specialists that are consulted on an ad hoc basis. In addition to the PI, the team members may include the following:

1. other engineers/scientists/managers with special technical capabilities in certain specific disciplines;

2. . Energy Systems site staff;

(a) Site Environmental Coordinator

(b) Sites Waste Manager

(c) Site ER Manager

3. Procurement/Purchasing staff;

4. Legal staff;

5. permitting specialists;

6. NEPA specialists; and

7. Demonstration Coordinator. 


\subsection{CHARACTERIZE AND QUANTIFY PROBLEM AREA OR NEED (PI AND PREDEMONSTRATION MANAGEMENT TEAM RESPONSIBLE)}

Definition of the waste management problem area or need will generally require further characterization and quantification. It is especially important at this stage for the PI and predemonstration management team to work closely with the DOE and Energy Systems site representatives to ensure thorough understanding of the problem and a close working relationship with the owners of the problem. Characterization of the problem area will include not only chemical, physical, and biological data, but also regulatory compliance issues and all information concerning possible technical solutions. Typical characterization and quantification data could include:

1. waste stream identification;

2. characterization data;

(a) chemical constituents

(1) quantities

(2) concentrations

(3) physical attributes

(b) site factors

(1) topography

(2) geohydrology

3. regulatory concerns and decisions; and

4. temporal factors.

\section{DENTIFY POSSIBLE SOLUTIONS TO PROBLEM AREAS OR NEEDS (PI AND PREDEMONSTRATION MANAGEMENT TEAM RESPONSIBLE)}

The knowledge and information gained during the characterization step will facilitate development of possible technical solutions to the problem area. The technical solutions should be evaluated and judged primarily on a technical basis. However, consideration should also be given the site's particular mission and other problem areas. Hence, communication with site representatives continues to be of especial importance. Evaluation of the problem area inay indicate the need for laboratory bench-scale studies, treatability studies, or a largc- 
scale demonstration to provide additional information on possible technical solutions to the waste problem. Management steps could include:

1. Interface with Energy Systems sites.

2. Interface with DOE Site Manager and DOE/OR Program Manager(s).

3. Evaluate/select technologies, methodologies, an/or equipment pertaining to the problem area.

4. Determine if current technologies may be applied to the problem area without additional treatability studies or demonstration evaluation. If so, recommend accordingly to Energy Systems management responsible for the problem area. If item 4 does not address the problem area, then proceed with steps 5 and 6 given below.

5. Determine if laboratory bench-scale studies or treatability studies are necessary to evaluate the problem area. If so, include the justification for these studies in the demonstration proposal (Sect. 2.7).

6. Determine if a demonstration is necessary for evaluation purposes. If so, develop a demonstration proposal (Sect. 2.8).

\subsection{DEVELOP PREDEMONSTRATION LABORATORY BENCH-SCALE OR TREATABILTY STUDIES PROPOSAL IF DETERMINED NECESSARY IN SECT. 26, ITEM 5 (PI AND PREDEMONSTRATION MANAGEMENT TEAM RESPONSIBLE). LABORATORY BENCH-SCALE OR TREATABILITY STUDIES WILL BE INCLUDED IN THE DEMONSTRATION PROPOSAL AS OUTLINED IN SECT. 2.8, ITEM 11}

Preliminary R\&D at the bench scale (e.g., treatability studies) may be necessary to further evaluate potential technologies and to scope demonstration efforts. The treatability studies proposal may stand alone or be considered an integral part of the total demonstration package (i.e., integrated into a demonstration proposai). If such studies are proposed and funded, management of the studies will include many of the same elements that are involved in demonstration management (See Sects. 3 and 4).

Permits or exemptions for treatability studies. Researchers must meet certain requirements to conduct treatability studies on Resource Conservation and Recovery Act (RCRA) hazardous waste (See Appendix A). 
Bench-scale or treatability studies will address, but are not limited to, the following elements:

1. Laboratory bench-scale studies

(a) evaluate the chemistry of the waste treatment processes;

(b) validate the engineering flowsheet;

(c) determine environmental, safety, and health (ES\&H) factors;

(d) determine potential technical problems; and

(e) provide process data for scale-up purposes, for example;

2. Treatability studies

(a) further validate and/or develop engineering flowsheet;

(b) evaluate equipment operations/capabilities;

(c) determine ES\&H factors; and

(d) provide engineering and equipment data for scale-up purposes, for example.

\subsection{PREPARE DEMONSTRATION PROPOSAL IF DETERMINED NECESSARY IN SECT. 26, ITEM 6 (PI AND PREDEMONSTRATION MANAGEMENT TEAM OR THE PM, IF SELECTED)}

Many sequential steps are required to prepare a demonstration proposal. Especially important is effective communication with sites and DOE representatives in order to develop clear definitive statements concerning the background information, need, technical aspects, schedule, and anticipated funding requirements. Important factors include:

1. Interface with Energy Systems sites.

2. Interface with Energy Systems Site Demonstration Manager and WR\&D Demonstration Coordinator.

3. Interface with Energy Systems Site Environmental Coordinator.

4. Interface with DOE Site Manager.

5. Interface with Energy Systems senior management.

6. Interface with DOE/OR. 
7. Interface with Energy Systenis divisions, programs, or groups, especially the Central ER/WM organization, and the WR\&D Director.

8. Define demonstration objectives.

(a) Clear statement of goals

(b) Clear understanding of who is the customer

9. Determine if private vendor will be contracted for conducting the demonstration.

10. Determine if the demonstration will be conducted on-site or off-site.

11. Prepare the demonstration proposal and include laboratory bench-scale or treatability studies proposal if appropriate (S'ect. 2.7 above).

(a) Prepare the Technical Task Plan (TTP) (currently required document for RDDT\&E proposals to DOE).

(1) Task description

(2) Major subtasks

(3) Schedule

(4) Estimated cost

(b) The TTP replaces the Activity Data Sheet (ADS), which is not required at this time by $\mathrm{DOE}$. However, some divisions/programs may require an $\mathrm{ADS}$ on a project.

(c) Prepare other forms as required.

12. Obtain approval for demonstration proposal.

(a) Line management

(b) Energy Systems site representatives

(c) Energy Systems Site Demonstration Manager

(d) CWMD Director (WM demonstrations)

(e) ERD Director (for ER demonstration)

(f) Energy Systems central management

(1) WR\&D Program

(2) Work for Others Office (as needed)

(3) Other program offices (as needed)

(g) DOE Site Manager

(h) DOE/OR ER and WM representatives 
13. Submit proposal to appropriate potential funding agency.
(a) $\mathrm{DOE} / \mathrm{OR}$
(b) $\mathrm{DOE} / \mathrm{HQ}$
(c) Other federal agency
(d) Energy Systems
(e) State
(f) Private sector vendor

14. Respond to feedback received from funding agency.

\section{FACILITATE FINANCIAL ACTIONS AFTER FUNDING APPROVAL (PI OR PM, IF SELECTED, RESPONSIBLE)}

The PI interacts with the DOE Site Manager, DOE/OR, Energy Systems staff, and/or predemonstration management team in the areas of:

1. Funding appropriation

(a) Ensure that the funds are available for conducting the demonstration.

2. Funding receipt - upon notification of funds
(a) Prepare financial plan for the demonstration activity.
(b) Open charge account numbers.
(c) Open work orders.

\section{CONTRACT WTTH PRIVATE VENDOR, AS DETERMINED IN SECT. 2.9, ITEM 9 (PI AND PREDEMONSTRATION MANAGEMENT TEAM OR PM, IF SELECTED, RESPONSIBLE)}

Steps for developing a contract with private vendors are outlined below (for more detailed discussion see Appendix B):

1. Prepare draft Statement of Work (SOW). This includes a description of work requested.

(a) Description of work

(1) Objectives 
(2) Boundary conditions

(3) Task(s)

(4) Deliverables

(5) Schedule

(6) Funding

2. Review draft SOW for completeness and accuracy. Reviewers include:

(a) Appropriate reviewers as needed

(b) Procurement

(c) Reviewers in the approval chain as needed

3. Prepare final SOW.

4. Prepare a "Request for Individual Consultant or Research and Development Subcontract" form (1127 Form).

5. If only one particular vendor is to be used, prepare a "Justification for Sole Source Procurement" form (UCN-15918).

6. Submit the SOW, 1127 Form, and Sole Source Justification (if needed) to:

(a) The sponsoring Energy Systems division/organization for approval

(b) Energy Systems Procurement

7. Energy Systems Procurement prepares Request for Proposal (RFP).

(a) PI and predemonstration management team review RFP

(b) Procurement issues RFP

8. Evaluate RFP responses.

(a) Procurement, PI, and predemonstration management team evaluate responses

(b) Procurement, PI, and demonstration management team approve the vendor(s) to be awarded the subcontracts

9. Subcontract with the vendor.

(a) Procurement/Purchasing prepares the subcontracts

(b) Procurement/Purchasing awards the subcontracts

10. Manage subcontract.

(a) PI (and subsequently the PM) deals directly with the vendor project manager. 


\section{ORGANIZATION FOR DEMONSTRATION MANAGEMENT}

Demonstration management is conducted by the PM with the support of the DMT. Management oversight consists of demonstration readiness reviews, operation approval by the management oversight team, and final demonstration approval by the DOE Site Manager and the appropriate DOE/OR Program Manager or representative. Thus, senior management involvement consists of two tiers or levels of management: (1) oversight to ensure demonstration operational readiness and (2) approval to permit the demonstration operation.

Qversight to ensure operational readiness. The management oversight team participates in the demonstration readiness reviews and ensures the regulatory compliance, and operational readiness of the demonstration.

Approval to permit the demonstration operation. Management participates in final demonstration readiness review and recommends approval for the demonstration to be conducted. The DOE Site Manager and DOE/OR PM give final approval for the demonstration to proceed.

Operational Readiness Process (ORP). It is Energy Systems policy (GP-24) to conduct formal operational readiness processes, including focused readiness reviews, to ensure that a given activity is ready to proceed to the next increment of work by identifying and minimizing the risks associated with mission success. The resources committed to any ORP should be consistent with the subject activity's cost, schedule, complexity, and probability and consequences of failure (i.e., quality, safety, environmental). It is the responsibility of the PM to ensure that the ORP is considered and the decision basis documented for startup of significant, new, or modified, activities including technology demonstration.

The ORP applies to all Energy Systems facilities, operations, processes, systems, construction efforts, and projects. ORP is a management tool that establishes and verifies the status and degree of readiness of an activity to startup or to proceed with the next phase of work. Formal mechanisms are described in this procedure for recording the measures taken to ensure the achievement of the desired state of readiness. ORP complements other quality assurance (QA), ES\&H, engineering, and management policies and procedures. 


\subsection{PROJECT MANAGER (SELECTED BY ENERGY SYSTEMS STAFF)}

The PM is responsible for management of the demonstration. The PM has the support of a DMT, which reports to him/her for its responsibility in this activity. Generally, a PM is selected by Energy Systems program management after consultation with other Energy Systems management staff as outlined below:

1. selection by Energy Systems program management;

2. input from, or communication with, appropriate Energy System line management and the DOE Site Manager; and

3. input from, or communication with, DOE/OR.

\subsection{PROJECT MANAGER RESPONSIBILITIES}

The PM has the principal responsibilities for ensuring completion of the demonstration. This includes conducting the demonstration within budget allocations and meeting demonstration deliverables on time. Operating with the advice and consent of appropriate program and line management, the PM selects and develops a demonstration management team. The PM responsibilities include:

1. Ensure that no work is started without necessary DOE/OR and Energy Systems approvals and appropriate funding in hand. If it is the judgment of the PM that the demonstration can not be accomplished within the approved funding level, before starting the demonstration activity the PM must either (a) seek to modify the task deliverables and schedule to match the available funds or (b) not start the demonstration until adequate funding is secured. Demonstrations must be accomplished within the approved funding level.

2. Develop communications with the DOE Program and Site Managers, Energy Systems management oversight staff, Site Demonstration Manager, WR\&D Demonstration Coordinator, Site Environmental Coordinator, line management, and matrix or program staff, as needed.

3. Select and coordinate the DMT activities. 
4. Ensure that procedures are in place for ES\&H and that the demonstration activities are conducted in accordance with the procedures.

5. Initiate safety documentation.

6. Ensure preparation of QA and security plans.

7. Prepare the readiness review statement for documenting the decision basis.

8. Secure all necessary approvals and permits.

9. Undertake to successfully execute the demonstration.

10. Maintain cost control and comply with budget guidelines.

11. Meet deliverables schedule.

12. Hold periodic information meetings with Energy Systems management.

13. Hold periodic information meetings for DOE Program and Site Managers, as requested.

14. Prepare (monthly) reports. Technology demonstration reporting through the WR\&D Program Office to DOE/OR and DOE/HQ Office of Technology Development (OTD).

\subsection{DEMONSTRATION MANAGEMENT TEAM (GENERALLY SELECTED BY PM WTTH INPUT FROM DOE AND ENERGY SYSTEMS STAFF)}

The DMT consists of several professionals and specialists. Team members will vary on an ad hoc basis depending upon the magnitude, nature, and location of the demonstration. Team members may include any or all of the following:

1. PM (Team Coordinator)

2. WR\&D Demonstration Coordinator

3. Engineers/scientists

4. Technicians

5. Financial Officer

6. WR\&D Program QA Officer

7. QA specialists

8. Statisticians

9. Industrial safety specialists

10. Environmental specialists

11. OSHA specialists 
12. Chemists/analytical chemists

13. Industrial hygienists

14. Health physicists

15. Security specialists

16. Fire protection

17. Plant and Equipment staff

18. Shift superintendent/emergency preparedness

19. NEPA specialists

20. Permitting specialists

21. Regulatory compliance specialists

22. Transportation specialists

23. Computer operators/technicians

24. Geohydrologists

25. Criticality safety specialist/engineer

26. Training specialist

27. Scientists/engineers with expertise in special areas

\subsection{DEMONSTRATION MANAGEMENT TEAM RESPONSIBILITIES}

The PM and the DMT work closely together to accomplish the demonstration. The tearn assignments and work are coordinated by the PM or designee. The DMT generally consists of several "permanent" members and many specialists who function on an hoc basis. The full-time team members assist in the operational management aspects of the demonstration (e.g., maintenance of documentation files, QAVC, logistics support, engineering consultation, coordination of sampling and analysis). The ad hoc specialist team members assist in areas requiring specialized professional training and experience (e.g., NEPA documentation specialists assist in developing appropriate documentation for obtaining the required environmental permits, industrial safety experts review the safety aspects of the demonstration). DMT responsibilities include, but are not limited to, the following: 
1. Prepare the Project Description.

2. Prepare the Project Plan.

(a) Management plan

(b) Task schedule

(c) Task budget and financial plan

3. Review all plans and demonstration activities.

4. Participate in the ORP (See GP-24), demonstration reviews, senior management readiness reviews, and approval meetings.

5. Facilitate site security compliance.

6. Ensure appropriate demonstration waste management.

7. Ensure regulatory compliance.

8. Coordinate permitting and environmental compliance activities.

9. Coordinate EPA compliance activities.

10. Ensure meeting of site environmental requirements.

11. Ensure safe demonstration operations.

12. Ensure compliance with OSHA and site industrial hygiene standards.

13. Ensure compliance with health physics standards.

14. Accomplish procurement activities as needed.

15. Evaluate ES\&H standards of vendor sites as necessary.

16. Prepare and ensure compliance with demonstration QA plan (Energy Systems or vendor as needed).

17. Develop and maintain a documentation file.

18. Characterize waste as needed.

19. Coordinate site preparation for demonstration.

20. Control demonstration site access.

21. Develop and coordinate public relations activities as needed.

\subsection{DOE AND ENERGY SYSTEMS MANAGEMENT OVERSIGHT TEAM}

The management oversight team consists of the senior management staff (or designated representatives) responsible for reviewing and giving final approval for conducting the demonstration. Management oversight consists of demonstration readiness reviews, operation 
approval by the management oversight team, and final demonstration approval by the DOE Site Manager and the appropriate DOE/OR Program Manager or representative. Thus, senior management involvement consists of two tiers or levels of management: (1) oversight to ensure demonstration operations readiness and (2) approval to permit the demonstration opeiation.

Oversight to ensure operational readiness. The management oversight team participates in the demonstration readiness review and ensures the regulatory compliance and operational readiness of the demonstration. If a Readiness Review Board (RRB) is required, the RRB makes recommendations regarding proceeding with the activity's next increment of work (See ORP, GP-24).

Approval to permit the demonstration operation. Management participates in final demonstration readiness review and recommends approval for the demonstration to be conducted. The DOE Site Manager and DOE/OR Program Manager give final approval for the demonstration to proceed.

The PM and DMT are responsible for notification of the senior management oversight team concerning appropriate meetings. Interim meetings may be held for information purposes. The Energy Systems senior staff members or representatives may vary depending upon demonstration location, the site involved, and demonstration objectives. Team members will likely include an appropriate subset of the following possible senior management staff:

\section{DOE Site Manager}

2. DOE/OK Program Manager

3. Energy Systems Vice President for Technical Operations

(a) ERD Director

4. Energy Systems Vice President for Applied Technology

(a) Energy Systems K-25 Site Manager

(b) CWMD Director

5. Energy Systems Vice President for Enrichment

(a) Energy Systems Portsmouth Gaseous Diffusion Plant (GDP) Site Manager

(b) Energy Systems Paducah GDP Site Manager

(c) Portsmouth GDP Demonstration Manager

(d) Paducah GDP Demonstration Manager 
6. Energy Systems Vice President for Oak Ridge National Laboratory (ORNL)
(a) ORNL representative
(b) ORNL Demonstration Manager
(c) WR\&D Director

7. Energy Systems Vice President and Manager for Y-12 Plant

8. Energy Systems Environmental \& Safety Activities Director 


\section{MANAGEMENT STEPS LEADING TO DEMONSTRATION APPROVAL}

Demonstrations include a complex array of activities, some of which will occur sequentially, but many of which most likely will take place concomitantly. Most of the parallel activities occur at the front end; these consist principally of securing necessary permits, ensuring regulatory compliance, meeting site ES\&H standards, and obtaining Energy Systems and DOE approvals. After approval, the actual conduct and completion of the demonstration consist of a series of sequential management steps.

\subsection{SCHEDULE AND CONDUCT INITIAL ORGANIZATION MEETING (PM AND DMT RESPONSIBLE)}

The initial meeting of the demonstration management team lays the foundation for successful accomplishment of the demonstration. The desired objectives of this meeting are:

1. Inform the management team of member assignments and responsibilities.

2. Establish demonstration line management.

3. Establish demonstration approval chain.

4. Establish appropriate communications links with:

(a) Demonstration personnel

(b) Energy Systems site representatives (including site plant shift superintendents, Site Demonstration Manager, Site Environmental Coordinator, etc.)

(c) Energy Systems line management

(d) Energy Systems senior management

(e) DOE Site Manager

(f) DOE/OR Program Manager

5. Initiate the following:

(a) Preparation of the Project Description

(b) Preparation of the Project Plan

(1) Management plan

(2) Task schedule (project demonstration schedule) 
(3) Task budget and financial plan (project demonstration cost)

(c) Review of site security requirements

(d) Review of site waste management requirements

(e) Review of all regulatory compliance issues

(f) Permitting activities

(g) NEPA compliance activities

(h) Appropriate environmental activities

(i) Appropriate industrial safety activities

(j) Appropriate industrial hygiene activities

(k) Appropriate health physics activities

(l) Appropriate fire prevention and fire protection activities

(m) Vendor site ES\&H evaluations as necessary

(n) Criticality safety activities

(o) Development of an emergency plan in the unlikely event that something goes wrong

(p) Procurement activities as needed

(q) Development of demonstration QA plan

(r) Waste characterization activities (if necessary)

(s) Site preparation activities

(t) Public relations activities as needed

\subsection{PREPARE PROJECT DESCRIPTION AND OBTANN APPROVAL (PM AND DMT RESPONSIBLE). SEE APPENDIX C FOR EXAMPLE PROJECT}

The Project Description represents an extension of the basic control document prepared for the original funding request. The Project Description is used for initiation of demonstration activities (e.g., NEPA review permitting). The Project Description also forms the basis for later preparation of the more extensive and detailed Project Plan. Consequently, it will contain all or most of the elements of the Project Plan, but in less detail; that is, the Project Plan represents an extension of the Project Description.

An example Table of Contents for a Project Description follows. Note that other elements may be necessary, depending upon the particular demonstration being described. For very simple demonstrations, some elements may be omitted. 
1. Introduction

1.1 Objective of the Project

1.2 Scope

1.3 Background and Rationale

1.4 Project Organization

1.5 Preliminary Studies

1.5.1 Laboratory Tests

1.5.2 Bench-scale Tests

2. Site Description

2.1 Location

2.2 Characterization

3. Demonstration Systems Design

4. Schedule

5. Site Requirements

5.1 Spaces and Location

5.2 Access and Security

5.3 Personnel Staging

5.4 Site Preparation

5.5 Utilities

5.6 Emergency Preparedness and Response

6. Waste Generation and Disposal

6.1 Composition and Volume of Expected Waste Streams

6.1.1 Liquids

6.1.2 Gases

6.1.3 Sludge and Solids

6.2 Waste Disposal

7. Health and Safety

8. $\mathrm{QA}$

9. Permitting

\subsection{NEPA}

9.2 RCRA Research Development and Demonstration (RD\&D) Permit or Treatability Exclusion 


\subsection{Site Requirements}

9.3.1 NPDES Permits, As Required

9.3.2 Air permits, As Required

10. Contracts and Legal Issues

Mauagement steps required in this area include:

1. Prepare Project Description.

2. Obtain required approvals as needed.

(a) PM and DMT

(b) Energy Systems line management

(1) Site Demonstration Manager

(2) Site Environmental Coordinator

(3) Site Manager or representative

(c) DOE Site Manager

(d) DOE/OR Program Manager or representatives

\subsection{PREPARE PROJECT PLAN (PM AND DMT RESPONSIBLE)}

A comprehensive Project Plan is the tool used by the PM to properly conduct the demonstration. This includes compliance with all applicable federal, state, and local regulations, DOE Orders, and Energy Systems policies and procedures. See Appendix D for example Project Plan.

The Project Plan is expected to provide the basis for coordination of all parties involved directly in performing the demonstration and keeping those informed who have an interest in how the demonstration is proceeding. The Project Plan represents an extension of, and builds upon, the previously prepared Project Description (See Sect. 4.2).

The essential Project Plan requirements are outlined below. (Not all items in the outline will be applicable to every demonstration, and project plans for individual demonstrations should be customized consistent with the requirements for the demonstration.) 


\section{PROJECT PLAN OUTLINE}

1. Title

Exact title as used in all documents

2. Background and purpose

Project description, purpose relative to technology needs, and other objectives.

3. Funding baseline and contingency factor

Funding or estimated cost and the contingency factor with a brief statement of the relation of funding to the scope of the project. The project funding and scope should always be consistent. Projects should normally not proceed without an approved financial plan with funding consistent with the scope. Any variance should be documented and approved by authority at the appropriate level (See Sect. 4.4).

4. Data to be generated

Plans for data generation. Typical data are:
(a) Analytical data before and after the demonstration
(b) Physical characterization data
(c) Treatability data
(d) Secondary waste data
(e) Commitment to sampling and analysis plan, if applicable

5. Waste materials

Waste material description, characterization, handling, and disposal.

6. Project approach

Project approach with any special plans. Examples are:
(a) Project phases
(b) Sarnple runs
(c) Full-scale trial runs
(d) Laboratory-scale tests 
7. Permitting

Plans and requirements for permits along with responsibilities for each step of the process. Some steps are:
(a) Prepare data
(b) Complete forms
(c) Request letters
(d) Conduct meetings relative to permitting

8. Site preparation and equipment setup Interfacing requirements with responsibilities. Interfaces may typically include:
(a) Utilities (air, water, electricity, telephone, etc.)
(b) Office space
(c) Site layout map
(d) Radiological surveys
(e) ES\&H
(f) Security limits
(g) Fire protection
(h) Contractor orientation
(i) Other interfaces as needed

9. Emergency Plan

An emergency plan should be developed in the unlikely event that something goes wrong. Responders (shift superintendents, fire responders, emergency squad, etc.) must have orientation training on the demonstration prior to startup.

10. Readiness review and approval to proceed (See GP-24)

Commitment to a readiness review and how the readiness review will be conducted. Necessary elements include:
(a) Responsibilities
(b) Actions required
(c) Approvals required to proceed 
(d) How the approvals will be obtained

(e) How approvals will be documented

11. Mobilization

Requirements and ground rules for the demonstration. Elements may include:

(a) List of contractor equipment to be brought on-site.

(b) List of support services or other equipment to be furnished by Energy Systems.

(c) Personnel to be on-site at equipment arrival.

(d) Verification and documentation of acceptances of positioning of equipment.

(e) Equipment setup description and responsibilities

(f) Notification requirements

(g) Hours when equipment arrival can be accommodated

12. Conduct of the demonstration

How the demonstration will be conducted. Items that may need to be considered and defined include:

(a) Applicable plans, procedures, etc.

(b) Control and required approvals for field changes

(c) Stop work authority

(d) Schedules

(e) Treatment/processing

(f) Material staging/feeding

(g) Waste volumes and types generated by the demonstration process. (A waste management plan should be developed if the volumes and types are significant.)

(h) Residue waste collection, management, and disposal. (A waste management plan should be developed if the demonstration is complex.)

(i) Chain of command and shutdown authority

(j) Decontamination (including responsibilities)

(k) Equipment disassembly and removal

(l) Site restoration (including responsibilities)

(m) Off-normal or unusual occurrence notifications to Plant Shift Superintendent 
13. Project radiological controls

Radiological control and implementation. Elements should include:

(a) Applicable work procedures

(b) Work permits

(d) Other required radiological documents

(e) As low as reasonably achievable (ALARA) requirements

Other items that may be included are:

(a) Site preparation and radiological restrictions

(b) Site responsibilities and boundaries

(c) Personnel monitoring

(d) Instrumentation

(e) Decontamination

(f) Protective equipment

(g) Radiation protection

(h) Qualification and training

14. Industrial safety and hygiene controls What industrial safety factors must be considered and to which activities they will be applied.

Why and what industrial hygiene controls are necessary and to what activities they will be applied. Include such items as:
(a) Protective clothing
(b) Exposure to hazardous chemicals

15. Closeout of demonstration

A closure plan should be prepared to ensure appropriate management of all waste materials/equipment meets regulatory requirements.

(a) Approval for disassembly or moving of demonstration equipment

(b) Decontaminate and/or decommission equipment as necessary

(c) Restore demonstration site to acceptable criteria. 
(d) Dispose or store treated and untreated waste. (If the demonstration is complex, a waste management plan should be prepared.)

(e) Dispose, store, or treat secondary waste. (If the demonstration is complex, a waste management plan should be prepared.)

(f) Depending upon the magnitude of the demonstration, RCRA closure may be necessary

16. Final report

Requirements for the final report and strategy for developing and preparing the report. Items to be considered are:
(a) Responsibilities for preparation
(b) Description of equipment
(c) Description of processing
(d) Demonstration results
(e) Problems
(f) Unusual experiences
(g) Evaluation of data
(h) Unexpected changes
(i) Emissions
(j) Unit costs of processing
(k) ES\&H experiences
(l) Radiological experiences
(m) Safety assessments/studies impact
(n) Conclusion
(o) Approvals required
(p) Distribution requirements

17. Schedule baseline

Project schedule including all steps with appropriate explanations. 
18. Planned subcontracting and estimated cost

Some projects will include preplanned subcontracting (other than supply and expensetype items). Describe work to be subcontracted, where possible; its estimated cost; and justification for subcontracting. If possible, let subcontracts on a firm fixed price and on a competitive basis to enable control of subcontracting costs.

19. Project responsibilities

All organizations both directly and indirectly involved in any phase or aspect of the project should be listed in this section along with a description of the involvement, responsibilities, and names of responsible individuals. Include reporting and briefing responsibilities.

20. Ground rules for changes

Lucument the required method and procedure for making and approving changes to the Project Plan after it is approved. The Project Plan should be a controlled document. The PM should maintain a history of changes with appropriate description of the changes. Changes in the Project Plan must have ES\&H approval prior to initiation. Changes may require permit modification, NEPA documentation, etc.

\section{Approvals}

The approvals section should include, as a minimum, the following dated signatures:
(a) PM
(b) Energy Systems WR\&D Program Director
(c) Site Manager
(d) DOE Site Manager
(e) DOE/OR Program Manager

22. Distribution

Approved distribution list. PM to maintain and keep distribution list current. Management steps in the Project Plan area include:

(a) Prepare a comprehensive Project Plan.

(b) Obtain required approvals as needed 
(1) PM and DMT

(2) Energy Systems line management

(3) Site Demonstration Manager

(4) Site Environmental Coordinator

(5) Site Manager or representative

(6) WR\&D Program Director

(7) DOE Site Manager

(8) DOE/OR Manager or representatives

(c) Maintain the Project Plan and document required changes.

(d) Use the Project Plan as a "road map" to accomplish the demonstration activities.

\subsection{PREPARE PROJECT DEMONSTRATION COST AND SCHEDULE (PM RESPONSIBLE)}

One of the first action items to be accomplished after defining project goals is to develop a budget and schedule for the project. The budget and schedule will then be used to track progress on the project. In order to develop a schedule and budget, the PM must first identify all the tasks that are involved in order to accomplish the goal(s) of the project. After defining the tasks, the next step is to estimate the time or duration required to complete each task. After all the tasks and tneir durations have been determined, they must be laid out in a logical manner, identifying the timing relationship between the tasks. In any project, some tasks must be completed before others can begin. This timing relationship between tasks is called dependency. Setting milestones as checkpoints, or interim deadlines, will help measure progress on the project. When these are integrated, the project sshedule will be developed. An example of a project schedule for a demonstration, in which an outside vendor will perform the treatment, is shown in Fig. 2. Many of the tasks identified in this schedule, such as planning, permitting, procurement, and equipment preparation, are common to most demonstrations. Some software packages, such as Timeline $^{\bullet}$ or Harvard Project Management ${ }^{\bullet}$, are invaluable for assisting in the schedule preparation. However, the results are only as good as the accuracy of the information.

Having completed the schedules, the next planning step is to calculate project costs. There are numerous considerations: What are the overhead costs? What unexpected hidden 


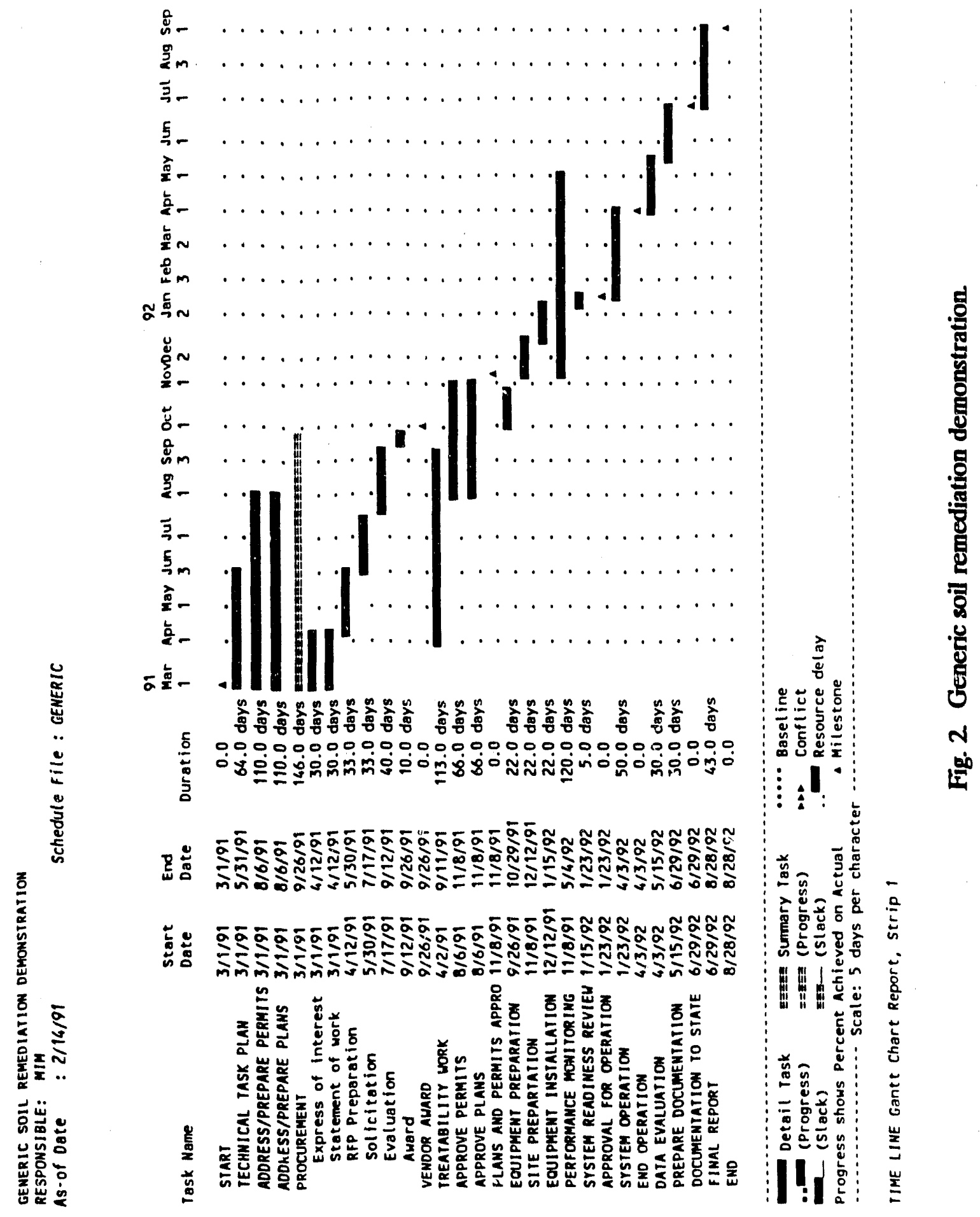


costs can be identified? Can costs be reduced by employing strategies such as quantity buying or task combining? Calculating project costs can be simplified by identifying costs associated with each task. In this way, the PM can prepare a clear, accurate, and realistic budget that is easy to substantiate. The task-by-task approach ensures that there are supporting facts to defend the budget during the approval process. One of the important steps is to include a contingency. The contingency should be a percentage of the project costs reflecting the uncertainty. An example of a budget for the above-mentioned demonstration is shown in Table 1.

Strong management and relentless tracking may be required to meet designated milestones. Monitoring the project's progress regularly helps identify problem areas early. If there is slippage in the schedule or if costs are higher than expected to complete a task, it is important to isolate and correct the problem(s) and to develop alternate strategies to get the project back on schedule and/or within cost.

\subsection{ENSURE COMPLIANCE WTH SITE SECURITY REQUIREMENTS AND COMPLIANCE WITH CLASSIFICATION REQUIREMENTS. (PM AND DMT COORDINATE WITH SITE SECURITY STAFF)}

1. Arrange security briefing with site security manager for the DMT.

2. Ensure Energy Systems staff compliance with site security standards.

(a) Arrange for passes, badges, and escorts as appropriate

(b) Arrange for vehicle access as appropriate

3. Brief vendor staff concerning site security requirements as necessary. The briefer must be a certified trainer.

4. Ensure vendor staff compliance with site security requirements.

5. Ensure compliance with classification requirements if classified waste streams or materials are involved in the demonstration activities. 
Table 1. Generic Soil Remediation Demonstration

(FY-91 and FY-92)

\begin{tabular}{|c|c|c|c|c|c|c|}
\hline & Title/person & Rate S/M & FY-91 & FY -92 & Vendor cost & Total \\
\hline (1) & Project management & $\$ 10,500$ & 7 & 12 & & 19 \\
\hline (2) & Technical task plan & $\$ 10,500$ & 1.5 & & & 1.5 \\
\hline (3) & Permits and plans & $\$ 10,500$ & 4 & & & 4 \\
\hline (4) & Procurement & $\$ 10,500$ & 3 & & & 3 \\
\hline (5) & Treatability & $\$ 10,500$ & 3 & & & 3 \\
\hline (6) & Performance monitoring & $\$ 10,500$ & $\mathbf{0}$ & 7 & & 7 \\
\hline (7) & Site prep./equip. installation & $\$ 6,000$ & 0 & 4 & & 4 \\
\hline (8) & Data eval. and doc. prep. & $\$ 10,500$ & $\mathbf{0}$ & 4 & & 4 \\
\hline (9) & Final report & $\$ 10,500$ & 0 & 2 & & 2 \\
\hline & TOTAL & - & 18.5 & 29 & $\mathbf{0}$ & 47.5 \\
\hline (10) & Intra-cost centers & & 194,250 & 286,500 & $\mathbf{0}$ & 480,750 \\
\hline (11) & Intra-division cost center & & & & & $\mathbf{0}$ \\
\hline (12) & Inter-division cost center & & & & & $\mathbf{0}$ \\
\hline (14) & Shop and maintenance (mater & & & & & 0 \\
\hline$(15+17)$ & Consultant/R\&D subs. & & & & & $\mathbf{0}$ \\
\hline (16) & Travel & & 20,000 & 30,000 & & 50,000 \\
\hline (18) & Major materials (nonexempt) & & & & & $\mathbf{0}$ \\
\hline (19) & Supplies & & 6,287 & 9,622 & & 15,910 \\
\hline$(20)$ & Major materials (exempt) & & & & & $\mathbf{0}$ \\
\hline (21) & Materials and subs. (exempt) & & 20,000 & 20,000 & 500,000 & 540,000 \\
\hline$(22-24)$ & Misc., computer, and tech. in & & 29,054 & 44,612 & 50,000 & 123,666 \\
\hline$(26)$ & P\&E shops and maintenance & & & & & 0 \\
\hline$(27-31)$ & Support (Anal., QA, HP, Wa & p., etc.) & 50,000 & 100,000 & & 150,000 \\
\hline$(33-45)$ & Total other costs & & 17,515 & 41,187 & 65,265 & 123,967 \\
\hline$(46)$ & Total gross costs & & 337,106 & 531,922 & 615,265 & $1,484,293$ \\
\hline (50) & Total G\&A + GPS & & 158,553 & 255,961 & 57,633 & 472,146 \\
\hline (51) & NET OPERATTNG COSTS & & $\$ 495,659$ & $\$ 787,883$ & $\$ 672898$ & $\$ 1,956,439$ \\
\hline \multicolumn{3}{|c|}{ ACCUMULATED COSTS, \$K (1,000's) } & $\$ 495,659$ & $\$ 1,283,542$ & $\$ 1,956,439$ & $\$ 1,956,439$ \\
\hline
\end{tabular}

NOTES

Contingency appraximately $10 \%$ on misc. line before overhead. Supplies appraximately $2 \%$ before overhead.

G\&A $=50 \%$ 


\subsection{ENSURE COMPLIANCE WITH SITE WASTE MANAGEMENT REQUIREMENTS (PM AND DMT COORDINATE, WITH SITE ENVIRONMENTAL COORDINATOR AS CONSULTANT)}

1. Arrange waste management briefing with Site Environmental Coordinator for the DMT.

2. Develop a management plan for waste to be treated, the treated waste, and the wastes generated from the demonstration. (See Appendix E for example waste management plan.)

3. Ensure compliance with the waste management plan.

\subsection{ENSURE DEMONSTRATION REGULATORY COMPLIANCE (PM AND DMT COORDINATE, WTH SITE ENVIRONMENTAL COORDINATOR, SITE ENVIRONMENTAL PROTECTION OFFICERS, AND SITE RCRA COMPLIANCE STAFF AS CONSULTANTS). SEE ALSO SECTS. 4.8 AND 4.9}

Some regulatory compliance issues will not be dealt with directly by demonstration organizers. That is, demonstrations conducted under the auspices of a site will generally fall under the regulatory umbrella of that site. For example, demonstrations will not generally need an NPDES permit but must comply with the site NPDES permits; demonstrations may also be covered by the site's Part A and Part B RCRA permits. RCRA RD\&D permits and NEPA documentation are special regulatory issues that are dealt with in more detail in Sects. 4.8 and 4.9 .

1. Arrange regulatory compliance briefing with Site Environmental Coordinator or other regulatory compliance authority for DMT.

2. Develop a regulatory compliance plan for the demonstration activity. The plan should include a review of all compliance issues and development of all necessary permits:

(a) State/EPA RCRA RD\&D permit as needed (See Sect. 4.8)

(b) State/EPA RCRA treatability studies exclusion as needed (See Sect. 4.8)

(c) State air emissions permit as needed

(d) Underground injection permit as needed

(e) Site NPDES permit modifications (if required)

3. Ensure compliance with the regulatory compliance plan. 


\subsection{OBTAIN NECESSARY STATE/EPA RESEARCH, DEVELOPMENT, AND DEMONSTRATION PERMITS OR TREATABILITY STUDIES EXCLUSIONS (PM AND DMT COORDINATE, WITH SITE RCRA COMPLIANCE STAFF AND PERMITTING SPECIALISTS AS CONSULTANTS)}

Waste treatment demonstrations may vary in size and quantities of waste treated. Small demonstrations may qualify for treatability studies exclusion from RCRA hazardous waste regulations. Large- or full-:icale demonstration may require an RD\&D permit. RD\&D permits are issued by the state of Tennessee for treatment facilities for studies involving innovative and experimental hazardous waste treatment technologies for which specific treatment of disposal permit standards is not promulgated. An RD\&D permit covers both facility construction and operation and is granted on an annual basis. Renewals are allowed for up to 3 years. The PM should consult with Site RCRA compliance staff members very early in the planning process to avoid possible lengthy delays in the RD\&D permitting process.

Management steps to ensure compliance include:

1. Contact Site Environmental Protection Officer or Site RCRA compliance staff for assistance.

2. Determine whether the demonstration qualifies for a treatability studies exclusion or requires an $R D \& D$ permit. The requirements for small-scale treatability studies are:

(a) Studies use no more than $1000 \mathrm{~kg}$, of nonacute hazardous waste (i.e., characteristically hazardous, spent solvents or U-listed wastes); $1 \mathrm{~kg}$ of acute hazardous waste (i.e., P-listed wastes); or $250 \mathrm{~kg}$ of soil, water, or debris contaminated with acute hazardous waste

(b) No more than a total of $250 \mathrm{~kg}$ of "as received" waste from the generator can be tested on a single day

(c) No more than $1000 \mathrm{~kg}$ of waste (excluding treatment residues that are generated) may be stored in the laboratory

3. If the demonstration meets the waste quantity criteria, submit the information on studies to the Site RCRA compliance staff (e.g., N. S. Dailey, ORNL; A. G. Hodgson, K-25 Site; M. S. Burris, Y-12 Plant and ORNL/Y-12) for their facility by February 7 of each 
year, beginning in February 1991. The RCRA compliance staff will then compile the overall submittal for their respective facilities.

4. Submit notification forms for planned treatability studies to the RCRA compliance staff a minimum of $10 \mathrm{~d}$ in advance of the receipt (via mail or shipping) of any hazardous waste for the purpose of conducting treatability studies.

5. Contact RCRA compliance staff for guidance on how to arrange for the delivery (via mail or shipping) of RCRA hazardous waste.

6. If a treatability studies exclusion is approved, ensure compliance with treatability exclusion requirements. These requirements are:

(a) Return wastes and residues to the generator or ship to a permitted or interim status facility within $90 \mathrm{~d}$ after the study ceases or within 1 year of its receipt from the generator, whichever occurs first

(b) Maintain records that demonstrate compliance with treatment rate limits, storage time, and quantity limits

(c) Maintain records on treatment information, shipping, papers, and study contracts or agreements

(d) Prepare and submit to the Tennessee Department of Health and Environment (TDHE) and EPA an annual report on all treatability studie: (PM assists Site RCRA compliance staff)

(e) Maintain all records that demonstrate compliance with the regulations for 3 years following the completion of each study

7. Determine if the demonstration requires an RD\&D permit

(a) Research efforts involving quantities of hazardous wastes in excess of that allowed under the treatability exclusion may require an RD\&D permit

8. If the demonstration requires an RD\&D permit, submit RD\&D permit application to the TDHE. The review and approval process may require 1 to 2 years and considerable expense. The RD\&D permit application addresses:
(a) Facility operation
(b) Maintenance
(c) Closure
(d) Remedial action
(e) Sampling 
9. If an RD\&D permit is issued, ensure compliance with permit requirements. The TDHE RD\&D permit may impose:

(a) Limits on the types and quantities of hazardous waste used in the demonstration

(b) Any or all of the standards set for permitted treatment of disposal facilities

4.9 ENSURE COMPLIANCE WITH NEPA REQUIREMENT (PM AND DMT RESPONSIBLE FOR COORDINATING WITH SITE NEPA COORDINATOR). THE PREPARATION OF NEPA DOCUMENTATION IS CONSIDERED IN MORE DETAIL IN APPENDIX F

The following steps should be undertaken:

1. Each demonstration activity must have on record a DOE-signed NEPA decision document, such as a Categorical Exclusion Determination (CXD), a Finding of No Significant Impact (FONSI), or a Record of Decision (ROD). The demonstration operation may not begin without DOE-signed NEPA documentation.

2. Contact the Site Environmental Coordinator or site regulatory compliance staff [(e.g., ORNL Environmental and Documentation Section (4-5774)] or the ORNL Environmental Coordinator (4-5776) for assistance in arranging the NEPA Environmental Assessment (EA) and preparing supporting EPA documentation as early as possible in the planning stage.

3. Provide a brief description of the project including anticipated schedules for construction and/or operation.

4. Arrange for a site visit.

5. Supply information for preparing the draft NEPA and supporting documents.

6. Review each draft.

7. Transmit comments and/or corrections.

8. Endorse the documentation in concurrence with document contents.

9. If the scope of the planned project changes significantly at any time prior to or subsequent to completion of the NEPA process, the PM repeats the above steps for the modification. 
10. Prepare supporting documentation.

(a) Supporting documentation for a CXD consists of the Project Description Memorandum [formerly called the Activities Description Memorandum (AcDM) or Environmental ALARA Memorandum (EAM)].

(b) Supporting documentation for a FONSI is an EA.

(c) Supporting documentation for a ROD is an Environmental Impact Statement (EIS).

\subsection{ENSURE MEETING OF SITE ENVIRONMENTAL REQUIREMENTS (PM AND DMT RESPONSIBLE, WITH SITE ENVIRONMENTAL COORDINATOR AS CONSULTANT)}

Although historically, ES\&H issues have generally been managed by one site group, the recent management trend has been to separate the three areas. This is in part due to increasing regulatory complexity and resulting requirements for increased personnel specialization. Some management aspects of the three areas (Sects. 4.9, 4.10, and 4.12) may be integrated. This demonstration guidance manual has treated the three areas separately but has indicated areas of possible integration. Integration is especially valid for vendor site evaluations in the ES\&H area. ES\&H evaluation criteria have been collected into an offsite facilities checklist developed by the Energy Systems CWMD. The "Martin Marietta Energy Systems, Inc., Offsite Facilities Conducting Treatability Studies Checklist" is presented in Appendix G. This checklist includes detailed ES\&H evaluation information for vendor sites. A similar but more extensive checklist is available for vendor sites involved in full-scale waste treatment activities.

Management steps for the environmental area include:

1. Arrange environmental requirements briefing with Site Environmental Coordinator for DMT.

2. Conduct an environmental review of the project in consultation with the Site Environmental Coordinator. (An Environmental Review Summary form is presented in Appendix $\mathrm{H}$ ).

3. Develop a management plan for compliance with all environmental requirements.

4. Ensure compliance with the environmental plan. 
5. Evaluate vendor ES\&H plan as needed (See also Sects. 4.11 and 4.12).

6. Initiate vendor site ES\&H evaluations as necessary (See also Sects. 4.11 and 4.12 and Appendix G).

\subsection{ENSURE SAFE DEMONSTRATION OPERATIONS (PM AND DMT RESPONSIBLE FOR COORDINATION WITH SITE INDUSTRIAL SAFETY STAFF)}

Safety assessments are critically important for demonstration management. (See Appendix I for example safety assessment.) Demonstration safety assessments are conducted by site safety specialists. Depending upon the findings, a more extensive Final Safety Assessment Report (FSAR) may be required. Site safety specialists generally have the responsibility for the preparation of such a document. The safety assessment may be integrated into a health and safety plan document for the demonstration. The health and safety plan is prepared in collaboration with the site industrial hygiene and industrial safety staffs (See also Sect. 4.12 and Appendix J).

Management steps for the safety area are:

1. Arrange safety briefing with site industrial safety staff for the DMT.

2. Assist site safety specialists as needed in preparation of the safety assessment. The site safety specialists will prepare the safety assessment.

3. Assist site safety specialists as needed in preparation of the FSAR if required.

4. Develop a management plan for ensuring safe demonstration operations.

5. Ensure compliance with the safety management plan.

\subsection{ENSURE COMPLIANCE WITH OSHA AND SITE INDUSTRIAL HYGIENE STANDARDS (PM AND DMT RESPONSIBLE, WITH SITE INDUSTRIAL HYGIENE STAFF AS CONSULTANTS)}

Access to demonstration sites must be limited to those persons with $24-\mathrm{h}$ initial OSHA/SARA training and up-to-date 8-h annual refresher training (29 CFR 1910.120). Sites may also have special access requirements. Management steps for the industrial hygiene area are: 
1. Arrange safety briefing with site industrial hygiene staff for DMT.

2. Assist site industrial hyglene staff as needed in preparation of the health and safety report if required. The site industrial hyglene staff will prepare the health and safety repnrt.

3. Ensure required OSHA/SARA training for demonstration personnel.

4. Develop a site control plan to control the potential of employee exposure to hazardous substances.

5. Develop an industrial hygiene management plan for ensuring safe demonstration operations relative to OSHA standards.

6. Ensure compliance with the industrial hygiene management plan.

\subsection{ENSURE COMPLIANCE WITH HEALTH PHYSICS REQUIREMENTS (PM AND DMT TO COORDINATE WITH SITE HEALTH PHYSICS STAFF)}

Management steps for the radiological safety (Health Physics) area are:

1. Arrange safety briefing with site health physics staff for the DMT.

2. Assist site health physics staff as necessary in evaluation of demonstration site and demonstration operations.

3. Develop a health physics plan to control the potential of employee exposure to radiological hazards as necessary.

4. Ensure compliance with the health physics plan.

\subsection{EVALUATE ES\&H STANDARDS OF VENDOR SITES AS NECESSARY (PM AND DMT WITH CWMD AND ENVIRONMENTAL AND SAFETY ACTTVITIES STAFF)}

ES\&H evaluation criteria have been collected into an offsite facilities checklist developed by the Energy Systems CWMD. The "Martin Marietta Energy Systems, Inc., Offsite Facilities Conducting Treatability Studies Checklist" is presented in Appendix G. This checklist includes detailed ES\&H evaluation information for vendor sites. A similar but more extensive checklist is available for vendor sites involved in full-scale waste treatment activities (See also Sect. 4.10). 
Management steps for evaluation of vendor ES\&H include:

1. Evaluate vendor ES\&H plan as needed (See also Sects. 4.10 through 4.12).

2. Initiate vendor site ES\&H evaluations as necessary (See also Sects. 4.10 through 4.12 and Appendix G).

\subsection{ENSURE COMPLIANCE WITH ENGINEERING POLICIES AND PROCEDURES (PM AND DMT RESPONSIBLE, WITH SITE ENGINEERING STAFF AS CONSULTANTS)}

The engineering staff for each site will have knowledge of the engineering policies and procedures applicable at that site. These policies and procedures have been developed to assist the sites in prevention of environmental/safety-related problems (e.g., diking for storage tanks). For example, an important Y-12 Plant document is Design Standards for Hazardous/Toxic Waste and Material Storage Tanks, Dikes, and Transfer Stations, Y/TS-104. Compliance with site engineering policies and procedures will help ensure adequate coverage of environmental and safety concerns.

\subsection{ACCOMPLISH PROCUREMENT ACTIVITIES AS NEEDED (PM AND DMT RESPONSIBLE THROUGH ENERGY SYSTEMS PROCUREMENT/ PURCHASING STAFF)}

Management steps for the procurement activities area are:

1. Arrange a procurement briefing with Energy Systems Procurement/Purchasing staff for the demonstration management staff.

2. Follow standard procurement procedures including appropriate documentation.

\subsection{PREPARE AND ENSURE COMPLIANCE WITH DEMONSTRATION QUALITY ASSURANCE PLAN (PM AND DMT RESPONSIBLE, WTTH SITE QA STAFF AS CONSULTANTS)}

A properly prepared and used QA plan provides a pathway for monitoring the performance of projects in accordance with applicable management requirements. (See 
Appendix $\mathrm{K}$ for example of QA plan.) The demonstration QA plan includes project quality procedures, work plans, reports, and documentation. Quality control $(\mathrm{QC})$ is asserted through routine surveillance and, as appropriate, periodic audits. In order to correct nonconforming items or data and to satisfy findings issued during each audit, necessary corrective actions will be identified in the surveillances and audits. Management steps include:

1. Develop a demonstration QA plan early in the project cycle.

2. Evaluate vendor QA plan as needed.

3. Develop and maintain a documentation file (See also Sect. 4.17).

4. Conduct QA surveillance as needed and take indicated and necessary corrective actions.

5. Ensure compliance with the demonstration QA plan.

\subsection{DEVELOP AND MAINTAIN A RECORD AND DOCUMENTATION FILE (PM AND DMT RESPONSIBLE, WTTH SITE QA STAFF AS CONSULTANTS)}

All important documents must be maintained in an appropriate file or location. This is important for QA purposes and to provide a "permanent" record of the demonstration. Management steps include:

1. Develop and maintain a documentation file for all significant documents, for example:
(a) Proposal preparation documentation
(b) SOW
(c) RFP
(d) Proposal approvals
(e) Proposal funding approvals
(f) Financial plans
(g) Vendor contracts
(h) Project Description
(i) Project Plan
(j) All specific management plans
(k) Equipment drawings
(l) Engineering flowsheets 
(m) Quantities of material used and the ultimate disposition of these materials.

(n) Secondary waste(s) management

2. Ensure that the documentation file complies with the Energy Systems Policy for Document Control (ESS.6.1)

\subsection{PERFORM NECESSARY SITE AND/OR WASTE CHARACTERIZATIONS (PM AND DMT RESPONSIBLE, WITH SITE MANAGEMENT, ANALYTICAL, AND STATISTICAL STAFF AS CONSULTANTS)}

Additional characterization information may be required. Such characterization may require the development of a sampling and analysis plan and subsequent chemical analyses. Management steps include:

1. Consult with statisticians, hydrogeologists, and risk assessment experts as necessary for development of sampling and analysis plan.

2. Develop sampling and analysis plan.

3. Sample and analyze in conformance with the sampling and analysis plan.

\subsection{COORDINATE STTE PREPARATION FOR DEMONSTRATION (PM AND DMT TEAM RESPONSIBLE ASSISTED BY SITE ENVIRONMENTAL COORDINATOR AND PLANT AND EQUIPMENT STAFF)}

1. Ensure compliance with site waste management requirements.

2. Ensure compliance with site security requirements.

3. Coordinate site or plant services requirements.
(a) Plant and Equipment staff
(b) Engineering Division staff
(c) Site security staff
(d) Site utilities staff
(e) Site fire department staff
(I) Site waste management staff

4. Coordinate sampling and analytical nzeds. 
5. Ensure compliance with all required site work permits.

6. Ensure compliance with all applicable plans and requirements (e.g., ES\&H plans, QA plans).

\subsection{CONTROL ACCESS TO DEMONSTRATION SITE (PM AND DMT RESPONSIBLE)}

Ensures that only authorized people are granted access to the demonstration site (See also Sect. 4.12).

\subsection{DEVELOP AND COORDINATE PUBLIC RELATIONS (PR') ACTIVTIIES AS NEEDED (PM AND DMT RESPONSIBLE THROUGH ENERGY SYSTEMS PR DEPARTMENT)}

1. Obtain adequate photo documentation.

2. Consider PR at appropriate times.
(a) Vendor contract letting
(b) Demonstration ending
(c) "Successful" happenings
(d) Publication of results

2. Coordinate PR activities with site management and the site PR representative.

\subsection{SCHEDULE AND CUORDINATE DEMONSTRATION REVIEWS, SENIOR MANAGEMENT READINEAS REVIEWS, AND APPROVAL MEETINGS (PM AND DMT RESPONSIBLE)}

The readiness review plan (See Appendix L) prepared in accordance with Energy Systems policy (ORP, GP-24) identifies the number of readiness reviews. Two readiness reviews are recommended at a minimum. The first review is designed to permit a review of all factors to determine if the demoustration is ready to be presented to DOE and Energy Systems senior management for readiness review and approval to proceed. If the demonstration is considered ready after the first review, the senior management review should be scheduled. Management steps include: 
1. Ensure the preparation of a readiness review plan.

2. Define responsibilities for the review.

3. Define required actions.
(a) Project Plan review
(b) Safety assessment review
(c) Site risk assessment
(d) Regulatory compliance review
(e) Site preparation review
(f) Demonstration operations review
(g) Other pertinent considerations

4. Establish approvals required to proceed with the demonstration.

5. Determine how the approvals will be obtained.

6. Determine how the approvals will be documented.

7. Schedule demonstration reviews as necessary.

8. Schedule senior management reviews as necessary.

9. Obtain necessary approvals.

(a) Vendor as needed

(b) Energy Systems management (as appropriate)

(1) WR\&D Program Director

(2) Site Demonstration Coordinator

(3) Site Environmental Coordinator

(4) Site Manager or representative

(5) CWMD Director or representative

(6) ERD Director or representative

(7) ES\&H Director or representative

(c) DOE Site Manager

(d) DOE Program Manager or representative

10. Obtain document approvals. 


\section{MANAGEMENT STEPS FOR THE CONDUCT OF DEMONSTRATION AND CLOSEOUT}

After approval by the Energy Systems senior management oversight team, the DOE Site Manager, and the DOE/OR Program Manager or representative, the demonstration is ready for performance. The following sequential management steps are required:

\subsection{DEMONSTRATION SETUP (PM AND DMT RESPONSIBLE)}

1. Ensure that the demonstration setup meets all established criteria
(a) Site preparation
(b) Utilities (electric, air, water)
(c) Building facilities
(d) Equipment installation
(e) Equipment checkout

2. Ensure compliance with the readiness review plan and consideration of all issues as may be required by the RRB or that have been identified in the operational readiness process (GP-24).

\subsection{ENSURE DEMONSTRATION READINESS (PM AND DMT RESPONSIBLE)}

Ensure that the readiness review process is complete for the demonstration and that the demonstration activities are in compliance with the readiness review criteria and plan.

1. Inspect site for adequate preparation.

2. Determine availability of utilities (electric, air, water, telephones).

3. Inspect building facilities for adequateness.

4. Inspect equipment.

5. Check out equipment to ensure operational readiness.

6. Ensure readiness of operational personnel.

(a) For safe operation 
(b) For collection of data

(c) For QA/QC

7. Alert ancillary site personnel.

8. Alert security concerning operational status.

9. Ensure site control processes are in place.

10. Ensure waste management plan is in effect.

11. Determine availability of waste to be treated.

12. Ensure capability of handling waste output.

13. Establish communications and chain of command as needed.

\subsection{OPERATE DEMONSTRATION AND COLLECT DATA (PM AND DMT RESPONSIBLE)}

1. Ensure compliance with Project Plan.

2. Ensure maintenance of appropriate operational logs.

3. Ensure collection of requisite data.

4. Ensure filing of appropriate QA documentation.

5. Ensure adherence to ES\&H standards.

6. Ensure good management practices.

\subsection{CLOSEOUT OF DEMONSTRATION (PM AND DMT RESPONSIBLE)}

1. Obtain approval for disassembly or moving of demonstration equipment. Consult with:
(a) Site Health Physics
(b) Site Industrial Hygiene
(c) Site ES\&H representative
(d) Vendor representative as necessary

2. Decontaminate and/or decommission (D\&D) equipment as necessary. Consult with:
(a) Site D\&D management
(b) Site D\&D personnel
(c) Site Waste Manager 
(d) Site Environmental Coordinator

(e) Vendor representative as necessary

3. Restore demonstration sites to acceptable criteria as defined in Project Plan. Consult with:

(a) Site Plant and Equipment personnel

(b) Site Environmental Coordinator

(c) Site Demonstration Manager

(d) Vendor representative as necessary

4. Dispose or store treated and untreated waste. Waste management should be conducted in compliance with the project plan or specific demonstration waste management plan, if prepared. Consult with:
(a) Site Waste Manager
(b) Site Environmental Coordinator
(c) Vendor representative as necessary

5. Dispose, store, or treat secondary waste. Waste management should be conducted in compliance with the project plan or specific demonstration waste management plan, if prepared.

(a) Site Waste Manager

(b) Site Environmental Coordinator

6. Depending upon the magnitude of the demonstration, RCRA closure may be necessary.

\subsection{ANALYZE PROCESS AND OPERATIONS DATA (PM AND DMT RESPONSIBLE)}

The analysis of process and operations data is critically important for evaluation of the demonstration technology or equipment. Standard and thorough scientific and engineering analysis should permit development of statistically significant conclusions from the demonstration. Analysis should include, but not be limited to, the following categories:

1. Chemical data

2. Engineering data

3. I'rocess effectiveness 
4. Cost estimations

5. Personnel requirements

6. Lessons learned

\subsection{PREPARE DEMONSTRATION REPORTS (PM AND DMT RESPONSIBLE)}

The final step in a successful demonstration is the documentation of the demonstration results. This is usually accomplished by publication of the final report. Without dissemination of demonstration conclusions and information the demonstration can not be considered as completed.

Management steps include:

1. Ensure preparation of vendor reports as necessary.

2. Prepare Energy Systems reports as required.

3. Close out all open accounts and/or work orders.

4. Prepare financial reports as required.

5. Initiate and conduct technology transfer, if appropriate.

6. Prepare appropriate PR materials on the demonstration, such as technical papers, brochures, and video. 


\section{APPENDIX A}

\section{REQUTREMENTS FOR RESEARCHERS INITIATING TREATABILITY STUDIES ON HAZARDOUS WASTES DEFINED UNDER THE RESOURCE CONSERVATION AND RECOVERY ACT (RCRA)}

\section{Small-Scale Treatability Studies}

This discussion outlines the requirements that all researchers must meet in order to maintain the treatability study exemptions while conducting treatability studies on RCRA hazardous wastes. First, the regulations stipulate certain operating limitations must be met. These limitations are:

1. No more than $1000 \mathrm{~kg}$ of nonacute hazardous waste (i.e., characteristically hazardous, spent solvents, or U-listed waste); $1 \mathrm{~kg}$ of acute hazardous waste (i.e., P-listed waste); or $250 \mathrm{~kg}$ of soil, water, or debris contaminated with acute hazardous waste is received for use in the study. ${ }^{1}$

2. No more than a total of $250 \mathrm{~kg}$ of "as received" waste from the generator can be tested on a single day.

3. No more than $1000 \mathrm{~kg}$ of waste (excluding treatment residues that are generated) may be stored in the laboratory.

4. Wastes and residues must be returned to the generator or shipped to a permitted or interim status facility within $90 \mathrm{~d}$ after the study stops or within 1 year of its receipt from the generator, whichever occurs first.

Second, adequate records pertaining to the study must be maintained. The records must demonstrate compliance with the treatment rates limits, the storage time, and quantity limits. Additional records to be maintained include treatment information, shipping papers, and study contracts or agreements. In addition, an annual report on all treatability studies must be

${ }^{1}$ Refer to Title 40 Code of Federal Regulations part 261.20 through 261.33 or Tennessee Rule 1200-1-11-.02(3) through 40 for information on acute and nonacute hazardous wastes. 
prepared and submitted annually to the regulators. All of the above records, which demonstrate compliance with the regulations, must be maintained for 3 years following the completion of each study.

Researchers must submit the information for their studies to RCRA compliance staff (N. S. Dailey, ORNL; A. G. Hodgson, K-25; M. S. Burris, Y-12 and ORNL/Y-12) for their facility by February 7 of each year, beginning in February 1991. The RCRA compliance staff will then compile the overall submittal for their respective facilities.

In order to promote compliance with the regulations, all researchers must submit notification forms for planned treatability studies to the RCRA compliance staff. That information must be submitted a minimum of $10 \mathrm{~d}$ in advance of the receipt (via mail or shipping) of any hazardous waste for the purpose of conducting treatability studies. RCRA compliance staff should be contacted for guidance on how to arrange for the delivery (via mail or shipping) of RCRA hazarcious waste.

Further information on treatability studies is being transmitted to all ORNL Division Directors and Environmental Protection Officers. That information package includes the notification forms and annual report information to submit. Contact your Environmental Protection Officer or your RCRA compliance staff for a copy of the information package.

\section{Research, Development, and Demonstration (RD\&D) Permits}

RD\&D Permits are issued by the state of Tennessee for treatment facilities for studies involving innovative and experimental hazardous waste treatment technologies for which specific treatment or disposal permit standards are not promulgated. An RD\&D permit covers both facility construction and operation and is granted on an annual basis. Renewals are allowed for up to 3 years.

Researcil cfforts involving quantities of hazardous wastes in excess of that allowed under the treatability exclusion would require submittal of an RD\&D permit application to the Tennessee Department of Health and Environment (TDHE). That application would address facility operation, maintenance, closure, remedial action, and sampling. The final operating permit issued by TDHE can impose limits on the types and quantities of hazardous waste used in the research. That permit can also impose any or all of the standards set for 
permitted treatment or disposal facilities. The overall submittal and TDHE review and approval process could take up to 1 to 2 years to complete and could be very costly.

Thus, researchers planning larger-scale studies on hazardous waste must consult with their RCRA compliance staff members very early in the planning process for that research. If not, lengthy delays may be incurred as a result of the RD\&D permitting process. 


\section{APPENDIX B \\ PROCUREMENT OF VENDOR CONTRACT}

1. The demonstration project manager (PM) assumes the responsibility for procuring the outside vendor. He prepares the draft statement of work (SOW) which describes the services/processes/products requested from the private sector depending upon the project boundary conditions (e.g., objectives, funding, schedules). The PM can prepare the SOW himself/herself or, depending upon the magnitude of the project, can involve the demonstration management team (DMT) in the preparation of the draft SOW.

2. The draft SOW is reviewed by the appropriate people (e.g., the DMT and the project sponsor) for completeness and accuracy.

3. The PM reviews the comments received on the draft SOW and makes the necessary corrections.

4. The PM then prepares the 1127 Form for placing the subcontract. If the demonstration is to be contracted to only one particular vendor, the PM needs to also complete the "Justification for Sole Source Procurement" form (UCN-15918).

5. The PM submits the above package [Form 1127, SOW, Sole Source Justification (if needed)] to the sponsoring Energy Systems (ES) division/organization for approval and onward transmission to ES Procurement.

6. ES Procurement prepares and issues the Request for Proposals (RFPs) to obtain the needed services/processes/products. The PM should work with ES Procurement staff and review the RFP for completeness and accuracy.

7. The DMT reviews responses to the RFP and approves the vendor(s) to be awarded the subcontracts.

8. Procurement/Purchasing prepares and executes the contracts with the vendor organizations that are to be awarded the subcontracts.

9. The PM then deals directly with the vendor project manager. 
APPENDIX C

EXAMPLE OF PROJECT DESCRIPTION

\section{Co-Metabolic Bioreactor Demonstration at the Oak Ridge K-25 Facility}

\section{Version 4}

S. E. Herbes

T. L. Donaldson

M. I. Morris

A. V. Palumbo

G. W. Strandberg

November 1990

Prepared by the Oak Ridge National Laboratory Oak Ridge, Tennessee 37831 operated by MARTIN MARIETTA ENERGY SYSTEMS, INC. for the U. S. DEPARTMENT OF ENERGY under contract DE-AC05-840R21400

\section{CAUTION}

This document has not been given final patent clearance and is for internal use only. If this is to be given public releas:; it must be cleared through the site Technical Information Office which will see that the proper patent and technical information reviews are completed in accordance with Energy Systems policy. 


\section{Table of Contents}

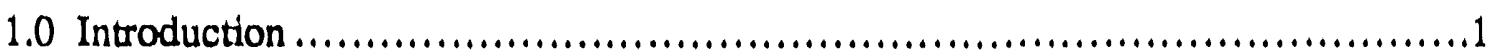

1.1. Objectives of the Project.............................................

1.2. Scope ..............................................................

1.3. Background and Rationale .......................................

1.4. Project Organization.................................................

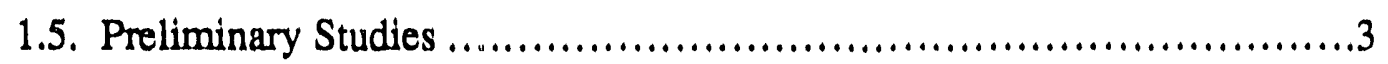

1.5.1. Laboratory tests ............................................

1.5.2. Bench-scale tests........................................4

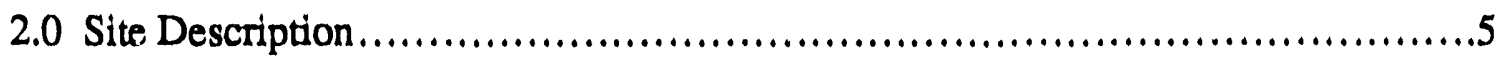

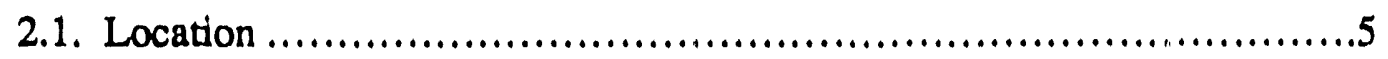

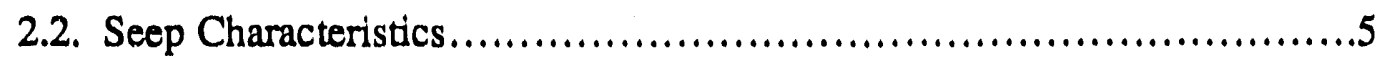

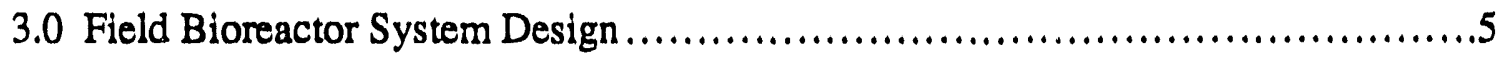

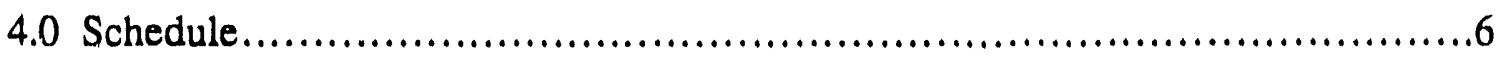

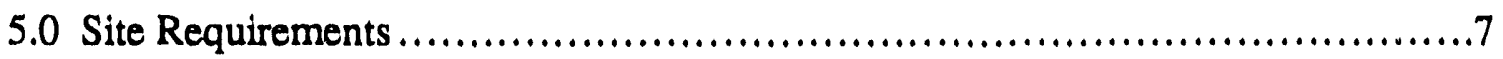

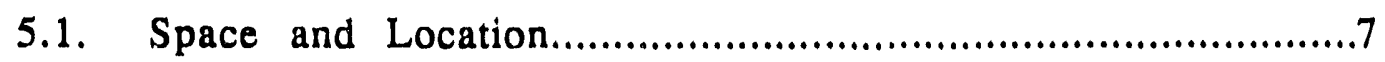

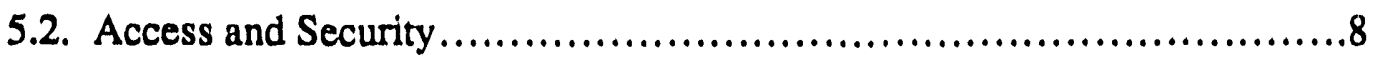

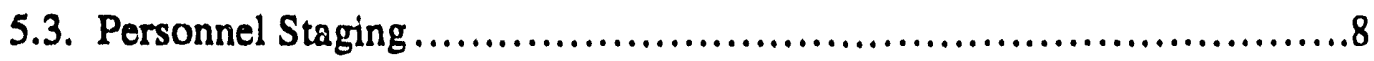

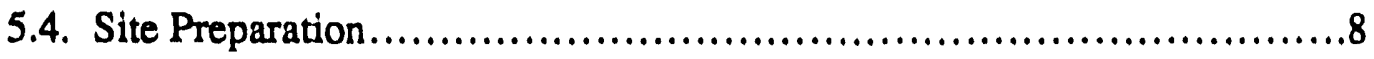

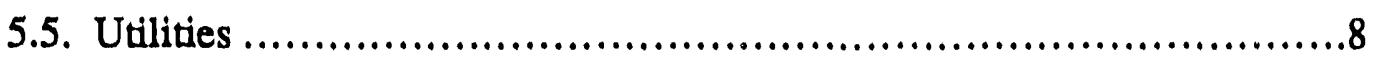

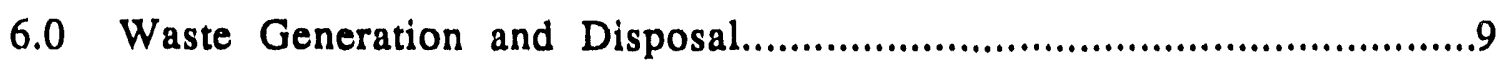

6.1. Composition and Volume of Expected Waste Streams .....................9

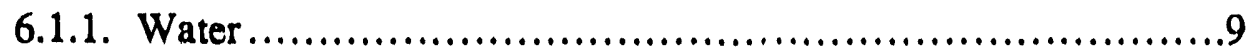

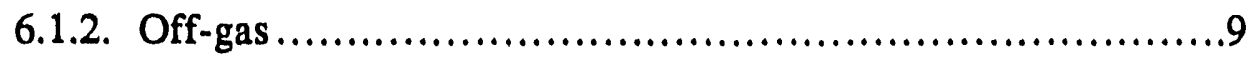

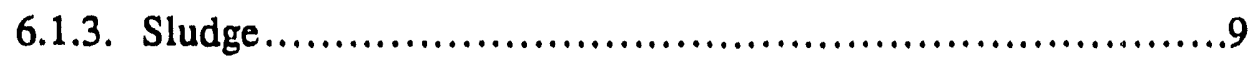

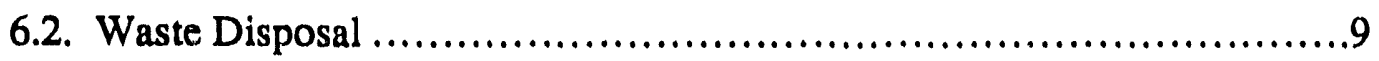

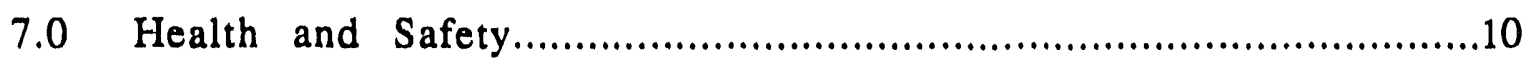

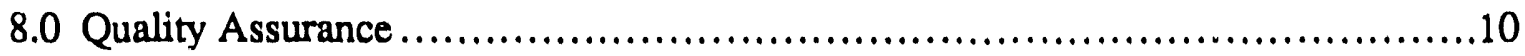

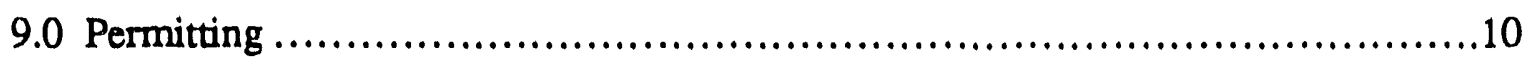

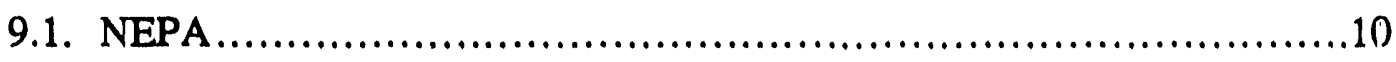

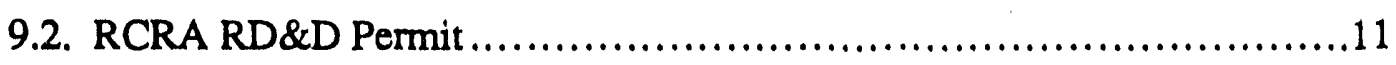

9.3. Site Requirements ....................................................

10.0 Contracts and Legal Issues .............................................11 


\section{Co-Metabolic Btoreactor Demonstration at the Oak Ridge K-25 Facility}

\subsection{Introduction}

This demonstration project is to be conducted by Oak Ridge National Laboratory (ORNL) for the U. S. Department of Energy (DOE) Office of Technology Development. The project consists of installation and operation of two types of biological treatment systems (i. e. bioreactors), using as influent groundwater contaminated with mixed organic compounds from a seepage flow at the K-25 Plant in Oak Ridge, Tennessee. The demonstration will be conducted by ORNL staff and subcontractors, in collaboration with the K-25 Health, Safety, and Environmental Affairs (HS\&EA) Division and the Environmental Restoration Division.

\subsection{Objectives of the Project}

The goal of the project is to demonstrate the effectiveness of two innovative bioremediation technologies, based on co-metabolic processes, to remediate groundwater contaminated by mixed organic solvents at DOE sites. The specific project objectives include:

1. Maximize the rate and extent of removal of trichloroethylene (TCE) from the influent waste stream by each of the two bioremediation technologies;

2. Evaluate the effectiveness of removal of the other organic contaminants by the two systems;

3. Evaluate the process economics of the two systems;

4. Compare the relative performance of the two systems on the basis of the above criteria.

\subsection{Scope}

The project consists of:

1. Completion of bioreactor design, operation, QA/QC, health/safety, and waste management plans, and acquisition of all necessary permits;

2. Optimization of microbial cultures and nutrient levels through initial laboratory tests;

3. Optimization of bioreactor design and operating conditions through testing of benchscale units;

4. K-25 site preparation and utility hookup;

5. Modification of two existing skid-mounted bioreactor units;

6. Installation of one bioreactor unit, with associated reagent and waste containers, at the test site;

7. Operation of the unit for four months;

8. Subsequent installation of the second unit:

9. Operation of the two units simultaneously for a four-month period; 
10. Shutdown of site operation, decontamination of equipment, and disposal of generated waste;

11. Analysis of data and generation of a final report;

12. Communication of results to DOE and to private vendors through technology transfer.

\subsection{Background and Rationale}

Groundwater contaminated with organic compounds, especially solvents such as benzene, TCE, perchloroethene (PCE), carbon tetrachloride, and chlorinated ethanes, is a problem at many DOE sites. Some of the facilities at which these groundwater contaminants have been identified include: the Feed Materials Production Center (Fernald, OH); the three Oak Ridge facilities (K-25, Y-12, and ORNL); Mound Laboratory; the Kansas City Plant; and the Savannah River Plant.

One of the most promising new technologies for removal of these contaminants from groundwater is bioremediation, both by above-ground, contained units (i. e. bioreactors) and by in situ techniques. For TCE removal, bioremediation techniques employing two general groups of microorganisms are presently being investigated: methanotrophs (methane-utilizers), and toluene-utilizers. Both are based on co-metabolic degradation, i. e. fortuitous degradation of the target contaminant (TCE) by organisms which are utilizing another compound as a growtis sibstrate.

Application of methanotrophs to TCE degradation has been demonstrated at bench-scale by the CRNL researchers involved in this project, and at the field-scale by Battelle-Columbus Laboratories; the latter group constructed the bioreactor unit which will be employed during the initial phase of the present demonstration. Use of toluene-degrading microorganisms in TCE removal has been demonstrated in laboratory studies, initially by the U. S. Environmental Protection Agency (EPA) Gulf Breeze, Fla., Laboratory and more recently by other groups.

Work proposed during the initial three years of this project will consist of comparative demonstrition of the two bioreactor types utilizing groundwater contaminated with organic compounds which emerges as a seepage flow at the K-25 Plant in Oak Ridge. The seepage flow contains TCE, PCE, benzene, toluene, chlorinated ethanes, and other volatile organic solvents at a total concentration of several parts per million.

The K-25 site, as well as other Oak Ridge sites, are on the National Priority List, and thus falls under the jurisdiction of both CERCLA and DOE/EPA Interagency Agreements. These regulations require consideration of alternatives for remediation. This demonstration project will permit evaluation of two promising bioremediation technologies, and should lead to remediai alternatives which may prove both more effective and less costly than other altematives. More generally, the demonstration will provide valuable information on the applicability of bioremediation to a groundwater contamination problem which is a high priority at numerous DOE sites.

\subsection{Project Organization}

The project will consist of four tasks:

Task 1: Planning/permitting 
Task 2: Methanotroph bioreactor development/demonstration

Task 3: Toluene-degrading bioreactor development/demonstration

Task 4: Closure/reporting

Principal project staff, and their organizational affiliations and primary responsibilities, are detailed below:

\section{S. E. Herbes. Environmental Sciences Division (ESD): Project Coordinator}

- Overall responsibility for project

- Preparation and implementation of project planning documents, including technical, health and safety, waste management, and $\mathrm{QA} / \mathrm{QC}$ plans

- Preparation and submittal of all necessary permit and approval requests

- Reporting

T.L. Donaldson. Chemical Technology Division (CTD): Task 2 Coordinator

- Development and implementation of methanotroph bioreactor system

\section{A.V. Palumbo (ESD): Task 3 Coordinator}

- Development and implementation of toluene-degrading bioreactor system

- Culture acquisition/maintenance, laboratory screening, and nutrient optimization for both Tasks 2 and 3

- Development of biomonitoring techniques for bioreactor microbial populations for both Tasks 2 and 3

\section{G.W. Strandberg (CTD)}

- Planning and conducting of bench-scale bioreactor optimization studies for Task 2

\section{M. . Morris (CTD)}

- Development and implementation of task/schedule tracking system

- Development and implementation of budget/cost tracking system

- Liason with K-25 site organizations

\subsection{Preliminary Studies}

\subsubsection{Laboratory tests}

The purpose of the laboratory studies is to determine what cultures and culture conditions should be tested in the bench scale bioreactors. Dw, to their simplicity and rapidity, use of the batci iaboratory systems wiil ailiow testing of a greater number of combinations of 
cultures and conditions than will be possible with the bench scale bioreactors. Thus they will serve as a screening mechanism for bench scale bioreactor tests.

A series of laboratory tests using batch cultures will be used to compare the abilities of different methane- and toluene-utilizing consortia to degrade TCE in the presence of the contaminants found at the site. Initial tests will use synthetic media and TCE, to which will be added increasingly complex mixtures of the organic contaminants found at the site. Site seep water will then be used for treatability studies. The effect of changes in culture conditions, including supplemental carbon sources and modifications of nutrient conditions, will be tested to increase the rate and extent of TCE degradation.

Toluene-degrading and methane-utilizing cultures will be obtained from a number of sources. Methane-utilizing cultures presently on hand include three cultures isolated from the Y-12 Plant, and one mixed culture isolated from the Kansas City (Mo.) Plant. Additional methane-utilizing and toluene-degrading cultures will be obtained from outside companies and universities. Attempts will also be made to isolate toluene-degrading and methane-utilizing consortia from the K-25 site water by enrichment techniques.

Specific criteria for cultures and conditions to be tested in the bench scale bioreactors include:

- Rate and extent of TCE degradation

- Stability of the microbial degradation activity with continued exposure to the site water

- Rate and extent of degradation of other compounds of regulatory concem

- Nutrient requirements (i. e. site water supplements)

\subsubsection{Bench-scale tests}

Six bench-scale (approx. 1-L) fixed-film bioreactors will be operated using cultures selected from laboratory tests (Section 1.5.1). Initial tests will employ methane-utilizing microorganisms (Task 2); later tests will investigate toluene-degrading microorganisms (Task 3). Reactors will be established initially using a synthetic growth medium; the site seep water will then be used to derermine treatability. Physico-chemical adjustments of the influent water will be employed to optimize conditions for microbial activity and removal of organic contaminants. Specific criteria to determine which cultures will be utilized in the field demonstration will include:

- Rate and extent of TCE degradation;

- Rate and extent of degradation of other organic contaminants of regulatory concern;

- Nutrient requirements (including methane use);

- Culture stability;

- Need for site water pretreatment. 


\subsection{Site Description}

\subsection{Location}

The seep which will serve as influent to the bioreactor is located adjacent to the east side of Avenue D, about $110 \mathrm{ft}$ south of the center of the intersection with 9 th Street, on the eastern portion of the K-25 facility (Figure 1). The seep flows from a PVC pipe imbedded at the foot of a 6-ft-high slope, and presently drains through an open concrete channel along the road into a storm drain (SD-180-04) approximately $80 \mathrm{ft}$ north of the seep. The seep is located approximately $200 \mathrm{ft}$ west of the boundary of the K-1070-C/D Classified Burial Ground.

\subsection{Seep Characteristics}

The base seep flow has appeared, by occasional observation, to be relatively constant at several gal/min during spring and summer 1990. Flow increases during and immediately following storms, and reportedly has stopped completely during extended dry periods in the past (D. Kucsmas, pers. commun.).

Chemical characteristics of the seep were determined on water samples collected from the SD-180-04 storm drain during May-June 1987. More recent analyses were conducted on samples collected directly from the seep outflow during April 1990. The 1987 analyses are summarized in Table 1; the more recent data are included as Table 2.

\subsection{Field Bioreactor System Design}

The bioreactor systems operate on the principle of co-metabolic degradation of TCE and associated contaminants. Microorganisms are grown in the bioreactor in the presence of oxygen and nutrients, with an added carbon source (either methane or toluene). Degradation of TCE occurs fortuitously during utilization of the organic substrate.

The field demonstration will consist of operation of two bioreactor units: one during the period of June-Septeml -1991 , and the second during the same period in 1992. The two units may be operated in parallel during the 1992 operating campaign.

Each field bioreactor will consist of:

- Piping from the seep to the bioreactor unit;

- An influent pump and associated valving and controls;

- A pretreatment filter, ion exchange unit, steam stripper, and/or other pretreatment option(s) (yet to be selected);

- The bioreactor unit itself;

- One or more tanks for the carbon substrate (either pressurized methane or a dilute aqueous toluene solution);

- Tank for the nutrient feed solution (a dilute aqueous solution of ammonium phosphate plus trace minerals);

- An off-gas scrubber (if required); 
- Piping and valving for operation in recycle mode;

- Piping to return the effluent to the storm sewer;

- Safety monitoring instrumentation and process controls.

Two skid-mounted bioreactor units will be obtained from Tyndall Air Force Base for the field test. Each consists of two columns (approximately 12 in. diameter by $7 \mathrm{ft}$ tall) plus associated plumbing, pumps, and con'rol panel. The units will be shipped to ORNL for cleaning and any needed repairs. Minor modifications will be performed at this time. If preliminary studies indicate that pretreatment (filtration, water softening, etc.) is needed, equipment will be added to the skids at this time.

To protect the units from inclement weather they will be housed in a van trailer (approximately $47 \mathrm{ft}$ long) at the site.

A conceptual diagram of the methanotroph bioreactor system is shown in Figure 2. A single skid-mounted bioreactor unit is shown schematically in Figure 3. The methanotroph system to be operated during the 1991 campaign will involve pumping of the seep water influent into one of the skid-mounted units, where the water will be contacted with air and methane.

The methane concentration ( $3 \% \mathrm{v} / \mathrm{v}$ in air) will be maintained below the lower explosive limit $(5 \% \mathrm{v} / \mathrm{v})$ to minimize hazard, and the bioreactor will be equipped with a shut-down system to protect against dangerous methane levels. Methane-air will be stored in $300 \mathrm{cu}$. $\mathrm{ft}$. tanks at a pressure of approximately $3000 \mathrm{psig}$. The maximum use rate is expected to be one cylinder per day. A maximum of 5 cylinders will be connected through a manifold.

Initial tests indicate that pretreatment of the influent stream will almost certainly be required to avoid precipitation of iron in the bioreactors. If ion exchange is selected as a pretreatment procedure, an ion exchange column will be inserted just ahead of the surge and $\mathrm{pH}$ adjustment tank (Figure 2).

An alternate pretreatment technique which may be employed, either instead of or in parallel to ion exchange, is steam stripping. Incoming water will be routed through a conventional packed-bed steam-stripping column, in which a fraction of the water is volatilized via steam injection or superheating of the feed. Volatiles are carried overhead with the water vapor, treated water containing the non-volatile constituents would exit the bottom of the stripper. The overhead water vapor and volatiles are condensed and are input to the bioreactor for degradation of the volatile organics. Effluent from the bioneactors would be recycled into the steam stripper influent; the stripper bottoms would thus constitute the entire effluent stream. The technical feasibility of this process is still being evaluated, and a bench-scale demonstration will be conducted in late CY 1990.

\section{4.l Schedule}

The project was initiated on April 15, 1990. Work to date has included plan and permit preparation, initial laboratory-scale screening tests, construction and startup of bench-scale bioreactor units, and initial modification of the field bioreactor unit.

Major milestone dates for the field demonstration include the following:

- Initiate site preparation 
- Install bioreactor 1 equipment on-site

$2 / 12 / 91$

- Initiate bioreactor 1 starup/shakedown testing

$4 / 11 / 91$

- Initiate bioreactor 1 operation using site groundwater

$6 / 03 / 91$

- Complete initial bioreactor 1 operating campaign

9/27/91

-Install bioreactor 2 (toluene-degrading unit)

$1 / 30 / 92$

- Initiate bioreactor 2 startup/shakedown testing

$3 / 31 / 92$

- Initiate operation of bioreactor 2 using site groundwater

$5 / 29 / 92$

- Initiate operation of bioreactor 1 (2nd campaign) $\quad$ 6/02/92

- Terminate bioreactor operation $\quad$ 9/28/92

- Complete decommissioning

$12 / 30 / 92$

- End of project

$12 / 30 / 92$

A Gantt chart showing the phases of the project which relate to the field demonstration is shown in Figure 4. Activities have been scheduled to meet a startup date for the methanotroph bioreactor, using site groundwater, of 3 June 1991. To meet this schedule, the K-25 Readiness Review must be completed to permit initial startup/shakedown of the bioreactor by 11 April 1991.

\subsection{Site Requirements}

\subsection{Space and Location}

The two skid-mounted units with associated tanks and equipment will require protection from inclement weather, and thus will be housed in a van trailer. The trailer will require an area of approximately $12 \mathrm{ft} \times 50 \mathrm{ft}$.

The two units should be placed as close as possible to the seep. Options for locating the units include:

1. Construction of a gravel pad adjacent to the east side of Avenue $D$;

2. On Avenue $D$ itself (which is presently barricaded about $100 \mathrm{ft}$ south of the seep;

3. The asphalt parking lot on the west side of Avenue D adjacent to Bldg. 1098-G.

To minimize site preparation, the preferred location of th: trailer containing the bioreactor units is Option 3. This location will necessitate installation of pipes across Avenue $D$ to transport water from the seep to the bioreactors and to return the effluent to the seep discharge point. 


\subsection{Access and Security}

The bioreactor demonstration site is within a secured area of the K-25 facility. Access to this site by personnel other than L-cleared Martin Marietta Energy Systems employees will require an escort by a cleared employee. Access requirements will be detailed in a formal Health and Safety Plan.

The site control procedure will be developed and shall be implemented to control the potential of employee exposure to hazardous substances. These requirements will be mandatory for all on-site personnel. The requirements for access will be based on 29 CFR 1910.120, Hazardous Waste Operations and Emergency Response, Final Rule, March 6, 1989. In addition, K-25 Health Physics, Industrial Hygiene, Safety, and the Plant Support and Protection Division, and others, may have special requirements concerning site access that will be incorporated into the Health and Safety Plan.

The primary requirement associated with work at the site will be proof of completion of 24 hours of initial OSHA/SARA training and up-to-date 8-hour annual refresher training. Personnel that do not have proof of completion of the above training shall be denied approval to work at the site.

\subsection{Personnel Staging}

Personnel staging requirements will be detailed in the formal Health and Safety Plan to be prepared for the field demonstration.

\subsection{Site Preparation}

Site preparation requirements will include:

- A gravel pad (approximately $12 \mathrm{ft}$ by $50 \mathrm{ft}$ ) if the van trailer for the bioreactors is placed on the grass adjacent to Avenue D. This would not be required for the other two options.

- A dike and liner beneath the trailer may be required as secondary containment; an alternate containment design is a drip pan beneath each skid-mounted bioreactor unit within the trailer.

- A water line for the seep effluent will need to be installed across Avenue $D$ if the units are set up in the Bldg. 1098-G parking lot.

\subsection{Utilities}

The project will require the following:

- Process water (maximum flow: $1 \mathrm{gal} / \mathrm{min}$ ) for preparation of nutrient solutions and general equipment washing and flushing;

- Electricity (120 VAC, $30 \mathrm{amp})$;

- Compressed air (50 psi $\sigma)$.

- Low-pressure steam (if steam stripping is selected for pretreatment). 


\subsection{Waste Generation and Disposal}

\subsection{Composition and Volume of Expected Waste Streams}

\subsubsection{Water}

The treated bioreactor effluent (maximum flow: $1 \mathrm{gal} / \mathrm{min}$ ) will contain the same volatile organics as the untreated seep water (although decreased incrementally in concentration due to microbial degradation). Added constituents will include: dissolved methane; microorganisms washed from the bioreactors (estimated final concentration: $10 \mathrm{mg} / \mathrm{L}$ of suspended microorganisms); nutrients and trace metals added to the influent to support the microbial culture and incompletely removed by the microorganisms.

Nutrients which may be added to the seep flow are listed in Table 3. Nutrients will be added as a concentrated aqueous solution and will be diluted 1:100 by the seep flow. The effluent stream will contain these constituents at concentrations no greater than those listed in Table 3.

If steam stripping is used as pretreatment, the concentrations of inorganic constituents in the seep water would be unchanged. If ion exchange is used, concentrations of iron, magnesium, and calcium will be reduced in the effluent stream.

\subsubsection{Off-gas}

The expected off-gas flow rate is $0.2 \mathrm{cfm}$; constituents will include methane (approximately $0.01 \mathrm{cfm})$, and trace concentrations of TCE and other VOCs.

\subsubsection{Sludge}

A chemical sludge, consisting of precipitated iron, may be produced if pretreatment of the influent is required. The quantity of sludge produced is unlikely to exceed $1 \mathrm{lb} /$ day.

If ion exchange is employed as a pretreatment option, spent ion exchange resin will be produced. The rate of production is likely to be less than one 20-lb cartridge per month. The use of steam stripping as a pretreatment would produce no solid waste.

Biosludge will be produced periodically from flushing of the bioreactors. The total volume produced is not expected to exceed $5 \mathrm{cu}$. ft $(300 \mathrm{lb})$ over the life of the demonstration.

\subsection{Waste Disposal}

Water treated through the bioreactor(s) will be returned directly to the storm drain at the point of removal, for disposal in the same manner as the untreated portion of the seep flow. Maximum flow will be $1 \mathrm{gal} / \mathrm{min}$.

Initially the effluent will be stored in the effluent holding tank while analyses are conducted to ensure that added constituents (e. g., toluene) are not present at concentrations above acceptable levels. Periodic grab-sample monitoring of the effluent to the holding tank will be continued throughout the duration of the demonstration.

Off-gas will be vented directly to the atmosphere. Samples will be collected on a regular basis and analyzed for VOCs and radioactivity to ensure compliance with K-25 air permit litilitations. 
Each batch of waste chemical sludge or biosludge will be analyzed for radioactivity and for RCRA-hazardous constituents, by EP or TCLP extraction and analysis prior to disposal. If radioactivity exceeds $\mathrm{K}-25$ guidelines, and if the waste is found to be hazardous by RCRA guidelines, it will be stored at $\mathrm{K}-25$ for ultimate disposal as mixed waste. If determined to be either radioactive or hazardous, but not both, the waste will be disposed of as appropriate.

\section{Z.e Health and Safety}

The Project Description (and portions of the Technical Work Plan, if necessary) will be reviewed by the MMES Central Engineering organization to determine whether a Safety Assessment will be required. If an Assessment is required, it will be prepared by the Central Engineering organization.

A Health and Safety Plan will be prepared by the project as part of the Technical Work Plan, and will be subject to approval by both ORNL and K-25 safety committees. The plan will address:

- Training requirements for on-site personnel;

- Potential hazards involved in operation of the equipment;

- Hazardous materials to be stored or handled (e. g. methane);

- Radiation monitoring requirements.

Prior to any on-site activities a review of health, safety, and waste disposal issues, and project plans to address these issues, will be conducted by the K-25 Health and Safety Council.

\subsection{Quality Assurance}

A QA Plan will be prepared for the project as part of the Technical Work Plan. The Plan will encompass all aspects of the proposed work, and will be in accordance with ORNL and K-25 QA program requirements developed in response to DOE 5700.6 orders. The Plan will be reviewed and approved by appropriate staff in both ORNL and K-25 QA organizations.

\subsection{Permitting}

\subsection{NEPA}

To ensure compliance with NEPA requirements, a Project Description Memorandum (PDM) has been prepared by the ORNL NEPA coordination office. The PDM was submitted to the K-25 HS\&EA Division for review, and was submitted to DOE-ORO through the ORNL NEPA coordinator's office on August 8, 1990. On August 31, 1990 a recommendation was submitted to the DOE Office of Technology Development by ORO that the a Memo-to-File be signed stating that no significant environmental impacts are expected from project activities, and that NEPA documentation has been satisfied. 


\subsection{RCRA RD\&D Permit}

The position of the ORNL Environmental Compliance office is that RCRA RD\&D permit approval by the State of Tennessee is not required for this project. Information equivalent to that required in an RD\&D permit application will be submitted to the Tennessee Department of Health and Environment (TDHE) to inform the regulators of the proposed demonstration.

\subsection{Site Requirements}

Project activities may necessitate regulatory review for compliance with existing site permits, approval of additional permits or modification of existing permits, or waiver of particular permitting requirements. The following permitting determinations are anuicipated:

- Whether modification of existing K-25 permits from TDHE for storage and disposal of liquid and solid RCRA-hazardous waste will be required;

- Whether modification of existing K-25 air discharge permits from TDHE will be required.

Any necessary permit modifications or applications will be prepared by project or ORNL Environmental Compliance organization staff, after consultation with appropriate K-25 staff. Any permit modifications or applications will be submitted to the K-25 HS\&EA Division for review, approval, and submittal to TDHE.

Other K-25 site work permit applications, including maintenance work requests, safety work permits, and an excavation permit (if required for site leveling), will be prepared by project staff and submitted through the appropriate K-25 organization.

\subsection{Contracts and Legal Issues}

The field demonstration may require use of a subcontractor to install and/or operate parts of one of the bioreactor systems. Before any subcontractor is permitted on site to work on the project, a contract or written agreement will be required to be in place that addresses:

- Operator training requirements;

- Indemnification;

- Review and implementation of a Health and Safety Plan for the subcontracted work;

- Disposition of wastes produced;

- Disposition of contaminated equipment;

- Equipment maintenance;

- Project delays caused by either contractors or MMES.

Contracts or agreements will be prepared with assistance from MMES Purchasing and the MMES Legal Department as needed. 
Soncentration $(\mu \mathrm{g} / \mathrm{L})$

Compound

Maximum

Minimum

Volatiles

Benzene

Chloroethane

Chloroform

1,1-Dichloroethane

1,1-Dichloroethene

1,2-Dichloroethane

Methylene chloride

Tetrachloroethene

Toluene

Trans-1,2-Dichloroethene

1,1,1-Trichloroethane

1,1,2-Trichloroethane

Trichloroethene

Vinyl chloride

Semivolatiles

2-Methylnaphthalene

4-Methylphenol

Acenaphthene

Anthracene

Dibenzofuran

Ethylhenzene

Fluorene

Naphthalene

Phenanthrene

\section{Nonspecific Parameters}

Oil \& Grease

Alpha activity

Beta activity
250

160

5

3800

530

31

8000

50

650

950

4600

24

250

140

230

$<10$

$<5$

2300

250

$<5$

1900

$<5$

440

670

3000

$<5$

140

$<10$

$\begin{array}{lr}44 & * \\ 2 & * \\ 2 \text { (est.) } & <5 \\ 3 & 2 \\ 1 & * \\ 250 & 190 \\ 2 & 2 \\ 48 & 14 \\ 2 \text { (est.) } & <5\end{array}$

$\begin{array}{lr}2000 & <2000 \\ 4.9 \mathrm{pCi} / \mathrm{L} & <2 \mathrm{pCi} / \mathrm{L} \\ 8.2 \mathrm{pCi} / \mathrm{L} & <2 \mathrm{pCi} / \mathrm{L}\end{array}$


Water Quality Parameters

$\begin{array}{lcc}\text { Alkalinity } & 301 \mathrm{mg} / \mathrm{L} & 254 \mathrm{mg} / \mathrm{L} \\ \text { Chemical Oxygen Demand } & 52 \mathrm{mg} / \mathrm{L} & <5 \mathrm{~m} ; / / \mathrm{L} \\ \text { Conductivity } & 767 \mu \mathrm{mho} / \mathrm{cm} & 679 \mu \mathrm{mho} / \mathrm{cm} \\ \text { Dissolved oxygen } & 3.6 \mathrm{mg} / \mathrm{L} & 1.5 \mathrm{mg} / \mathrm{L} \\ \text { Hardness } & 321 \mathrm{mg} / \mathrm{L} & 290 \mathrm{mg} / \mathrm{L} \\ \text { Iron } & 41 \mathrm{mg} / \mathrm{L} & 32 \mathrm{mg} / \mathrm{L} \\ \mathrm{pH} & 7.3 & 6.3 \\ \text { Temperature } & 17^{\circ} \mathrm{C} & 15^{\circ} \mathrm{C} \\ \text { Total Organic Carbon } & 24.9 \mathrm{mg} / \mathrm{L} & 12.3 \mathrm{mg} / \mathrm{L} \\ \text { Total Dissolved Solids } & 498 \mathrm{mg} / \mathrm{L} & 380 \mathrm{mg} / \mathrm{L} \\ \text { Total Suspended Solids } & 51 \mathrm{mg} / \mathrm{L} & 16 \mathrm{mg} / \mathrm{L}\end{array}$

* Only one analysis performed.

Source: Appendix B, "RCRA Facility Investigation Plan, K-1070-C/D Classified Burial Ground, Oak Ridge Gaseous Diffusion Plant, Oak Ridge, Tennessee," Report No. K/HS140, Revision 1, May 1989. 


\begin{tabular}{|c|c|c|c|c|}
\hline Chemical & $\begin{array}{l}\text { Number } \\
\text { Detected }\end{array}$ & $\begin{array}{l}\text { Range of } \\
\text { Detection } \\
\text { Limits }\end{array}$ & $\begin{array}{l}\text { Range > } \\
\text { Detection } \\
\text { Limit }\end{array}$ & $\begin{array}{l}\text { Avorage } \\
\text { Detection } \\
\text { Limit }\end{array}$ \\
\hline 1,1,1-Trichloroethane & $4 / 4$ & .... & $4.9 \cdot-6.8$ & 5.9 \\
\hline 1,1,2-Trichloroethane & $2 / 4$ & $0.25 \cdot 0.25$ & $0.02 .5--0.03 .3$ & 0.029 \\
\hline 1,1-Dichloroethane & $4 / 4$ & $\ldots$ & $0.98 \times 1$ & 0.995 \\
\hline 1,1-Dich oroethene & $4 / 4$ & $\because$ & $0.51 \ldots 0.64$ & 0.57 \\
\hline 1,2-Dichloroethene (total) & $4 / 4$ & $\because \cdots$ & $0.58-0.81$ & 0.68 \\
\hline 1-Ethyl-2-methyl-benzene & $2 / 2$ & $\because$ & $0.33--0.33$ & 0.33 \\
\hline 1-Methyl Naphtlialene & $2 / 2$ & $\therefore$ & $0.068-0.069$ & 0.0685 \\
\hline 1.-Pentanol & $2 / 2$ & $\therefore$ & $0.33-0.38$ & 0.35 .5 \\
\hline Ih-Indene, 1-ethyllndene & $1 / 1$ & $\therefore$ & $0.042 \cdots-0.042$ & 0.042 \\
\hline Ih-Indene, 2,3-Dihydro-Methyl & $2 \longdiv { 2 }$ &.$\cdots$ & $0.033 \cdots 0.06$ & 0.0465 \\
\hline 2-Butanone & $1 / 4$ & $0.2--0.5$ & $0.022--0.022$ & 0.022 \\
\hline 2-Methylnaphthalene & $5 / 5$ & .... & $0.076 \cdots-0.092$ & 0.087 \\
\hline 3-Octanone & $2 / 2$ & $\because$ & $0.025-0.038$ & 0.0315 \\
\hline Acenaphthene & $5 / 5$ & 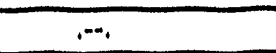 & $0.002--0.003$ & 0.0026 \\
\hline Alpha Activity & $1 / 5$ & $1--2$ & $1 \cdots 1$ & 1 \\
\hline Aluminum & $3 / 5$ & $0.04--0.104$ & $0.091--0.144$ & 0.12 \\
\hline Aroclor-1221 & $1 / 5$ & $0.00057-0.0063$ & $0.00071-0.00071$ & 0.00071 \\
\hline Aroclor -1232 & $2 / 5$ & $0.00057-.0 .0054$ & $0.00091-0.0011$ & 0.001 \\
\hline Aroclor-1242 & $2 / 5$ & $0.00057-40.0025$ & $0.00069-0.00078$ & 0.000735 \\
\hline Aroclor -1248 & $1 / 5$ & $0.00057-0.0006$ & $0.0038-0.0038$ & 0.0038 \\
\hline Barium & $5 / 5$ & $\cdots$ & $0.434-0.513$ & 0.46 \\
\hline Benzene & $4 / 4$ & $\therefore$ & $1.2-1.3$ & 1.2 \\
\hline Benzene 2-Ethyl-1,4-Dimethyl & $1 / 1$ & $\ldots$ & $0.033 \cdot 0.033$ & 0.033 \\
\hline Beryllium & $1 / 5$ & $0.001-0.001$ & $0.001-0.001$ & 0.001 \\
\hline Bromacil (ACN) & $2 / 2$ &.-- & $0.017-0.018$ & 0.0175 \\
\hline Butane, 1,1'-axybis(2,1-ethanediyloxy)bis & $7 \Pi$ & $\ldots$ & $0.64--1.6$ & 1.2 \\
\hline Butane, 2-Methyl- & $4 / 4$ &.$\cdots$ & $0.27--0.45$ & 0.345 \\
\hline Cadmium & $1 / 5$ & $0.005-0.005$ & $0.005--0.005$ & 0.005 \\
\hline Calcium & $5 / 5$ & .-. & 69.8--93.9 & 82.3 \\
\hline Chromium & $3 / 5$ & $0.01-0.01$ & $0.014--0.03$ & 0.02 \\
\hline Cobalt & $2 / 5$ & $0.02--0.02$ & $0.021--0.032$ & 0.0265 \\
\hline Copper & $2 / 5$ & $0.01-0.01$ & $0.018-0.025$ & 0.0215 \\
\hline Di-n-butylphtalate & $2 / 5$ & $0.011--0.012$ & $0.003-0.004$ & 0.0035 \\
\hline Diacetone Alcohol & $2 / 2$ & $\ldots$ & $0.022--0.028$ & 0.025 \\
\hline Dibenzofuran & $3 / 5$ & $0.011-0.012$ & $0.002 m-0.003$ & 0.0027 \\
\hline Diethyl Benzene & $1 / 1$ & .... & $0.024--0.024$ & 0.024 \\
\hline Dimethyl Napthalene & $2 / 2$ & $\cdots$ & $0.015-0.032$ & 0.0235 \\
\hline Ethenyl Methyl Benzene & $2 / 2$ & 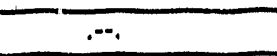 & $0.05-0.08$ & 0.065 \\
\hline Ethyl Dimethyl Benzene & $4 / 4$ &.$\cdots$ & $0.024--0.031$ & 0.027 \\
\hline Ethyl Methyl Benzene & $7 \pi$ & $\therefore$ & $0.06-0.19$ & 0.14 \\
\hline Ethyl Benzene & $4 / 4$ & $\ldots$ & $0.31--0.43$ & 0.37 \\
\hline Fluorene & $5 / 5$ & $\cdots$ & $0.003-0.004$ & 0.0038 \\
\hline Freon 113 & $3 / 3$ & $\therefore$ & $1.9 \cdots-2.8$ & 2.2 \\
\hline Freon 123 & $4 / 4$ & $\cdots$ & $1.7-.2 .8$ & 2.15 \\
\hline Gamma Activity & $2 / 5$ & $0-0$ & $0--0$ & 0 \\
\hline Heptachlor epoxide & $1 / 5$ & $0.000057--0.00006$ & $0.00012--0.0012$ & 0.00012 \\
\hline Hydroperoxide, 1-Methy!pentyl & $4 / 4$ & .... & $0.5 m-0.85$ & 0.703 \\
\hline Iron & $5 / 5$ & $\ldots$ & $18.1-26.8$ & 21.5 \\
\hline Lead & $2 / 5$ & $0.03--0.03$ & $0.036-0.041$ & 0.0385 \\
\hline Magnesium & $5 / 5$ &.$\cdots$ & $9.78-12.9$ & 11.3 \\
\hline Manganese & $5 / 5$ & $\therefore$ & i i $.4 \ldots i \overline{3} . \overline{7}$ & $\mathrm{i} \overline{2} . \overline{7}$ \\
\hline Methyl Methyl Ethyl Benzene & $1 / 1$ & $\ldots$ & $0.036--0.036$ & 0.036 \\
\hline
\end{tabular}




\begin{tabular}{|c|c|c|c|c|}
\hline Methyl Napthalene & $1 / 1$ & $\cdots$ & $0.044-0.044$ & 0.044 \\
\hline Methyl Propenyl Benzene & $3 / 3$ & $\cdots$ & $0.019-0.035$ & 0.024 \\
\hline Methylcyclobutane & $1 / 1$ & $\cdots$ & $0.3 \cdots-0.3$ & 0.3 \\
\hline Methylcyclopentane & $2 / 2$ & $\cdots$ & $0.17 \cdot 0.18$ & 0.175 \\
\hline Mothylene Chloride & $\overline{2 / 4}$ & $0.1-0.1$ & $0.16 \cdots 0.46$ & 0.31 \\
\hline Methylpropyl Benzene & $6 / 6$ & $\ldots$ & $0.014 \cdots-0,038$ & 0.026 \\
\hline Molybdenum & $1 / 2$ & $0.02 \cdots-0.02$ & $0.145-0.145$ & 0.145 \\
\hline Naphthalene & $5 / 5$ & .... & $0.093--0.13$ & 0.11 \\
\hline Naphthalene, -Dimethyl- & $3 / 3$ & $\cdots$ & $0.017-0.024$ & 0.02 \\
\hline Nickel & $1 / 5$ & $0.02-0.02$ & $0.02 \cdots-0.02$ & 0.02 \\
\hline Pentane & $3 / 3$ & $\ldots$ & $0.31--0.5 .5$ & 0.44 \\
\hline Phenanthrene & $5 / 5$ & $\ldots$ & $0.004-0.005$ & 0.0042 \\
\hline Potassium & $4 / 5$ & $1.9 \cdots 1.9$ & $2.23 \cdots 2.73$ & 2.5 \\
\hline Propane, 2-Methoxy-2-Methyl & $2 / 2$ & ... & $0.11--0.15$ & 0.13 \\
\hline Propenyl Benzene & $1 / 1$ & $\cdots$ & $0.077 \ldots-0.077$ & 0.077 \\
\hline Sillicon & $2 / 2$ & $\cdots$ & $4.21-6.1$ & 5.2 \\
\hline Silver & 2/5 & $0.005--0.005$ & $0.006--0.133$ & 0.0695 \\
\hline Sodium & $5 / 5$ & , .". & $11.1 \ldots 15.2$ & 13.1 \\
\hline Strontium & $2 / 2$ & ..... & $0.053 \cdots-0.105$ & 0.079 \\
\hline Tetrachloroethene & $2 / 4$ & $0.25-0.25$ & $0.063-0.067$ & 0.065 \\
\hline Tetramethyl Benzene & $4 / 4$ & $\ldots$ & $0.02--0.031$ & 0.023 \\
\hline Thorium & $1 / 2$ & $0.05 \cdots 0.0 .5$ & $0.881--0.881$ & 0.88 \\
\hline Toluene & $4 / 4$ & $\ldots$ & $2.7 \ldots 3.1$ & 2.9 \\
\hline Trichloroethene & $4 / 4$ &.$\cdots$ & $0.33-0.43$ & 0.385 \\
\hline Trimethyl Benzene & $21 / 21$ & $\cdots$ & $0.058-0.46$ & 0.16 \\
\hline Unknown & $21 / 21$ & $\cdots$ & $0.017-0.055$ & 0.033 \\
\hline Unknown Hydrocarbon & $28 / 28$ & ... & $0.018--0.23$ & 0.060 \\
\hline Uranium 238 & $1 / 2$ & $0.2-0.2$ & $4.44--4.44$ & 4.44 \\
\hline Vanadium & $3 / 5$ & $0.01-0.01$ & $0.01--0.014$ & 0.0127 \\
\hline Xylene (total) & $4 / 4$ & .... & $1.4-.1 .9$ & 1.625 \\
\hline Zinc & $4 / 5$ & $0.01-0.01$ & $0.01-0.0688$ & 0.042 \\
\hline bis(2-Ethylhexyl)phthalate & $1 / 5$ & $0.011-0.012$ & $0.004-0.004$ & 0.004 \\
\hline n-Propylbenzene & $6 / 6$ & $\ldots$ & $0.031--0.86$ & 0.17 \\
\hline
\end{tabular}

Source: D. Miller, personal communication to S. E. Herbes, 10/8/90. Excerpted from "Site Characterization Summary: K-1070-C/D Classified Burial Ground," Report No. K/ER-4/D1 (Draft): Appendix C (Surface Water Sampling Data). Environmental Restoration Division/K-25 Environmental Restoration Program, March 1990.

Table 2. Contaminants detected in Storm Drain SD-180-04 (new sampling point designation: SU-31) at the K-25 Facility, April 1990. All concentrations reported in units of $\mathrm{mg} / \mathrm{L}$ except alpha and gamma activity $(\mathrm{pCi} / \mathrm{L})$. Underlining indicates chlorinated volatiles and aromatic compounds which may be degraded to some extent in the bioreactor. 


\begin{tabular}{lcc}
\multicolumn{1}{c}{ Constituent } & $\begin{array}{c}\text { Nutrient mineral salts } \\
\text { Concentration }(\mathrm{mg} / \mathrm{L})\end{array}$ & $\begin{array}{c}\text { Incremental Conc. } \\
\text { Increase }(\mathrm{mg} / \mathrm{L})^{*}\end{array}$ \\
$\mathrm{MgSO}_{4.7 \mathrm{H}_{2} \mathrm{O}}$ & 10 & 0.1 \\
$\mathrm{CaCl}_{2}$ & 5 & 0.05 \\
$\mathrm{KNO}_{3}$ & 2000 & 20 \\
$\mathrm{NH}_{4} \mathrm{Cl}$ & 200 & 2 \\
$\mathrm{FeCl}_{3}$ & 0.5 & 0.005 \\
$\mathrm{KH}_{2} \mathrm{PC} 4$ & 2000 & 20 \\
$\mathrm{Trace}_{4}$ elements** & 10 & 0.1
\end{tabular}

*Incremental increase in concentration over existing seep water levels.

** $\mathrm{HBO}_{3}, \mathrm{CoCl}_{2} .6 \mathrm{H}_{2} \mathrm{O}, \mathrm{MnSO}_{4}, \mathrm{ZnCl}_{2}, \mathrm{CuCl}_{2} .2 \mathrm{H}_{2} \mathrm{O}$, and $\mathrm{Na}_{2} \mathrm{MoO}_{4} .2 \mathrm{H}_{2} \mathrm{O}$.

Concentration figures given are total of all added trace elements.

Table 3. Concentrations of nutrients added to the seep water influent to bioreactors. 


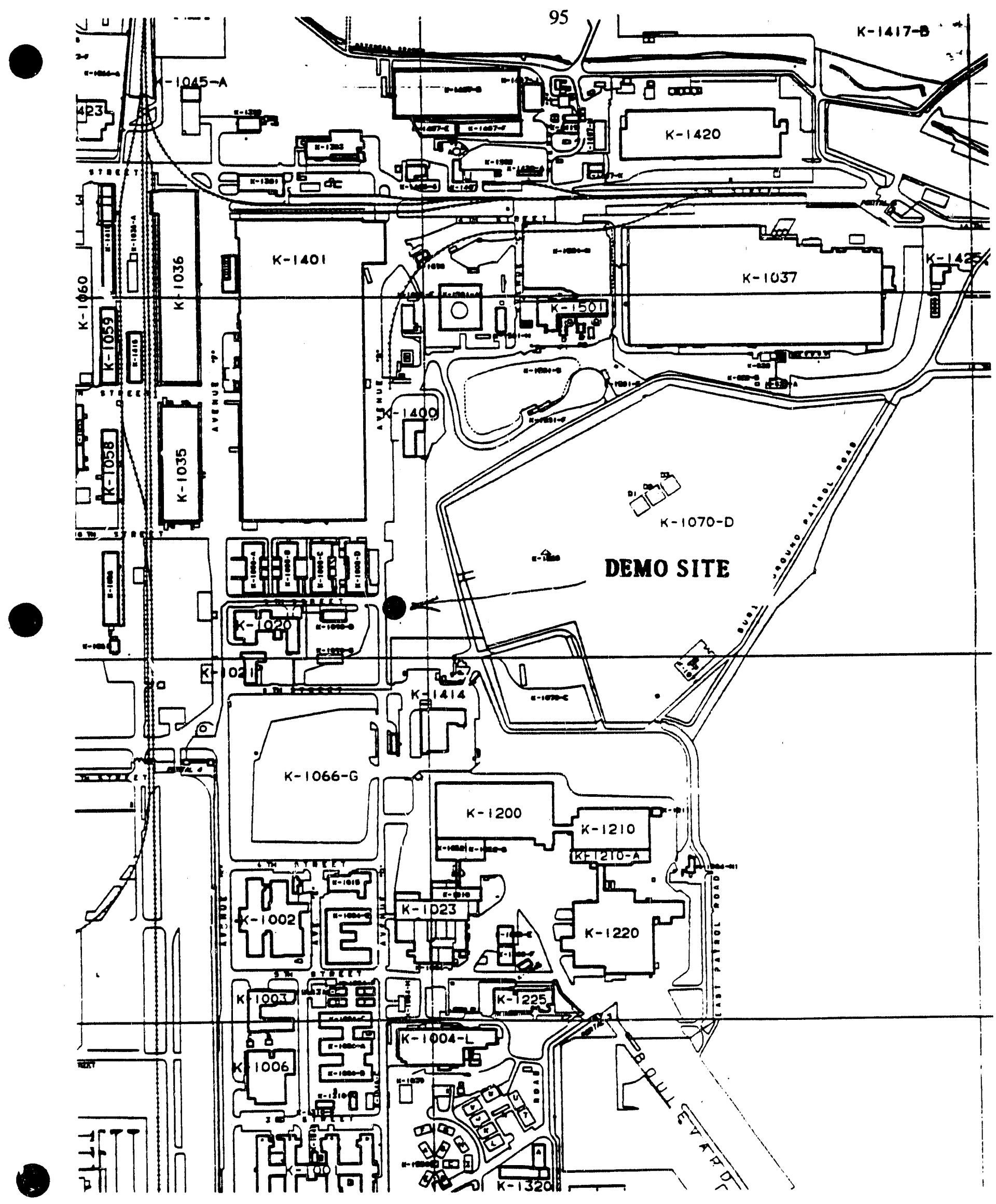

Figure 1. Site of the proposed co-metabolic bioreactor demonstration at the Oak Ridge K-25 Facility. 


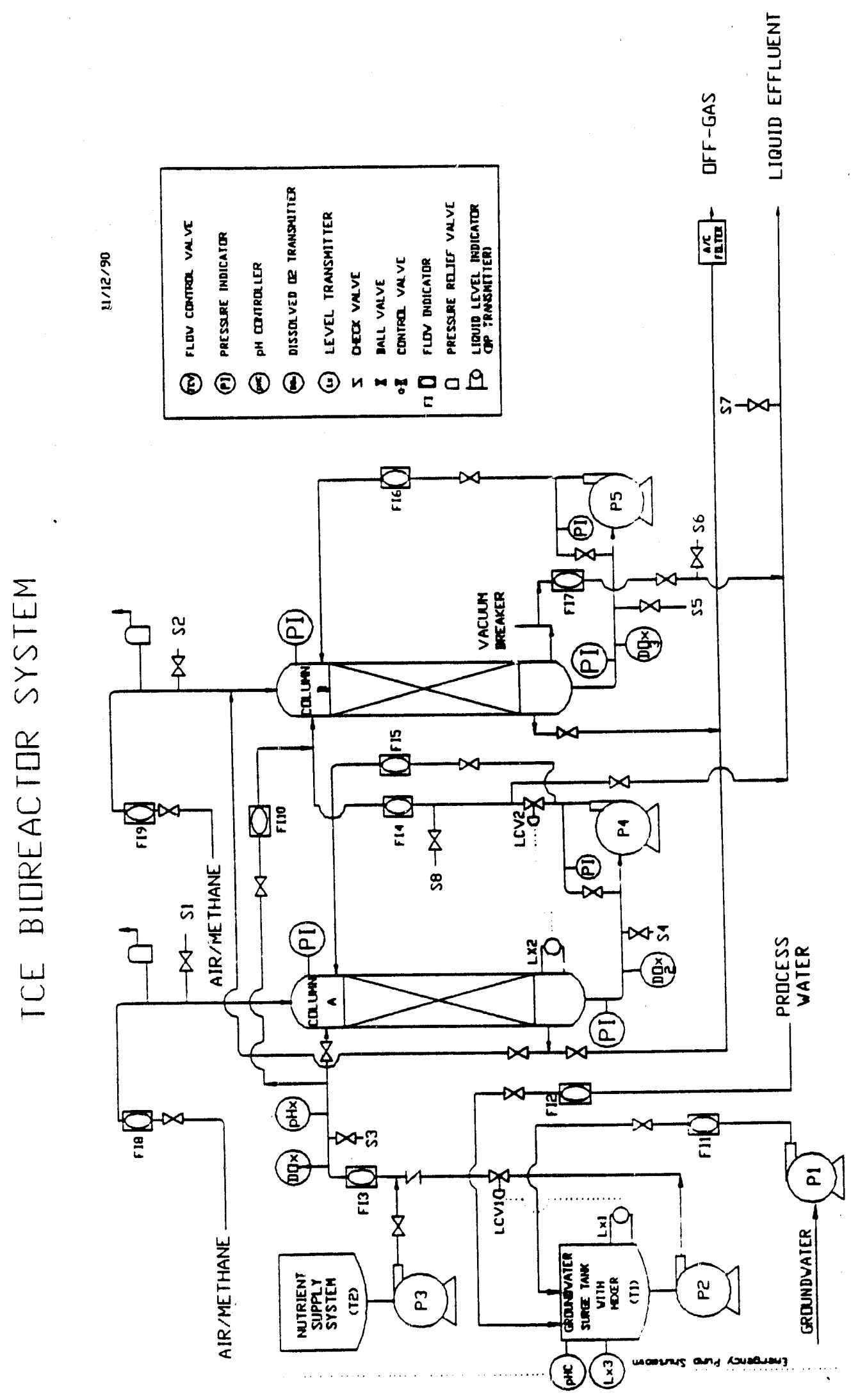

है 


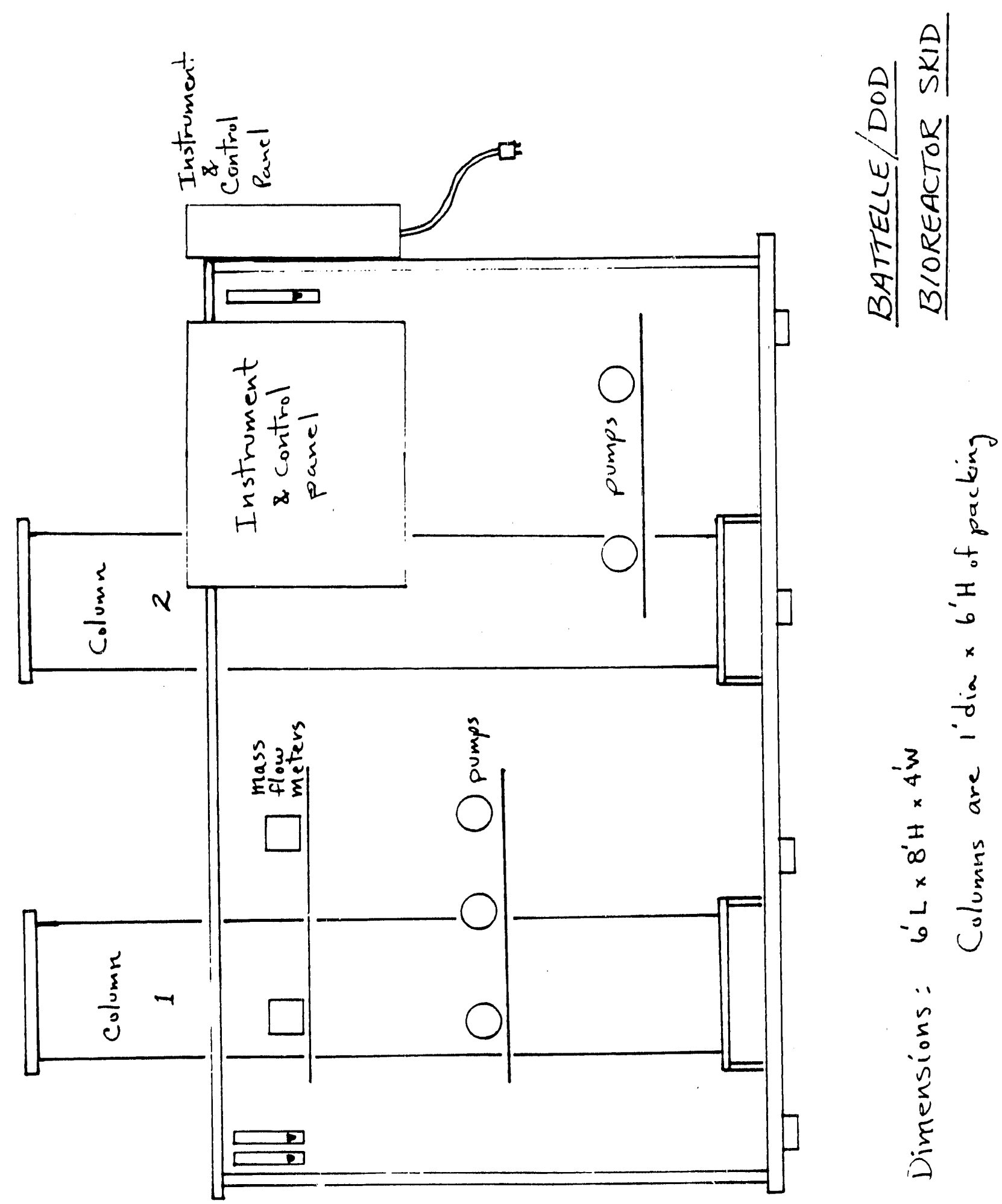

Figure 3. Layout of the skid-mounted methanotrophic bioreactor unit. 


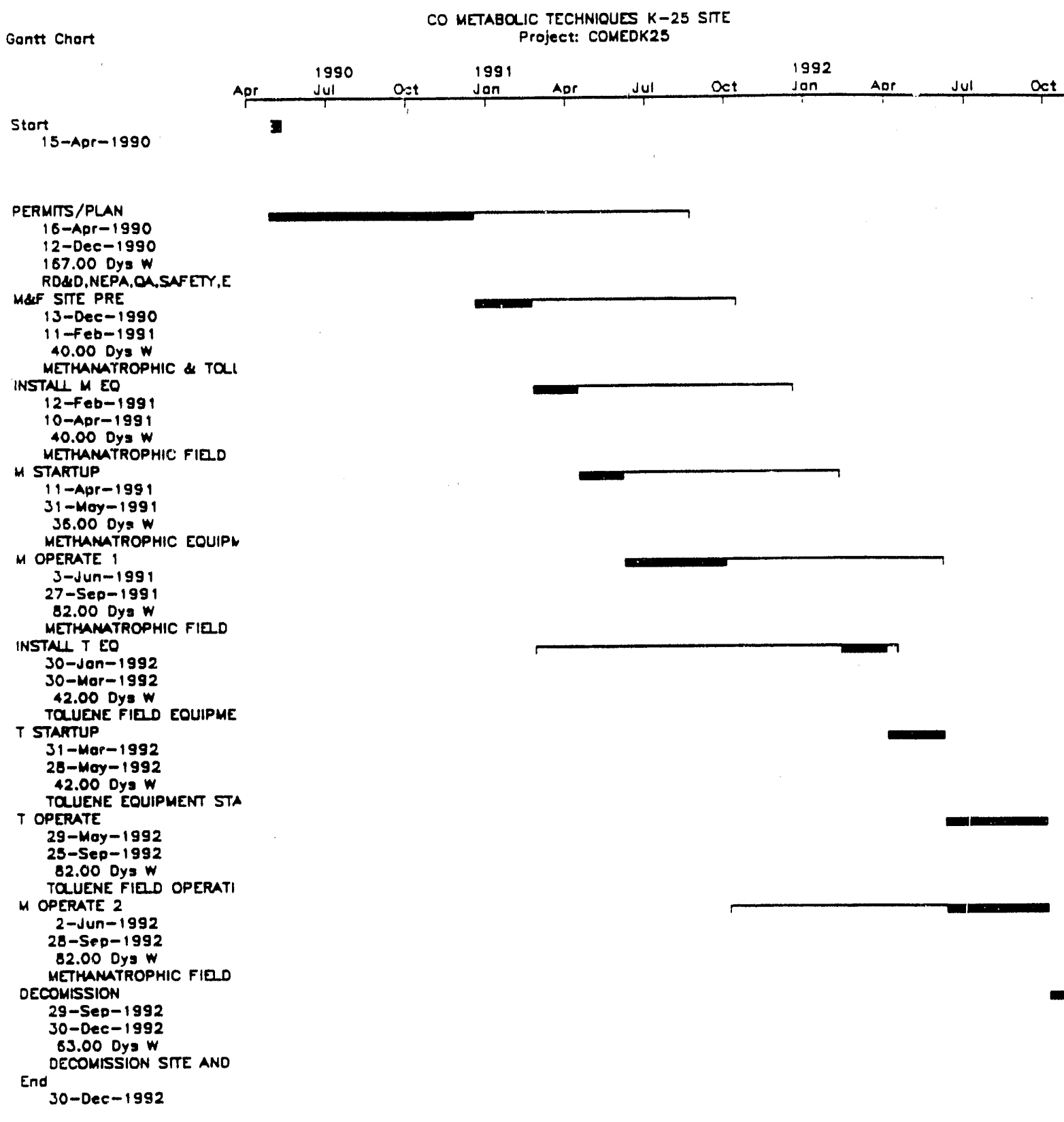

23-Aug-1990 1993 Jon

Stort

ERMTS/PLAR

16-Apr-1990

2-Dec-1990

METHANATRO

$12-f e b-1991$

MOTHAMATROPHIC FIED

STARTUP

11-Apr-199

1 -Moy-199

OPERATE

3-Jun-1991

7-Sep-1991

METHAMATROPHIC FIED

4TUENE FID DOUIPME

MTMAMTROPHIC FIg

30-Dec- 1992
DIC TECHNIOUES $K-25$ STIE

P.ject: COMEDK25 


\author{
APPENDIX D \\ EXAMPLE OF PROJECT TEST PLAN
}

\title{
CO-METABOLIC BIOREACTOR DEMONSTRATION AT THE OAK RIDGE $\mathrm{K}-25$ SITE
}

November 1991

Revision 0

\author{
Prepared by the \\ OAK RIDGE NATIONAL LABORATORY \\ Oak Ridge, Tennessee 37831 \\ operated by \\ MARTIN MARIETTA ENERGY SYSTEMS, INC. \\ for the \\ U. S. DEPARTMENT OF ENERGY \\ under contract DE-AC05-84OR21400
}

\section{CAUTION}

This document has not been given final patent clearance and is for internal use only. If this is to be given public release, it must be cleared through the site Technical Information Office which will see that the proper patent and technical information reviews are completed in accordance with Energy Systems policy. 
Approvals

$\underline{\text { Name }}$

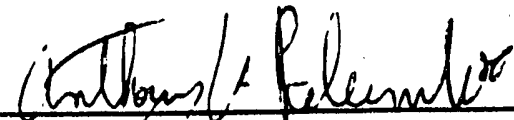

A. V. Balumbo, Task 2 Leader

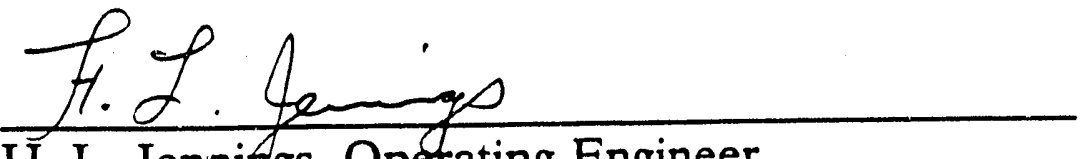

H. L. Jenniffgs, Operating Engineer

Y. X Kimalitom -

T. L. Donaldson, Task 3 Leader

- SE. Hewer

S. E. Herbes, Project Manager
Date
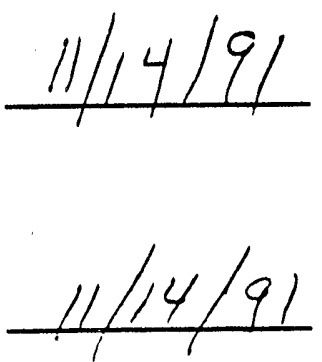

$1114 / 91$

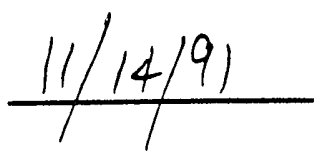




\section{CONTENTS}

$\underline{\text { Page }}$

LIST OF FIGURES $\ldots \ldots \ldots \ldots \ldots \ldots \ldots \ldots \ldots \ldots \ldots \ldots \ldots \ldots \ldots \ldots \ldots \ldots \ldots$

LIST OF TABLES $\ldots \ldots \ldots \ldots \ldots \ldots \ldots \ldots \ldots \ldots \ldots \ldots \ldots \ldots \ldots \ldots \ldots \ldots \ldots$

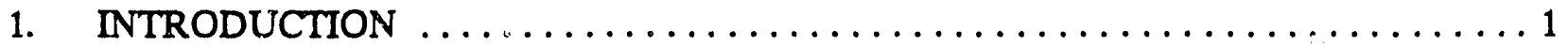

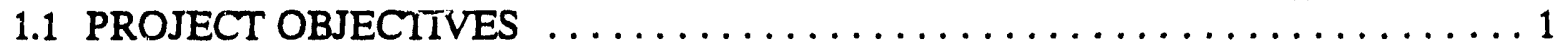

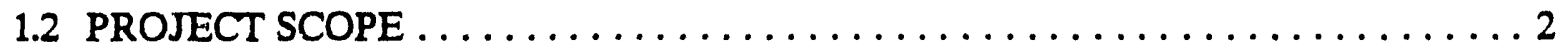

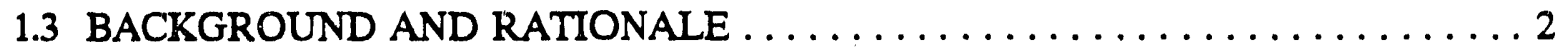

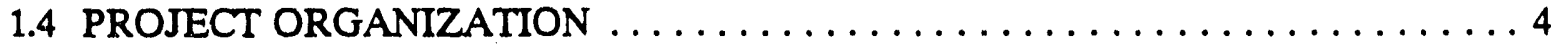

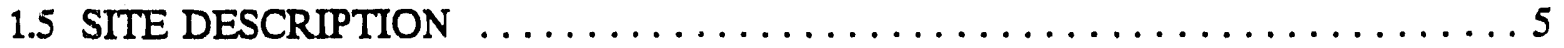

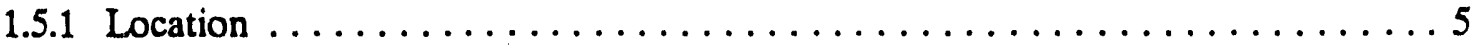

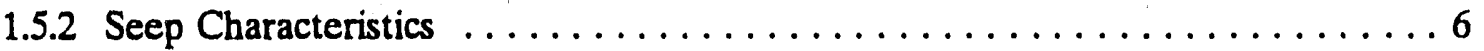

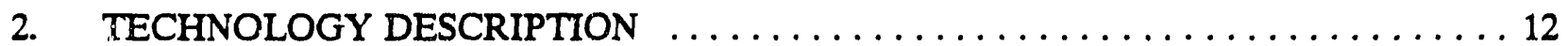

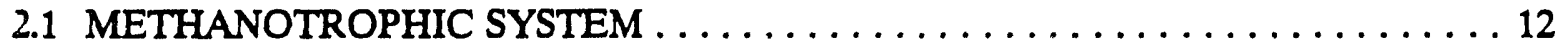

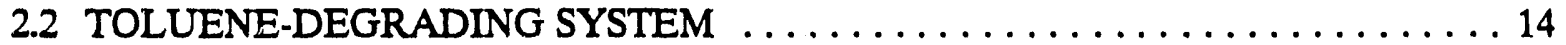

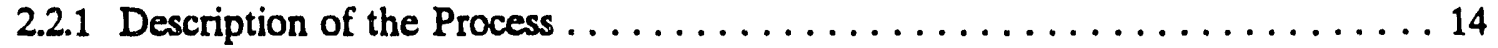

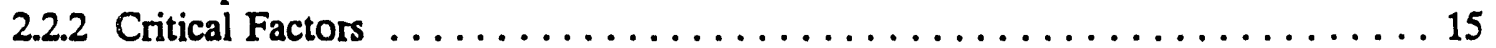

3. PRELIMINARY TESTS: METHANOTROPH SYSTEM $\ldots \ldots \ldots \ldots \ldots \ldots \ldots \ldots 17$

3.1 CULTURE SCREENING/ASSESSMENT $\ldots \ldots \ldots \ldots \ldots \ldots \ldots \ldots \ldots \ldots \ldots$

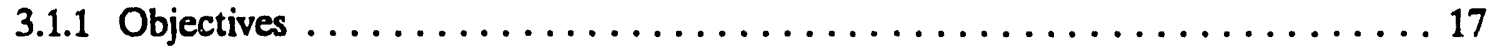

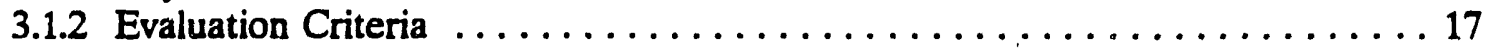

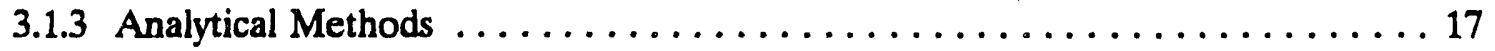

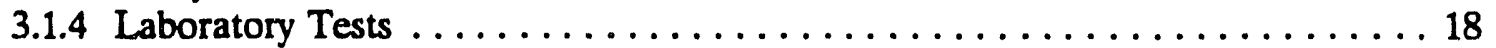

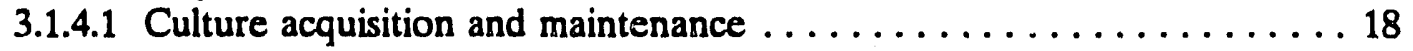

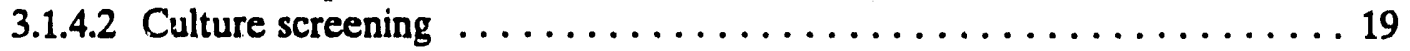

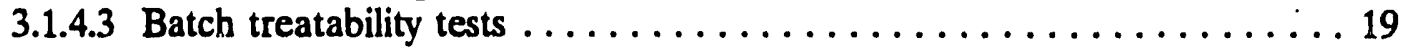

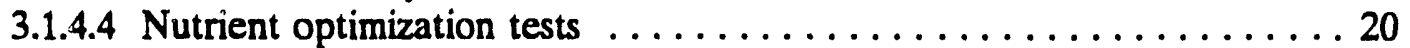

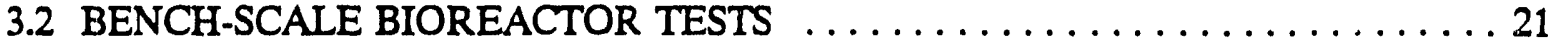

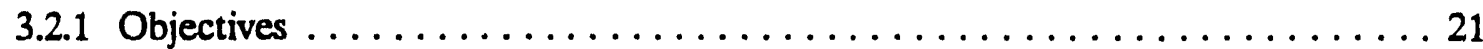

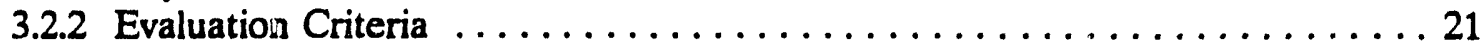

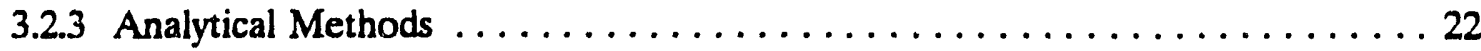

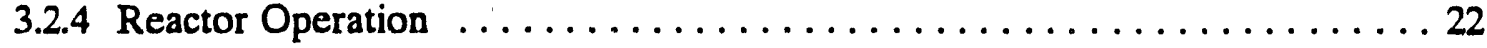

4. PRELIMINARY TESTS: TOLUENE-DEGRADING SYSTEM $\ldots \ldots \ldots \ldots \ldots \ldots$

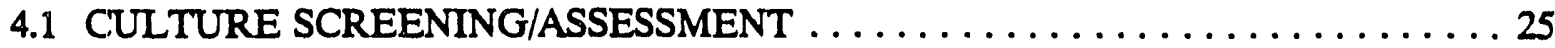

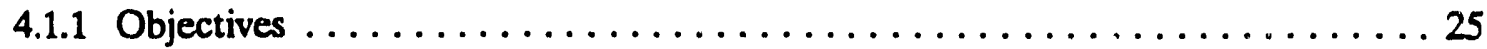

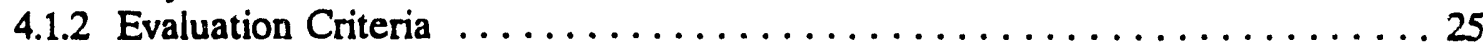

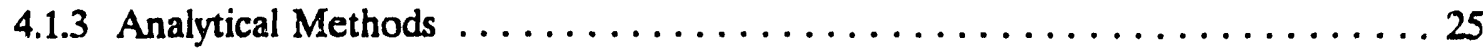

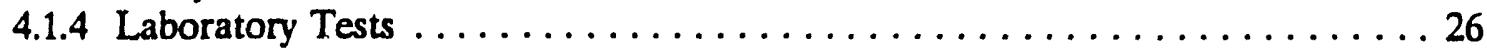

4.1.4.1 Culture acquisition and maintenance $\ldots \ldots \ldots \ldots \ldots \ldots \ldots \ldots \ldots \ldots \ldots \ldots \ldots$ 


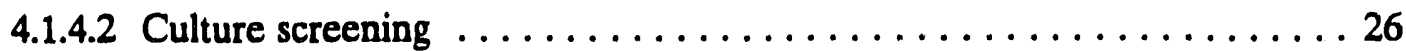

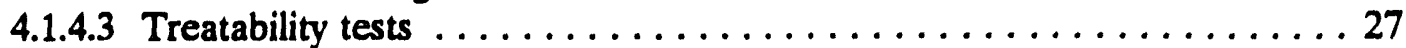

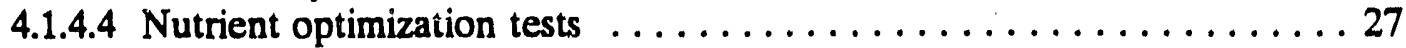

4.2 BENCH-SCALE BIOREACTOR TESTS $\ldots \ldots \ldots \ldots \ldots \ldots \ldots \ldots \ldots 28$

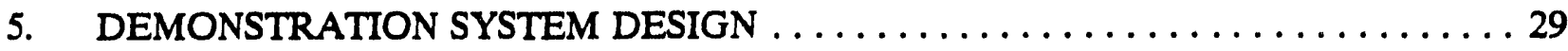

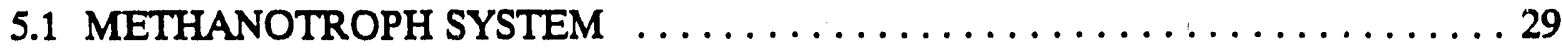

5.2 TOLUENE-DEGRADING SYSTEM $\ldots \ldots \ldots \ldots \ldots \ldots \ldots \ldots \ldots \ldots \ldots, \ldots \ldots \ldots$

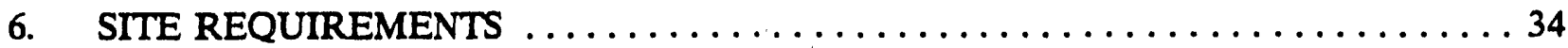

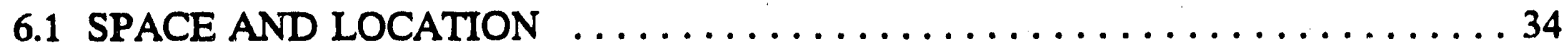

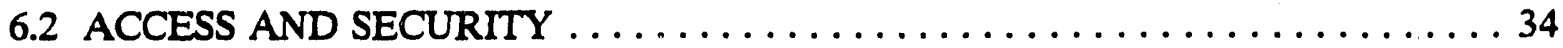

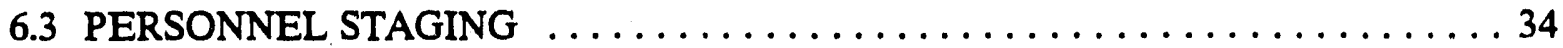

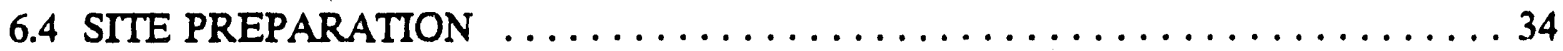

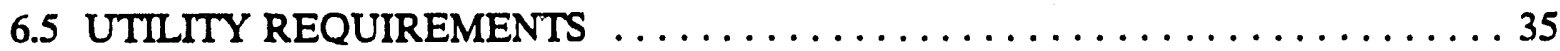

6.6 WASTE GENERATION AND DISPOSAL $\ldots \ldots \ldots \ldots \ldots \ldots \ldots \ldots \ldots \ldots$

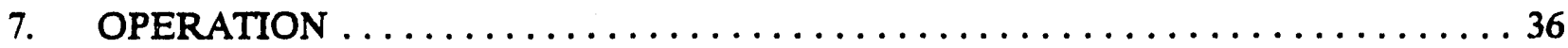

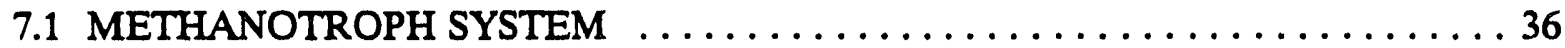

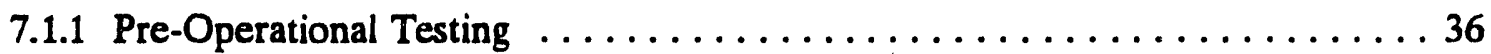

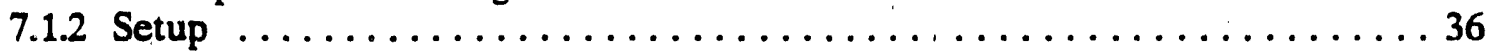

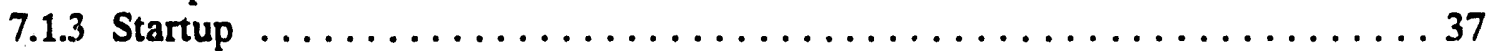

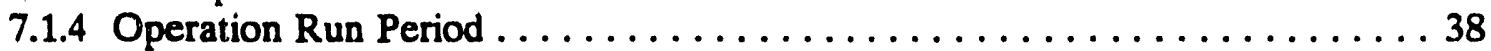

7.2 TOLUENE-DEGRADING SYSTEM $\ldots \ldots \ldots \ldots \ldots \ldots \ldots \ldots \ldots \ldots \ldots 40$

7.3 DEMOBILIZATION AND DECONTAMINATION $\ldots \ldots \ldots \ldots \ldots \ldots \ldots, 40$

8. REPORTING AND TECHNOLOGY TRANSFER $\ldots \ldots \ldots \ldots \ldots \ldots \ldots \ldots$

9. ENVIRONMENTAL COMPLIANCE $\ldots \ldots \ldots \ldots \ldots \ldots \ldots \ldots \ldots \ldots \ldots$

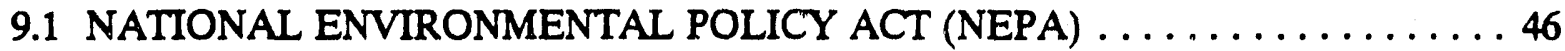

9.2 RESOURCE CONSERVATION AND RECOVERY ACT (RCRA) $\ldots \ldots \ldots .46$

9.2.1 Bench-Scale Treatability Tests $\ldots \ldots \ldots \ldots \ldots \ldots \ldots \ldots \ldots \ldots \ldots, \ldots \ldots$

9.2.2 Technology Demonstration $\ldots \ldots \ldots \ldots \ldots \ldots \ldots \ldots \ldots \ldots \ldots \ldots, \ldots \ldots \ldots$

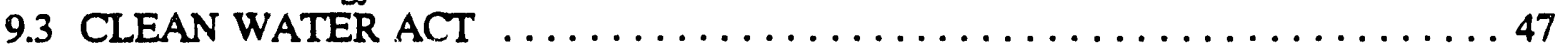

9.4 CLEAN AIR ACT $\ldots \ldots \ldots \ldots \ldots \ldots \ldots \ldots \ldots \ldots \ldots \ldots \ldots \ldots \ldots, \ldots \ldots \ldots$

10. CONTRACTS AND LEGAL ISSUES $\ldots \ldots \ldots \ldots \ldots \ldots \ldots \ldots \ldots$

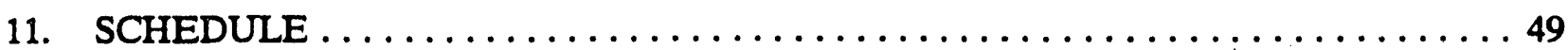


APPENDICES
A. WASTE MANAGEMENT PLAN
B. HEALTH AND SAFETY PLAN
C. QA/QC PLAN
D. SAFETY ASSESSMENT
E. SAMPLING PLAN 


\section{LIST OF FIGURES}

Figure

Page

1 Location of the cometabolic bioreactor demonstration at the K-25 Site $\ldots \ldots \ldots \ldots 7$

2 Layout of the methanotrophic bioreactor system in the van trailer $\ldots \ldots \ldots \ldots 31$

3 System flowsheet for methanotrophic bioreactor system and air oxidation and steam stripper pretreatment systems $\ldots \ldots \ldots \ldots \ldots \ldots \ldots \ldots \ldots \ldots \ldots \ldots \ldots \ldots \ldots$

4 Site plan for bioreactor demonstration $\ldots \ldots \ldots \ldots \ldots \ldots \ldots \ldots \ldots \ldots \ldots \ldots$

5 Operational mode $1:$ steam stripper pretreatment $\ldots \ldots \ldots \ldots \ldots \ldots \ldots \ldots \ldots$

6 Operational mode 2: air oxidation pretreatment with steam stripping post-treatment $\ldots \ldots \ldots \ldots \ldots \ldots \ldots \ldots \ldots \ldots \ldots \ldots$

7 Operational mode 3: direct treatment of seep water with steam stripping post-treatment $\ldots \ldots \ldots \ldots \ldots \ldots \ldots \ldots \ldots \ldots \ldots 44$

8 Gannt chart of schedule for the cometabolic bioreactor demonstration project . . . . 50

\section{LIST OF TABLES}

Table

Page

1 Contaminants detected in Storm Drair SD180-04 at the K-25 Site, May-June $1987 \ldots \ldots \ldots \ldots \ldots \ldots \ldots \ldots \ldots \ldots \ldots \ldots . \ldots \ldots$

2 Contaminants detected in Storm Drain SD180-04 (new sampling point designation:

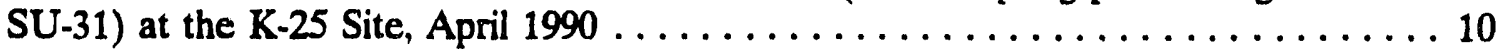




\section{INTRODUCTION}

This demonstration project is to be conducted by Oak Ridge National Laboratory (ORNL) for the U. S. Department of Energy (DOE) Office of Technology Development. The project consists of installation and operation of two types of biological treatment systems (i. e. bioreactors), using as influent groundwater contaminated with mixed organic compounds from a seepage flow at the K-25 Plant in Oak Ridge, Tennessee. The demonstration will be conducted by ORNL staff and subcontractors, in collaboration with the K-25 Health, Safety, and Environmental Affairs (HS\&EA) Division and the Environmental Restoration Division.

The purpose of this Test Plan is to plan the activities which will be components of both the preparatory activities for the demonstration and the field demonstration itself. This plan is intended to be a "living document," which will be modified and augmented during the course of the project as necessary to meet the project objectives.

\subsection{PROJECT OBJECTIVES}

The goal of the project is to demonstrate the effectiveness of two innovative bioremediation technologies, based on co-metabolic processes, to remediate groundwater contaminated by mixed organic solvents at DOE sites. The specific project objectives include:

1. Maximize the rate and extent of removal of trichloroethylene (TCE) from the influent waste stream by each of the two bioremediation technologies;

2. Evaluate the effectiveness of removal of the other organic contaminants by the two systems;

3. Evaluate the process economics of the two systems;

4. Compare the relative performance of the two systems on the basis of the above criteria. 


\subsection{PROJECT SCOPE}

The project consists of:

1. Completion of bioreactor design, operation, QA/QC, health/safety, and waste management plans, and acquisition of all necessary permits;

2. Optimization of microbial cultures and nutrient levels through initial laboratory tests;

3. Optimization of bioreactor design and operating conditions through testing of bench-scale units;

4. K-25 site preparation and utility hookup;

5. Modification of two existing skid-mounted bioreactor units;

6. Installation of one bioreactor unit, with associated reagent and waste containers, at the test site;

7. Operation of the unit for four months;

8. Subsiquent installation of the second unit;

9. Operation of the two units simultaneously for a four-month period;

10. Shutdown of site operation, decontamination of equipment, and disposal of generated waste;

11. Analysis of data and generation of a final report;

12. Communication of results to DOE and to private vendors through technology transfer.

\subsection{BACKGROUND AND RATIONALE}

Groundwater contaminated with organic compounds, especially solvents such as benzene, TCE, perchloroethene (PCE), carbon tetrachloride, and chlorinated ethanes, is a problem at many DOE sites. Some of the facilities at which these groundwater contaminants have been identified 
include: the Feed Materials Production Center (Fernald, OH); the three Oak Ridge facilities (K-25, Y-12, and ORNL); Mound Laboratory; the Kansas City Plant; and the Savannah River Plant.

One of the most promising new technologies for removal of these contaminants from groundwater is bioremediation, both by above-ground, contained units (i. e. bioreactors) and by in situ techniques. For TCE removal, bioremediation techniques employing two general groups of microorganisms are presently being investigated: methanotrophs (methane-utilizers), and pseudomonads (toluene-utilizers). Both are based on co-metabolic degradation, i. e. fortuitous degradation of the target contaminant (TCE) by organisms which are utilizing another compound as a growth substrate. The energy-producing and co-metabolic reactions involved are:

1) Methanotroph growth

$$
\mathrm{CH}_{4}+2 \mathrm{O}_{2} \rightarrow \mathrm{CO}_{2}-2 \mathrm{H}_{2} \mathrm{O}
$$

2) Pseudomonad growth

$$
\mathrm{C}_{1} \mathrm{H}_{8}+9 \mathrm{O}_{2} \rightarrow 7 \mathrm{CO}_{2}+4 \mathrm{H}_{2} \mathrm{O}
$$

3) Co-metabolism

$\mathrm{TCE}+\mathrm{O}_{2} \rightarrow$ TCE-epoxide $\rightarrow$ miscellaneous degradation products

Application of methanotrophs to TCE degradation has been demonstrated at bench-scale by the ORNL researchers involved in this project, and at the field-scale by Battelle-Columbus Laboratories; the latter group constructed the bioreactor unit which will be employed during the initial phase of the present demonstration. Use of toluene-degrading microorganisms in TCE removal has been demonstrated in laboratory studies, initially by the U. S. Environmental Protection Agency (EPA) Gulf Breeze, Fla., Laboratory and more recently by other groups.

Work proposed during the initial three years of this project will consist of comparative demonstration of the two bioreactor types utilizing groundwater contaminated with organic compounds which emerges as a seepage flow at the K-25 Plant in Oak Ridge. The seepage flow 
contains TCE, PCE, benzene, toluene, chlorinated ethanes, and other volatile organic solvents at a total concentration of several parts per million.

The K-25 site, as well as other Oak Ridge sites, are on the National Priority List, and thus falls under the jurisdiction of both CERCLA and DOE/EPA Interagency Agreements. These regulations require consideration of alternatives for remediation. This demonstration project will permit evaluation of two promising bioremediation technologies, and should lead to remedial alternatives which may prove both more effective and less costly than other alternatives. More generally, the demonstration will provide valuable information on the applicability of bioremediation to a groundwater containination problein which is a high priority at numerous DOE sites.

\subsection{PROJECT ORGANIZATION}

The project will consist of four tasks:

Task 1: Planning/permitting

Task 2: Methanotroph bioreactor development/demomstration

Task 3: Toluene-degrading bioreactor development/demonstration

Task 4: Closure/reporting

Principal project staff, and their organizational affiliations and primary responsibilities, are detailed below:

S. E. Herbes, Environmental Sciences Division (ESD): Project Manager

- Overall responsibility for project

- Preparation and implementation of project planning documents, including technical, health and safety, waste management, and QAVQC plans

- Preparation and submittal of all necessary permit and approval requests

- Reporting 
M. I. Morris, Chemical Technology Division (CTD), Demonstration Coordinator - Coordination of contarts and work tasks with K-25 Site personnel - Liaison with K-25 site organizations - Development and implementation of task/schedule tracking system - Development and implementation of́ budgei/cost tracking system

T. L. Donaldson (CTD): Task 2 Coordinator

- Development and implementation of methanotroph bioreactor system

A. V. Palumbo (ESD): Task 3 Coordinator

- Development and implementation of toluene-degrading bioreac

- Culture acquisition/maintenance, laboratory screening, and nutrient optimization for both Tasks 2 and 3

- Develofment of biomonitoring techniques for bioreactor microbial populations for both Tasks 2 and 3

H. L. Jennings (CTD)

- Installation, testing, and operation of methanotroph bioreactor system

\subsection{SITE DESCRIPTION}

\subsubsection{Location}

The seep which will serve as influent to the bioreactor is located adjacent to the cast side of Avenue $D$, about $110 \mathrm{ft}$ south of the center of the intersection with 9 th Street, on the eastern portion of the K-25 facility (Figure 1). The seep flows from a PVC pipe imbedded at the foot of a 6-ft-high slope, and presently drains through an open concrete channel along the road into a storm drain (SD-180-04) approximately $80 \mathrm{ft}$ north of the seep. The seep is located approximately $200 \mathrm{ft}$ west of the boundary of the K-1070-C/D Classified Burial Ground. 


\subsubsection{Seep Characteristics}

The base seep flow has appeared, by occasional observation, to be relatively constant at several gal/min during spring and summer 1990. Flow increases during and immediately following storms, and reportedly has stopped completely during extended dry periods in the past (D. Kucsmas, pers. commun.).

Chemical characteristics of the seep were determined on water samples collected from the SD-180-04 storm drain during May-June 1987. More recent analyses were conducted on samples sollected directly from the seep outflow during April 1990. The 1987 analyses are summarized in Table 1; the more recent data are included as Table 2. 


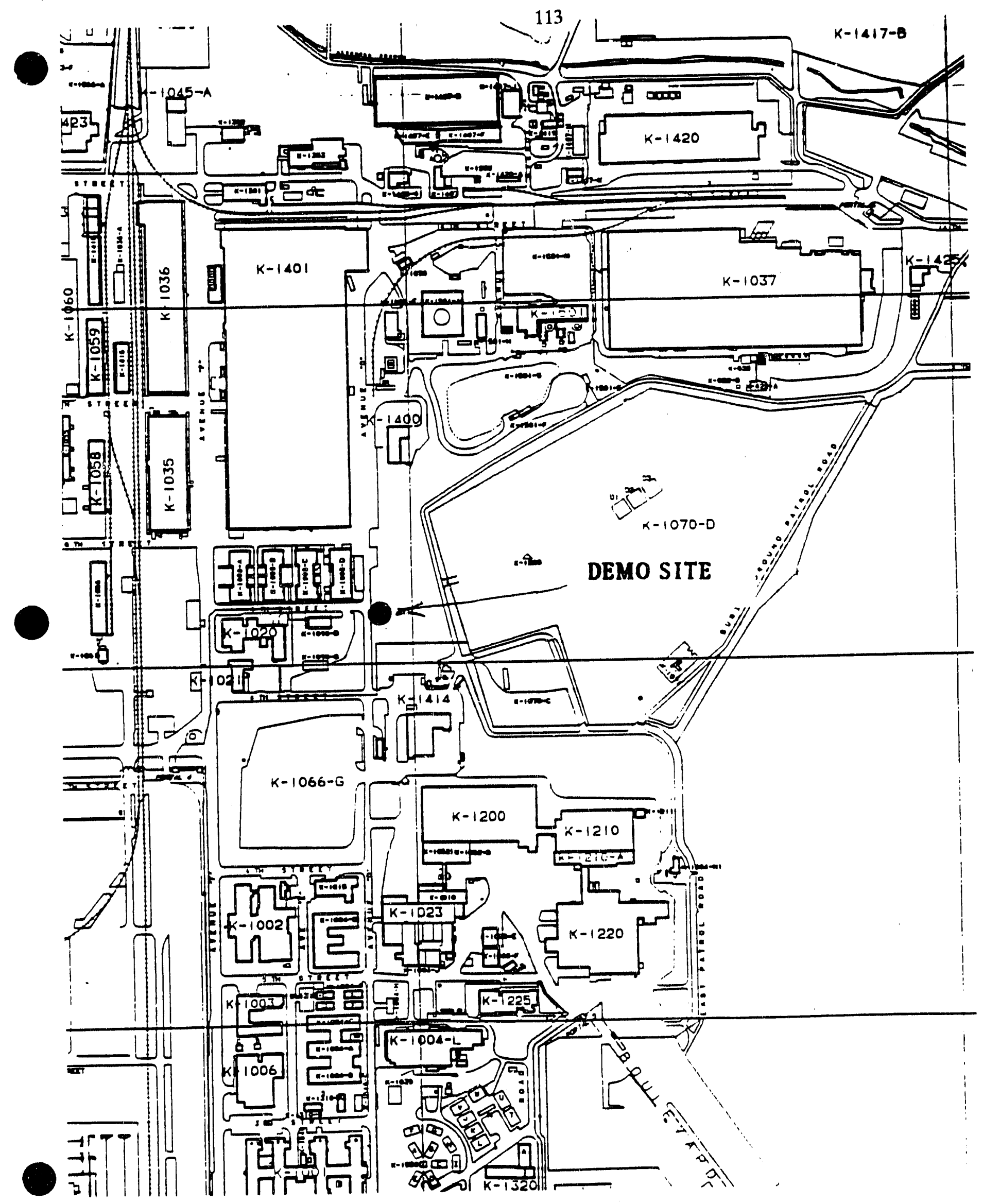

Figure 1. Site of the proposed co-metabolic bioreactor demonstration at the Oak Ridge K-25 Facility. 
Table 1. Contaminants detected in Storm Drain SD-180-04 at the K-25 Facility May-June 1987

\section{Compound}

Volariles

Benzene

Chloroethane

Chloroform

1,1-Dichloroethane

1,1-Dichloroethene

1,2-Dichloroethane

Methylene chloride

Tetrachloroethene

Toluene

Trans-1,2-Dichloroethene

1,1,1-Trichloroethane

1,1,2-Trichloroethane

Trichloroethene

Vinyl chloride

Semivolatiles

2-Methylnaphthalene

4-Methylphenol

Acenaphthene

Anthracene

Dibenzofuran

Ethylbenzene

Fluorene

Naphthalene

Phenanthrene

Nonspecific Parameters

Oil \& Grease

Alpha activity

Beta activity
Concentration ( $4 \mathrm{~g} / \mathrm{L})$

Maximum

Minimum

$\begin{array}{rr}250 & 230 \\ 160 & <10 \\ 5 & <5 \\ 3800 & 2300 \\ 530 & 250 \\ 31 & <5 \\ 8000 & 1900 \\ 50 & <5 \\ 650 & 440 \\ 950 & 670 \\ 4600 & 3000 \\ 24 & <5 \\ 250 & 140 \\ 140 & <10\end{array}$

$\begin{array}{cr}44 & * \\ 2 & * \\ 2 \text { (est.) } & <5 \\ 3 & 2 \\ 1 & * \\ 250 & 190 \\ 2 & 2 \\ 48 & 14 \\ 2 \text { (est.) } & <5\end{array}$

$\begin{array}{rr}2000 & <2000 \\ 4.9 \mathrm{pCi} / \mathrm{L} & <2 \mathrm{pCi} / \mathrm{L} \\ 8.2 \mathrm{pCi} / \mathrm{L} & <2 \mathrm{pCi} / \mathrm{L}\end{array}$


Table 1. (continued)

Water Quality Paramerers

$\begin{array}{lcc}\text { Alkalinity } & 301 \mathrm{mg} / \mathrm{L} & 254 \mathrm{mg} / \mathrm{L} \\ \text { Chemical Oxygen Demand } & 52 \mathrm{mg} / \mathrm{L} & <5 \mathrm{mg} / \mathrm{L} \\ \text { Conductivity } & 767 \mu \mathrm{mho} / \mathrm{cm} & 679 \mu \mathrm{mho} / \mathrm{cm} \\ \text { Dissolved oxygen } & 3.6 \mathrm{mg} / \mathrm{L} & 1.5 \mathrm{mg} / \mathrm{L} \\ \text { Hardness } & 321 \mathrm{mg} / \mathrm{L} & 290 \mathrm{mg} / \mathrm{L} \\ \text { Iron } & 41 \mathrm{mg} / \mathrm{L} & 32 \mathrm{mg} / \mathrm{L} \\ \mathrm{pH} & 7.3 & 6.3 \\ \text { Temperature } & 17^{\circ} \mathrm{C} & 15^{\circ} \mathrm{C} \\ \text { Total Organic Carbon } & 24.9 \mathrm{mg} / \mathrm{L} & 12.3 \mathrm{mg} / \mathrm{L} \\ \text { Total Dissolved Solids } & 498 \mathrm{mg} / \mathrm{L} & 380 \mathrm{mg} / \mathrm{L} \\ \text { Total Suspended Solids } & 51 \mathrm{mg} / \mathrm{L} & 16 \mathrm{mg} / \mathrm{L}\end{array}$

* Only one analysis performed.

Source: Appendix B, "RCRA Facility Investigation Plan, K-1070-C/D Classified Burial Ground, Oak Ridge Gaseous Diffusion Plant, Oak Ridge, Tennessee," Report No. K/HS140, Revision 1, May 1989. 
Table 2. Contaminants detected in Storm Drain SD-180-04 (new sampling point designation: (SU-31) at the K-25 Facility, April 1990. All concentrations reported in units of mg/L except alpha and gamma activity (pCi/L). Underlining indictes chlorinated volatiles and aromatic compounds which may be degraded to some extent in the bioreactor.

\begin{tabular}{|c|c|c|c|c|}
\hline Chemical & $\begin{array}{l}\text { Number } \\
\text { Detected }\end{array}$ & $\begin{array}{l}\text { Range of } \\
\text { Detection } \\
\text { Limits }\end{array}$ & $\begin{array}{l}\text { Range > } \\
\text { Detection } \\
\text { Limit }\end{array}$ & $\begin{array}{l}\text { Average } \\
\text { Detection } \\
\text { Limit }\end{array}$ \\
\hline 1,1,1-Trichloroethane & $4 / 4$ &.- & $4.9--6.8$ & 5.9 \\
\hline 1,1,2-Trichloroethane & $2 / 4$ & $0.25-0.25$ & $0.025-0.033$ & 0.029 \\
\hline 1,1-Dichloroethane & $4 / 4$ &.$\cdots$ & $0.98 \div-1$ & 0.995 \\
\hline 1,1-Dichloroethene & $4 / 4$ & $\cdots$ & $0.51-0.64$ & 0.57 \\
\hline 1,2-Dichloroethene (total) & $4 / 4$ & $\cdots$ & $0.58-0.81$ & 0.68 \\
\hline 1-Ethyl-2-methyl-benzene & $2 / 2$ & $\cdots$ & $0.33-0.33$ & 0.33 \\
\hline 1-Methyl Naphthalene & $\overline{2 / 2}$ & $\cdots$ & $0.068-0.069$ & 0.11685 \\
\hline 1-Pentanol & $2 / 2$ & $\cdots$ & $0.33-0.38$ & 0.35 \\
\hline 1h-Indene, 1-ethylindene & $1 / 1$ & $\cdots$ & $0.042-0.042$ & $0.0 \sqrt{2}$ \\
\hline Ih-Indene, 2,3-Dihydro-Methyl & $2 / 2$ & $\cdots$ & $0.033-0.06$ & $0.04 \overline{65}$ \\
\hline 2-Butanone & $1 / 4$ & $0.2-0.5$ & $0.022-0.022$ & 0.022 \\
\hline 2-Methylnaphthalene & $5 / 5$ & .- & $0.076-0.092$ & 0.087 \\
\hline 3-Octanone & $2 / 2$ & $\cdots$ & $0.025-0.038$ & 0.0315 \\
\hline Acenaphthene & $5 / 5$ &.$\cdots$ & $0.002-0.003$ & 0.0026 \\
\hline Alpha Activity & $1 / 5$ & $1-2$ & $1-1$ & 1 \\
\hline Aluminum & $3 / 5$ & $0.04-0.104$ & $0.091-0.144$ & 0.12 \\
\hline Aroclor-1221 & $1 / 5$ & $0.00057-0.0063$ & $0.00071 \ldots 0.00071$ & 0.00071 \\
\hline Aroclor-1232 & $2 / 5$ & $0.00057-0.0054$ & $0.00091-0.0011$ & $\overline{0.001}$ \\
\hline Aroclor-1242 & $2 / 5$ & $0.00057-0.0025$ & $0.00069-0.00078$ & 0.000735 \\
\hline Aroclor-1248 & $1 / 5$ & $0.00057-0.0006$ & $0.0038-0.0038$ & 0.0038 \\
\hline Barium & $5 / 5$ & 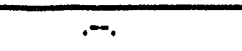 & $0.434-0.513$ & 0.46 \\
\hline Benzene & $4 / 4$ &.$\cdots$ & $1.2-1.3$ & 1.2 \\
\hline Benzene 2-Ethyl-1,4-Dimethyl & $1 / 1$ & .-- & $0.033-0.033$ & 0.033 \\
\hline Beryllium & $1 / 5$ & $0.001-0.001$ & $0.001-0.001$ & 0.001 \\
\hline Bromacil (ACN) & $2 / 2$ & .-. & $0.017-0.018$ & 0.0175 \\
\hline Butane, 1,1'-axybis(2,1-ethanediyloxy)bis & $7 \pi$ & $\therefore$. & $0.64-1.6$ & 1.2 \\
\hline Butane, 2-Methyl- & $4 / 4$ &..- & $0.27-0.45$ & $\overline{0.345}$ \\
\hline Cadmium & $1 / 5$ & $0.005-0.005$ & $0.005-0.005$ & 0.005 \\
\hline Calcium & $5 / 5$ & .-. & $69.8--93.9$ & 82.3 \\
\hline Chromium & $3 / 5$ & $0.01-0.01$ & $0.014-0.03$ & 0.02 \\
\hline Cobalt & $2 / 5$ & $0.02--0.02$ & $0.021-0.032$ & 0.0265 \\
\hline Copper & 2/5 & $0.01-0.01$ & $0.018-0.025$ & 0.0215 \\
\hline Di-n-butylphtalate & $2 / 5$ & $0.011-0.012$ & $0.003-0.004$ & 0.0035 \\
\hline Diacetone Alcohol & $2 / 2$ & .-. & $0.022--0.028$ & 0.025 \\
\hline Dibenzofuran & $3 / 5$ & $0.011-0.012$ & $0.002-0.003$ & 0.0027 \\
\hline Diethyl Benzene & $1 / 1$ & .-. & $0.024-0.024$ & 0.024 \\
\hline Dimethyl Napthalene & $2 / 2$ & $\cdots$ & $0.015-0.032$ & 0.0235 \\
\hline Ethenyl Methyl Benzene & $2 / 2$ & $\cdots$ & $0.05-0.08$ & 0.065 \\
\hline Ethyl Dimethyl Benzene & $4 / 4$ & $\cdots$ & $0.024-0.031$ & 0.027 \\
\hline Ethyl Methyl Benzene & $7 \pi$ & $\cdots$ & $0.06-0.19$ & 0.14 \\
\hline Ethyl Benzene & $4 / 4$ & $\cdots$ & $0.31-0.43$ & 0.37 \\
\hline Fluorene & $5 / 5$ &.$\cdots$ & $0.003-0.004$ & 0.0038 \\
\hline
\end{tabular}




\begin{tabular}{|c|c|c|c|c|}
\hline Freon 113 & $3 / 3$ & 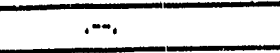 & $1.9--2.8$ & 2.2 \\
\hline Freon 123 & $4 / 4$ &.$\cdots$ & $1.7--2.8$ & 2.15 \\
\hline Gamma Activity & $2 / 5$ & $0 \ldots$ & $0 .-0$ & 0 \\
\hline Heptachlor epoxide & $1 / 5$ & $0.000057-0,00006$ & $0.00012--0.0012$ & 0.00012 \\
\hline Hydroperoxide, 1-Methylpentyl & $4 / 4$ & $\ldots$ & $0.5--0.85$ & 0.703 \\
\hline Iron & $5 / 5$ &.$\cdots$ & $18.1-.26 .8$ & 21.5 \\
\hline Lead & $2 / 5$ & $0.03-0.03$ & $0.036-0.041$ & 0.0385 \\
\hline Magnesium & $5 / 5$ &.$\cdots$ & $9.78-12.9$ & 11.3 \\
\hline Manganese & $5 / 5$ &.- & $11.4--13.7$ & 12.7 \\
\hline Methyl Methyl Ethyl Benzene & $1 / 1$ & .-. & $0.036--0.036$ & 0.036 \\
\hline Methyl Napthalene & $1 / 1$ & $\therefore$ & $0.044--0.044$ & 0.044 \\
\hline Methyl Propenyl Benzene & $3 / 3$ &.$\cdots$ & $0.019-0.035$ & 0.024 \\
\hline Methylcyclobutane & $1 / 1$ &.$\cdots$ & $0.3-0.3$ & 0.3 \\
\hline Methylcyclopentane & $2 / 2$ &.$\cdots$ & $0.17--0.18$ & 0.175 \\
\hline Methylene Chloride & $2 / 4$ & $0.1-0.1$ & $0.16--10.46$ & 0.31 \\
\hline Methylpropyl Benzene & $6 / 6$ &.$\cdots$ & $0.014--0.038$ & 0.026 \\
\hline Molybdenum & $1 / 2$ & $0.02--0.02$ & $0.145--0.145$ & 0.145 \\
\hline Naphthalene & $5 / 5$ & ... & $0.093--0.13$ & 0.11 \\
\hline Naphthalene, -Dimethyl- & $3 / 3$ & 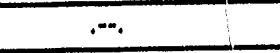 & $0.017-0.024$ & 0.02 \\
\hline Nickel & $1 / 5$ & $0.02--0.02$ & $0.02,-0.02$ & 0.02 \\
\hline Pentane & $3 / 3$ &.$\cdots$ & $0.31--0.55$ & 0.44 \\
\hline Phenanthrene & $5 / 5$ &.$\cdots$ & $0.004-0.005$ & 0.0042 \\
\hline Potassium & $4 / 5$ & $1.9-1.9$ & $2.23--2.73$ & 2.5 \\
\hline Propane, 2-Methoxy-2-Methyl & $2 / 2$ & .-. & $0.11-0.15$ & 0.13 \\
\hline Propenyl Benzene & $1 / 1$ &.$\cdots$ & $0.077--0.077$ & 0.077 \\
\hline Silicon & $2 / 2$ &.$\cdots$ & $4.21-6.1$ & 5.2 \\
\hline Sitver & $2 / 5$ & $0.005-0.005$ & $0.006-0.133$ & 0.0695 \\
\hline Sodium & $5 / 5$ & ... & $11.1--15.2$ & 13.1 \\
\hline Strontium & $2 / 2$ & .-.. & $0.053-0.105$ & 0.079 \\
\hline Tetrachliroethene & $2 / 4$ & $0.25-0.25$ & $0.063--0.067$ & 0.065 \\
\hline Tetrameth $1 /$ Benzene & $4 / 4$ &.. & $0.02-0.031$ & 0.023 \\
\hline Thorium & $1 / 2$ & $0.05-0.05$ & $0.881--0.881$ & 0.88 \\
\hline Toluene & $4 / 4$ &..- & $2.7--3.1$ & 2.9 \\
\hline Trichloroethene & $4 / 4$ & - & $0.33-0.43$ & 0.385 \\
\hline Trimethyl Benzene & $21 / 21$ &.$\cdots$ & $0.058-0.46$ & 0.16 \\
\hline Unknown & $21 / 21$ & 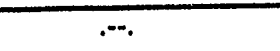 & $0.017--0.055$ & 0.033 \\
\hline Unknown Hydrocarbon & $28 / 28$ & . & $0.018-0.23$ & 0.060 \\
\hline Uranium 238 & $1 / 2$ & $0.2-0.2$ & $4.44--4.44$ & 4.44 \\
\hline Vanadium & $3 / 5$ & $0.01-0.01$ & $0.01-0.014$ & 0.0127 \\
\hline Xylene (total) & $4 / 4$ & $\cdots$ & $1.4--1.9$ & 1.625 \\
\hline Zinc & $4 / 5$ & $0.01-0.01$ & $0.01--0.068$ & 0.042 \\
\hline bis(2-Ethylhexyl)phthalate & $1 / 5$ & $0.011--0.012$ & $0.004-0.004$ & 0.004 \\
\hline n-Propylbenzene & $6 / 6$ &..- & $0.031--0.86$ & 0.17 \\
\hline
\end{tabular}

Source: D. Miller, personal communication to S. E. Herbes, 10/8/90. Excerpted from "Site Characterization Summary: K-1070-C/D Classified Burial Ground," Report No. K/ER-4/D1 (Draft): Appendix C (Surface Water Sampling Data). Environmental Restoration Division/K-25 Environmental Restoration Program, March 1990. 


\section{TECHNOLOGY DESCRIPTION}

\subsection{METHANOTROPHIC SYSTEM}

This technology is based on the biological degradation of chlorinated aliphatics by methane-utilizing microorganisms (methanotrophs). These microorganisms oxidize methane to generate energy for life functions. A key enzyme in the metabolism of methane is called methane monooxygenase. In addition to its role in methane metabolism, it is sufficiently non-specific that it also catalyzes the epoxidation of chlorinated alkenes such as trichloroethylene (TCE). This phenomenon of simultaneous transformation of secondary substrates is termed "cometabolism." It appears that most methanotrophic microorganisms have the capability for cometabolism of chlorinateci alkenes. Mixed cultures containing other types of microorganisms aid in the overall destruction of the substrates.

Formation of the epoxide appears to be the rate-limiting step; further hydrolysis and biodegradation occur relatively rapidly. Tests with radiolabeled TCE have shown that the majority of the TCE carbon is mineralized to carbon dioxide and a small amount is incorporated into cell mass. Although intermediate degradation products are surely produced, they appear to be below analytical detection limits. A variety of chlorinated alkenes can be degraded by this mechanism. A notable exception appears to be tetrachloroethylene; it is believed to be highly resistant to oxidation, but can be biodegraded anaerobically.

The process technology to be demonstrated in this project is based on the trickle-bed bioreactur concept. Mixed cultures containing methanotrophs and other microorganisms are induced to grown in biofilms on the surface of a support matrix such as pall rings in a columnar bioreactor. The contaminated water to be treated is applied to the top of the column and then trickles down over the surfaces of the biofilms. This action provides intimate contact of the water with the 
microorganisms. Air (oxygen) and methane are also provided to the continuous gas phase in the trickle-bed bioreactor to support the methanotrophs. Treated water and off-gas are removed from the bottom of the bioreactor.

In our laboratory-scale studies this bioreactor concept has been shown to degrade $1 \mathrm{ppm}$ or greater TCE to less than $50 \mathrm{ppb}$ when the liquid residence time is several hours. Fifty percent degradation is achievable in about one hour Work by other investigators has shown reduction of TCE to below detection limits after several days.

Laboratory and bench studies have identified a number of important variables and issues relevant to successful operation of a pilot-scale demonstration of this technology. These issues are discussed below.

- TCE concentrations in excess of $100 \mathrm{ppm}$ are toxic/inhibitory to the microbial cultures. However, this is not a practical problem because the TCE in the K-25 Site seep water is $<1 \mathrm{ppm}$.

o Studies to date have shown that effluent concentrations of $50 \mathrm{ppb}$ can be achieved in several hours. Further reductions require substantially longer residence times. The explanation is not yet known.

o Several metals, notably manganese and copper, affect the bioactivity of the microbial cultures. While optimal conditions can be identified in laboratory studies, it is not clear yet if control of these trace metals will be necessary in field operations.

- Dissolved iron in excess of $1 \mathrm{ppm}$ may cause problems because of formation and precipitation of oxides on the biofilms, which will probably reduce the accessibility of the water to the biofilms. Biodegradation rates will thus decrease. However, some natural shedding and regeneration will occur, perhaps 
enhanced by the deposition of iron oxides. This behavior is not understood. A similar pilot study by Battelle employed pretreatment (deionization/water softening) to remove minerals.

o Not all microbial cultures form satisfactory biofilms. It will be important to inoculate the bioreactor with a culture that does form stable films. Laboratory studies have shown that the films persist for months; verification of this ruggedness will be a significant aspect of the process demonstration.

\subsection{TOLUENE-DEGR IDING SYSTEM}

The toluene degrading system will use above ground bioreactors containing mixed cultures of toluene oxidizing bacteria to degrade TCE in the K-25 site water. The water will be diverted from the seep into the bioreactor system where concentration of TCE and related compounds will be reduced. The treated water will then be released to the storm drain or diverted to the K-25 treatment facility. The technology for treatment by toluene-degrading bacteria has not been demonstrated in a bioreactor thus the time to the site demonstration will be longer than that planned for the methanotroph system.

\subsubsection{Description of the Process}

The basic technology of the toluene-degrading system is very similar to that of the methanotroph system in that both are based on the co-metabolic degradation of TCE by non-specific oxygenase enzymes. Work on the promotion of TCE degradation toluene degraders by a number of investigators has indicated that the co-metabolic degradation of TCE by pseudomonads can be stimulated by aromatic compounds. One strain has been shown to degrade a large number of organic contaminants either by direct oxidation and utilization as a carbon and energy source or by 
co-metabolism. Reports in the literature indicate that this isolate, when grown on aromatic compounds (e.g. toluene), is able to co-metabolize chlorinated alkenes such as trichloroethylene. The bacteria will grown on and degrade a number of aromatic compounds including phenol, toluene, o-cresol, and m-cresol. Other pseudomonas also have this co-metabolic capacity and have been shown to rapidly degrade TCE and other chlorinated ethylenes such as cis and trans-1,2-Dichloroethylene and 1,1-Dichloroethylene. This type of culture should be ideal for situations such as those at the proposed site where chlorinated alkenes are mixed with aromatics such as benzene and toluene since the bacteria can use the aromatics as growth substrates while co-metabolizing the chlorinated compounds.

\subsubsection{Critical Factors}

The critical factors for the toluene-degrading system are similar to those for the methanotroph system with the possible exception of the problems with delivery of the source of the reducing power, toluene and related compounds in this case and methane in the methanotroph system. The critical factors that must be investigated in the preliminary tests in order to ensure successful demonstration of the technology include the following:

- Selection of the cultures based on the following criteria

- Maximum rate of TCE degradation

- Maximum extent of TCE degradation

- Stability of the culture

- Minimum effect of the other contaminants on the above

- Degradation of other contaminants present in the site water that are also of regulatory concern. 
- Establishment of culture conditions, to meet above criteria, including:

- Determination of appropriate co-metabolizable substrate and appropriate concentrations

- Determination of appropriate inorganic nutrient levels (including trace metals)

- Optimization of design of bioreactor to:

- Minimize possible competitive inhibition with the growth substrate

- Maximize degradation rates, thus mininizing system design and cost

- Allow for ease of maintenance and cleaning

- Utilize reagents efficiently 


\section{PRELIMINARY TESTS: METHANOTROPH SYSTEM}

\subsection{CULTURE SCREENING/ASSESSMENT}

\subsubsection{Objectives}

The objectives of the culture screening and assessment are to provide cultures for testing in the bench scale bioreactors that have the best chance of meeting the over all goals of the project. The critical questions to be addressed are:

1) What consortia if any has the greatest capacity (rates and extents) for TCE degradation?

2) What consortia exhibits the greatest tolerance to the other organics in the site water?

3) What consortia also degrades the other organics in the site water?

\subsubsection{Evaluation Criteria}

The evaluation criteria are essentially the same as those listed for the methanotrophs. The most important criteria is the ability of the consortia to reduce concentrations of TCE to the lowest extent possible. The "best" culture would be the one that achieved the fastest decrease to drinking water standards. Cultures will be passed on for bioreactor tests if they achieve either rapid degradation or complete degradation. The second criteria will be the ability of the culture to maintain a high degree of degradative activity in the presence of the mixed organics in the site water. The third criteria will be the ability of the consortia to degrade the other organics in the site water particularly those that are of regulatory concern.

\subsubsection{Analytical Methods}

Batch experiments will be run to compare the performance of the consortia in reference to the evaluation criteria. TCE and related compounds will be analyzed on a gas chromatographic (GC) 
system and in selected experiments the fate of the TCE will be followed by radiolabel techniques. Concentrations of oxygen and methane are also determined using GC techniques. Microbial biomass is determined by direct counts of the bacteria or by protein measurement. Detailed procedures have been summarized in the Technology Status Report.

\subsubsection{Laboratory Tests}

The proposed work consists of a series of laboratory tests using batch cultures to compare the abilities of different methane utilizing consortia to degrade TCE in the presence of the contaminants found at the site and to determine what culture conditions result in the highest rates and greatest extent of TCE degradation. Initial tests will use synthetic media and TCE to which will be added increasingly complex mixtures of the organic contaminants found at the site. Contaminants to be included are those found at highest concentration in the seep water (see below) including methylene chloride, 1,1,1,-Trichloroethane, and 1,1,-Dichloroethane and the effect of these organics will be test over the range reported for the seep water. Site seep water will then be used for treatability studies.

\subsubsection{Culture acquisition and maintenance}

Cultures have been and are being obtained by enrichment of contaminated water from a number of DOE sites and from other investigators at universities and at commercial firms. Methaneutilizing cultures on hand include three cultures isolated from Y-12 and one mixed culture isolated from the DOE Kansas City Plant. Attempts will also be made to isolate additional methane-utilizing consortia from the site water by enrichment techniques.

Pure cultures of methanotrophs will be added to specific consortia to determine if the presence of these organisms increases TCE degradation. Pure cultures being maintained include both type I and type II methanotrophs and represent the most commonly used methanotrophic cultures 
for examination of TCE degradation (OB3b) and the first pure culture that was demonstrated to be able to degrade TCE (46-1).

\subsubsection{Culture screening}

The ability of the consortia to degrade TCE at concentrations found at the site, 140 to 250 $\mu \mathrm{g} / \mathrm{L}$, will be compared in experiments with synthetic media. The effects of the other contaminants found at the site on the degradation of TCE will be assessed in a series of experiments where mixtures of increasing complexity are added to the syrnthetic media. The effects of added toluene will be examined first since it is a growth substrate for the toluene degraders whose capabilities will be compared to the methanotrophs (Section 4.0). After the effects of the toluene on TCE degradation by the various mixed are assessed. The effects of toluene + methylene chloride (the most abundant contaminant) will be determined. The effects of the other contaminants found at high concentrations (e.g. 1,1,1,-Trichloroethane and 1,1,-Dichloroethane) and those that are known to effect TCE degradation (e.g. PCE). The concentrations of contaminants added will be determined based on the maximum and minimum concentrations reported in the site water. The cultures which perform best in these tests (according to the criteria defined in 3.1.2) will be used in the bench scale bioreactor studies (3.2).

\subsubsection{Batch treatability tests}

Batch treatability tests integrate the effects of all of the components present in the site water on the TCE degradation activity exhibited by the cultures. The culture screening can help determine which cultures are most likely do well in the site water and can determine which, if any, of the components of the site water have a negative effect on TCE degradation but the treatability tests are the critical component. These experiments will compare the TCE degradation of the consortia at 
various dilutions (100 to $10 \%$ site water) of the site water in mineral salts media. These experiments will be conducted using radiolabeled TCE, or in selected experiments GC techniques will be employed to measure degradation of a variety of the contaminants. Choice of analytical technique will be based on the object of the experiment (e.g. if degradation of chlorinated compounds other than TCE needs to be measured GC techniques must be used). The results of these tests and the culture screening tests (3.1.4.2) will be used to determine if site water will need to be diluted or pretreated prior to use in the bioreactors. The results of these experiments will be verified in the bench scale bioreactor studies (3.2).

\subsubsection{Nutrient optimization tests}

The effect of changes in culture conditions will be tested with the aim of increasing the rate and extent of degradation. For example, the effect of addition of formate, as a supplemental carbon and energy source, on the rate and extent of TCE degradation by the methane utilizing cultures will be examined as will the major nutrient requirements. The effect of variations in this composition including reduction in the phosphorous concentration, which is used both as a nutrient source and a pH buffer, elimination of the ammonium, elimination of the copper and addition of formate will be tested.

The composition of the synthetic media will be compared to chemical analysis of the site water to determine what nutrients need to be added. The effect of any inorganic compounds present at higher concentrations than those found in the synthetic media on TCE degradation will be determined in experiments with mineral salts medium modified by addition of the inorganic compound in question to concentrations found in the site water. These studies will help determine what inorganic nutrients need to be added to the site water and will also determine if the presence of any inorganics in the site water are likely to inhibit or reduce TCE degradation. The information from 
these tests will be used to determine optimum nutrient feeds for the bench scale bioreactor systems (3.2).

\subsection{BENCH-SCALE BIOREACTOR TESTS}

\subsubsection{Objectives}

The objectives of the bench-scale bioreactor tests are to evaluate several methanotrophic cultures in a bench-scale bioreactor mode and to determine the effects of various parameters deemed significant from shake-flask studies. Six cultures will be selected from initial laboratory studies, inoculated into small fixed-film bioreactor systems, and their behavior evaluated using both synthetic and pretreated (to remove iron) real wastes. Based in part on this evaluation, one of the cultures will be selected for use in the field-scale demonstration reactors.

\subsubsection{Evaluation Criteria}

Specific criteria are to be used in evaluating the cultures. Although many of these criteria will have already been met in selecting cultures from the laboratory experiments (see 3.1.1), changing to a bioreactor environment could induce and/or reveal positive or negative characteristics.

Certain characteristics of the culture are of importance. It must be able to establish and maintain itself as a biofilm within the reactor. Another characteristic of interest is the culture's ability to grow and maintain TCE degrading activity with minimal close attention to adjustable environmental parameters (e.g. pH, nutrient concentration). The culture must, of course, be able to maintain viability and TCE degrauing activity with the actual site water. This possibly entails resistance to the effects of heavy metals and certainly, to other hazardous organic compounds present in the waste stream. 
With regard to the cultures degradative capabilities the primary criteria for selection are more concrete, namely the rate of TCE degradation, the minimum TCE concentration achievable, and whether other hazardous compounds are concurrently degraded (3.1.2).

Degradation rates will be determined by analysis (see below) of the component of interest in the influent (liquid) and effluent (liquid and off-gas) streams. The degradation rate will be calculated as:

$$
I_{L}-E_{L}-E_{O}
$$

where $I_{L}=T C E$ in influent liquid $(u g / h r) ; E_{L}=T C E$ in effluent liquid (ug/hr); and $E_{G}=T C E$ in effluent gas (ug/hr).

\subsubsection{Analytical Methods}

The compounds of interest (TCE and other hazardous organics) will be monitored by gas chromatography. The gas chromatograph to be used is a Hewlett-Packard (HP) Model 5890A equipped with both an electron capture detector (for halogenated compounds) and a flame-ionization detector (for other VOC's). The response of the detectors will be integrated and plotted with a HP Model 3396A recording integrator. The data will also be stored on a HP Model 9114B disk storage system for subsequent retrieval and/or manipulation. An HP Model $7673 \mathrm{~A}$ autosampler will be used for routine analysis of hexane extracted compounds. The column used for separation will be a Megabore $\mathrm{DB}+1$ capillary column (J\&W Scientific Corp). Additional VOCs will be monitored by GC as feasible.

\subsubsection{Reactor Operation}

The bench-scale bioreactors consist of $5 \mathrm{~cm}$ by $0.6 \mathrm{~m}$ heavy wall glass tubes. The bottom is sealed by a stainless steel plate with a Viton rubber gasket. The plate and gasket are held in place 
using a bolted flange. The plate has a single $0.9 \mathrm{~cm}$ outlet port for both liquid and gas effluent. Provision is made for influent (by redirecting influent stream through a tee in line) and effluent liquid streams (from bottom drain line). Off-gas sampling will be accomplished through a septum-sealed tee in the drain line.

The columns will be packed with $1.6 \mathrm{~cm}$ polyethylene pall rings which will serve as the biofilm support. These have proved successful in earlier studies.

The influent waste (synthetic and real) will be introduced to the reactor through two stainless steel tubes ( $1.6 \mathrm{~mm} \mathrm{i.d.).} \mathrm{The} \mathrm{liquid} \mathrm{will} \mathrm{be} \mathrm{allowed} \mathrm{to} \mathrm{enter} \mathrm{the} \mathrm{reactor} \mathrm{dropwise} \mathrm{and} \mathrm{fall} \mathrm{upon} \mathrm{a}$ stainless steel screen placed over the packing. The screen will split the drops and more evenly distribute the liquid over the packing.

When synthetic waste is fed to the reactors, the nutrient mineral salts (see 3.1.1.4) and TCE will be prepared in a 20 -fold concentrated aqueous solution. This solution will be pumped (using a peristaltic pump with Viton tubing) to a "sealed" mixing vessel where it will be diluted with process water and forced by the internal pressure in the mixing vessel into the bioreactor. The flow rates of the two liquid streams entering the mixing vessel will determine the flow rate (generally $4-6 \mathrm{~mL} / \mathrm{min}$ ) of the influent stream to the bioreactor. The actual waste will be introduced to the reactor in a similar manner except that provision will be made to introduce nutrients deemed necessary from laboratory studies and/or to dilute it with process water if required.

The primary substrate for the microorganisms, methane, will be introduced at the top of the reactor. It will be supplied as a premixed preparation of $3 \%(v / v)$ methane in air (Matheson Gas Products) at an appropriate flow rate (to be determined - approximately $5 \mathrm{~mL} / \mathrm{min}$ ).

The reactors will be inoculated initially with a previously prepared suspension of the cultures of interest. The medium used will be one based on the findings of the laboratory studies. The system will be operated under total recycle using a synthetic waste without TCE until visible signs of biofilm 
formation are evident. The system will then be switched to a single-pass mode of operation using a TCE containing feed. TCE degradation will be followed until a reasonably steady degradation rate has been achieved. Experiments will then be performed to verify the similarity in behavior of the culture to what has been found in laboratory shake-flasks tests. Of primary interest is the rate and extent (lower limit) of TCE degradation achievable. If the culture is not performing like its parent shake-flask culture, alterations in operating conditions will be made (based on previous and on-going laboratory findings) in an attempt to either improve the performance or determine the reason(s) for unsatisfactory performance.

When data indicate that the culture is performing in a suitable manner, real waste will be introduced to the system and the performance of the culture reassessed. As necessary, modifications (nutrient supplementation, $\mathrm{pH}$ adjustment, waste pretreatment, etc.) will be made to improve performance or to understand reasons for poor performance. During these experiments we will follow TCE degradation and possibly the removal of other VOC's from the waste water.

At the conclusion of the experimental effort, the reactors will be disassembled. The biomass will be removed from the support by vigorous agitation in water, recovered by centrifugation, and the dry weight determined $\left(110^{\circ} \mathrm{C}\right)$. The results of TCE degradation experiments with the individual reactors will be reassessed to determine the significance, if any, of biomass concentration to reactor performance.

The results of these experiments will be used in the selection of one of the cultures for use in the field demonstration reactor and where applicable to define operating parameters. 


\section{PRELIMINARY TESTS: TOLUENE-DEGRADING SYSTEM}

The sections below describe work that is planned work at ORNL. In addition to in house work on this system, researchers at other organizations with experience with these bacteria may be involved in aspects of the work. Details of this planned collaboration have not been worked out and are not described in this section. Thus, the details given below describe the planned work, but are subject to modification as collaborative relationships are developed.

\subsection{CULTURE SCREENING/ASSESSMENT}

\subsubsection{Objectives}

As with the methanotrophs, the objectives of the culture screening and assessment are to provide cultures for testing in the bench scale bioreactors that have the greatest likelihood of meeting the overall goals of the project. Critical questions to be addressed are the same as those listed in Section 3.1.1.

\subsubsection{Evaluation Criteria}

The evaluation criteria are essentially the same as those listed for the methanotrophs (see Section 3.1.2).

\subsubsection{Analytical Methods}

As with the methanotroph work, batch experiments will be run to compare the performance of the consortia in reference to the evaluation criteria. TCE and related compounds will be analyzed on a GC system; in selected experiments the fate of the TCE will be followed by radiolabel 
techniques. Concentrations of oxygen and toluene will also be determined using GC techniques. Microbial biomass will be determined by direct counts of the bacteria or by protein measurement.

\subsubsection{Laboratory Tests}

The proposed work consists of a series of laboratory tests using batch cultures to compare the abilities of different toluene-utilizing isolates and consortia to degrade TCE in the presence of the contaminants found at the site and to determine what culture conditions result in the highest rates and greatest extent of TCE degradation. The work will parallel that described in section 3.1.4.

\subsubsection{Culture acquisition and maintenance}

Cultures will be obtained by enrichment of contaminated water from the K-25 site and a number of isolates are being obtained from other investigators at universities and at commercial firms and from the American Type Culture Collection (ATCC).

Pure cultures of toluene degraders will be added to specific consortia to determine if the presence of these organisms increases TCE degradation. Pure cultures are on hand that were obtained from the ATCC.

Cultures are maintained in frozen condition when not in use. Starter cultures are generated from the frozen stocks.

\subsubsection{Culture screening}

As described for the methanotrophs in section 3.1.3.2 the ability of the consortia to degrade TCE at concentrations found at the site, 140 to $250 \mu \mathrm{g} / \mathrm{L}$, will be compared in experiments with synthetic media. Unlike the experiments with the methanotrophs toluene will be present in all experiments. The effect of methylene chloride (the most abundant contaminant) will be determined 
first and the effects of the other contaminants found at high concentrations (e.g. 1,1,1,-trichloroethane and 1,1,-dichloroethane) and those that are known to effect TCE degradation (e.g. PCE) will also be examined. The concentrations of contaminants added will be determined based on the maximum and minimum concentrations reported in the site water. The cultures which perform best in these tests (according to the criteria defined in 3.1.2) will be used in the bench scale bioreactor studies (4.2).

\subsubsection{Treatability tests}

As with the methanotrophs the most important step in these preliminary tests are the treatability studies with the site water and these will be as described in Section 4.1.4.3. These tests integrate the effects of all of the components present in the site water on the TCE degradation activity exhibited by the cultures. Again, the results of these tests and the culture screening tests (Section 4.1.4.2) will be used to determine if site water will need to be diluted or pretreated prior to use in the bioreactors. The results of these experiments will be verified in the bench scale bioreactor studies (Section 4.2).

\subsubsection{Nutrient optimization tests}

The effect of changes in culture conditions will be tested with the aim of increasing the rate and extent of degradation. For example, the effect of addition of toluene, as a supplemental carbon and energy source to the toluene present in the site water, on the rate and extent of TCE degradation by the toluene-utilizing cultures will be examined as will the major nutrient requirements. The composition of the synthetic NATE media is listed in Section 3.1.4.4 and the tests will be done as described in that section. The information from these tests will be used to determine optimum nutrient feeds for the bench scale bioreactor systems (Section 4.2). 


\subsection{BENCH-SCALE BIOREACTOR TESTS}

The bench-scale bioreactor tests will be conducted by ORNL and/or by a separate research organization under subcontract to ORNL. These tests have not yet been fully defined. 


\section{DEMONSTRATION SYSTEM DESIGN}

\subsection{METHANOTROPH SYSTEM}

The field demonstration will consist of operation of a skid-mounted bioreactor unit for a period of four months. A similar campaign may be conducted later in parallel with the demonstration of the toluene-degrading system, depending on continued availability of the unit.

The skid-mounted bioreactor unit will be obtained from Tyndall Air Force Base (on loan). The skid contains two bioreactor columns, each approximately 16-in-diam and 6-ft-tall, plus associated piping and pumps and controls. The skid has been shipped to ORNL, and any necessary repairs and modifications will be carried out at ORNL prior to transporting the skid to the K-25 demo site. Addition of any capabilities, such as water pretreatment, off-gas treatment, etc. will be provided at

ORNL. Need for such auxiliaries will be determined following inspection of the skid as-received, discussions with K-25 site personnel, and evaluation of the composition of the feel water.

The important components of the bioreactor system, either provided on the Air Force skid or to be added at ORNL, are:

o Four-gallon sump at seep to collect water for feed pump intake;

o Piping from the seep to the skid unit;

- Feed pump with associated valves and controls;

o Steam stripper and air oxidation pretreatment systems;

o Bioreactor columns and packing material for retention of biofilms;

- Methane-air supply mixture (3\% v/v) supply (cylinders);

o Tankage and metering pump for nutrients (mixture to be determined via laboratory-scale treatability studies) and pH adjustment; 
o Piping and valving for liquid recycle during startup and discharge to tankage during operation;

- Tankage for effluent water;

- Safety monitoring and shutdown systems;

- Process control and monitoring equipment (temperature, dissolved oxygen, $\mathrm{pH}$ at several locations).

This equipment package will serve to obtain water at $\sim 1 \mathrm{gpm}$ maximum from the seep, adjust the $\mathrm{pH}$ to -7 if necessary, add nutrients, and deiiver the water to the top of the first bioreactor column. A mixture of $3 \%$ methane in air will be provided to the bioreactors in concurrent flow with the liquid to minimize stripping of the volatile organics to the gas phase.

The layout of equipment in the van trailer is shown in Figure 2. A schematic diagram of piping and valving of the system is shown in Figure 3.

\subsection{TOLUENE-DEGRADNNG SYSTEM}

The toluene-degrading system will be designed at a later time. The system will be designed as a separate module which will be installed either in the van trailer or adjacent to it on the site. The unit will be designed to operate independently from the methanotrophic system, and will use the same influent flow as the methanotrophic system. 


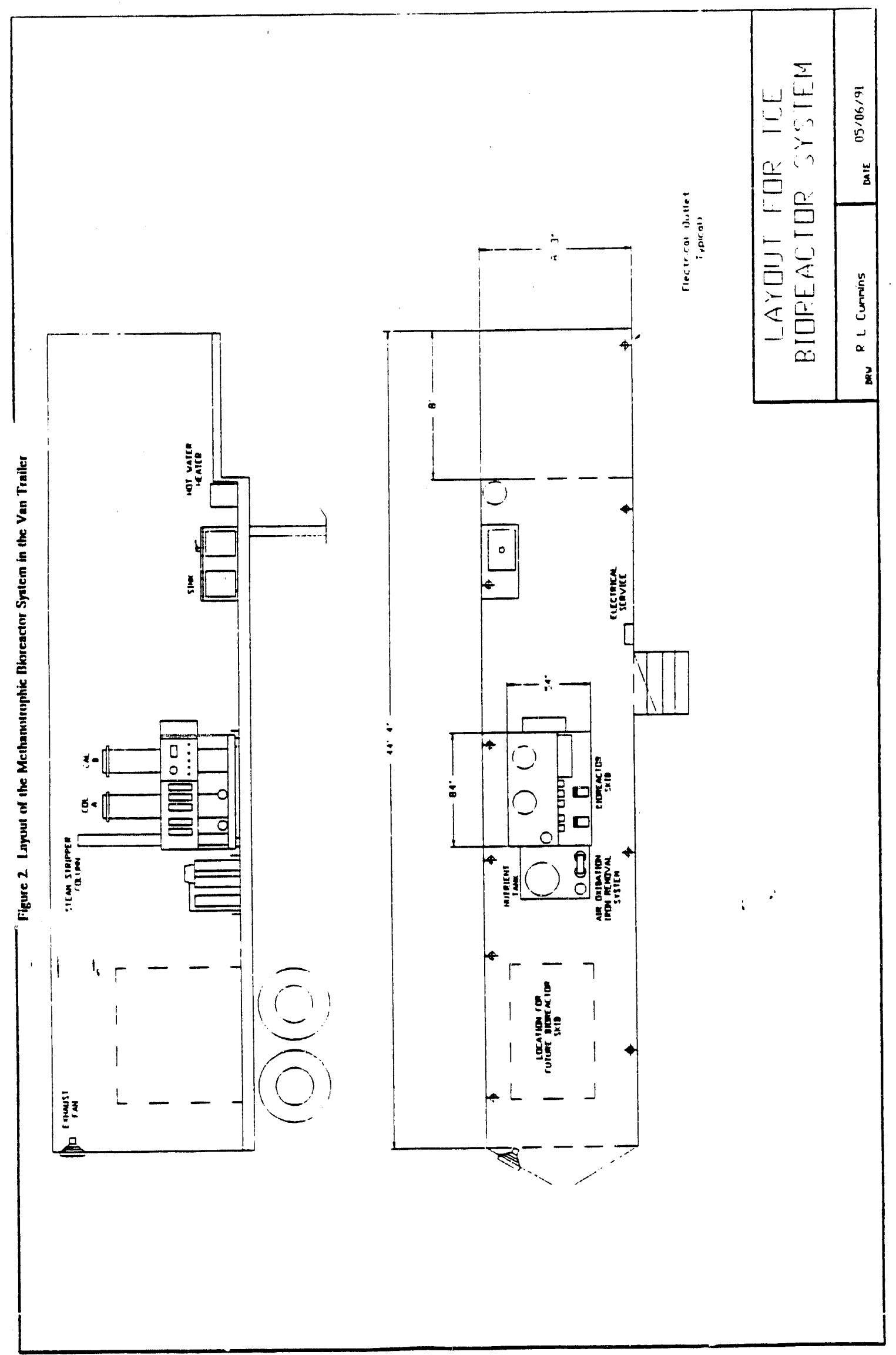




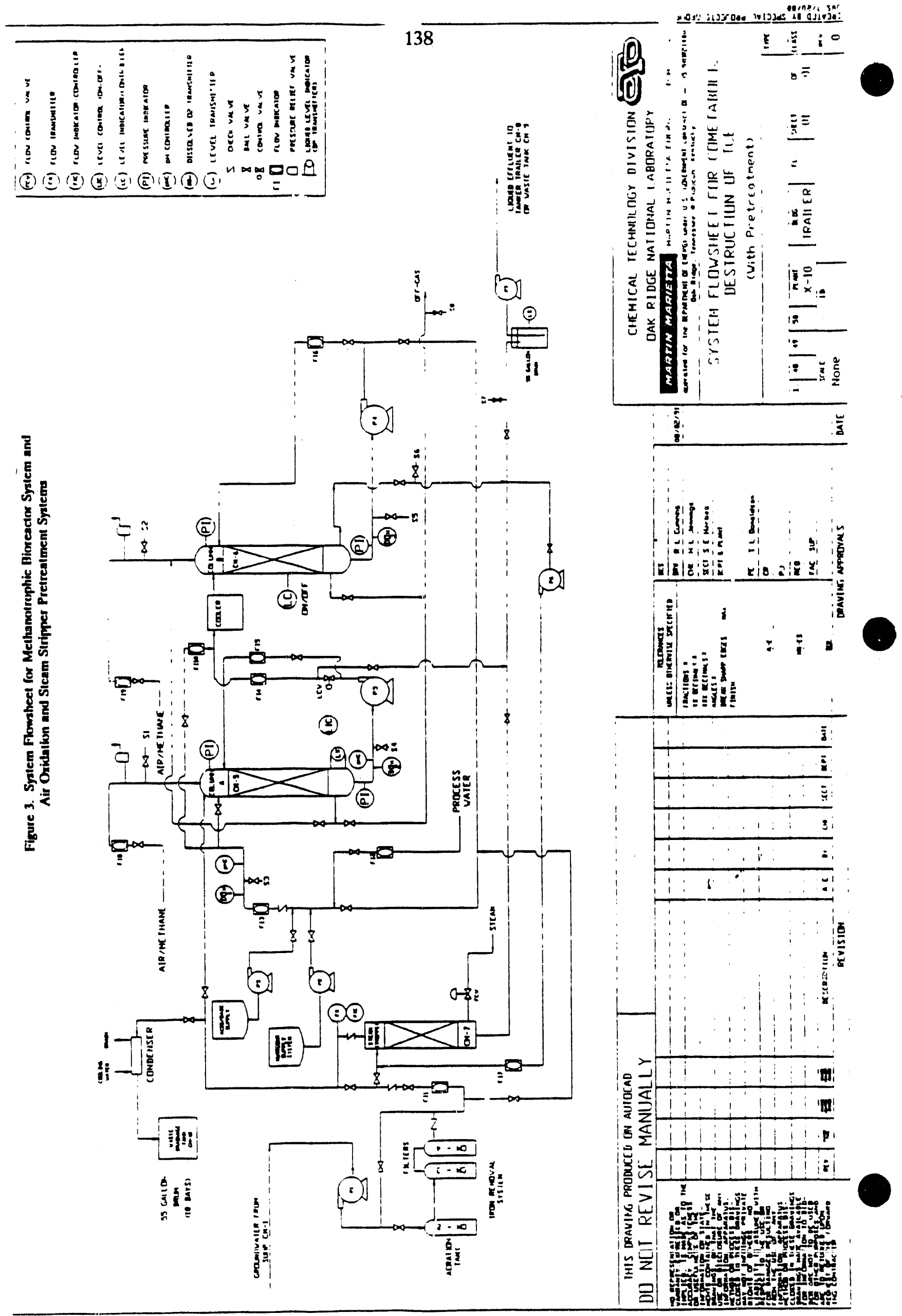




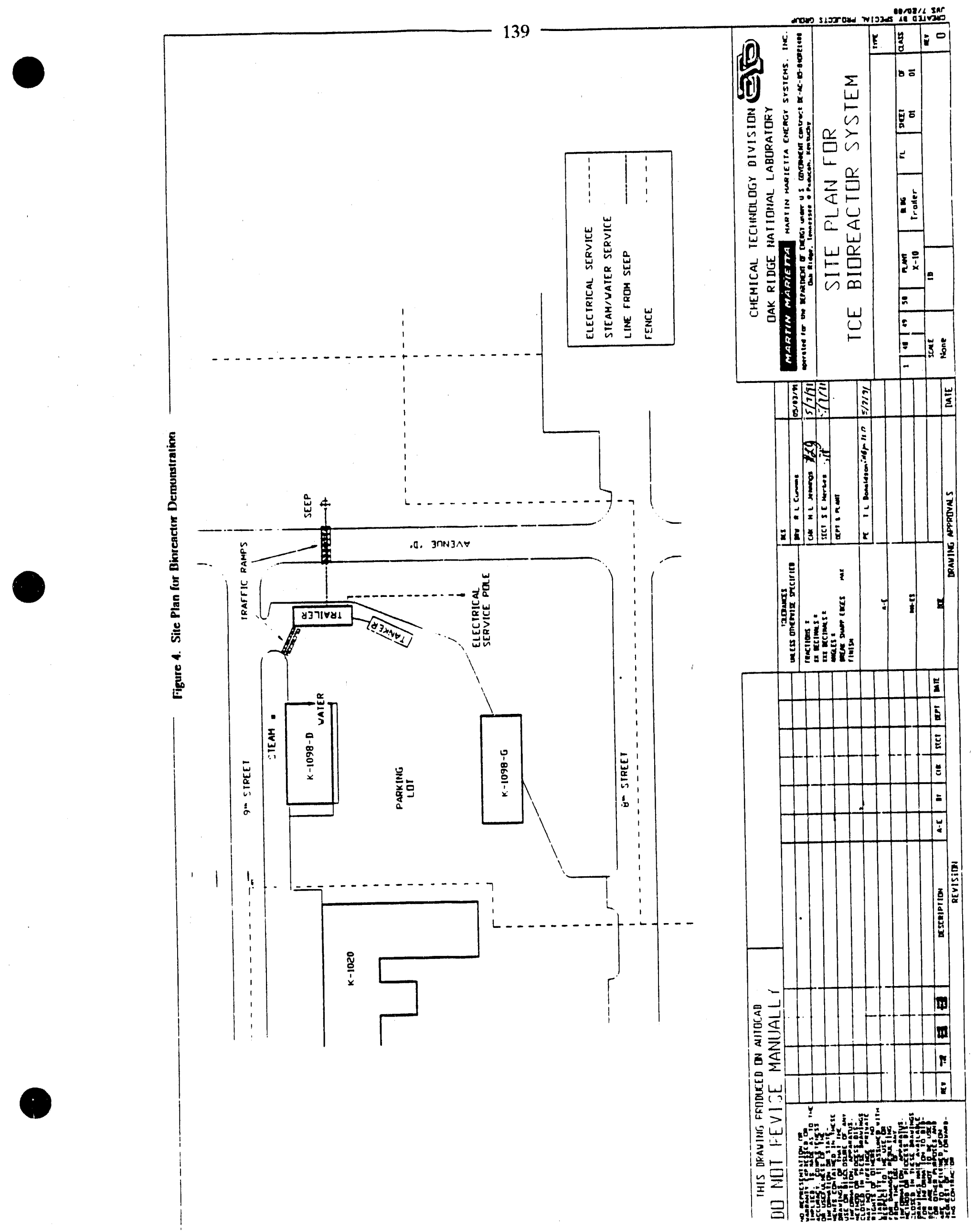




\section{SITE REQUIREMENTS}

\subsection{SPACE AND LOCATION}

The skid-mounted unit with associated tanks and equipment will require an area $\sim 12 \mathrm{ft} \times 80$ ft. This area will provide room for the processing trailer containing the methanotrophic bioreactor unit, pretreatment equipment, an additional bioreactor skid for the toluene demonstration (if the unit cannot be mounted in the trailer), and a tanker trailer for waste transportation and disposal.

The processing trailer and waste-holding trailer will be parked along the eastern-most curb in the parking lot adjacent to Building K-1098-D. This will provide easy access to all units and provide a level surface for the trailers. The site plan is shown in Figure 4.

\subsection{ACCESS AND SECURITY}

The seep and all of the field demonstration facilities are located within the limited area of the K-25 site. Access to the limited area of the $\mathrm{K}-25$ site is available to all $\mathrm{L}$ and $\mathrm{Q}$-cleared Martin Marietta Energy Systems (MMES), DOE and MMES subcontractor personnel. All uncleared personnel shall be escorted by an L or Q-cleared photo badged person. All visitors (Non MMES, DOE and/or MMES subcontractors) requiring access to the $\mathrm{K}-25$ site shall make arrangements and obtain permission for their visit from the Visitor Control Section of the K-25 site. This must be done a minimum of 24 hours in advance.

\subsection{PERSONNEL STAGING}

Because the demonstration site is only 15 minutes from ORNL, minimal personnel staging requirements will be necessary. Operating staff will dress out appropriately (Health and Safety Plan; Appendix B) before entering the K-25 Site. 
Project staff will use bathroom and lunchroom facilities in Building K-1098-D as necessary during operation of the demonstration.

\subsection{SITE PREPARATION}

Since the parking lot of Building K-1098-D provides a paved and level surface for our bioreactor system, preparation of the site to provide access will be minimal. Temporary utility services will be needed as discussed below. A 4-gallon stainless steel sump will be installed directly under the seep across the road and to the east of the parking lot. Piping will be installed to supply seep water to the bioreactor system in the process trailer. A traffic ramp will be installed to permit traffic to cross the seep-water supply lines.

\subsection{UTILITY REQUIREMENTS}

Utility needs will include process water ( $\sim 1 \mathrm{gpm})$, electricity (240 VAC, $50 \mathrm{amp})$, and steam (15 psi). Supply lines for the process water and steam will be run from Building K-1098-D. A traffic ramp will be installed to allow vehicle access to the parking lot. Electrical service will be obtained from an existing pole in the southeast comer of the parking lot. A pole will be set next to the trailer to facilitate running electrical service overhead.

Telephone service is needed for safety reasons. This service will be provided by cellular phone due to the cost and logistics involved in running a hard line to the trailer.

\subsection{WASTE GENERATION AND DISPOSAL}

The waste streams to be produced by the demonstration are defined and characterized, and procedures for their disposal are delineated, in the Waste Management Plan (Appendix A). 


\section{OPERATION}

\subsection{METHANOTROPH SYSTEM}

\subsubsection{Pre-Operational testing}

A series of pre-operational tests will be performed prior to the operation of the bioreactor system with seep water as the influent to the system. During these pre-operational tests process water and air will be utilized to assess the hydraulic integrity of the bioreactor unit and all pertinent pretreatment and support systems. Instrumentation will also be checked for proper operation. Steam will be supplied to the steam stripper to verify that it will work as designed.

During these pre-operational tests, existing procedures will be further developed and verified while all modes of operation which are likely to be used will be tested.

\subsubsection{Setup}

The bioreactor trailer and associated equipment will be transported to the site from ORNL and parked in the lot adjacent to building K-1098-D. Accommodations for 3\% methane/air cylinders will be made at ORNL before transporting to the site. Some on-site plumbing may be needed to complete the seep vater supply (e.g., install the feed sump) and to route the treated water effluent to the waste tank. A flexible steam line will be run from a header on the outside wall of Building $\mathrm{K}$-1098-D through a traffic ramp to the process trailer. A process water line will also be connected to the trailer from the same wall in the same manner. The last remaining step to operability will be to simply plug in the electrical service line. 


\subsubsection{Startup}

Operating conditions for the process equipment will be selected earlier in accordance with results of the bench-scale bioreactor studies. These conditions include principally nutrient levels and pH. These conditions will be detailed in the Technology Status Report (to be submitted separately). Other conditions are already known, as discussed below.

Process water and air alone will be used initially for shakedown purposes. The process water supply will be connected to a recycle tank to allow for recirculation of water through all process components. Air alone (no methane) will be supplied to the gas system. Operational aspects of the equipment will be checked and verified under these conditions to ensure that all pumps, valves, meters, sensors, recorders, etc. are working properly and that system operation is stable with no leaks. A satisfactory performance period shall be 24 hours of continuous operation under the conditions described above, at a liquid flowrate of $1 \mathrm{gpm}$ and a gas (air) flowrate of $0.1 \mathrm{cfm}$. When this goal has been reached, operation will progress to inoculation and addition of dilute site water, as described below.

To inoculate the bioreactor, a sealed recycle tank will be filled with process water and the required nutrients to promote growth of the microrganisms. Liquid effluent will be returned to this recycle tank rather than discharged to our waste tank. An inoculum of several liters of culture (prepared at ORNL) will be added to the tank. Methane at $3 \%$ in air will be provided to the bioreactors on a continuous basis at approximately $0.1 \mathrm{cfm}$ total gas flow.

Makeup water will be added as needed each day during the startup period. Nutrient levels and $\mathrm{pH}$ will be checked and adjustments made as necessary.

After approximately one week, several liters of seep water will be added to the recycle tank to begin acclimation of the culture. Over a period of one month, the quantity of seep water will be 
gradually increased until the system is operating on $100 \%$ seep water. At this point, operation will be converted from recycle to once-through using seep water.

During the startup period, gas and liquid samples will be taken at least daily and analyzed to assess bioactivity. The primary indicator for bioactivity will be methane consumption. Assays for TCE and VOCs in the water will also be conducted daily to assess degradation activity. Grab samples will be obtained in the mornings, transported to ORNL, and assayed in the afternoons. If necessary, adjustments can be made to process conditions the same day; non-critical action can be postponed until the following day.

\subsubsection{Operation Run Period}

The equipment will be operated continuously ( 24 hours/day) at stable conditions for approximately one month after startup and achievement of steady state, as described above. The operating conditions for this run period will be chosen based on results from the bench-scale reactor studies.

Three operational modes will be evaluated during the initial four-month testing period. In mode 1 (Figure 5) the steam stripping unit will be employed to remove VOCs from the influent seep water. The VOCs contained in the stripper overhead will be directed to the bioreactor columns, which will be operated in series. The bioreactor effluent will be returned to the stripper influent stream. The stripper bottoms will be disposed of (see Waste Management Plan, Appendix A).

In mode 2 (Figure 6) an air oxidation system will replace the steam stripper. An air stream will remove iron from the seep water by precipitation; the oxidizer effluent and VOC-laden vapor will be directed to the bioreactor. The bioreactor effluent will be directed to the steam stripper, which in this mode will be used as an effluent polishing step to remove VOCs, thus permitting disposal of the bulk of the effluent (Appendix A; Waste Management Plan). 
In mode 3 (Figure 7) the seep influent will be directed to the bioreactor columns without pretreatment. Due to the potential for iron precipitation in the bioreactor units and thus possibly fouling of the columns, this mode will be tested at the end of the operating period. Bench-scale tests will be employed to evaluate the likelihood of clogging before the test is undertaken.

Continuous operation or a 24-hour/day basis is desirable. To achieve this goal, monitoring systems have been installed on the skid-mounted unit to detect undesirable conditions such as tank overflow etc. These controls along with periodic checks by the K-25 shift supervisor or his designee should allow the system to run unattended overnight with little problem. On weekends, an ORNL employee would visit the site at least once to take data and provide any maintenance that may be needed.

Routine operational duties will be handled primarily by an ORNL team member who will travel to the site each morning. Duties will include a general inspection of the status of the equipment to check for proper operation, any leaks, record operation parameters, maintain nutrients and gas supplies, service water pretreatment equipment, etc.

Grab samples of the feed water, the water between the two columns, and the effluent water will be taken upon arrival at the site each morning, provided that a preliminary inspection indicates that the process is operating properly. Sampling procedures will follow good practice to avoid volatilization of organics. A comprehensive sampling plan is included as Appendix E.

Samples will be transported to ORNL for analysis of TCE the same afternoon by ORNL project staff. Twice per week, TSS and VSS will be determined for the water samples. Once per week, aliquots of the water samples will be submitted to the ORNL Analytical Chemistry Division for verification of TCE concentration and measurement of other VOCs.

An off-gas sample will be collected daily and analyzed for TCE, VOCs, and methane to assess the extent of stripping and methane consumption. 
The operator will monitor the quantity of the water present in the waste tank, and will arrange for disposal periodically as necessary (see Waste Management Plan, Appendix A).

\subsection{TOLUENE-DEGRADING SYSTEM}

The plan for operation of the toluene-degrading system will be developed and added at a later time.

\subsection{DEMOBILIZATION AND DECONTAMINATION}

To decommission the unit, the packing will be removed from the two bioreactor columns, placed in 55-gal drums, and washed with water to remove the biofilms. The wash water will be rough-filtered to remove the majority of the biomass and then will be disposed in the same manner as the treated effluent water from the process. The sludge will be drummed for subsequent disposal. Samples will be taken for analysis to determine the appropriate disposal method.

The process equipment will be flushed with process water for 24 hours. After this treatment, the flow will be stopped and flooded conditions will be maintained for another 24 hours. Wash water will be disposed of in the same manner as the treated process effluent.

Following flushing, the contents of the system will be sampled and analyzed for organics and radionuclides to determine if the level of decontamination is adequate per HP requirements. If so, the equipment will be disconnected from the site utilities and prepared for return shipment to Tyndall Air Force Base. Any auxiliary equipment added to the system at ORNL will be removed before the unit is returned to the Air Force.

Temporary utility services (water, steam, electrical) will be disconnected from the trailer and traffic ramps will be removed. The sump tank along with its associated piping and traffic ramp will be removed from the seep supply line. The sump tank and piping will be flushed with process water, 
which will be analyzed and disposed of in the same manner as the treated process effluent. Finally, the process trailer and tanker trailer will be transported to storage at ORNL. 


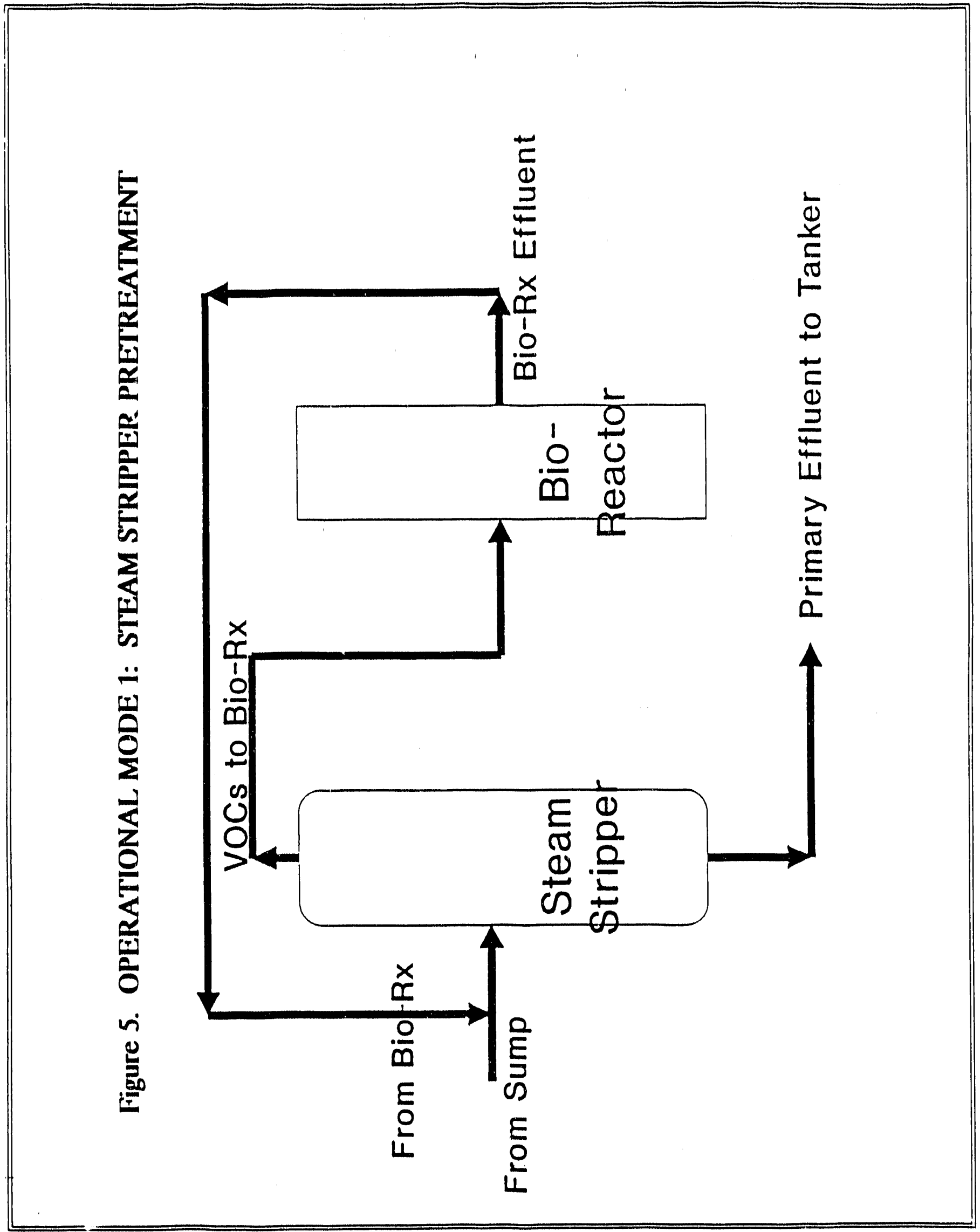




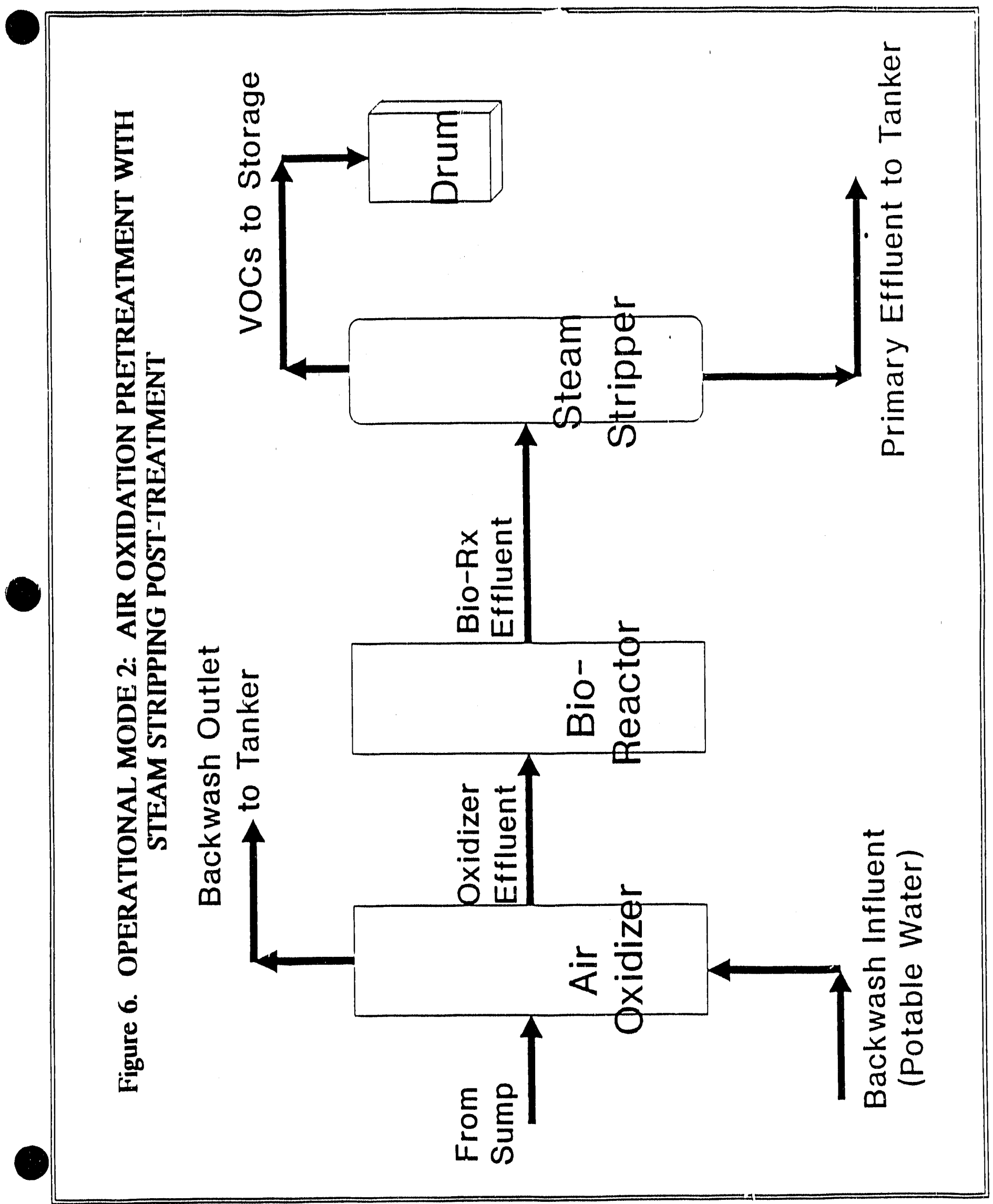




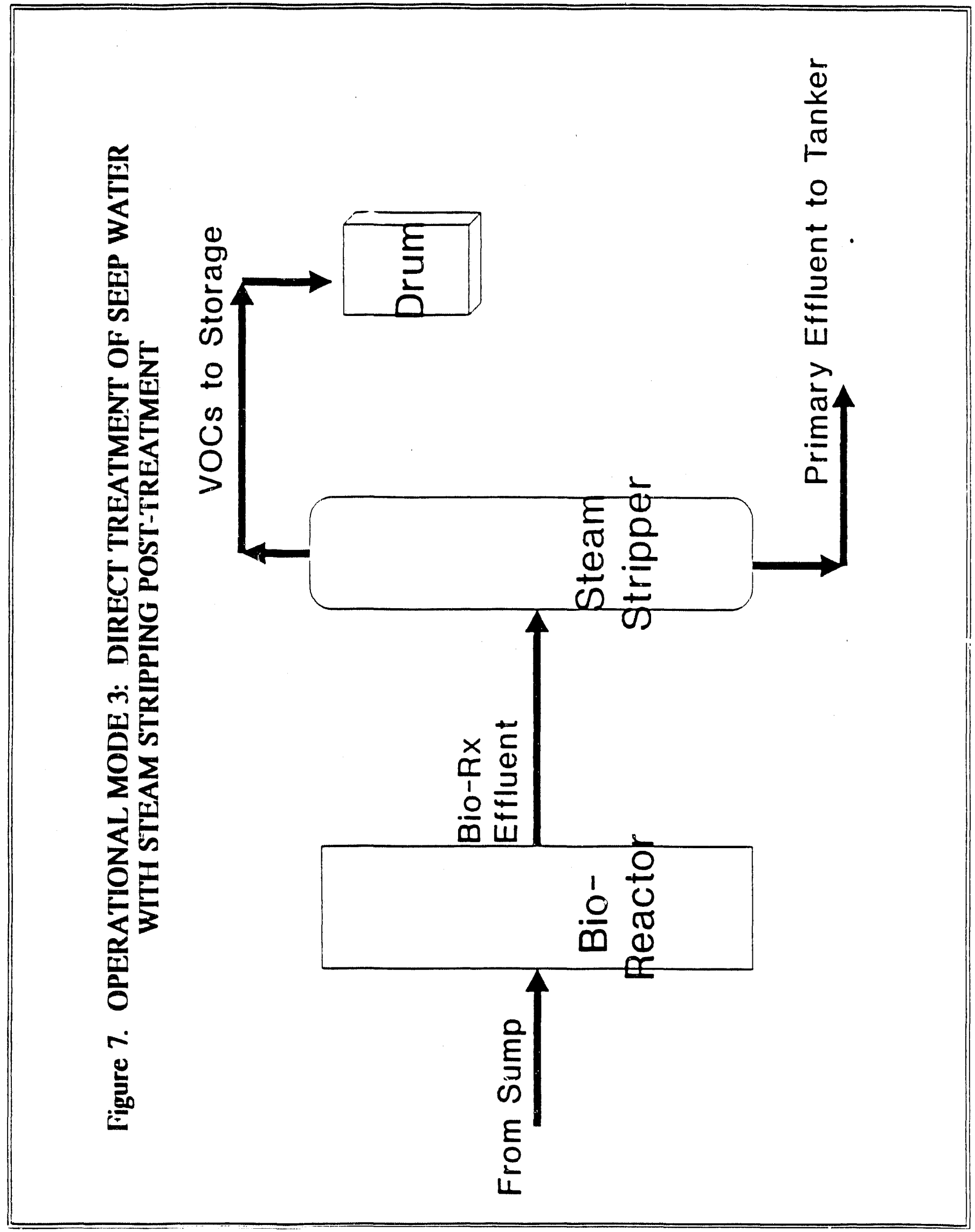




\section{REPORTING AND TECHNOLOGY TRANSFER}

Reporting to DOE will occur through monthly progress reports coordinated through the ORNL Waste R\&D Program Office. Noteworthy events during preparation and conducting of the demonstration will be reported as "weekly highlights" through the Program Office.

Prior to initiation of operation, the ORNL Public Relations Office will be contacted to arrange for appropriate publicity for the demonstration. Activities may include a press release and/or opportunity for press to observe the demonstration system.

Following shutdown of the initial bioreactor campaign the site will be decommissioned a DT\&E Technology Evaluation Report will be prepared. The report will summarize the results of the demonstration campaign, and will recommend following tests to optimize the more promising of the technologies and to demonstrate its effectiveness at other DOE sites.

Technology transfer will occur throughout the demonstration through presentations by project staff at scientific and technical meetings. Explicit opportunities for technology transfer will be coordinated through the Martin Marietta Office of Technology Transfer. 


\section{ENVIRONMENTAL COMPLIANCE}

\subsection{NATIONAL ENVIRONMENTAL POLICY ACT (NEPA)}

Prior to initiation of any activities at the demonstration site, writt'n approval shall be obtained from DOE-HQ that all NEPA requirements have been satisfied. The request for project review and approval shall be coordinated through the ORNL Environmental Review and Documentation Office.

[A request for approval of the project through Memorandum-to File (MTF) was submitted to DOE on September 7, 1990. The MTF was signed by L. P. Duffy on September 27, 1990.]

\subsection{RESOURCE CONSERVATION AND RECOVERY ACT (RCRA)}

\subsubsection{Bench-Scale Treatability Tests}

Notification of intent to conduct treatability tests will be submitted to the ORNL Office of Environmental Regulatory Compliance prior to initiation of laboratory and bench-scale tests.

Logs will be maintained by authorized project staff to record all waste received at ORNL from the K-25 Site. Annual reports of waste treatment testing will be submitted through the ORNL Office of Environmental Regulatory Compliance.

\subsubsection{Tectnology Demonstration}

Approval shall be obtained from both the Tennessee Department of Health and Environment (TDHE) and the U. S. Environmental Protection Agency (USEPA) for compliance with all RCRA requirements prior to initiation of operation using site groundwater. Contact with regulatory agencies shall be coordinated through the ORNL Office of Environmental Regulatory Compliance, which will work in conjunction with the K-25 Site Environmental Compliance Group to ensure appropriate 
submittal of all necessary permit applications.

[In a letter dated February 7, 1991 to R. C. Sleeman, DOE Environmental Restoration Division, E. C. Leming, DOE Oversight Coordinator for the TDHE suggested that the demonstration be managed under the Tennessee Water Quality Control Act via Permit-by-Rule modification. A Permit-by-Rule submittal will be prepared and submitted from the ORNL Office of Environmental Regulatory Compliance to the K-25 Environmental Compliance Group for submittal to the TDHE prior to initiation of operation.

In a conference telephone call on May 9, 1991 with C. L. Baker (K-25 Site Environmental Compliance Group) and N. S. Dailey (ORNL Office of Environmental Regulatory Compliance), L. Romanowski of the USEPA stated that the proposed bioremediation unit would be exempt from permitting by the USEPA. A copy of the Permit-by-Rule submittal will be sent for information purposes to Mr. Romanowski.]

\subsection{CLEAN WATER ACT}

The effluent from the bioreactor shall be collected and discharged to an NPDES-permitted wastewater treatment facility at the K-25 Site (See "Waste Management Plan").

\subsection{CLEAN AIR ACT}

The project design and maximum atmospheric emission levels shall be reviewed by the K-25 Site Environmental Complance Group to determine whether a modification to the existing K-25 Site permit will be required.

[In a memorandum to S. E. Herbes dated March 26, 1991, L. W. Long stated that "the Environmental Management Division has determined that no air permits will be required for this facility."! 


\section{CONTRACTS AND LEGAL ISSUES}

The field demonstration may require use of a subcontractor or industrial partner to install and/or operate parts of one of the bioreactor systems. Before any subcontractor or industrial partner is permitted on site to work on the project, a contract or written agreement will be required to be in place that addresses:

- Operator training requirements;

- Indemnification;

- Review and implementation of a Health and Safety Plan for the subcontracted work;

- Disposition of wastes produced;

- Disposition of contaminated equipment;

- Equipment maintenance;

- Project delays caused by either contractors or MMES.

Contracts or agreements will be prepared with assistance from MMES Purchasing and the MMES Legal Department as needed. 


\section{SCHEDULE}

A Gannt chart which summarizes the project schedule (updated as of July 1991) is included as Figure 8. The key project milestone is initiation of bioreactor operation using site groundwater on or before September 30, 1991.

Operation of the bioreactor units is planned to terminate on January 31, 1993. Site decommissioning is planned for completion by April 30, 1993. Submittal of the final report and completion of all other project requirements is planned for September 30, 1993. 


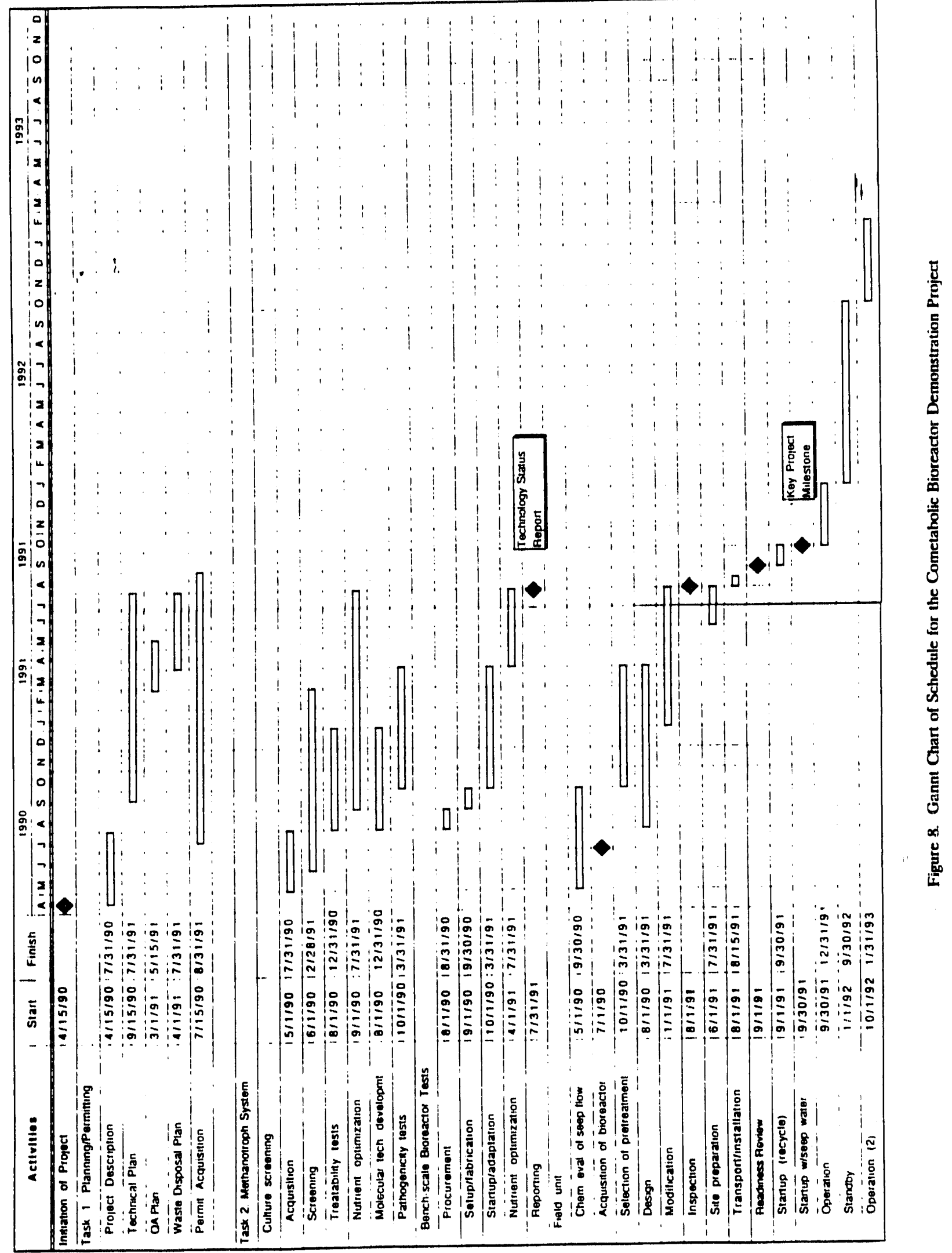




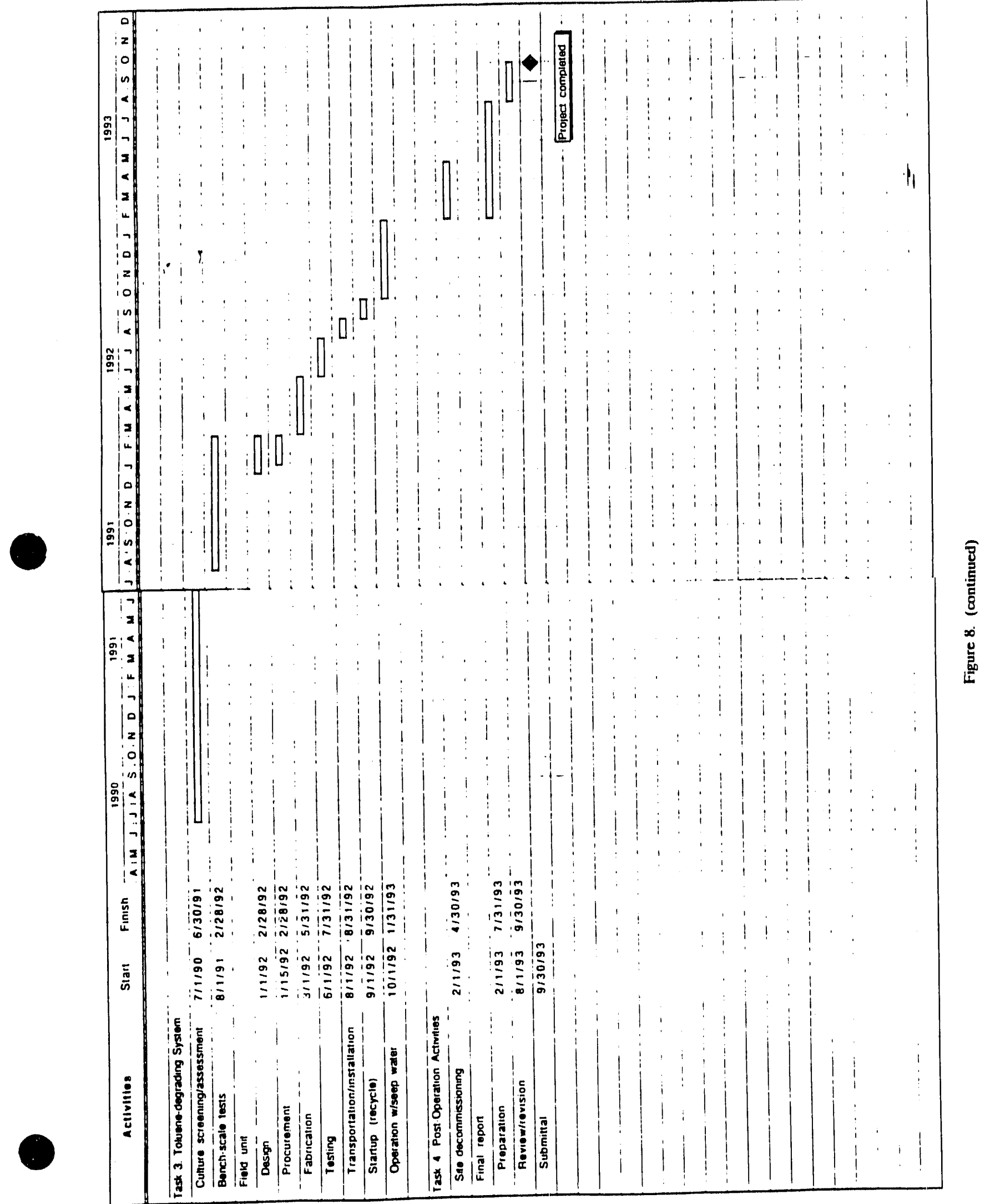




\title{
APPENDIX E
}

\section{EXAMPLE OF WASTE MANAGEMENT PLAN}

\section{Co-Metabolic Bioreactor Demonstration at the Oak Ridge K-25 Site}

\author{
M. I. Morris \\ S. E. Herbes \\ T. L. Donaldson \\ R. M. Counce
}

July 26, 1991

MARTIN MARIETTA ENERGY SYSTEMS, Inc. Oak Ridge, Tennessee

\author{
Prepared for the U. S. Department , I Energy \\ Under U. S. Govertment Contract DE-AC-05-84OR21400
}

\section{CAUTION}

This document has not been given final patent clearance and is for internal use only. If this is to be given public release, it must be cleared through the site Technical Information Office which will see that the proper patent and technical information reviews are completed in accordance with Energy Systems policy. 
APPROVALS

WASTE MANAGEMENT PLAN

Co-Metabaolic Bioreactor Demonstration at the Oak Ridge K.25 Site
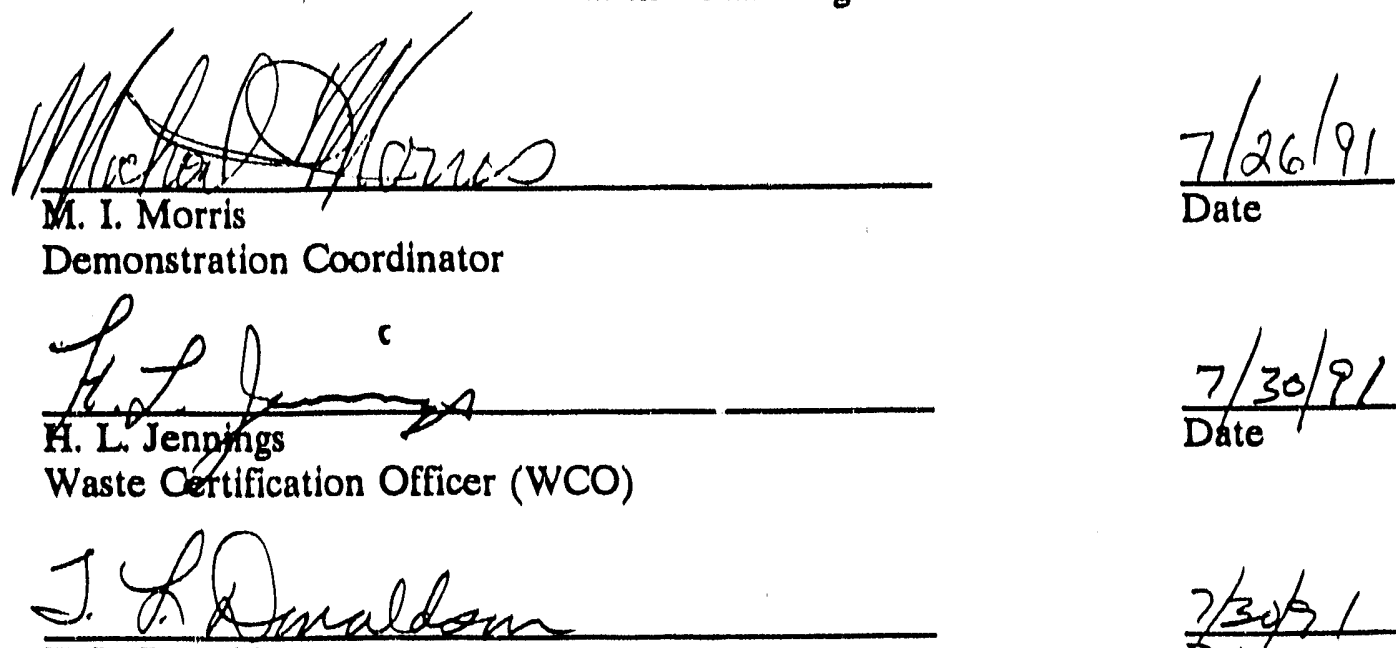

T. L. Donaldson

Project Task Leader

\section{Sterolun E. buber}

S. E. Herbes

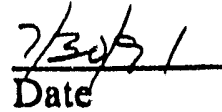

Principal Investigator

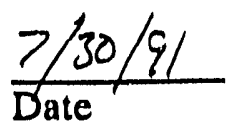

R. D. Gibby

Date

K-25 Site Environmental Complience

G. A. Conner

Date

K-25 Site Waste Management Storage

Date

M. J. Shelton

K-25 Site Waste Management Transportation

Date

T. A. Bowers

K-25 Site Waste Management Treatment 


\section{WASTE MANAGEMENT PLAN: ORNL BIOREACTOR DEMONSTRATION AT THE K-25 SITE}

\subsection{OBJECTTVE}

The objective of this Plan is to define the steps required to treat and dispose of wastewater and other waste materials generated by operation of a bioreactor demonstration project (DOE RDDT\&E Project OR-369-AB: Demonstration of Co-metabolic Techniques") in accordance with all applicable operating procedures of the K-25 Site, as well as in compliance with regulations and requirements of both state and federal regulatory authorities.

\subsection{Approvals}

This Plan shall be reviewed and approved in writing by the K-25 Plant Waste Disposal Coordinator (PWDC) and CNF Process Engineer prior to initiation of operation of the bioreactor demonstration system.

\subsection{Responsibilities}

The ORNI. Waste R\&D Program Demonstration Coordinator shall be responsible for coordinating with the K-25 PWDC all work activities at the demonstration site associated with waste disposal.

Prior to initiation of operation of the demonstration, the Project Manager shall designate a Project Waste Certification Officer (WCO). The WCO shall be responsible for certifying that all waste materials meet the criteria of the K-25 PWDC for disposal and shall coordinate all disposal schedules with the K-25 Site Waste Management Division.

\section{APPROACH}

\section{Waste Stream Characterization}

This Waste Disposal Plan has been developed based on initial seep water characterization data (Appendix A). These data were used in conjunction with knowledge of anticipated process conditions to generate contaminant concentrations expected in the primary effluent stream under the three principal modes of operation.

\section{Additional Seep Characterization Data Collection}

Prior to installation and operation of the bioreactor, samples will be collected from the seep (which will serve as influent to the bio:eactor) and will be analyzed for the constituents listed as waste acceptance criteria of the K-25 Central Neutralization Facility (CNF) [item A(2) in Conner, G. D. and M. A. McGaha, "The Oak Ridge Gaseous Diffusion Plant K-1407-H and K-1407-A Central Neutralization Facility: Waste Acceptance Criteria," Report No. K/SS-538, February 1990.]

Two sampling campaigns will be conducted within the six-month period prior to generation 
of effluent for treatment and discharge. The results of these sampling campaigns will be reported to the K-25 Waste Management Division. If the preoperational seep analyses indicate that a change in seepage composition has occurred and that additional criteria may be exceeded, the K-25 Waste Management Division may request that this Plan be modifled and resubmitted to the K-25 Waste Management Division for review and approval.

\subsection{WASTE CHARACTERIZATION}

Three types of waste will be produced by the Co-Metabolic Bioreactor Demonstration: (1) contaminated water, (2) contaminated off-gas, and (3) sludge.

\subsection{Primary and Secondary Bioreactor Effluent Streams}

A portion of the seep stream will be routed to the experimental system; the remainder of the seep will continue to flow as is currently the case. The portion of the water routed to the experimental system will subsequently be routed to a tank truck and disposed of as per appropriate regulation for the K-25 site. The water effluent from the experimental system will be of three primary types coinciding with the three primary modes of system operation: (1) steam stripping of the groundwater, (2) iron removal by air oxidation prior to introduction of groundwater to the bioreactors, and (3) direct introduction of the groundwater into the bioreactors without prior iron removal. Modes 1, 2, and 3 are shown in Figures 1, 2, and 3 respectively.

Operational mode 1 has a primary effluent liquid stream; operational modes 2 and 3 have a primary effluent liquid stream and a smaller secondary effluent liquid stream. Estimates of organic compound concentration in water from the bioreactor system for these modes of operation are presented in Table 3.1. These concentrations are particular to the design and operation of the experimental system and are not necessarily representative of a system installed to accomplish total remediation of the seep stream.

Almost all of the volatile organic compounds will be removed from the groundwater by the steam stripper in mode 1 of operation; essentially only the organic components of the seep stream are introduced into the bioreactor which operates in almost complete recycle. For operating modes 2 and 3 , the groundwater flows through the bioreactor and then is routed to the steam stripper for removal of residual hydrocarbon species. The overhead stream from the steam stripper is condensed as the secondary liquid effluent stream.

Effluent liquid flow rates from the bioreactor demonstration are shown in Table 3.2. Water requirements for the backwash of the iron removal filter are discussed later. Trace amounts of suspended solids from natural shedding of the biomass, as well as nutrients added to the groundwater, will also be present. The nutrients include trace quantities of calcium nitrate, magnesium sulfate, phosphates, and minerals; these materials are added to maintain the metabolic vitality of the biomass.

\subsection{Water for Backwash of Filter for Iron Removal System}

Water is required for backwash of the iron removal filter during Mode 2 operation. The backwash cycle is based on the quantity of water per cycle flowing through the filtration 


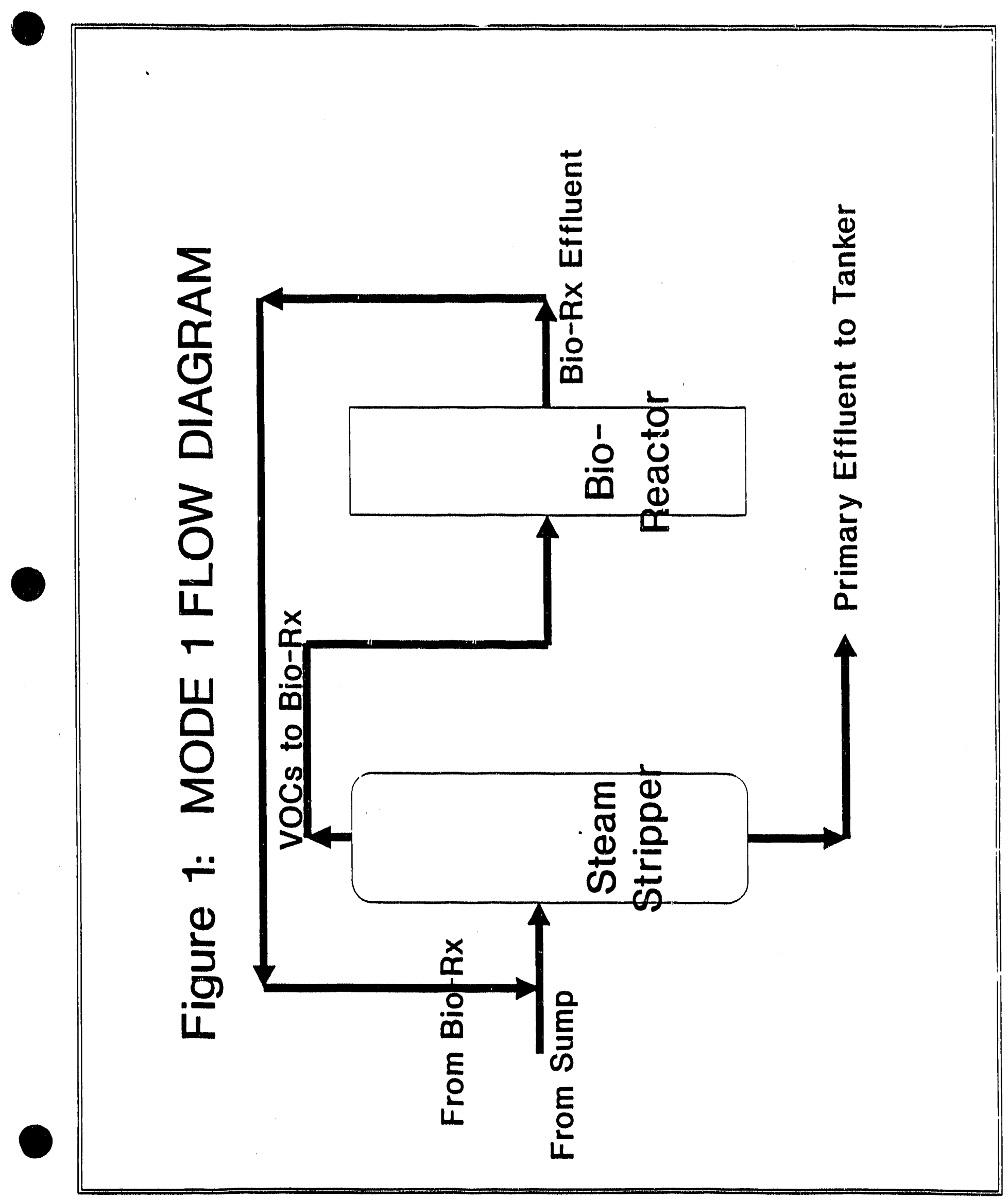




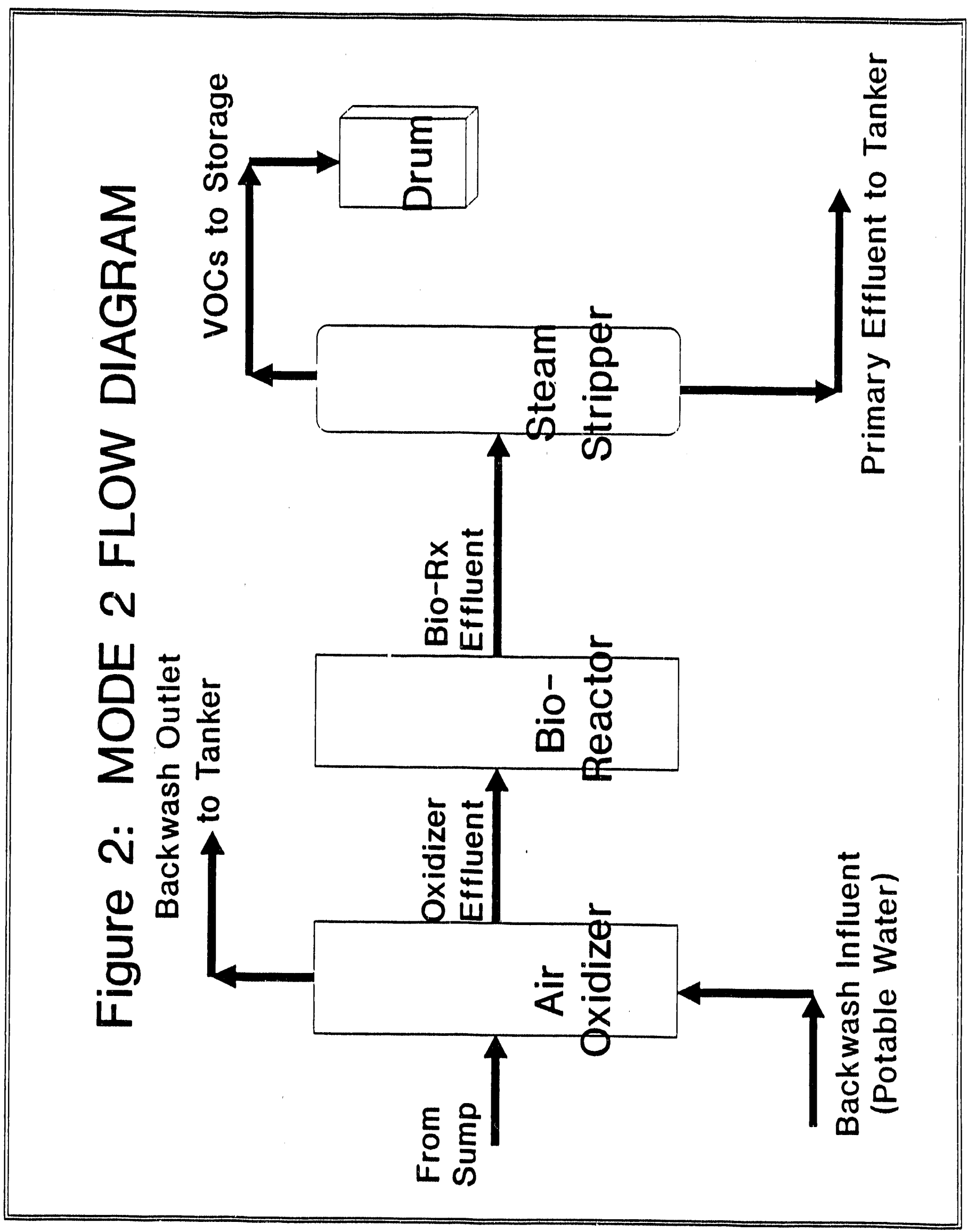




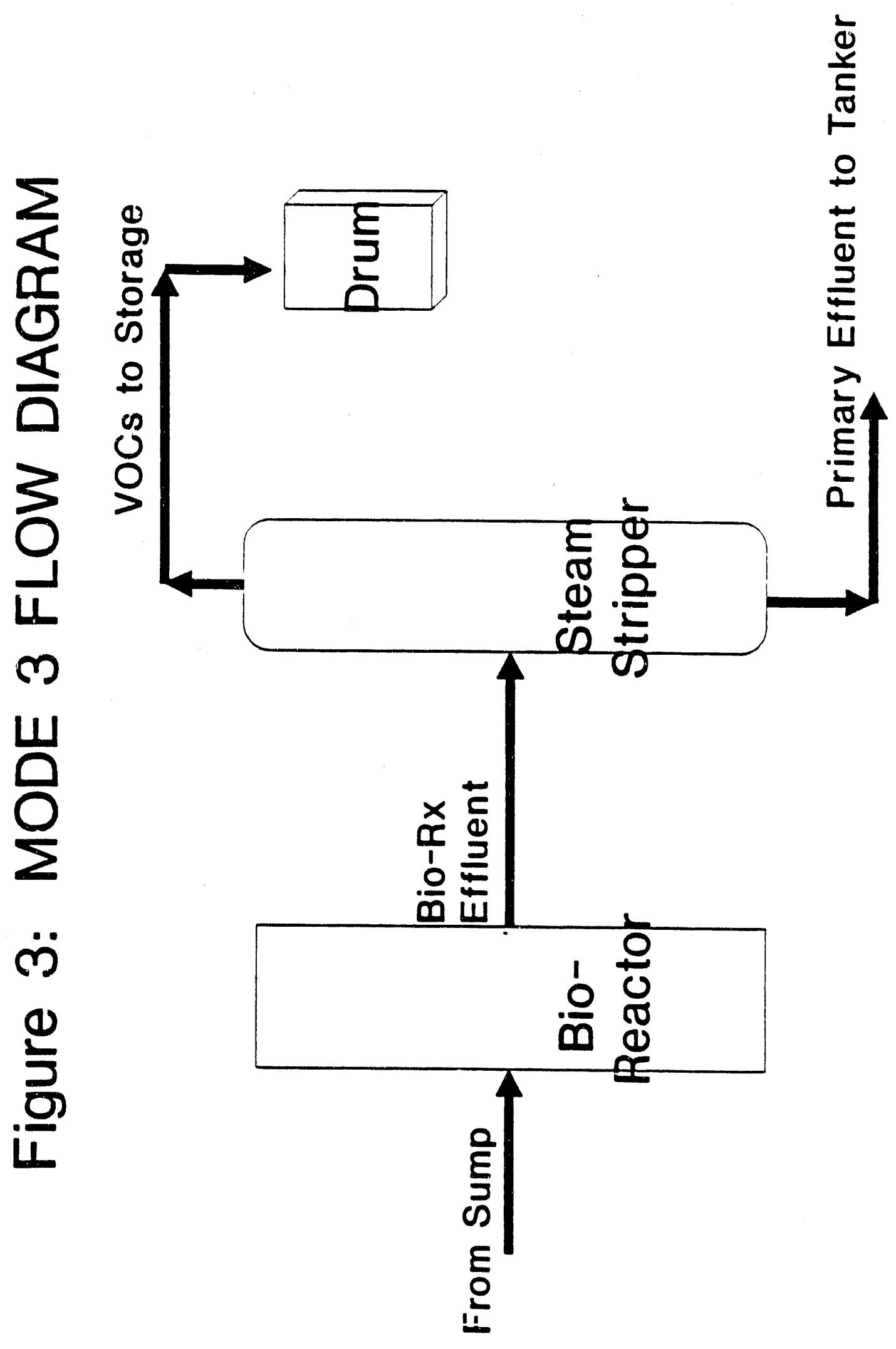


Table 3.1. Estimated Maximum Concentrations of Organic Materials in Effluent Water from Bioreactor System for the 3 Modes of System Operation

\begin{tabular}{|c|c|c|c|}
\hline & \multirow{2}{*}{\multicolumn{3}{|c|}{ CONCENTRATION $(\mu \mathrm{g} / \mathrm{L})$}} \\
\hline & & & \\
\hline COMPOUNDS & \multicolumn{3}{|c|}{ MODE OF OPERATION } \\
\hline & \multirow{2}{*}{$\frac{1}{\text { Primary Effluent }}$} & \multicolumn{2}{|c|}{2 and 3} \\
\hline Volatiles & & Primary Effluent & Secondary Effluent \\
\hline Benzene & 3 & 3 & 123,750 \\
\hline Chloroethane & 2 & 2 & 79,200 \\
\hline Chloroform & - & - & 2,475 \\
\hline 1,1-Dichloroethane & 38 & 38 & $1,881,000$ \\
\hline 1,1-Dichloroethene & 5 & 5 & 262,350 \\
\hline 1,2-Dichloroethane & $\dot{-}$ & - & 15,345 \\
\hline Ethylbenzene & 3 & 3 & 123,750 \\
\hline Methylene chloride & 80 & 80 & $3,960,000$ \\
\hline Tetrachloroethene & 1 & 1 & 24,750 \\
\hline Toluene & 7 & 7 & 321,750 \\
\hline Trans-1,2-Dichloroethene & 10 & 10 & 470,250 \\
\hline 1,1,1-Trichloroethane & 46 & 46 & $2,277,000$ \\
\hline 1,1,2-Tricitloroethane & - & - & 20,790 \\
\hline Trichloroethe "., & 3 & 3 & 123,750 \\
\hline Vinyl chloride & 2 & 2 & 69,300 \\
\hline \multicolumn{4}{|l|}{ Semivolatiles } \\
\hline 2-Methylnaphthalene & 44 & 44 & $\ldots$ \\
\hline 4-Methyiphenol & 2 & 2 & ..... \\
\hline Acenaphthene & 2 & 2 & ....- \\
\hline Anthracene & 3 & 3 & $\ldots$ \\
\hline Dibenzofuran & 1 & 1 & (....- \\
\hline Fluorene & 2 & 2 & $\ldots$ \\
\hline Naphthalene & 48 & 48 & …-.. \\
\hline Phenanthrene & 2 & 2 & ...... \\
\hline
\end{tabular}

"Míutes of Opcration: (1) steam stripping of the groundupater, (2) irnn removal by air oxidation, and (3) direct introduction of the groundwater to the bioreactors. 
Table 3.2. Liquid Flowrates from Co-Metabolic Bioreactor Test

\begin{tabular}{|l|c|}
\hline \multicolumn{2}{|c|}{ EFFLUENT FROM BIOREACTOR SYSTEM } \\
\hline Mode 1 Primary Effluent & $2.3 \mathrm{GPM}$ \\
\hline Mode 2 and 3 Primary Effluent & $1 \mathrm{GPM}$ \\
\hline Mode 2 and 3 Secondary Effluent & $0.1 \mathrm{GPM}$ \\
\hline $\begin{array}{l}\text { Backwash of Iron Removal Filter for Mode } \\
\text { 2 of Operation }\end{array}$ & $0.025 \mathrm{GPM}^{\circ}$ \\
\hline
\end{tabular}

Backwash requires $50 \mathrm{gal}$ of water and automatically done after processing $2000 \mathrm{gal}$ of water.

system; current plans call for a backwash after each 2000 gal of water treatment. Each backwash requires $-50 \mathrm{gal}$ over a 15 -min period. The maximum iron removal rate for a $1 \mathrm{GPM}$ flow of water is estimated to be $155,000 \mu \mathrm{g} / \mathrm{min}$. The iron concentration in the backwash solution is estimated to be $0.016 \mathrm{~g} / \mathrm{L}$. This backwash solution will also contain trace amounts of the original organic contaminants of the secp stream.

\subsection{Off-Gas}

The anticipated maximum off-gas flow rate is $-0.2 \mathrm{cfm}$; the composition will be $>95 \%$ air, $<5 \%$ methane, and trace amounts of TCE and other volatile organics. This stream will be vented to the air without treatment. Off-gas samples will be collected weekly and analyzed for volatile organics and othe: species under regulatory requirements.

\subsection{Sludge}

A chemical sludge, consisting of minerals (principally iron) removed from the feed water, will be produced in Mode 2. Biosludge may be produced from periodic flushing of the bioreactor.

\subsection{WASTE STREAM MANAGEMENT}

The expected chemical composition of the primary and secondary bioreactor effluent streams are compared with the CNF waste acceptance criteria in Table 4.1. The principal criterion of concern is Total Toxic Organics (TTO). The raw seep water exceeds the TTO criterion by more than 10 -fold. The primary effluent stream will be reduced approximately 99\% in TTO during operation of the bioreactor and steam stripper (both in pre- and post-treatment modes of operation); the TTO level thus is expected to fall well below the CNF criterion. The secondary effluent stream will exceed the TTO criterion by about 
Table 4.1 Acceptance Criteria for Central Neutralization Facility (CNF) $(\mathrm{mg} / \mathrm{L})$ us Maximum Expected Concentrations/Activities of Primary Effluent Streams to CNF

\begin{tabular}{|c|c|c|c|c|c||}
\hline CONSTIUENT & CRITERIA* & SEEP** & MODE 1 & MODE 2 & MODE 3 \\
\hline Cadmium & 2.6 & .005 & .005 & .005 & .005 \\
\hline Chromium & 2.89 & .02 & .02 & .02 & .02 \\
\hline Copper & 2.0 .7 & .02 & .02 & .02 & .02 \\
\hline Lead & 14.3 & .04 & .04 & .04 & .04 \\
\hline Nickel & 17 & .02 & .02 & .02 & .02 \\
\hline Silver & 1.2 & .07 & .07 & .07 & .07 \\
\hline Zinc & 9.25 & .04 & .04 & .04 & .04 \\
\hline Cyanide & .65 & & & & .25 \\
\hline TTO*** & 2.13 & 24.9 & .25 & .25 & .25 \\
\hline Oil/grease & 26 & 2 & 2 & 2 & 5.9 \\
\hline TSS & 270 & 51 & 51 & 51 & 04.9 \\
\hline Total $\alpha$ & & $4.9 \mathrm{pCi} / \mathrm{L}$ & $4.9 \mathrm{pCi} / \mathrm{L}$ & $4.9 \mathrm{pCi} / \mathrm{L}$ & $4.9 \mathrm{pCi} / \mathrm{L}$ \\
\hline Total $\beta$ & & $8.9 \mathrm{pCi} / \mathrm{L}$ & $8.9 \mathrm{pCi} / \mathrm{L}$ & $8.9 \mathrm{pCi} / \mathrm{L}$ & $8.9 \mathrm{pCi} / \mathrm{L}$ \\
\hline Total $\gamma$ & & 0 & 0 & 0 & 0 \\
\hline pH & & $6.3-7.3$ & $6.3-7.3$ & $6.3-7.3$ & $6.3-7.3$ \\
\hline
\end{tabular}

*Waste Acceptance Criteria for the CNF Facility.

**Untreated ground water.

***Total toxic organics. 
1000-fold. Waste management for these two streams, as well as for the other expected streams, are summarized below.

\subsection{Primary Aqueous Effluent Stream}

\subsubsection{Collection}

The primary aqueous effluent stream of the project will consist of a stream flowing at essentially the same rate as the withdrawal rate from the seep (a maximum of $2.3 \mathrm{gpm}$; Table 3.2). Following processing through the bioreactor system, this stream shall be collected in a 6300-gallon, 304-stainless steel tanker trailer.

The tanker trailer shall be located adjacent to the bioreactor demonstration trailer at the west side of the parking lot between buildings K-1098-D and K-1098-G. The tanker shall be positioned to allow access for the towing vehicle.

The tanker shall be inspected by the ORNL Garage and certified to meet all applicable (Department of Transportation (DOT) requirements (MC-312) prior to transport onto the K-25 Site. The tanker shall be inspected by a representative of the K-25 Waste Disposal Department prior to use for waste disposal.

The tanker location shall be designated a 90-Day RCRA Waste Storage Area. This 90 day storage area will be diked and have a volume of 6,300 gallons plus 5 inches of precipitation. The height of the dike will be a minimum of 17 inches. Any precipitation collected will be pumped from the diked area to the tanker and disposed of in the same manner as the treated effluent. The WCO shall be responsible for ensuring that the regulatory requirements of Waste Storage Area designation are met.

If, due to precipitation or other problems, the CNF collection sump cannot handle the tanker volume, the CNF operator will notify the project WCO.

\subsubsection{Transport}

The Demonstration Coordinator shall arrange with the Transportation Department of the K-25 Waste Management Division for a regular schedule for transport of the tanker to the CNF. Transport of the tanker to the CNF and return shall be the responsibility of the Waste Management Division.

Transport shall be contingent upon certification by the WCO that the wastewater meets CNF disposal criteria (discussed below).

\subsubsection{Interim Storage}

During transport of the tanker to the CNF and unloading of the wastewater, effluent shall be stored in a 1,500-gallon polyethylene tank at the demonstration site. The tank shall be placed within the diked 90 day storage area. Upon return of the tanker to the demonstration site, wastewater collected in the polyethylene tank shall be pumped into the tanker. The WCO shall sonduct a weekly inspection of the tank.

\subsubsection{Certitication for Compliance with CNF W̄aste Ácceptance Criteria}

Samples shall be collected during effluent generation at times at which the tanker trailer is 
approximately $25 \%, 50 \%, 75 \%$, and $95 \%$ full. These samples shall be composited and analyzed for $\mathrm{pH}$, dissolved oxygen, and conductivity. These analyses shall be used by the WCO to certify that the composition of the waste stream has not changed significantly since the beginning of the operational run.

\subsubsection{Confirmatory Sampling and Analysis}

During initiation of each of the three operating modes, samples will be collected in appropriate sampling containers (recommended by the K-25 Analytical Services Laboratory) from an effluent sampling port prior to introduction to the tanker. These samples will be collected at times at which the tanker trailer is approximately $25 \%, 50 \%, 75 \%$, and $95 \%$ full. The samples will be composited, and will be preserved or refrigerated immediately upon collection according ta standard K-25 Analytical Services procedures.

Samples will be analyzed by the K-25 Analytical Services Laboratory for the following parameters:

- Total alpha and beta activity

(Method: EPA-900)

- Total VOCs

(Method: EPA-8240)

- Total SVOs

(Method: EPA-8270)

- Total organic carbon

(Method: EPA-415.2)

- Total metals by ICP

(Method: EPA-6010)

- Total uranium

(Method to be determined)

The initial tanker load and every subsequent tenth tanker will be sampled and analyzed to confirm the continuing acceptability of the eftluent stream to the CNF waste acceptance criteria.

\section{Secondary Aqueous Effluent Stream}

Under two modes of operation the bioreactor effluent will be recycled to the steam stripper for final treatment before disposal. This step will generate a secondary effluent, which is a low-flow stream containing relatively high concentrations of VOCs (Table 3.1). This stream will not meet the CNF waste acceptance criterion for TTO.

\subsection{Collection}

The secondary effluent stream shall be collected in a stainless steel 55-gallon drum located adjacent to the bioreactor trailer in a Satellite Waste Storage Area.

\subsection{Certification and Disposal}

The waste composition shall be estimated based on the known composition of the influent stream and the calculated concentration of VOCs based on the relative volumes of the primary and secondary effluent flows, and certified by the WCO.

The drum shall be sealed and packaged for on-site or off-site disposal as RCRA Hazardous Waste in accordance with the K-25 Site waste handling procedures. The WCO shall notify the K.25 pulDC to schedule waste pickipp and disposât. 


\subsection{Backwash from Iron Removal Filter}

\subsubsection{Collection}

During operation of the air oxidation system, the iron removal filter will be backwashed every 2000 gal. The backwash water will be pumped into the tanker and disposed of at the $\mathrm{CNF}$, along with the primary effluent. The minerals in the backwash water are simply those removed from the seep water, and the concentration will not exceed the CNF waste disposal criteria.

\subsection{Bioreactor Sludge}

\subsubsection{Collection}

During the course of the bioreactor demonstration, it may become necessary to backflush biomass from the bioreactor to avoid clogging. If this step is required, process water will be flushed through the bioreactor and collected in a stainless steel 55-gallon drum. The drum shall be located in the Satellite Waste Storage Area (Section 4.21), and shall be placed in a sheet-metal spillage collection pan.

\subsubsection{Certification and Disposal}

A composite sample of the initial drum of backflush water shall be collected and analyzed by the K-25 Analytical Services Laboratory for the parameters described in Section 4.21. In addition, total suspended solids will be determined.

If the analyses indicate that the backflush, upon dilution in the tanker, will meet the CNF waste disposal criteria detailed in $\mathrm{K} / \mathrm{SS}-538$, the bioreactor backflush water will be pumped into the tanker and disposed of at the CNF along with the primary effluent. If addition of the bioreactor backflush water to the tanker will exceed the CNF criteria, then bioreactor the backflush water will be stored for appropriate disposal.

\subsection{Rinse Water}

During operation of the bioreactor demonstration, a small volume (at most several gallons per day) of process water will used in the sink installed in the trailer for rinsing sample collection bottles and for washing hands. This water will contain small amounts of detergent or soap. The water shall be collected in a 5-gallon polyethylene container located under the sink and shall be discharged directly to the tanker.

Due to the limited volume and known composition, no analyses shall be conducted on this wastewater stream. 


\section{APPENDIX F \\ NEPA COMPLIANCE}

Each demonstration activity must have on record a DOE-signed EPA decision document, such as a Categorical Exclusion Determination (CXD), Finding of No Significant Impact (FONSI), or Record of Decision (ROD:). To obtain these NEPA documents, An EPA environmental assessment must be conducted and supporting NEPA documentation must be prepared.

To obtain the requisite documentation, the PM (1) contacts the Site Environmental Coordinator or the Site Regulatory Compliance Staff [for example, ORNL Environmental and Documentation Section (4-5774) or the ORNL Environmental Coordinator (4-5776)] AS EARLY AS POSSIBLE in the planning stages of a Demonstration Froject; (2) provides a brief description of the project, including anticipated schedules for construction and/or operation; (3) provides for a site visit and supplies information for preparing the draft NEPA and supporting documents; (4) reviews each draft and transmits comments and/or corrections; and (5) as appropriate, endorses the documentation in concurrence with document contents. If the scope of the planned project changes significantly at any time prior to, or subsequent to, completion of the NEPA process, the PM repeats steps (1) through (5) for the modification.

Supporting documentation may consist of an Activities Description Memorandum (AcDM) or Environmental ALARA Memorandum (EAM) in support of a CXD; an Environmental Assessment (EA) in support of a FONSI; or an Environmental Impact Statement (EIS) in support of a ROD. No demonstration operations may be started without a DOE-approved and signed EPA decision document on file. 


\begin{abstract}
APPENDIX G
MARTIN MARIETTA ENERGY SYSTEMS, INC., OFF-SITE FACILITIES CONDUCTING TREATABILITY STUDIES

CHECKLIST
\end{abstract}

\title{
I. FACILITY INFORMATION
}

NAME OF FACILITY:

LOCATION:

COUNTY:

TELEPHONE:

CON"TACTS:

DATE(S) VISITED:

REVIEWED BY: 


\section{FACILITY REVIEW - ADMINISTRATIVE ITEMS, TREATMENT SYSTEM, AND RECORDKEEPING}

1. List facility staff interviewed and their duties:

2. Who owns the facility?

3. Provide a brief description of facility activities:

4. Does the facility currently hold any permits and/or licenses (state or federal)? Check applicable items and obtain copies for review.

RCRA

TSCA

Air

NPDES

POTW Agreement

Others

Radioactive Materials License

5. Which office does inspections and enforcement, what is its address and phone number and who is the chief?

5.1 How many times (and going back how far) has this facility been inspected?

5.2 How often is the facility reinspected? 
5.3 Were inspection records reviewed?

5.4 What problems have inspections revealed/identified?

6. What is the compliance record like (going back five years)? List past and outstanding C.O.'s as well as types of violations found and penalties proposed vs collected.

7. EPA Identification Number $[261.4(f)(2)]$ :

8. Provide a brief description of the treatment system(s) to be utilized.

9. Processing rate of treatment unit $[261.4(f)(3)]$ : $\mathrm{Kg} / \mathrm{day}$.

NOTE: Must not exceed $250 \mathrm{Kg}$ of "as received" waste in a single day.

10. Notification of Regional Administrator/State Director of intent to conduct treatability study $[261.4(f)(1)]$. Obtain copy of notification letter.

Date of Notification 
11. Hazardous waste stream to be utilized in treatability study(ies):

EPA Waste Code(s)

Physical State:

Solid

Liquid

Solls

Acute Waste: Yes

No

Quantity $(\mathrm{Kg})$

12. Facility records verifying:

Treatment rate limits $[261.4(f)(3)]$ :

Yes

No

Note: Must not exceed $250 \mathrm{Kg}$ of "as received" waste in single day.

Waste in storage limits $[261.4(f)(4)]\}$

Yes

No

NOTE: The quantity of "as received" hazardous waste stored at the facility for the purpase of evaluation in treatability studies does not exceed $1000 \mathrm{Kg}$, the total of which can include $500 \mathrm{Kg}$ of soils, water, or debris contaminated with acute hazandous waste or $1 \mathrm{Kg}$ of acute hazandous waste.

13. Documentation of treatability studies $[261.4(f)(7) \&(8)]$ should include:

a) Name, address, and EPA identification number of waste generator.

b) Date waste shipment received.

c) Quantity of waste accepted.

d) Quantity of "as received" waste in storage each day.

e) Date treatment study initiated and amount of "as received" waste introduced to system each day.

f) Date treatment study concluded.

g) Date any unused sample or residues generated from treatment returned to generator.

h) Copies of treatment study contracts.

i) Copies of shipping documents. 
14. Are all records maintained for at least 3 years?

Yes

No

15. Does $\&$ mechanism exist for annual reporting to the regulatory agency $[261.4(f)(9)]$ ?

Yes

No

16. Does the facility have a documented contingency plan in the event of unusual occurrences?

Yes

No

17. What are facility security measures, i.e., prevention of unauthorized entry to storage/treatment areas?

18. Is there a documented training program for facility personnel?

Yes

No

18.1 Description of training:

18.2 Trainer's qualifications: 
19. What types of monitoring are utilized for radiation contamination control?

19.1 What are the regulated and/or administrative radiation levels for on-site processing/storage?

19.2 What are unrestricted release limits for waste treatment residuals?

20. Does the facility have an accounting system which documents quantities of radioactive materials present at their site?

Yes No

If yes, provide a description:

21. Do procedures exist to prevent cross-contamination of waste materials while being processed? Describe.

22. Does the facility have documented EH\&S plans and/or procedures in place? Describe: 
23. Are waste analysis for verification of treatability studies performed at this facility?

Yes No

23.1 Describe sampling tracking system:

23.2 Describe waste analysis recordkeeping practices:

¿3.3 Specify verification test methods and equipment:

23.4 What are the analytical QA practices (e.g., frequency of recalibration, control charts, spikes)?

23.5 Is the laboratory certified by an outside organization?

23.6 Overall impression of lab organization and quality: 
24. Waste Storage Area:

Warning signs

Containment

Secured

Indoors/Outdoors

Other comments 


\section{APPENDIX H \\ ENVIRONMENTAL REVIEW SUMMARY}

Project Title

Type ERDS Document Document Preparer

Task Leader Account or Work Order No.

ERDS ID No. Computer Code Est. Start Date

Project Status - Ongoing New Proposed Other

Project Location - Plant Valley Bidg. Room Other FY 19 Program Program Code

Division/Office

Projects/Activities

Div. Director Bldg/MS/PhoneNo.

Proj. Engineer Bldg/MS/PhoneNo.

Div. Rep. Bldg/MS/PhoneNo.

Supv. of Oper. Bldg/MS/PhoneNo.

LineItem/WBS/ESO/ADSNo.

CXD or PDM Required?

Planned Submittal Date

Briefly describe the project, including its purpose. 
Are any of the following encountered, handled, stored, used, or disposed of auring any phase of the project? Describe.

Y N U Radioactive Materials

Y N U Hazardous Materials

Y N U Mixed(Haz. and Rad. Materials)

Y N U Toxic Materials

Y N U PCBs

Y N U OilsorOilyWastes

Y N U Asbestos

Y N U Organic Chemicals

Y N U Heavy Metals

$\mathrm{Y} N \mathrm{U}$ Other

Does the project involve disposal or discharge into any of the following liquid waste collection and/or treatment systems? If yes, estimate quantity and describe.

Y N U Low-Level Waste

Y N U Process Waste

$Y N$ U Sanitary Waste

Y N U Storm Sewer

$Y, \bar{V}$ U Other

Does the project generate solid wastes? If yes, estimate amounts and describe disposal.

Y N U Radioactive

Y N U Hazardous

Y N U Mixed

Y N U Sanitary

Y N U Other

Does the project generate airborne wastes? If yes, estimate amounts and describe.

$Y N$ U Radioactive

Y N U Hazardous or Toxic

Y N U Mixed

$Y$ N U Other 
Does the project utilize above-ground tank or drum storage of any materials? If yes, estimate amounts and describe storage.

Y N U Radioactive

Y N U Hazardous or Toxic

Y N U Mixed

Y N U Other

Does the project utilize below-ground equipment, facilities, or tanks for storage, control, or transport of materials? If yes, estimate amounts and describe.

Y N U Radioactive

Y N U Hazardous or Toxic

Y N U Mixed

Y N U Other

Are uncontrolled emissions, discharges, or spills possible during any phase of the project? If yes, estimate amounts and describe.

Y N U Radioactive

Y N U Hazardous or Toxic

Y N U Mixed

Y N U Other

Are measures in place to prevent uncontrolled emissions, discharges, and/or spills? Describe.

Does any portion of the project require permitting? Describe. 
Does the project involve disturbance of any area on which an endangered or threatened species might be present? If yes, explain protective measures that will be taken.

Does the project involve disturbance of any site containing objects of historical significance? rf yes, explain protective measures that will be taken.

Will any portion of the project take place within the 100 -year floodplain of any surface waterway?

Will the proposed project utilize a new site or sites? If yes, will the site(s) be restorable when all project activities have been completed? 


\section{APPENDIX I \\ EXAMPLE OF SAFETY ASSESSMENT}

$K / D-S A-21.56$

W.0.: A-3204A-J1

Date: $5 / 6 / 91$

\section{APPROVALS}

SAFETY ASSESSMENT

Co-metabolic Bioreactor Demonstration at the Oak Ridge $\mathrm{K}-25$ site

\section{$2 / 5$ Hactman for}

B. A. Hannaford

System Safety Engineering - Technical Products

2for tractiman for

J.A. Hoffmeister

System Safety Engineering-K-25 site Coordinator

$$
5-9-91
$$

Date

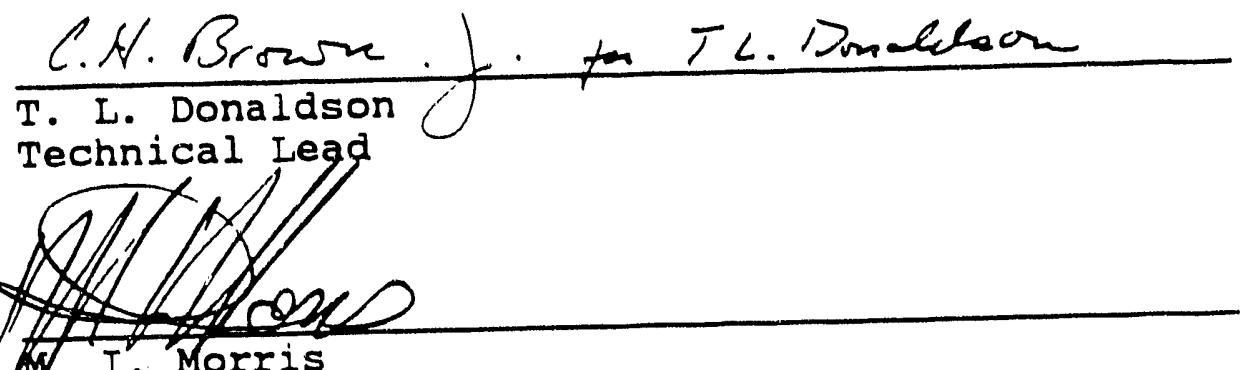

$\frac{5-10-9 /}{\text { Date }}$

Project Coordinator

\section{S. E Neubes}

S. E. Herbes

Principal Investigator

C. H. Peterson, Chairman

K-35 Site Environmental, Health \& Safety Council

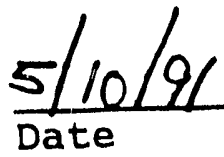

Date 
$K / D-S A-2156$

$A-3204 A-J 1$

\section{SAFETY ASSESSMENT}

Co-metabolic Bioreactor Demonstration

at the Oak Ridge $\mathrm{K}-25$ site

M. B. Andriulli

May 6, 1991

System Safety Engineering

MARTIN MARIETTA ENERGY SYSTEMS, InC. Oak Ridge, Tennessee

Prepared for the U. S. Department of Energy Under U. S. Government Contract DE-AC-05-840R21400 
$K / D-S A-2156$

$A-3204 A-J 1$

\title{
SAFETY ASSESSMENT
}

\begin{abstract}
Co-metabolic Bioreactor Demonstration
\end{abstract} at the Oak Ridge $k-25$ site

\section{INTRODUCTION}

The purpose of the co-metabolic bioreactor dcmonstration project is to demonstrate the effectiveness of bioremediation technologies, based on cu-metabolic processes, for treatment of groundwater contaminated by mixed organic solvents. The project consists of installation and operation of two types of bioreactors. Groundwater contaminated with mixed organic compounds from a seepage flow at the $k-25$ site will be used as influent. The seepage flow contains trichloroethene (TCE), perchloroethene (PCE), benzene, toluene, chlorinated ethanes, and other volatile organic solveits at a total concentration of several parts per million. since the seepage water is currently discharged by National Pollutant Discharge Elimination System (NPDES) permit, it is not considered in the hazard analysis. Effluent will be collected and transported to a licensed treatment facility.

Experimental studies of the microorganisms have not revealed any known pathogens, and past experience has indicated that conditions are not conducive to the development of pathogens. However, since the pathogenic dangers are unknown at this time, for purposes of this safety assessment it is assumed that the microorganisms are pathogenic. Evaluations will be performed, using standard techniques, on all cultures proposed for use in the bioreactors, on the raw seep water and on the bioreactor effluent.

The K-25 site is on the National friority List, and thus falls under the jurisdiction of both the Comprehensive Environmental Response, こumpensation, and Liability Act (CERCLA) and Department of Energy/Environmental Protection Agency (DOE/EPA) Interagency Agreements. These regulations require consideration of alternatives for remediation. This demonstration project will help evaluate the usefulness of bioremediation as a technology for solving groundwater contamination problems. 
The operation of this demonstration project is the responsibility of the Oak Ridge National Laboratory (ORNL) Environmental Sciences Division. Much of the field operational work will be conducted by staff of the ORNL Chemical Technology Division. Other divisions involved in some aspects of the project are the $\mathrm{K}-25$ Health, Safety and Environmental Affairs Division and the Environmental Restoration Division.

This safety assessment addresses the hazards associated with the operation of the Co-metabolic Bioreactor Demonstration Project at the oak Ridge $\mathrm{K}-25$ site.

\section{BUMQYARY}

The Co-metabolic Bioreactor Demonstration Project consists of installation and operation of two types of biological treatment systems using groundwater contaminated with mixed organic compounds from a seepage flow at the $K-25$ Site as influent. The goal of the project is to demonstrate the effectiveness of two innovative bioremediation technologies, based on co-metabolic processes to remediate groundwater contaminated by mixed organic solvents.

The primary hazard associated with the project is the presence of the microorganisms. Experimental studies of the microorganisms have not revealed any known pathogens, and past experience has indicated that conditions are not conducive to the development of pathogens. However, since the pathogenic dangers are unknown at this time, for purposes of this safety assessment jt is assumed that the microorganisms are pathogenic.

The hazards presented by the toxic and radioactive materials in the raw seepage water used as influent are not considered in the analysis, since they are currently discharged by NPDES permit. The hazard presented by the use of $3 \%$ methane mixed with air was determined to be a standard industrial hazard, provided that requirements are included in the operating procedures to assure that the quantity of methane in the air/methane mixture is below the lower flammability limit in air of 5.3\%. All other hazards involved in the project are determined to be standard industrial hazards.

The worst case accident scenario postulates a spill of the entire fluid contents of the bioreactor during transfer from the reactor to the container used for transport to the treatment facility. This results in a release of unsterilized effluent (mioxoorganisms are assumed to be pathogenic). This is assumed to flow into the storm drain. The effluent eventually flows to the Clinch River (Watts Bar Lake) where drinking water supplies could become contaminated. It was determined that individual weils wouid not lue lñ jeopardy since the hÿraulide gradient of 
the groundwater is expected to be toward the river. The sourca of drinking water for the $k-25$ site is about 2.5 miles upstream from the point of entry of the effluent to the clinch River, and should not be affected. The cities which extract drinking water from watts Bar Lake should not have their supplies affected since they are well away from the main flow and far enough downstream for the concentrations to be diluted to levels within the regulatory limits for coliform bacteria. Coliform bacterla are used as indicator organisms for microbial contamination in drinking water.

Based on the results of the hazard screening, it is recommended that this facility be considered a generally accepted hazard facility for purposes of design and safety documentation. A generally accepted hazard facility requires no further safety documentation. However, requirements should be included in the operating procedures to assure that the methane content in the methane/air mixture tanks is maintained below the lower flammability limit in air of $5.3 \%$.

\section{SITE DESCRIPTION}

The co-metabolic bioreactor demonstration facility will be located in the eastern portion of the $K-25$ site as close to the seep as possibl. The seep, which will serve as influent, is located adjacent to the east side of Avenue $D$, about 110 feet south of the center of the intersection with 9 th street and about 200 feet west of the boundary of the $K-1070-C / D$ Classified Burial Ground. Location of the facility at the $\mathrm{k}-25$ site is shown in Fig. 3.1.

\section{FACILITY/PROCESS DESCRIPTION}

Groundwater contaminated with organic compounds is a problem at many DOE sites. One of the new technologies for removal of these contaminants from groundwater is bioremediation, both by above-ground, contained units (i.e., bioreactors) and by in situ techniques. Bioremediation techniques employing two general groups of microorganisins [methanotrophs (methane-utilizers) and toluene-utilizers] are presently being investigated for TCE removal. Both are baseid on co-metabolic degradation (i.e.,fortuitous degradation) of the target contaminants (volatile organic solvents) by organisms which are utilizing a carbon source (methane or toluene) as a primary energy source.

The rork proposed will consist of comparative demonstration of bioreactors with two types of microbial systems (i.e., methane-utilizers and toluene-utilizers) using groundwater contaminated with organic compounds which emerges as a seepage flow at the $K-25$ site. The seepage flow contains TCE, PCE, 

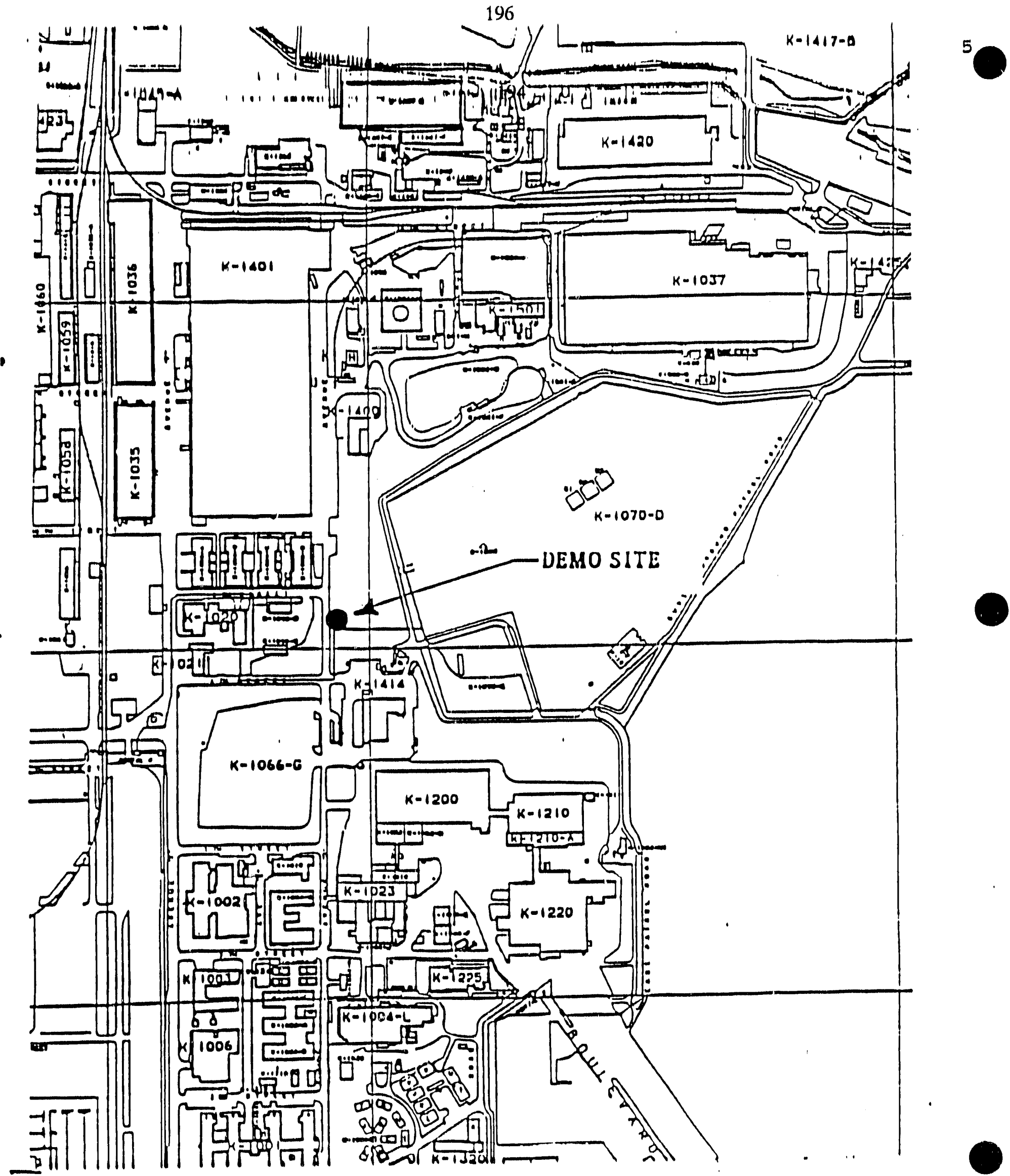
benzene, toluene, chlorinated ethanes, and other volatile organic solvents at a totril concentration of several parts per mililon $(\mathrm{ppm})$.

\subsection{FACILITY DEBCRIPTION}

The co-metabolic bioreactor demonstration project will consist of operation of two bioreactor units. During the first phase of the project a single bioreactor unit with the methanotrophs will be operated. During the second phase a bioreactor unit charged with the toluene-utilizers or one bioreactor unit of each type will be operated. Each unit will consist of:

\# piping from the seep to the bioreactor unit,

\# an influent pump and associated valving and controls,

\# a pretreatment filter, air oxidation unit (aeration tank), steam stripper or another pretreatment option if needed,

\# the bioreactor,

\# up to five standard $300-\mathrm{ft}^{3}$ compressed gas cylinders for the carbon substrate ( $3 \%$ methane in air) or a 55galion drum containing dilute aqueous toluene solution,

\# a 55-galion drum for the nutrient feed solution (a dilute aqueous solution of ammonium phosphate plus trace minerals),

\# an off-gas scrubber (if required by the air discharge permit),

\# piping and valving for operation in recycle mode,

\# piping and containers for the collection of effluent, and

\# safety monitoring instrumentation and process controls.

Two skid-mounted bioreactor units, each consisting of two columns (approximately 12 inches diameter by 7 feet hiah) plus associated plumbing, pumps, and control panel will be used. A conceptual diagram of the methanotroph bioreactor system is shown in Fig. 4.1.

The two skid-mounted units with associated tanks and equipment will require protection from inclement weather, and will be housed in a van trailer. The bioreactor will serve as 

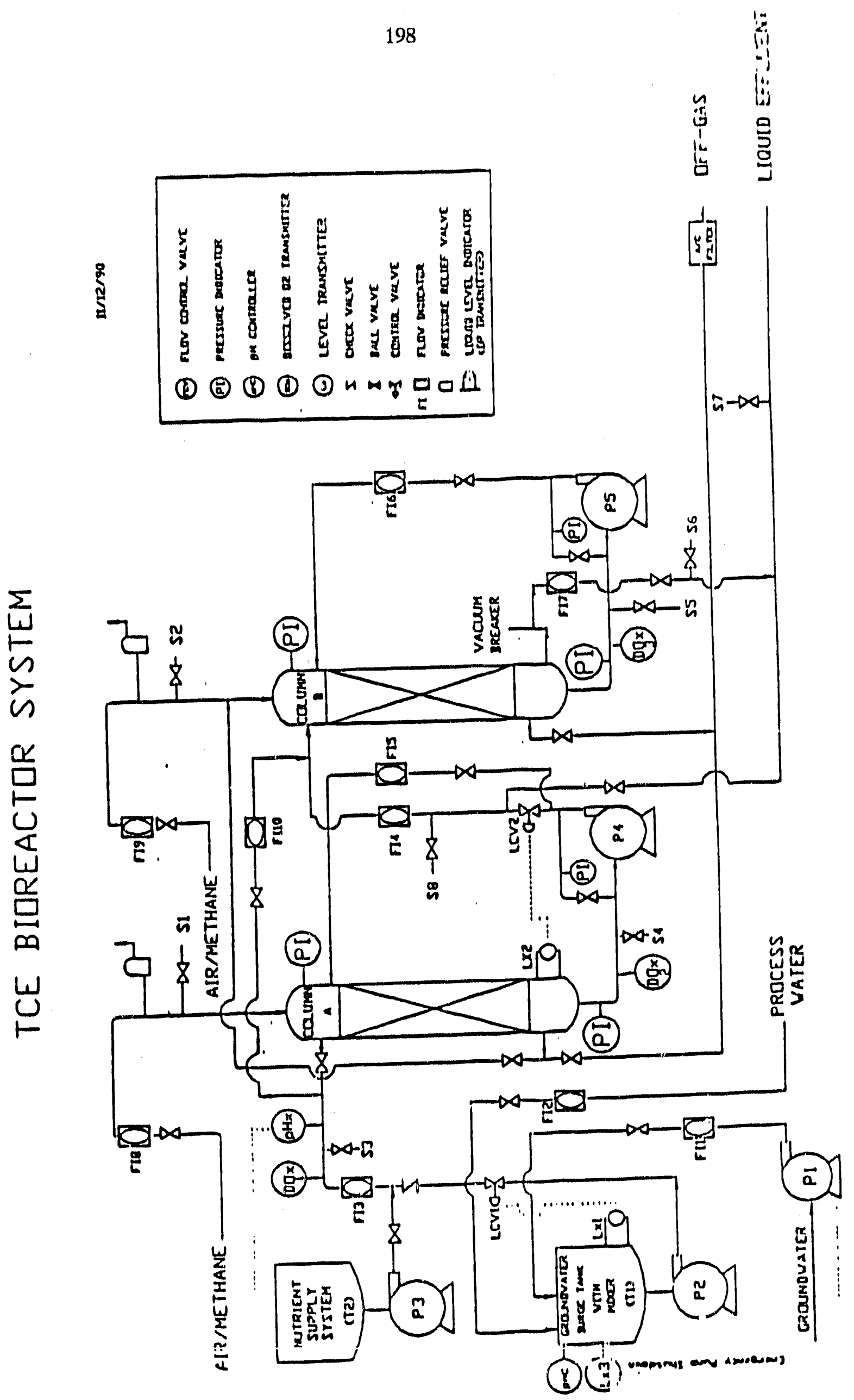

恶

U

$\frac{0}{1}$

4

是

$\square$

$\underset{v}{U}$

$\dot{-1}$
$\dot{\sigma}$
$\dot{\sigma}$ 
the primary confinement. A drip pan beneath each skid-mounted bioreactor unit within the trailer will serve as secondary confinement.

The utilities required by the facility are process water with a maximum flow rate of 1 gal/min $(3.79 \mathrm{~L} / \mathrm{min})$ for preparation of nutrient solutions and general equipment washing and flushing; an electrical sipply of $220 \mathrm{~V}$ ac and $50 \mathrm{~A}, 3$ phase; compressed air at $50 \mathrm{psig;}$ and low pressure process steam if steam stripper pretreatment is selected.

\subsection{PROCE8B DE8CRIPTION}

The bioreactor systems operate on the principle of cometabolic degradation of TCE and associated contaminants. Microorganisms are grown in line bioreactor in the presence of oxygen and nutrients, with an added carbon source. Methane will be used as the carbon source in one of the bioreactors and toluene will be used in the other. Degradation of TCE occurs fortuitously during utilization of the carbon source. The effluent produced should have lower concentrations of the initial volatile organic contaminants (VOCs) and some added constituents.

\subsubsection{InEluent}

The seep which will serve as influent to the bioreactor currently flows from a PVC pipe imbedded at the foot of a 6-ft high slope and drains through an open concrete whannel along the road into a storm drain (SD-180-04) approximately 80 feet north of the seep. The storm drain eventualiy empties into poplar creek and then into the Clinch River. A NPDES permit is currently helu which allows tilis discharge. During the past spring and summer (1990) base flow from the seep has appeared to be relatively constant. Flow increases during and immediately following storms and reportedly has stopped completely during extended dry periods. Chemical characteristics, determined on water samples, are summarized in Table 4.1.

Table 4.1 Contaminants Detected in storm Drain SD-180-04 at the R-25 Facility

\begin{tabular}{|c|c|c|c|c|}
\hline \multirow[t]{3}{*}{ Compound } & \multicolumn{4}{|c|}{ Concentration $(\mu \mathrm{g} / \mathrm{L})$} \\
\hline & \multicolumn{2}{|c|}{ May-Tune 1987} & \multicolumn{2}{|c|}{ March 199n } \\
\hline & Maximum & Minimum & Maximum & Minimum \\
\hline \multicolumn{5}{|c|}{ Volatiles } \\
\hline Benzene & $2 \underline{50}$ & 230 & 1300 & $120 \overline{0}$ \\
\hline Chloroethane & 160 & $<10$ & 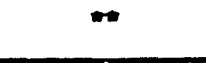 & $\omega$ \\
\hline
\end{tabular}


Table 4.1 (Continued)

\begin{tabular}{|c|c|c|c|c|}
\hline \multirow[t]{3}{*}{ Compound } & \multicolumn{4}{|c|}{ Concentration $(\mu \mathrm{g} / \mathrm{L})$} \\
\hline & \multicolumn{2}{|c|}{ May-June 1987} & \multicolumn{2}{|c|}{ March 1990} \\
\hline & Maximum & Minimum & Maximum & Minimum \\
\hline Chloroform & 5 & $<5$ & $*$ & 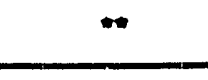 \\
\hline 1,1-Dichloroethane & 3800 & 2300 & 1000 & 998 \\
\hline 1,1-Dichloroethene & 530 & 250 & 640 & 510 \\
\hline 1,2-Dichloroethane & 31 & $<5$ & 810 & 580 \\
\hline Methylene chloride & 8000 & 1900 & 460 & 160 \\
\hline Tetrachloroethene & 50 & $<5$ & 67 & $<25$ \\
\hline Toluene & 650 & 440 & 3100 & 2700 \\
\hline $\begin{array}{l}\text { Trans-1,2- } \\
\text { Dichloroethene }\end{array}$ & 950 & 670 & $m$ & 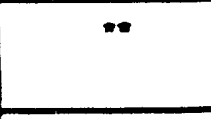 \\
\hline $\begin{array}{l}1,1,1- \\
\text { Trichloroethane }\end{array}$ & 4600 & 3000 & 6800 & 4900 \\
\hline $\begin{array}{l}1,1,2- \\
\text { Trichloroethane }\end{array}$ & 42 & $<5$ & 33 & $<25$ \\
\hline Trichloroethene & 250 & 140 & 430 & 330 \\
\hline vinyl chloride & 140 & $<10$ & 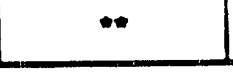 & $\because$ \\
\hline \multicolumn{5}{|c|}{ Semi-volatiles } \\
\hline 2-Methylnaphthalene & 44 & $\bullet$ & 44 & $\cdot$ \\
\hline 4-Methylphenol & 2 & - & $\bullet$ & $\infty$ \\
\hline Acenaphthene & 2 & $<5$ & 3 & 2 \\
\hline Anthracene & 3 & 2 & 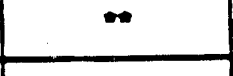 & $\cdots$ \\
\hline Dibenzofuras & 1 & $\dot{-}$ & 3 & 2 \\
\hline Ethylbenzene & 250 & 190 & 430 & 310 \\
\hline Fluorene & 2 & 2 & 4 & 3 \\
\hline Naphthalene & 48 & 14 & 130 & 93 \\
\hline Phenanthrene & 2 & $<5$ & 5 & 4 \\
\hline \multicolumn{5}{|c|}{ Nonspecific Parameters } \\
\hline oil and Grease & 2000 & $<2000$ & - & - \\
\hline Alpha Activity & $4.9 \mathrm{pCi} / \mathrm{L}$ & <ì pcili & I pciji & $\begin{array}{r}<i \\
\mathrm{p} c i / \mathrm{L}\end{array}$ \\
\hline Beta Activity & $8.2 \mathrm{pCi} / \mathrm{L}$ & $<2 \mathrm{pCi} / \mathrm{L}$ & $\bullet$ & $\cdots$ \\
\hline
\end{tabular}


Table 4.1 (Continued)

\begin{tabular}{|c|c|c|c|c|}
\hline \multirow[t]{3}{*}{ Compound } & \multicolumn{4}{|c|}{ Concentration $(\mu \mathrm{g} / \mathrm{L})$} \\
\hline & \multicolumn{2}{|c|}{ May-June 1987} & \multicolumn{2}{|c|}{ March 1990} \\
\hline & Maximum & Minimum & Maximum & Minimum \\
\hline Alkalinity & $301 \mathrm{mg} / \mathrm{L}$ & $254 \mathrm{mg} / \mathrm{I}$ & -- & -- \\
\hline $\begin{array}{l}\text { Chemical oxygen } \\
\text { Demand }\end{array}$ & $52 \mathrm{mg} / \mathrm{L}$ & $<5 \mathrm{mg} / \mathrm{L}$ & -- & -- \\
\hline Conductivity & $\begin{array}{l}767 \\
\mu m h o / \mathrm{cm} \\
\end{array}$ & $\begin{array}{l}679 \\
\mu \mathrm{ohm} / \mathrm{cm}\end{array}$ & -- & -- \\
\hline Dissolved Oxygen & $3.6 \mathrm{mg} / \mathrm{L}$ & $1.5 \mathrm{mg} / \mathrm{L}$ & -- & -- \\
\hline Hardness & $321 \mathrm{mg} / \mathrm{L}$ & $290 \mathrm{mg} / \mathrm{L}$ & - & - \\
\hline Iron & $41 \mathrm{mg} / \mathrm{L}$ & $32 \mathrm{mg} / \mathrm{L}$ & - & $-\infty$ \\
\hline $\mathrm{pH}$ & 7.3 & 6.3 & -- & -- \\
\hline Temperature & $17^{\circ} \mathrm{C}$ & $15^{\circ} \mathrm{C}$ & -- & -- \\
\hline Total Organic Carbon & $24.9 \mathrm{mg} / \mathrm{L}$ & $12.3 \mathrm{mg} / \mathrm{L}$ & - & -- \\
\hline $\begin{array}{l}\text { Total Dissolved } \\
\text { Solids }\end{array}$ & $498 \mathrm{mg} / \mathrm{L}$ & $380 \mathrm{mg} / \mathrm{L}$ & -- & $-\infty$ \\
\hline $\begin{array}{l}\text { Total suspended } \\
\text { Solids }\end{array}$ & $51 \mathrm{mg} / \mathrm{L}$ & $16 \mathrm{mg} / \mathrm{L}$ & -- & - \\
\hline
\end{tabular}

- only one analysis performed.

- Not reported.

\subsubsection{Pretreatment of Influent}

since iron and other minerals may precipitate in the aerobic environment of the bioreactor, the seepage water may need to undergo pretreatment. The pretreatment will consist of a filter, an air oxidation unit (aeration tank), steam stripper or another pretreatment option.

In the steam stripping process some of the incoming water is volatilized, and the VOCs are carried with the water vapor out of the steam stripper. These vapors are fully condensed creating a small vo'ume of aqueous feed to the bioreactor. This small volume of liquid which flows to the bioreactor is a fraction $(\approx 108)$ of the raw water flow to the steam stripper. The vocs are at a higher concentration than in the raw water, which will lead to better reaction kinetics in the bioreactor. The liquid efficient fram the hinreactor is recycled back to the steam stripper so that remaining vocs are not discharged from the process. The treated water discharged from the steam stripper contains all the non-volatile constituents. Iron and other minerals are excluded from the bioreactor. This effluent exits 
the bottom of the stiipper and will be collected and taken to a licensed treatment facility.

\subsubsection{Nutrients}

Nutrients are added to the influent to promote the metabolism of the microorganisms. As the microorganisms consume the added carbon source and nutrients, they also consume contaminants in the influent. The required amounts of nutrients to be added will depend on the nutrient levels present in the influent, the pretreatment process and the results of

experimental studies to evaluate nutrient requirements of several potential cultures. The worst case nutrient requirements, which would occur if the pretreatment process removes all the existing nutrient minerals from the feed water, would necessitate the addition of the nutrient concentrate diluted to approximately 1:100. A maximum of 50 gallons (190 L) of the nutrient concentrate, which is given in Table 4.2 , will be maintained at the site. Negligible consumption will occur in the bioreactor, so the effluent water will have about a 1:100 dilution of the nutrient concentrate. If the steam stripping pretreatment is used, the bioreactor effluent will be further diluted to a concentratjon of about 1:400 when it is recycled to the steam stripper and mixed with the incoming raw water. No limits are given in water quality standards for the compounds contained in the nutrient concentrate.

Table 4.2 Concentrations of Nutrients Added to the seep Water Influent to Bioreactors

\begin{tabular}{|c|c|c|}
\hline Constituent & $\begin{array}{c}\text { Nutrient } \\
\text { Mineral Salts } \\
\text { Concentration } \\
(\mathrm{mg} / \mathrm{L})\end{array}$ & $\begin{array}{c}\text { Incremental } \\
\text { Concentration } \\
\text { Increase } \\
(\mathrm{mg} / \mathrm{L})\end{array}$ \\
\hline $\mathrm{MgSO}_{6} \cdot 7 \mathrm{H}_{2} \mathrm{O}$ & 10 & 0.1 \\
\hline $\mathrm{CaCl}_{2}$ & 5 & 0.05 \\
\hline $\mathrm{KNO}_{3}$ & 2000 & 20 \\
\hline $\mathrm{NH}, \mathrm{Cl}$ & 200 & 2 \\
\hline $\mathrm{FeCl}_{3}$ & 0.5 & 0.005 \\
\hline $\mathrm{KH}_{2} \mathrm{PO}_{4}$ & 2000 & 20 \\
\hline -Trace elements" & 10 & 0.1 \\
\hline
\end{tabular}

- Incremental increase in concentration over existing seep water levels.

- $\mathrm{HBO}_{3}, \mathrm{CoCl}_{2} \cdot 6 \mathrm{H}_{2} \mathrm{O}, \mathrm{MnSO}_{4}, \mathrm{ZnCl}_{2}, \mathrm{CuCl}_{2} \cdot 2 \mathrm{H}_{2} \mathrm{O}$, ana $\mathrm{Na}_{2} \mathrm{HiOO}_{4} \cdot \overline{2}_{2} \mathrm{O}$. Concentration figures given are total of all added trace elements. 


\subsubsection{Bioreactor}

Each influent batch is treated in the bioreactor for approximately one hour. During this time the microorganisms are not suspended in the solution, but are attached to a substrate in the column. In terms of the entire volume of the bioreactor the concentration of the microbial component is about $100 \mathrm{~g} / \mathrm{L}$. The mixed culture of ten to twenty different bacteria will be dominated by methanotrophs in one bioreactor system and by toluene-utilizers in the other. A small number of the microorganisms will become detached from the substrate and will pass from the bioreactor with the effluent.

\subsubsection{Eefluent and Waste Disposal}

The treated bioreactor effluent ( 1 gal/min maximum flow rate) will contain the same volatile organics as the untreated seep water (although decreased in concentration due to microbial degradation) and some added constituents. Added constituents will include dissolved methane, microorganisms washed from the bioreactors $(\approx 10 \mathrm{mg} / L)$, nutrients and trace metals added to the influent to support microbial metabolism and incompletely removed by the microorganisms, and by-products of the microbial degradation. The by-products consist of carbon dioxide and water. Chlorine in trace amounts may also be a by-product.

Experimental studies of the microorganisms have not revealed any known pathogens, and past experience has indicated that conditions are not conducive to their presence (i.e., The selective pressures of the methane and the halogenated solvents do not favor known pathogens). However, pathogenic dangers, if any, have not been identified and are unknown at this time. An evaluation will be performed, using standard techniques, on all cultures proposed for use in the bioreactors and on the raw seep water. During operation of the bioreactor samples of the culture and the effluent will be taken periodically and analyzed by the same techniques to determine if any known pathogens have appeared.

Effluent will be collected and transported to a treatment facility within the $\mathrm{K}-25$ site or at ORNL.

In the event that the steam stripper pretreatment is used, the bioreactor effluent will be recycled to the steam stripper (Section 4.2.2). Microorganisms which detach from the biofilms and becone part of the effluent will remain in the water which is discharged from the steam stripper. This water will also be collected and transported to a treatment facility.

The expected off-gas flow rate is $0.2 \mathrm{cfm}$. Constituents will include methane (approximately $0.01 \mathrm{cfm}$ ) and trace 
concentrations of TCE and other vOCs. If allowed by $\mathrm{K}-25$ air permit stipulations, the off-gas will be vented directly to the atmosphere. Samples will be collected and analyzed for voCs and radioactivity on a regular basis to ensure compliance with $\mathrm{K}-25$ air permit limitations.

A chemical sludge, consisting of precipitated iron, may be produced if chemical pretreatment of the influent is required. The quantity of sludge produced is unlikely to exceed $1 \mathrm{lb} /$ day $(454 \mathrm{~g})$.

The bioreactors may require periodic flushing to remove biosludge. The expected volume to be produced is $5 \mathrm{ft}^{\frac{3}{3}}\left(0.14 \mathrm{~m}^{3}\right)$ or less for the duration of the demonstration project (approximately 8 months).

Waste sludge or biosludge will be analyzed to determine if it contains radioactive and/or hazardous materials. Appropriate disposal methods will be used.

\section{HAZNRD RMIY8IB}

The hazards associated with co-metabolic bioreactors are the potential and kinetic energies involved with the operation of the bioreactors (i.e., pumps, steam, electrical power, etc.), and the presence of mixed organic solvents, radioactive materials, bacterial organisms and flammable/explosive materials.

This will be a small scale operation and the potential and kinetic energies involved with the operation can be considered standard industrial hazards, which require no further analysis. The pumps will have a low flow capacity of approximately 1gal/min, the steam will be low pressure process steam, and the electrical needs will be $220 \mathrm{~V}$ ac, $50 \mathrm{~A}, 3$ phase, or typical industrial power.

The mixed organic solvents and any radioactive materials present in the raw seep water will not be considered in this hazard analysis. These materials are currently being discharged with a NPDES permit and a hazard analysis is not necessary at current or lower concentrations.

In the laboratory tests the volatile organic contaminant for which the process will be optimized, trichloroethene (TCE), has been reduced by approximately $50 \%$ in the effluent. It is expected that this will also be the case in the demonstration project.

There will be up to five $300-\mathrm{ft}^{3}$ cylinders of $3 z$ methane in air with pressures of about 3000 psig manifolded together. Methane is a non-toxic flammable/explosive compound which has a 
lower flammability limit in air of 5.38 and a lower detonability limit in air of $6.3 \%$. (9) Since a $3 \%$ mixture of methane and air will be used, this can be considered a standard industrial hazard, with no further analysis necessary, provided requirements are included in the operating procedures to assure that the quantity of methane in the air/methane mixture is below the lower flammability limit in air of $5.3 \%$ [i.e., quality assurance (QA) on purchase/use of cylinders].

The bacterial organisms will be analyzed as described below. It is assumed in the hazard analysis that the microorganisms are pathogenic, although experimental studies of the microorganisms have not revealed any known pathogens, and it is expected that none will appear.

\subsection{MARARD IEVEL BCREENING}

\subsubsection{Accident scenarios}

Two accident scenarios have been determined which will release microorganisms. These are: (1) catastrophic failure of a bioreactor, and (2) failure of equipment used to transfer effluent to containers for transport to a treatment facility.

Although the largest release of microorganisms would occur if there were a catastrophic failure of a bioreactor, this is not the worst case release. Approximately $35 \mathrm{gal}$ (133 I) of fluid from the bioreactor would be released into the trailer. Since most of the microorganisms will remain attached to the substrate, the fluid released will contain about $25 \mathrm{~g} / \mathrm{L}$ of microorganisms. Without taking credit for the drip pans beneath each bioreactor. unit, it is not likely that any fiuid would spill co the outside because the trailer has a large floor area ( $\approx 8 \mathrm{ft} \times 47 \mathrm{ft}$ ). Even assuming the fluid all spilled to the outside of the trailer, the concentration of the microorganisms which may reach a user as drinking water would be many times diluted before reaching any drinking water supplies. The fluid would spread out over an area of ground and infiltrate the soil. As the infiltration took place, many microorganisms would be filtered out of the fluid. The microorganism population would also be diminished due to a decrease in food supply, available oxygen and temperature. By the time any fluid reached the grouncwater, the number of organisms would be substantially reduced. Further filtration and dilution would occur in the groundwater before reaching any drinkins water supplies.

The second accident scenario assumes that transfer equipment fails while the reactor contents are being transferred to containers for transport to a treatment facility. This results in a release of approximately $35 \mathrm{gal}(133 \mathrm{~L})$ of fluid containing about $1 \mathrm{~m} \mathrm{mg} / \mathrm{I}$. of microorganisms. It is further assumeu that the 
release flows directly into the storm drain. The storm drain empties into Poplar creek or one of the small creeks that feed Poplar Creek and then into the Clinch River (Watts Bar Lake) where drinking water supplies could be affected.

\section{1 .2 Consequence Determination for scenario Two \\ 5.1.2.1 On-site at the co-metabolic Bioreactor Facility and at Nearby Facilities}

Drinking water supplies at the $\mathrm{k}-25$ site are not at risk since they come from the Clinch River, about 2.5 miles upstream of the confluence with Poplar creek. A release of effluent would affect operating personnel and personnel at nearby facilities only if the effluent is ingested. It is highly unlikely that any on-site personnel would drink from the storm drain or on-site streams, so a release is considered to have no on-site consequences.

\section{1 .2 .2 off-site}

Drinking water supplies downstream of a release would be obtained from individual wells and from municipal supplies. The hydraulic gradient of the groundwater tapped by the individual wells tends to be toward the river (groundwater boundaries tend to follow the watershed boundaries(4), therefore the wells should not be contaminated by the effluent.

The closest cities which draw water from Watts Bar Lake are Harriman, Kingston, and Rockwood. The Harriman water plant is on the Emory River 12.8 miles upstream from the confluence of the Emory and Clinch Rivers; the Kingston plant is on the Tennessee River approximately one-third mile upstream from the mouth of the Clinch River; and the Rockwood plant is in a cove of the lake approximately 2.25 miles from the main stream and 15 miles downstream from the mouth of the clinch River. Thus, the water supplies to these cities should be unaffected, since the stream flow in these areas would tend to keep the effluent away. On occasion, when the lake levels rise, some back flow can be expected. This could cause effluent to reach the inlet to water treatment plants. Effects on the public would then depend on the concentration of the microorganisms in the water.

The concentration of the microorganisms in the water can be determined from the amount released and the amount of dilution which takes place before reaching any drinking water supply. The 35-gal (133 L) of effluent, which has a microorganism concentration of approximately $10 \mathrm{mg} / \mathrm{L}$, is released at a maximum rate of $1 \mathrm{gal} / \mathrm{min}(3.79 \mathrm{I} / \mathrm{min})$. No dilution is assumed between the entry point into the storm drain and Poplar Creek. 
The individual microorganism cell can be assumed to be approximately spherical in shape with a diameter of about 2 microns. The density of the cells is approximately equal to the density of water $\left(998 \mathrm{mg} / \mathrm{ml}\left(20^{\circ} \mathrm{C}\right)\right.$. At a mass concentration of $10 \mathrm{mg} / \mathrm{L}$ this is approximately $2.39 \times 10^{6} \mathrm{cells} / \mathrm{ml}$.

The effluent flow rate of 1 gal/min is equivalent to $2.23 \mathrm{x}$ $10^{-3}$ cfs. The mean flow rate in poplar creek at the effluent point of entry is approximately $283 \mathrm{cfs}$. The dilution factor, based on the two flow rates, is $1.27 \times 10^{5}$. The dilution factor of 17.3 at the confluence of Poplar Creek and the clinch River is based on average flow rates of 292 cfs and 4763 cfs, respectively. The resulting concentration in the clinch $R$ iver at the mouth of Poplar creek then would be $1.09 \mathrm{cells} / \mathrm{ml}$. The dilution factor at the confluence of the Emory and the clinch Rivers is 3.95 , and at the confluence of the clinch and the Tennessee Rivers is 3.89 . These are based on average flows for the rivers. Therefore, when the 35 -gal of effluent reaches the Tennessee River, the concentration is estimated to be 0.071 cells/ml or 7.1 cells per $3.00 \mathrm{ml}$. Dilution also occurs in the streams and rivers as the effluent proceeds downstream. Other factors which cause a decrease in the numbers of the microorganisms include sedimentation, decrease in food supply and below optimum stream temperature. In addition, water used for a municipal drinking water supply is treated before being released for consumption.

\subsubsection{Discussion of Reoults and Hazard Lovel Determination}

EPA drinking water standards for maximum contaminant levels (MCLs) of microbiological contaminants are based on fecal coliform bacteria as an indicator organism. The maximum number of coliform bacteria allowed in the drinking water regulations is 1 per $100 \mathrm{ml}$ as the arithmetic mean of all samples examined per compliance period: 4 per $100 \mathrm{ml}$ in one sample when less than are examined per month; or 4 per $100 \mathrm{ml}$ in more than 5 of the samples when 20 or more are examined per month. (2) This compares with the estimated value of 7.1 cells per $100 \mathrm{ml}$. To put this into perspective, a number of militating factors exist for which no credit has been taken:

* The microorganisms are not likely to be pathogenic, as assumed.

* Attrition of the microorganisms will occur as a result of sedimentation, loss of nutrients, and unfavorable temperatures.

* Drinking water standards have been invoked, although potential receptors are almost universally protected by existing water treatment plants. 
\# Any effect of a spill will be transient.

Based on the above analysis there should be no effects to on-site personnel either at the facility or at nearby facilities, and there should be negligible or no effect on the public from an accidental release of unsterilized effluent from the bioreactor demonstration project.

Based on the results of the hazard screening, it is recommended that this facility be considered a generally accepted hazard facility for purposes of design and safety documentation. A generally accepted hazard facility requires no further safety documentation. However, requirements should be included in the operating procedures to assure that the quantity of methane in the air/methane mixture is maintained below the lower flammability limit of $5.3 \%$. 


\section{RERERENCEB}

1. J. Hord, 1976, Is Hydrogen Safe?, PB-262-551, NBS-TN-690, National Bureau of Standards, Department of Commerce, Washington, D. C.

2. Code of Federal Requlations, Title 40 . Protection of Environment, Part 141, National Primary Drinking Water Regulations, Section 14, Maximum Micxobiological Contaminant Levels.

3. RCRA Facility Investiqation Plan, $K-1070-C / D$ Classified Burial Ground, Oak Ridge Gaseous Diffusion Plant, Oak Ridge, Tennessee, Report No. K/HS-140, Appendix B, Revision 1, May 1989.

4. Warren Viessman, Jr., Gary L. Lewis, and John W. Knapp, Introduction to Hydrology, Harper \& Row, Publishers, New York, New York, 1989 . 


\title{
APPENDIX J
}

\author{
FXAMPLE OF HEALTH AND SAFETY PLAN
}

\section{CO-METABOLIC BIOREACTOR DEMONSTRATION AT THE K-25 SITE}

\author{
Prepared by the \\ Oak Ridge National Laboratory \\ Oak Ridge, Tennessee 37831 \\ Managed by \\ MARTIN MARIETTA ENERGY SYSTEMS, INC. \\ for the \\ U. S. DEPARTMENT OF ENERGY \\ under contract DE-AC05-84OR21400
}

\section{CAUTION}

This document has not been given final patent clearance and is for internal use only. If this is to be given public release, it must be cleared throı:gh the site Technical Information Office which will see that the proper patent and technical information reviews are completed in accordance with Energy Systems policy. 


\section{APPROVALS}

\section{Health and Safety Plan \\ Co-Metabolic Bioreactor Demonstration}

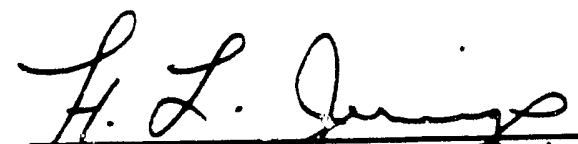

A. L. Jenninge Perating

Chemical Tedhology Division

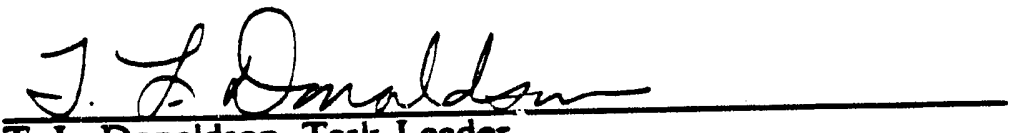

T. L Donaldson, Task Leader

Chemical Technology Division
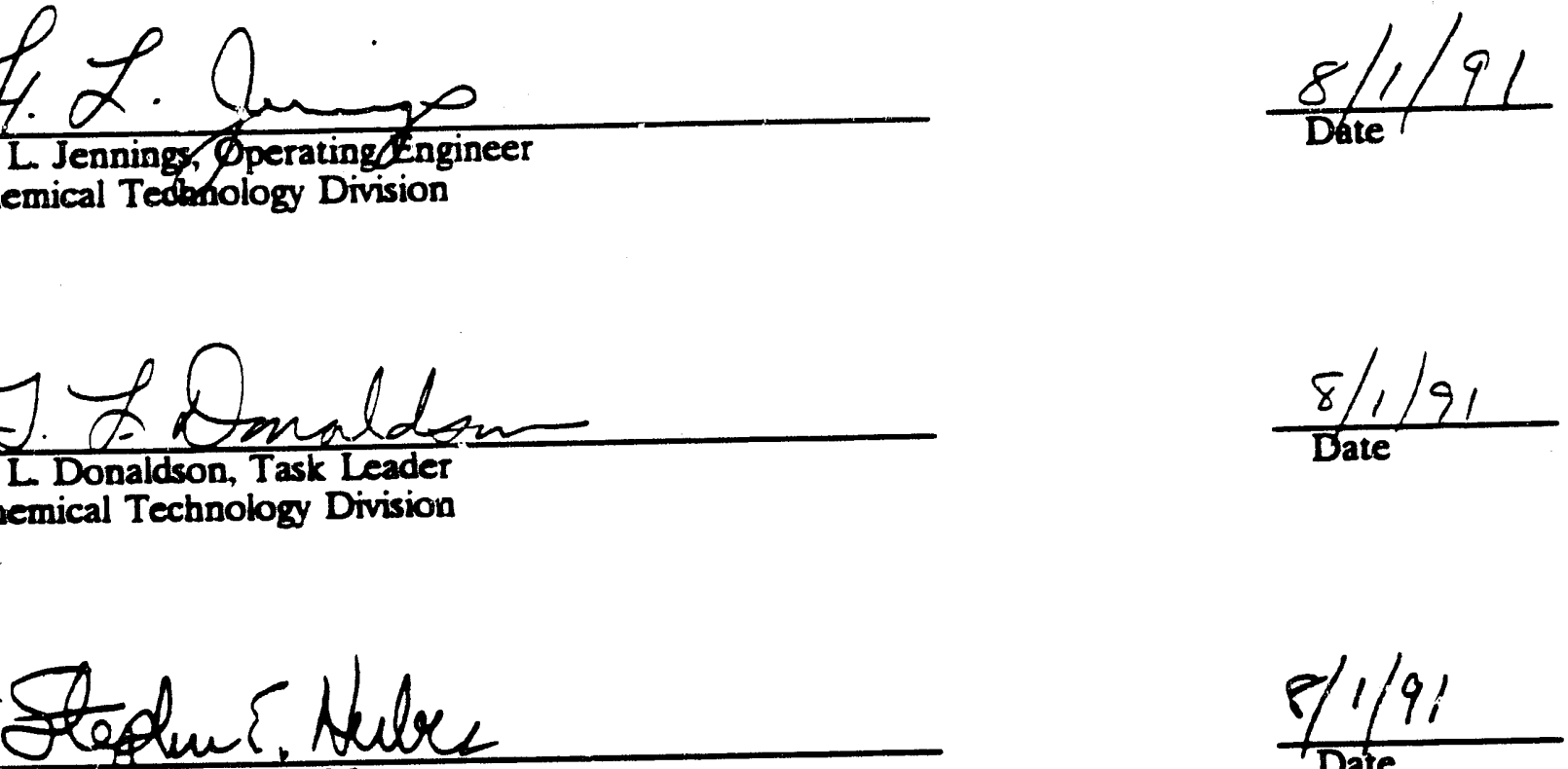

S. E Hefes, Project Manager

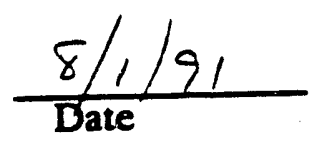

Environmental Sciences Division

K L Brady, Division Manager

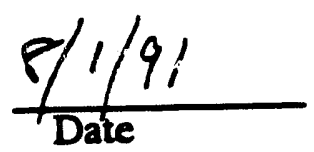

Health, Safety, and Environmental Management

C. H. Peterson, Chairman

Environmental, Health, \& Safety Council 


\section{CONTENTS}

FIGURES $\ldots \ldots \ldots \ldots \ldots \ldots \ldots \ldots \ldots \ldots \ldots \ldots \ldots \ldots \ldots \ldots \ldots \ldots \ldots$

TABLES $\ldots \ldots \ldots \ldots \ldots \ldots \ldots \ldots \ldots \ldots \ldots \ldots \ldots \ldots \ldots \ldots \ldots \ldots \ldots \ldots \ldots$

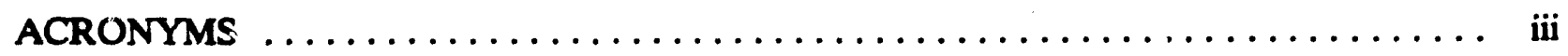

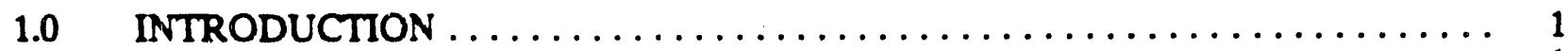

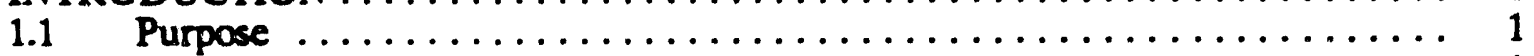

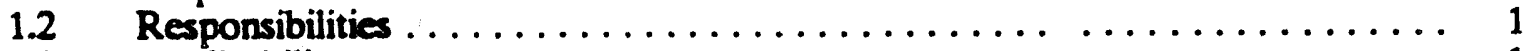

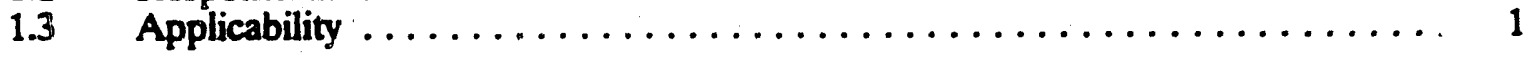

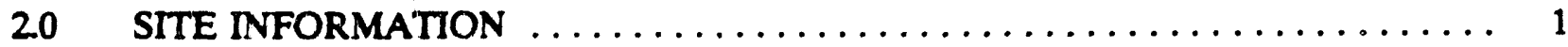

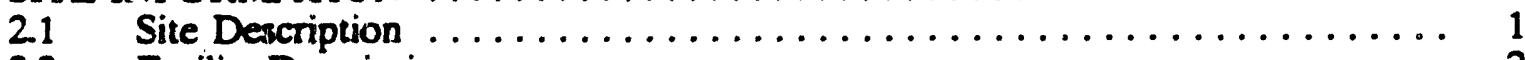

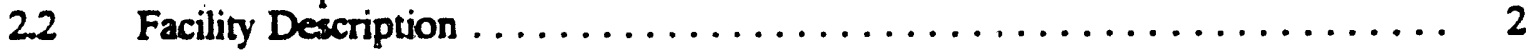

3.0 POTENTIAL HEALTH AND SAFETY CONCERNS $\ldots \ldots \ldots \ldots \ldots \ldots \ldots \ldots$

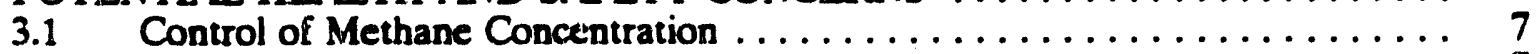

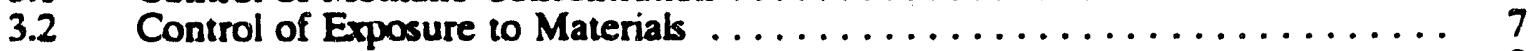

3.2 .1 Alkaline Materials ...................... 8

3.2 .2 Steam and Boiling Water ..................... 8

3.23 Contaminated Groundwater $\ldots \ldots \ldots \ldots \ldots \ldots \ldots \ldots \ldots \ldots$

3.24 Nutrients .......................... 8

3.3 Control of Exposure ro Pathogens $\ldots \ldots \ldots \ldots \ldots \ldots \ldots \ldots \ldots \ldots \ldots$

3.4 Control of Exposure to Radioactivity $\ldots \ldots \ldots \ldots \ldots \ldots \ldots \ldots \ldots \ldots \ldots \ldots$

3.5 Control of Heat Stress and Cold Exposure ................. 9

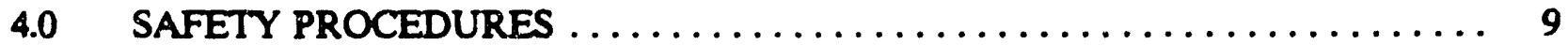

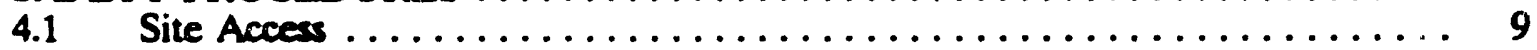

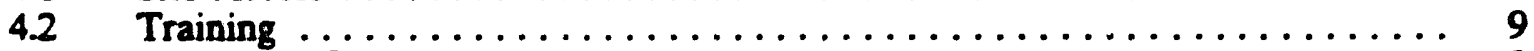

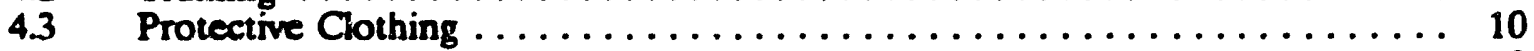

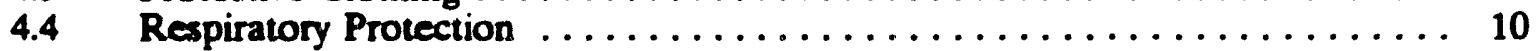

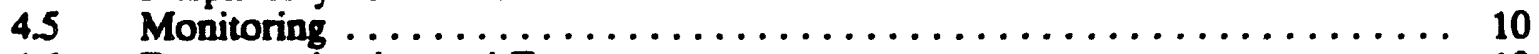

4.6 Decontamination and Egress ............................ 10

5.0 EMERGENCY INFORMATION $\ldots \ldots \ldots \ldots \ldots \ldots \ldots \ldots \ldots \ldots \ldots \ldots$

6.0 OCCURRENCE REPORTING $\ldots \ldots \ldots \ldots \ldots \ldots \ldots \ldots \ldots \ldots \ldots \ldots$

APPENDIX 1, Control of Heat Stress, Standard Practice Procedure $607 \ldots \ldots \ldots \ldots$ 


\section{FIGURES}

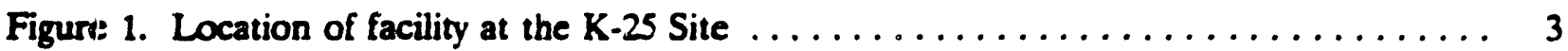

Figure 2. Decailed site plan for the bioreactor system $\ldots \ldots \ldots \ldots \ldots \ldots \ldots \ldots \ldots$

Figure 3. Process flow diagram of the methanotroph bioreactor system $\ldots \ldots \ldots \ldots \ldots$

Figure 4. Schematic of equipment layout in the trailer $\ldots \ldots \ldots \ldots \ldots \ldots \ldots \ldots$

\section{TABLES}

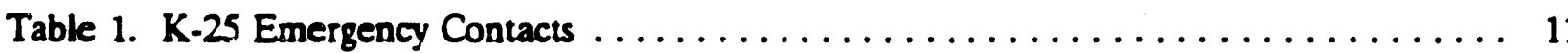

\section{ACRONYMS}

CGI Combustible Gas Indicator

DOE Department of Energy

HS\&EA Health, Safety, and Environmental Affairs

MSDS Material Safety Data Sheets

NPDES National Pollutant Discharge Elimination System

ORNL Oak Ridge National Laboratory

ORS Occurrence Reporting System

PID Photoionization detector

TCE Trichloroethylene

VOC Volatile organic contaminant 


\section{HEALTH AND SAFETY PLAN \\ FOR THE CO-METABOLIC BIOREACTUR DEMONSTRATION AT THE K-25 SITE}

\subsection{INTRODUCTION}

\subsection{Purpose}

The purpose of this plan is to assign responsibilities, establish personnel protection standards and mandatory safety practices and procedures, and provide for contingencies that may arise during operation of the co-metabolic bioreactor demonstration project at the K-25 Site, Oak Ridge, Tennessee. The effect of this Health and Safety Plan will be to minimize avoidable accidents, injuries, and worker exposure in the performance of normal site activities and to provide for contingencies that may arise while this effort is being conducted.

\section{Responsibilities}

Management of this demonstration project is the responsibility of the Oak Ridge National Laboratory (ORNL) Environmental Sciences Division. Much of the field operational work will be conducted by staff of the ORNL Chemical Technology Division. Other divisions inyolved in some aspects of the project are the K-25 Health, Safety and Environmental Affairs (HS\&EA) Division and the Environmental Restoration Division.

The Project Manager shall designate a Project Safety Officer. Compliance with this plan shall be the immediate responsibility of the Safety Officer.

\section{Applicability}

The provisions of this Health and Safety Plan are mandatory for ail on-site personnel and visitors engaged in any field activity of the co-metabolic bioreactor demonstration. All field personnel shall be provided a copy of this health and safety plan by the safety officer for their information. All work shall be completed in accordance with this plan. A pre-entry briefing shall be held by the safety officer prior to initiating any site activity and at such other times as necessary to ensure that personnel are apprised of the site health and safety plan and that this plan will be followed. Field personnel will be asked to sign and date an appropriate record signifying that this health and safety plan was distributed and that a pre-entry discussion was conducted.

\section{SITE DNFORMATION}

\section{Site Description}

The co-metabolic bioreactor demonstration facility will be located at the eastern edige of the 
building K-1098-D parking lot. The seep, which will serve as the influent, is adjacent to the east side of Avenue D, about 110 feet south of the center of the intersection with 9th Street and about 200 feet west of the boundary of the K-1070-C/D Classified Burial Ground. Location of the facility at the K-25 Site is shown in Figure 1. A detailed site plan for the bioreactor system is shown in Figure 2.

\section{Facility Description}

The co-metabolic bioreactor demonstration project will consist of the operation of two bioreactor units. During the first phase of the project a single bioreactor unit with raethanotrophs will be operated. During the second phase, a bioreactor unit charged with toluene-utilizers or one bioreactor unit of each type will be operated. Each unit will consist of:

- piping from the seep to the bioreactor unit,

- an influent pump and associated valves and controls,

- a pretreatment filter, air oxidation unit (aeration tank), steam stripper, or another pretreatment option if needed,

- the bioreactors,

- up to five standard $300 \mathrm{ft}^{3}$ compressed gas cylinders for the carbon substrate (3\% - methane in air) or a 55-gallon drum containing dilute aqueous toluene solution,

- an off-gas scrubber (if required by the air discharge permit),

- $\quad$ piping and valves for operation in recycle mode,

- piping and containers for the collection of effluent,

- safety monitoring instrumentation and process controls.

Two skid-mounted bioreactor units, each consisting of two columns ( $\approx 12$ inches diameter by 7 feet high) plus associated plumbing, pumps, and control panel will be used. A process flow diagram of the methanotroph bioreactor system is shown in Figure 3. These units will be housed in a van trailer to provide protection from inclement weather. The bioreactor will serve as the primary confinement. A stainless steel drip pan beneath each skid with the trailer will serve as secondary confinement. The drip pans will drain to a sump with a capacity of 55 gallons. Ventilation for the trailer will be provided by an exhaust fan mounted in the back door. A schematic of the equipment layout in the trailer is shown in Figure 4.

The utilities required are (1) process water for preparation of nutrient solutions and general equipment washing and flushing; (2) an AC electrical supply of 220 volts and 50 amps (3 phase); (3) compressed air at 50 psig; and (4) low pressure process steam for the steam stripper. 


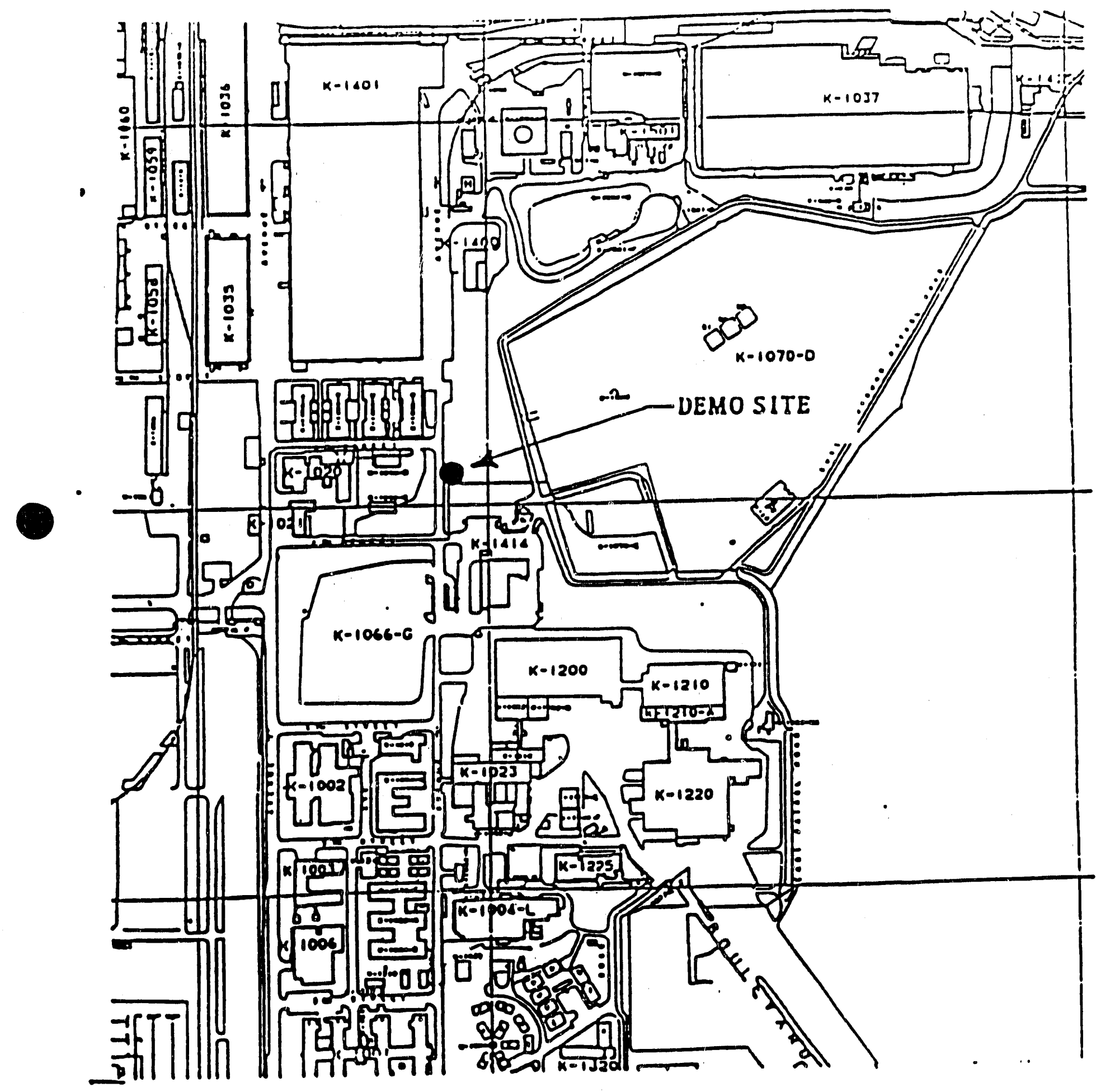

Figure 1. Location of demonstration at the K-25 Site 


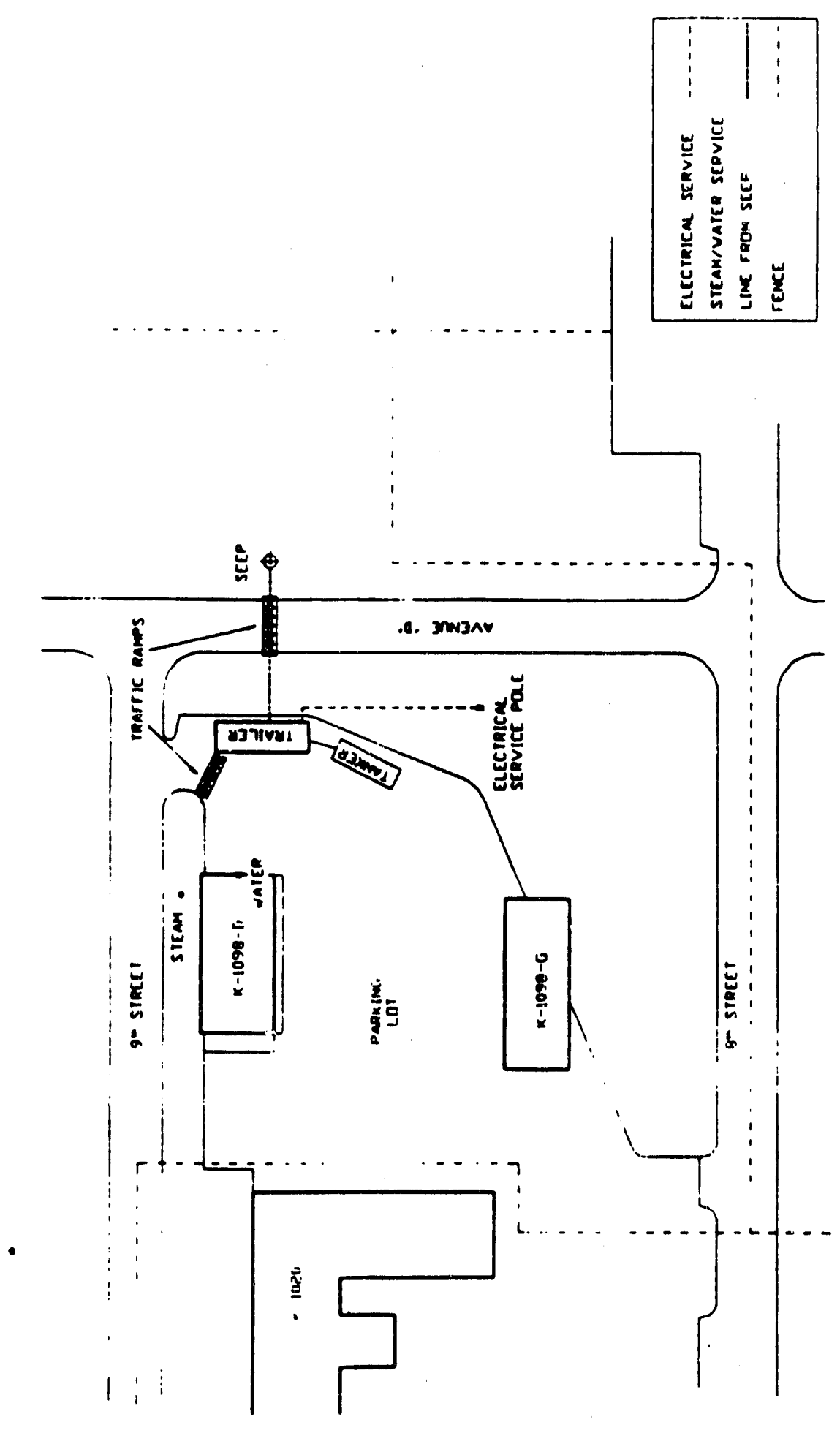

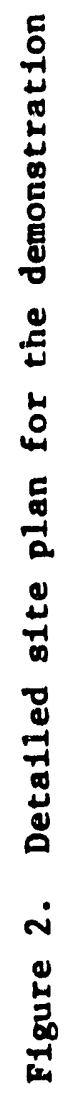



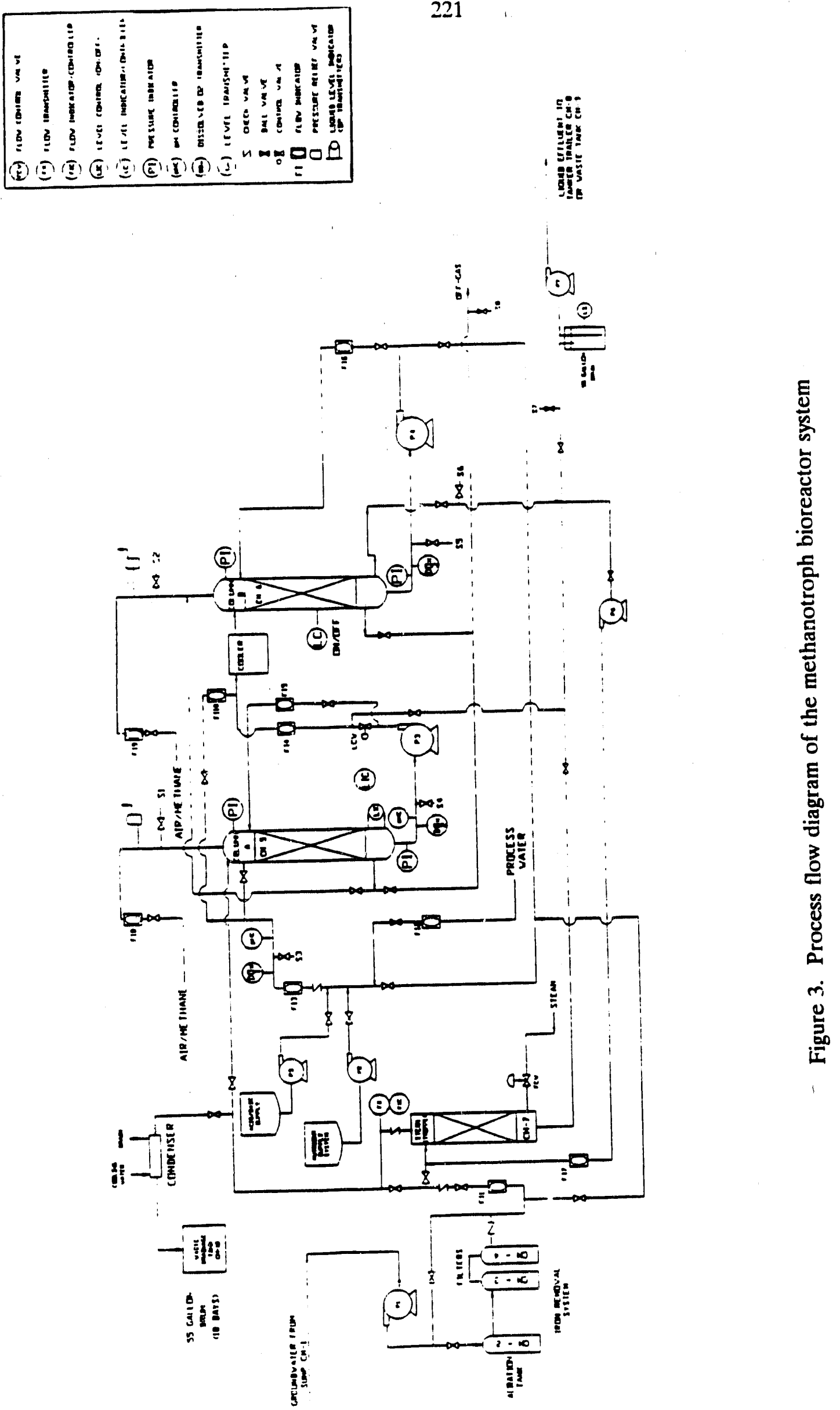


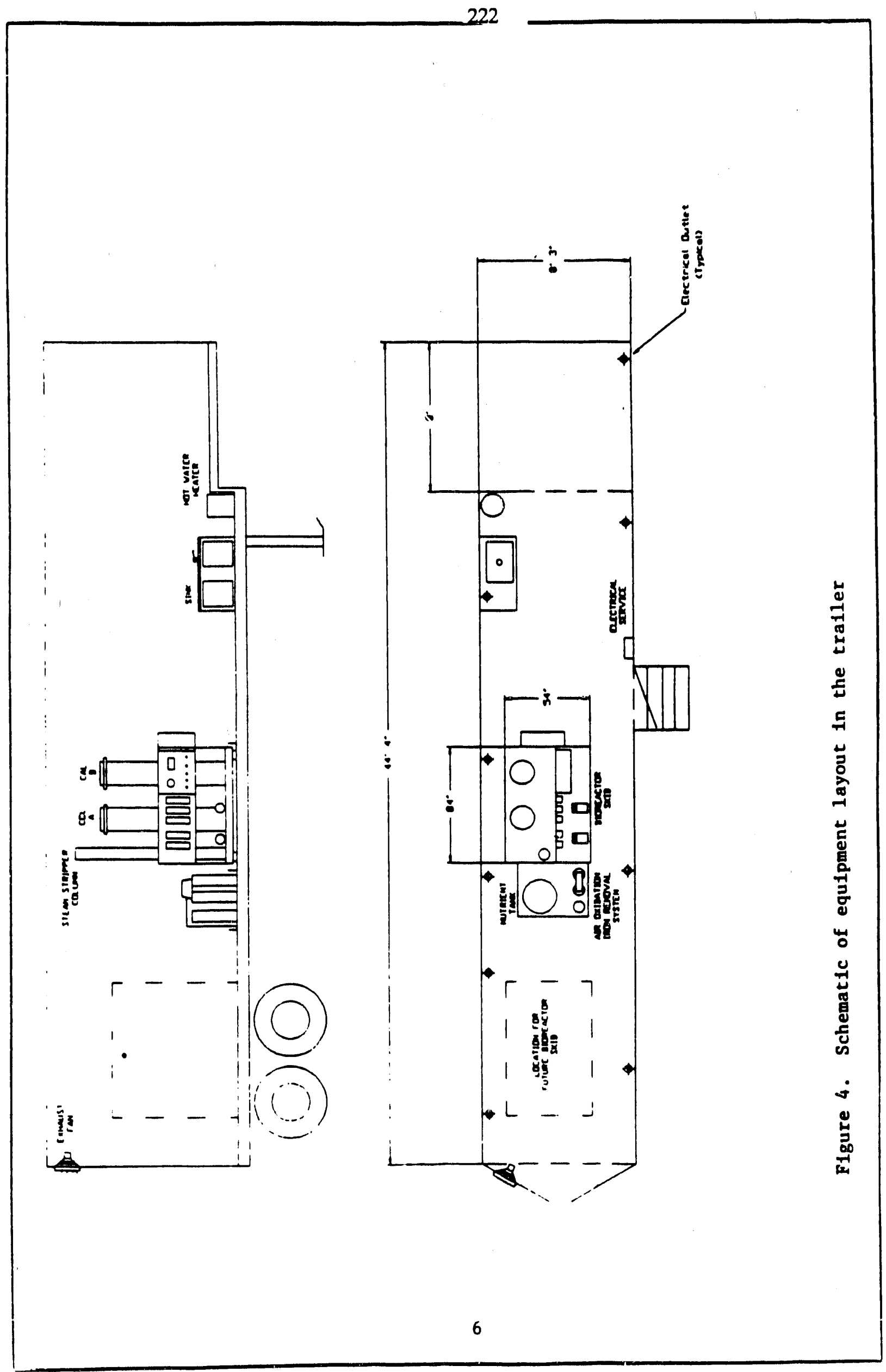


The facilities will be attended daily by project personnel. Weekend coverage will be arranged with K-25 shift personnel. In addition, automatic shutdown is provided if the liquid level rises in the bottom of the bioreactor column, or if liquid accumulates in the drip pans provided beneath each skid unit.

\subsection{POTENTIAL HEALTH AND SAFETY CONCERNS}

The health and safety concerns with co-metabolic bioreactors are the potential and kinetic energies involved with the operation of the bioreactors (i.e., pumps, steam, electrical power, etc.), and the presence of mixed organic solvents, radioactive materials, bacterial organisms, and flamniable/explosive materials. These hazards have been evaluated independently (M. B. Andriulli, "Safety Assessment: Co-metabolic Bioreactor Demonstration at the Oak Ridge K-25 Site," K/D-SA-2156, June 24, 1991).

Special potential safety hazards identified in the swety assessment include: (1) control of methane gas concentration, (2) exposure to materials, (3) cxposure to pathogens, and (4) exposure to radioactivity. In addition, heat stress in summer and cold expusure in winter are potential hazards.

\subsection{Control of Methane Concentration}

Up to five $300-\mathrm{ft}^{3}$ cylinders of $3 \%$ methane in air with pressures of $\approx 3000$ psig will be manifolded together to supply the required carbon source to the methanotrophs. Methane is a non-toxic, flammable/explosive compound that has a lower flammability limit in air of $5.3 \%$ and a lower detonability limit in air of $6.3 \%$. An analysis performed on a catastrophic failure of all 5 methane tanks inside the trailer has shown that the release will result in less than $4 \% \mathrm{v} / \mathrm{v}$ methane/air mixture in the trailer.

Methane gas (3\% in air) will be purchased from a commercial vendor (e.g., Matheson Gas Products) as a certified standard gas to ensure that the concentration remains below the lower flammability limit and the lower detonability limit. The Safety Officer or his designate shall confirm the written analysis of each tank prior to connection to the manifold to ensure that the concentration does not exceed the lower flammability limit.

Methane may act as an asphyxiant in an oxygen deficient atmosphere. The trailer is equipped with a ventilation fan to maintain a satisfactory oxygen atmosphere.

\section{Control of Exposure to Materiais}

Material Safety Data Sheets (MSDS) will be available on-site for all chemicals used or stored at the site. The types of materials handled include: (1) alkaline materials, (2) steam and boiling 
water, (3) contaminated water, and (4) nutrients.

\section{Alkaline Materials}

The $\mathrm{pH}$ of the water will be raised with alkaline materials such as sodium hydroxide, calcium hydroxide, and/or soda ash. These materis ls are corrosive to the skin and the eyes; therefore, safety glasses and appropriate gloves are required to be worn when handling these materials. If skin contact occurs, the affected areas should be rinsed thoroughly with water. If eye contact occurs, the available eyewash station will be used to rinse the eyes for at least 15 ruinutes and medical attention shall be obtained.

\section{Steam and Boiling Water}

Steam is supplied at 15 psig and used in the stripper at $\approx 100^{\circ} \mathrm{C}$. Serious burns could result from contact with steam, boiling water, or hot pipes and vessels. The steam stripper and associated piping will be insulated to protect personnel. Medical treatment shall be sought for any burns soon after contact.

\section{Contaminated Groundwater}

The groundwater is contaminated with various hydrocarbons, particularly trichloroethylene (TCE). Approximately $90 \%$ of these hydrocarbons are volatile organic contaminants (VOCs) and the remaining $10 \%$ are reported as oil and grease. Several of these compounds are potential carcinogens. Gloves, which are specified by the MSDS or recommended by the Industrial Hygiene Department, will be worn when sampling or contacting the water. If skin or eye contact occurs, the affected areas should be rinsed thoroughly with water.

\subsection{Nutrients}

The compounds used to make up the nutrient solution for the microorganisms are potential irritants to the skin and the eyes. Gloves, which are specified by the MSDS or recommended by the Industrial Hygiene Department, will be worn when contacting these compounds. Eye protection is also required wher. handling these compounds. If skin or eye contact occurs, the affected areas should be rinsed thoroughly with water.

\subsection{Control of Exposure to Pathogens}

Experimental studies of the microorganisms have not revealed any known pathogens, and it is not expected that any will appear. Evaluations will be performed, using standard techniques, on all 
cultures proposed for use in the bioreactors, on the raw seep water, and on the bioreactor effluent. If pathogens are found at any time, the system will not be operated until a suitable disposal method is arranged.

\subsection{Control of Exposure to Radioactivity}

Water samples collected from the seep water have been analyzed for alpha and beta activity. The maximum alpha and beta activity measured have been 4.9 and $8.2 \mathrm{pCi} / \mathrm{L}$, respectively. Since the contamination is very low and the seep water is currently discharged with a National Pollutant Discharge Elimination System (NPDES) permit, the control of radioactivity is not considered a hazard.

\subsection{Control of Heat Stress and Cold Exposure}

Summer temperatures can produce heat conditions that will severely restrict work time. At the K-25 Site, the evaluation of heat stress for persons wearing protective clothing and respirators is a standard part of the Industrial Hygiene Program. The plant's Standard Practice Procedure 607, "Control of Heat Stress," is included herewith as Attachment 1. In the event that heat stress symptoms begin, personnel shall seek shelter in an air-conditioned area. If symptoms persist, medical assistance shall be sought.

The current plan is to perform the demonstration during the warm months so that special precautions (e.g., heat tracing of water pipes) against cold weather are not required. Therefore exposure to cold temperatures is not considered a health hazard.

\subsection{SAFETY PROCEDURES}

\subsection{Site Access}

Routine access to the demonstration trailer and waste storage areas shall be limited to project staff, staff of the K-25 HS\&EA Division, and other personnel with clear oversight responsibilities for the activities at the site.

Access to the site by visitors shall be the responsibility of the Project Manager or his designate. All visitors to the site shall be accompanied by the Project Manager or his designate, and they shall be given an overview of this plan prior to gaining access.

\subsection{Training}

Prior to conducting work activities at the site, all project personnel shall have completed the following training: 


\section{- GET (K-25): Basic, Course No. 3250, \\ - HAZCOM Training.}

Additional training will be required for project staff serving as Waste Certification Officers as detailed in the Waste Generation and Disposal Plan for the project.

Training will be conducted for performance of specific procedures during the project. This training will be documented as detailed in the project QA/QC Plan.

\subsection{Protective Clothing}

Safety glasses shall be worn in the demonstration process area of the trailer and in the designated Waste Storage Area at all times.

Protective clothing shall consist of appropriate field clothing and safety shoes. Clothing shall be changed as soon as possible upon exposure to contaminated groundwater or chemicals.

\subsection{Respiratory Protection}

No respiratory protection is required on the site.

\section{Monitoring}

A schedule shall be developed in conjunction with the K-25 Site Industrial Hygiene Department for routine surveillance monitoring of the trailes. Monitoring shall include total volatile organic contaminants as measured by a photoionization detector (PID), and a combustible gas indicator (CGI). Monitoring shall occur at least once during startup of the demonstration, and at intervals deemed sufficient by the K.25 Industrial Hygiene Department to ensure that routine operation of the unit poses no unacceptable airborne exposure hazards.

\subsection{Decontamination and Egress}

No monitoring shall be required upon leaving the demonstration site. Workers shall wash their hands and dispose of gloves before leaving. Good personal hygiene should be practiced by all workers on the site.

\subsection{EMERGENCY INFORMATION}

The K-25 Plant Protection and Shift Operations Division provide 24-hour emergency response coverage, which is the responsibility of the Plant Shift Superintendent, Shift Operations Department. The Shift Superintendent is assisted by a well-trained plant emergency squad, and he/she is the overall coordinator of responses to emergencies such as fires, major equipment failure, hazardous materials 
releases or spills, natural disasters, and sabotage. Table 1 lists the K-25 departments and telephone numbers that may be contacted in an emergency.

Table 1. K-25 Emergency Contacts

\begin{tabular}{|l|c|}
\hline \multicolumn{1}{|c|}{ CONTACT } & TELEPHONE NUMBER \\
\hline Shift Superintendent & $\begin{array}{c}911 \text { (Plant Phone) } \\
574-3282 \text { (Cellular) }\end{array}$ \\
\hline Environmental Management & $574-8222$ \\
\hline Guard Department & $574-8315$ \\
\hline Health Physics & $574-9620$ \\
& $574-0332$ \\
\hline Industrial Hygiene & $574-8567$ \\
\hline Medical & $574-8562$ \\
\hline Public Relations & $574-8093$ \\
\hline Safety & $574-8568$ \\
\hline Security & $574-8326$ \\
\hline
\end{tabular}

'Contact the Shift Superintendent first. The Superintendent is the trained emergency response director.

\subsection{OCCURRENCE REPORTING}

As of August 30, 1990, the implementation of Department of Energy (DOE) Order 5000.3A, "Occurrence Reporting and Processing of Operations Information," became effective. The occurrence reporting system (ORS) may be initiated anytime an employee, contractor, or subcontractor reports problems, concerns, and adverse conditions or events that have or could have adverse or negative impact on safety, environment, health, quality, security, or operations. Occurrences are to be reported to the Project Manager or his designate, who will relay appropriate information to the Plant Shift Superintendent. The Plant Shift Superintendent officially notifies the required DOE offices in accord with the occurrence reporting procedure. 
APYENDIX 1, Control of Heat Streas, Standard Practice Procedure 607 
Altacinment 1

MARTIN MARIETTA ENERGY SYSTEMS. INC. OAK RIDGE GASEOUS DIFFUSION PLANT STANDARD PRACTICE PROCEDURE

\begin{tabular}{|ll}
\hline NUMBEA & \\
& 607 \\
\hline PAGE & 1 Of 7 \\
\hline OATE & $02 / 90$ \\
\hline
\end{tabular}

SUQUECT: CONTROL OF HEAT STRESS

A. POLICY: It is ORGDP policy to provide general guidelines for protection of employees who are required to work in a hot environment or who are required to wear protective clothing that can result in a hot micro-environment.

3. SCOPE: This procedure applies to all ORGDP employees. Other contractor and subcontractor personnel working at ORGDP will be provided with guidance in accordance with this procedure.

HOTE: The rationale for the Heat Stress Program is in Attachment 1.

\section{REFERENCES:}

American Conference of Governmental Industrial Hygienists, Threshold Limit Values and Biological Exposure Indices for 1989-1990, ACGIH, Cincinnati, Ohio

ESH-7, "Control of Occupational Exposuire to Cherical, Raúlation, and Physical Stresses"

NIOSH Publication No. 86-113 (April 1986), "Criteria for a Recommended Standard... Occupational Exposure to Hot Environments"

MIOSH, OSHA, USCG, and EPA Publication No. 85-115 (October 1985), "Occupational Safety and Health Guidance Manual for Hazardous Waste Site Activities"

\section{DEFINITIONS:}

1. Hot Environment - Any combination of air temperature, humidity,

- radiant heat, and wind speed that exceeds a wet bulb globe temptrature (WBGT) index of $84^{\circ} \mathrm{F}$.

2. Hot Micro-environment (Level i) - The area surrounding a person's body when wearing encapsulating semi-permeable or impermeable clothing in an environment with a shielded dry bulb air temperature greater than $70^{\circ} \mathrm{F}$ (standard mercury-in-glass thermometer with the bult shielded from radiant heat).

3. Hot Micro-environment (Level II) - The area surrounding a person's body when wearing encapsulating semi-permeable or impermeable clothing in an environment with a shielded dry bulb air temperature greater tha" $10^{\circ} \mathrm{F}$. 
MARTIN MARIETTA ENERGY SYSTEMS. INC.

NUAAEA
\begin{tabular}{l}
507 \\
\hline PAGE $22 f 7$ \\
\hline OATE $22 / 90$
\end{tabular}

OAK RIDGE GASEOUS DIFFUSION PLANT

STANDARD PRACTICE PROCEDURE

SUBSECT:

CORTROL OF HEAT STRESS

D. OEFINITIONS: - continued

4. Heat 11 iness - Any physiological disorder arising from a person's inability to maintain thermal balance due to heat stress.

5. Acclimatization - A series of physiological and psychological adjustments that occur in an individual during the first week (approximate) of exposure to heat stress so that, thereafter, the individual has increased capability to withstand hot working conditions.

o. Heat Stress - Physiological disorders due to an individual's inability to maintain thermal balance in hot environments.

7. Het Bulb Globe Temperature - The sum of 0.7 of the natural wet bulb, plus 0.3 of the globe temperature when indoors or outdoors with no solar load. The WBGT when outdoors with a solar load is 0.7 of the natural wet bulb, plus 0.2 of the globe temperature, plus 0.1 of the dry temperature.

E: RESPONSIBILITIES:

1. Supervisor

a. Ensures compliance with all applicable regulations, standards, and procedures pertaining to hot environments or hot microenvironments. (ESH-7 III[D][1],[8])

b. Requests Industrial Hygiene Department personnel to perform temperature measurements and identify areas that may produce hot environments or hot micro-environments.

(ESH-7 III[D][1], [2]; NIOSH Pub. No. 86-113, Chapter I,

. Section I (b) (2), (3), (4); ACGIH TLV Handbook, PP. 75-76)

c. Ensures that employees who have potential for this type of exposure must have satisfactorily completed a medical examination to assess their ability to work under heat stress

: conditions. Employees returning to work following an extended period of illness will be referred to the Medical Department for speciai examination and approvai pricr to work under heat stress conditions. (ESH-7 III[D][1]; NIOSH Pub. No. 86-113, Chapter I. Section $2[b][c])$ 
MARTIN MARIETTA ENERGY SYSTEMS. INC.

OAK RIDGE GASEOUS DIFFUSION PLANT

STANDARD PRACTICE PROCEDURE

\begin{tabular}{|ll}
\hline NUMEER & \\
& 607 \\
\hline PAGE & 3 OF I \\
\hline OATE & $02 / 90$ \\
\hline
\end{tabular}

SUBUECT: CONTROL OF HEAT STRESS

\section{E.1. RESPONSIBILITIES: - continued}

d. Ensures that employees who have potential for this type of exposure must have satisfactorily completed yearly microenvironmental heat stress training. (In addition to requirements of this procedure, training must include symptoms of common heat illnesses, corresponding first aid measures, embryo-fetal hazards, and proper use of approved cool suits and/or ice vests.) (ESH-7 III[D][7]; NIOSH Pub. No. 85-115, Pp. 8-21; NIOSH Pub. No. 86-113, Chapter 1, Section 6[a], (b])

e. Promotes acclimatization of newly assigned employees, as well as any returning to work after an absence of two weeks or more, by gradually increasing the anticipated work load and exposure time from 50 percent (Day 1), to 60 percent (Day 2), etc., until achieving 100 percent (Day 6). (ESH-7 III[D][8];

NIOSH Pub. No. 85-115, PP. 8-22, 8-23; NIOSH Pub. Wo. 86-113, Chapter VI[B][3][a]; ACGIH TLV Handbook PP. 80)

f. Permits employees to interrupt their work when necessary to prevent heat illness. Anyone displaying symptoms of heat illness or taking rest breaks with unusual frequency will be referred to the Medical Department for examination. However, rest breaks may bis taken more frequently during the acclimatization period. (ESH-7 III[D][3]; NIOSH Pub. No. 85-115, Pp. 8-21; NIOSH Pub. No. 86-113, Chapter VI[B][1])

g. Provides an adequate supply of cool, potable water with disposable drinking cups and a suitable water container near the work area but outside any established contamination zone. If desired, one level teaspoon of salt per gallon of water may be added to replenish that lost through perspiration.

- (NIOSH Pub. No. 85-115, pp. 8-21; NIOSH Pub. No. 86-113, Chapter I, Section $7[C][1][f]$; ACGIH Handbook, PP. 79-80)

h. Implements practical heat stress abateinent measures to protect and provide relief for employees. These may include scheduling work for cooler periods in the day, use of radiant heat shielding, insulation, fans, mobile or portable air conditioners, cool rooms, cool suits/vests, and the buddy

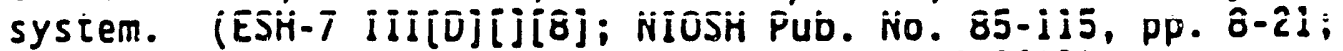
NIOSH Pub. No. 86-113, Chapter I, Section 7[a][2]) 
MARTIN MARIETTA ENERGY SYSTEMS. INC.

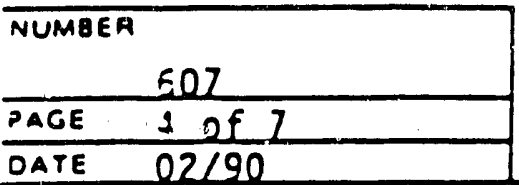

OAK RIDGE GASEOUS DIFFUSION PLANT

STANDARD PRACTICE PROCEDURE

SUQIECT:

CONTROL OF HEAT STRESS

\section{E.1. RESPONSIBILITIES: - continued}

NOTE: All employees working under Level II conditions must wear an approved cool suit/vest and be monitored by a similarly equipped back-up person. Use of a cool suit/vest and the buddy system are optional under Level I conditions.

i. Schedule overtime so that employees are not exposed to heat stress more than 12 hours per day. Personnel working under such conditions will not be required to work overtime if they feel physically unable to do so. (ESH-7 III[O][8]; NIOSH Pub. No. 85.115, pg. 8-21; NIOSH Pub. 86-113, Chapter I, Section $7[c][1][a])$

2. Employee

a. Reports their health status promptly upon returning to work after an extended illness. Any physical condition (e.g., saltfree diet) or prescriptive medicine that may impair one's ability to withstand heat stress will be reported to their supervisor as well as to the Medical Department for examination. (NIOSH Pub. No. 85-115, Pp. 8-22;

NIOSH Pub. 86-113, Chapter IV[A][6][d][2])

b. Maintains awareness of the symptoms of heat ilinesses and immediately notifies the supervisor when any of these conditions occur. (NIOSH Pub. Ho. 85.115, pp. 8-21; NIOSH Put. No. 86-113, Chapter I, Section 6[a])

c. Replenishes salt and water lost through perspiration by drinking extra fluids throughout the work shift and adding more salt to food. (NIOSH Pub. No. 85-115, PP. 8-21;

- NIOSH Pub. No. 86-113, Chapter I, Section $7[c][1][f])$

d. Attends a heat stress training program annually to increase awareness of potential hazards imposed by work in hot microenvironments and encourages use of approved countermeasures to reduce heat strain. (NIOSH Pub. No. 85-115, pp. 8-21;

NIOSH Pub. No. 96-113, Chapter 1, Section. 6[a])

e. Ârranges nonscineduied work óreaks tinrough seî́-pacing when necessary to prevent heat illness. (NIOSH Pub. No. 85-115, Pp. 8-21; NIOSH Pub. No. 86-1:3], Chapter 1, Section $7[c][1][a])$ 
MARTIN MARIETTA ENERGY SYSTEMS. INC.

OAK RIDGE GASEOUS DIFFUSION PLANT

STANDARD PRACTICE PROCEDURE

\begin{tabular}{|c|c|}
\hline NUMBEA & \\
\hline \begin{tabular}{|l|} 
PAGE \\
DATEE
\end{tabular} & 5 of 7 \\
\hline
\end{tabular}

SUQUECT: CONTROL OF HEAT STRESS

\section{E.2. RESPONSIBILITIES: - continued}

NOTE: Most activities in hot environments should be conducted with a buddy who is able to observe the partner for signs of heat exposure and who will notify the supervisor if help is needed. The buddy system is optional for Level I and mandatory for Level II hot micro-environments.

(NIOSH Pub. No. 86-113, Chapter IV, $[B][4][e]$ )

3. Industrial Hygiene Department

a. Establishes a procedure for heat stress monitoring for hot environments and hot micro-environments. (ESH-7 III[D][4]; NIOSH Pub. No. 85-115 pp. 8-20, 8-21; NIOSH Pub. No. 86-113, Chapter 1, Section $1[b])$

b. Identifies hot environments by conducting routine and special heat stress surveys in various work areas. Supervision will be notified of results anci will receive recommendations for appropriate health procection measures for specific jobs. (ESH-7 III[D][3], [4]; NIOSH Pub. No. 85-115 PP. 8-20, 8-21; NIOSH Pub. No. 86-113, Chapter $1[\mathrm{~b}][4])$

c. Identifies Level II hot micro-environments by conducting routine and special heat stress surveys. Supervisor will be notified of results and any recommendations.

(ESH-7 III[D][3], [4]; NIOSH Pub. No. 85-115, pp. 8-20, 8-21)

d. Performs work area surveillance and inspections on a periodic basis to ensure that provisions of this procedure have been implemented.' (ESH-7 III[O][2])

- e. Selects, develops, and updates heat stress training materials for potential heat stress conditions. (ESH-7 III[D][8])

f. Reviews proposals submitted by the Engineering Division. (ESH-7 III[D][2])

g. Collects and maintains hot environment monitoring data for specific work areas. (ESH-7 III[D][12]; NIOSH Pub. No. 86-113, Chapter 1, Section 8[a]) 
MARTIN MARIETTA ENERGY SYSTEMS. INC. OAK RIDGE GASEOUS DIFFUSION PLANT

NUPAEA
\begin{tabular}{l}
507 \\
\hline PAGE 0 OF 7 \\
\hline DATE $02 / 90$
\end{tabular}
STANDARD PRACTICE PROCEDURE SUQUECT:

CONTROL OF HEAT STRESS

E. RESPONSIBILITIES: - continued

4. Medical Department

a. Performs physical examinations every 18 months on all employees required to work in hot environments and hot microenvironments. Exams will include a review of previous medical history with special attention given to cardiovascular and pulmonary functions, prescriptive medicines, and heat-related illnesses. Applicants for jobs involving work in hot environments or hot micro-environments must be deemed fit to perform under conditions of heat stress as a qualification for employment. (ESH-7 III[O][8]; NIOSH Pub. No. 86-113, Chapter 1, Section 2[b][c])

b. Performs special medical evaluations for all employees returning from extended periods of illness prior to working under conditions of heat stress. (ESH-7 III[D][8]; NIOSH Pub. No. 86-113, Chapter VII[B][2][a][1])

c. Provides written notification to employees and their supervisors stating the ability or inability of an employee to work under conditions of heat stress. (When work restrictions are necessary, their nature and extent are also stated.) (NIOSH Pub. No. 86-113, Chapter 1, Section 2[f])

d. Establishes and maintains physical examinations and medical evaluation records. (ESH-7 III[O][3],[12];

NIOSH Pub. No. Chapter 1 , Section $8[b-e])$

5. Engineering Division

a. Designs or modifies work areas to minimize heat stress .conditions within limits of feasibility and available technology. (ESH-7 III[D][5]; NIOSH Pub. No. 85-113, Chapter I, Section $7[$ a])

b. Submits all engineering proposals to the Industrial Hygiene Department for review. (ESH-7 III[D][1],[2],[8]) 
MARTIN MARIETTA ENERGY SYSTEMS. INC.

OAK RIDGE GASEOUS DIFFUSION PLANT

STANDARD PRACTICE PROCEDURE

\begin{tabular}{|ll}
\hline NUMBEA \\
\hline PAGE & - \\
\hline OATE & $02 / 2$ \\
\hline
\end{tabular}

SUBUECT: CONTROL OF HEAT STRESS

F. SPECIAL REQUIREMENTS: For work areas or building enclosures where there is a reasonable likelihood of combination( $s$ ) of environmental and metabolic heat exceeding the maximum limit.

1. Readily visible warning signs containing information on the required protective clothing and/or equipment, hazardous effects of heat stress on human health, and information on emergency measures for heat injury or illness will be posted in work areas and at entrances to work areas or building enclosures. (NIOSH Pub. No. 86-113, Section 4[2])

2. In any area where there is likelihood of heat stress emergency situations occurring, the warning signs required will be supplemented with signs giving emergency and first aid instructions. (NIOSH Pub. No. 86-113, Section $4[b]$ )

3. All new and current workers, who are unacclimatized to heat and to work areas where there is a reasonable likelihood of heat injury or illness, will be kept informed through continuing education programs and heat-stress safety data sheets or on a form specified by the Occupational Safety and Health Administration. (NIOSH Pub. No. 96-113, Section 6[a][C]) 
MARTIN MARIETTA ENERGY SYSTEMS. INC.

OAK RIDGE GASEOUS DIFFUSION PLANT

STANDARD PRACTICE PROCEDURE

\begin{tabular}{|c|c|}
\hline NUMBER & \\
\hline 607 & Attachment \\
\hline PAGE & 1 of 4 \\
\hline OATE & $02 / 90$ \\
\hline
\end{tabular}

SUBUECT: CONTROL OF HEAT STRESS

This rationale was developed by a Heat Stress Committee as guidelines to assist in the control of heat stress hazards by Martin Marietta Energy Systems, Inc. Committee representatives were from ORGDP, ORNL, PGDP, $Y-12$ Plant, and PORTS.

\section{RATIONALE}

1. Environmental Monitoring Parameters

Present Energy Systems' health protection procedures utilize the WBGT index to identify hot environments. Adopted values differ from site to site (i.e., $Y-12=79^{\circ} \mathrm{F}$ [Oraft], PORTS $=82^{\circ} \mathrm{F}$, ORGDP $=84^{\circ} \mathrm{F}$, PGDP $=86^{\circ} \mathrm{F}$, and ORNL = None documented). These valves were selected based on clothing customarily worn by employees when working under conditions of heat stress; none were deemed adequate to determine micro-environmental heat stress caused by wearing semipermeable or impermeable clothing, which impedes sweat evaporation. The WBGT index is heavily ( 70 percent) weighted in favor of the natural wet bulb temperature that correlates with evaporation of sweat, a primary cooling mechanism that is severely impaired by such clothing.

a. Hot Environment (Level I) - In general, researchers favor use of an adjusted dry bulb air temperature that compensates for radiant heat load. For moderate work activity levels, this measurement becomes the basis for heat stress determinations when ambient temperatures rise above normal room temperature $\left(70^{\circ} \mathrm{F}\right)$. The committee members group agreed that virtually all employees who are required to wear impermeable clothing also work in areas that are predominantly room temperature or above. Adoption of a Level I hot environment limit of $70^{\circ} \mathrm{F}$, as determined by a simple dry bulb thermometer, therefore, complies with existing guidelines, reduces the potential number of special industrial hygiene survey requests from supervision, and eliminates possible

- conflicts regarding applicability of the procedure by including everyone wearing such clothing in the micro-environmental heat stress program.

b. Hot Environment (Level II) - NIOSH recommends that a ceiling limit (WBGT) be observed for combinations of environmental and metabolic heat above which no worker will be exposed without adequate heat. protective clothing and equipment. For an acclimatized individual wearing a customary, one-layer, long-sleeved work ensemble and working at a moderate activity level (300 kcal/hour), this limit would be $98.2^{\circ} \vec{F}\left(\overline{3}^{6} .8^{\circ} \bar{C}\right)$ WBGG $\bar{T}$. When a partiaijy air andjor vapor impermeable ensemble is worn, NIOSH suggests lowering the limit by $7.2^{\circ} \mathrm{F}\left(4^{\circ} \mathrm{C}\right)$ to $91^{\circ} \mathrm{F}\left(32.8^{\circ} \mathrm{C}\right)$ WBGT and using adjusted dry bulb air 
MARTIN MARIETTA ENERGY SYSTEMS. INC.

\begin{tabular}{|c|c|c|}
\hline PUUASB & & \\
\hline 607 & At tachment & \\
\hline PACE & 2 of 4 & \\
\hline DATE & 02100 & \\
\hline
\end{tabular}

OAK RIDGE GASEOUS DIFFUSION PLANT

STANDARD PRACTICE PROCEDURE

SURECT:

CONTROL OF HEAT STRESS

temperature criteria. Kenney suggests lowering the WBGT value $12.6^{\circ} \mathrm{F}\left(T^{\circ} \mathrm{C}\right)$ for similar conditions, thus yielding $85.6^{\circ} \mathrm{F}$ $\left(29^{\circ} 8^{\circ} \mathrm{C}\right)$. Given cell floor (e.g.. PORTS $X-333$ building, $112^{\circ} \mathrm{F}$ globe temperature, $10-40$ percent relative humidity, and $100 \mathrm{fpm}$ air velocity), the ceiling limit would correspond to $110^{\circ} \mathrm{F}$ dry bulb temperature with 37 percent relative humidity under the illOSH reduction and $110^{\circ} \mathrm{F}$ dry bulb temperature with 17 percent relative humidity under Kenney's. The committee agreed that adoption of $110^{\circ} \mathrm{F}$ as a dry bulb air temperature ceiling limit was desirable and recommends that it be established as a level II hot microenvironment where cool suits/vests and the buddy system are mandatory.

2. Personal Monitoring Parameters

ilIOSH/OSHA/EPA recommend physiological monitoring for workers wearing encapsulating semipermeable or impermeable clothing when the dry bulb temperature exceeds $70^{\circ} \mathrm{F}$. Parameters include a 30 -second heart rate, oral temperature, and body water loss with acceptable maximums for each. After considering available information, committee members were not in favor of utilizing physiological, monitoring guidelines. Current heat stress programs in place at each facility do not require physiological monitoring, and a need has not been demonstrated to implement such measures. Self-paced employees trained to recognize early symptoms of heat ilinesses can remove themselves from further exposures and return to work when able to do so. Use of cool suits/vests and the buddy system should provide adequate protection under Level II conditions.

Members of the group expressed an interest in evaluating the new Metrosonics HS-383 personal heat stress monitor. This device monitors heart rate and skin temperature, logs data, interfaces with personal computers, and features visual and audible alarms to alert workers when they have approximately 10 minutes of safe work time remaining. Unit cost is less than $\$ 1500$.

3. Work-Rest Regimen/Self-Pacing

Although work-rest guidelines based on clothing ensemble, activity level, and radiant load exist (e.g., Westinghouse. [EPRI] and NIOSH/OSHA/EPA), they are difficult to administrate. Current Energy Systems' heat stress programs utflize self-pacing (sometimes called seif-determinationj. The commit̂tee agreeud that thís measure has proven adequate in preventing heat illness and recommends its use for hot micro-environmental policy. 
MARTIN MARIETTA ENERGY SYSTEMS. INC.

OAK RIDGE GASEOUS DIFFUSION PLANT

STANDARD PRACTICE PROCEDURE

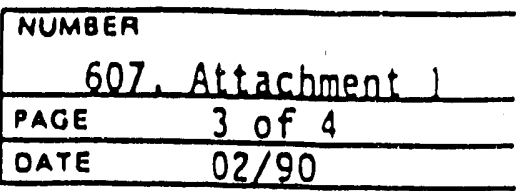

SUBNECT: CONTROL OF HEAT STRESS

4. Mandatory Heat Stress Physical Examinations

In addition to traditional aspects of heat stress exams, NIOSH/OSHA/EPA states that a "stress test" (graded exercise) may be administered at the discretion of the examining physician, particularly where heat stress may occur. Also, NIOSH recommends that examining physicians question workers regarding their reproductive history, pregnancies, and possible heat related infertility. Committee members do not advocate routine use of stress tests (even for Level II workers) or reproductive questionnaires. However, medical directors may wish to discuss the advisability of utilizing these measures.

5. Employee Education

Training currently given to workers in hot environments needs to be supplemented. Information describing stress imposed by wearing semipermeable and impermeable clothing, proper use of special personal protective equipment (e.g., cool suits/vests) and implementation of the buddy system should be given to workers in hot micro-environments. The committee agreed that reproductive considerations presented by NIOSH (pregnancy, infertility, and teratogenicity) should be included in heat stress training and embryo-fetus protection training.

6. Embryo-Fetus Protection

NIOSH presents concerns regarding heat-induced infertility, teratogenicity, and abortion. Animal experiments indicate that hyperthermia in pregnant females may result in embryo death and gross structural defects. While evidence for similar effects in humans is less convincing, recent retrospective epidemiologic studies have associated hyperthermia during the first trimester of pregnancy with birth defects, especially in central nervous system development (e.g., anencephaly). NIOSH concludes by stating that, "It appears prudent to monitor the body temperature of a pregnant worker exposed to total heat loads above the recommended exposure limit every hour or so to ensure that the body temperature does not exceed $39^{\circ} \mathrm{C}-39.5^{\circ} \mathrm{C}\left(102^{\circ} \mathrm{F}-103^{\circ} \mathrm{F}\right)$ during the first trimester of pregnancy." The comnittee members do not recommend implementation of this NIOSH suggestion. Female employees do :not typically report pregnancy untll several weeks of gestation have elapsed. Depending on potential hazards, pregnant employees may be restricted from jobs requiring personal protective clothing. Awareness of potential hyperthermia hazards appears to be the best protection option. This awareness should be promoted in heat stress and embryofetus training programs. 
MARTIN MARIETTA ENERGY SYSTEMS. INC.

\begin{tabular}{|c|c|}
\hline NUIABEA & \\
\hline 507 & ittachment 1 \\
\hline PAGE & \& of 4 \\
\hline DATE & $02 / 00$ \\
\hline
\end{tabular}
OAK RIDGE GASEOUS DIFFUSION PLANT STANDARD PRACTICE PROCEDURE SUBJECT:

\section{Cool Suits/Vests}

NIOSH recommends that personal protective equipment be required whenever the established cEiling limit is exceeded, and NIOSH/OSHA/EPA notes that under certain conditions "a cooling garment may be needed." Researchers agree that proper use of these devices promotes both comfort and safety and often increases "stay time" from a few minutes to more than one hour. The committee agreed and recommended that cool suits/vests be made available to workers in hot micro-environmenis as optional for Level I and mandatory for Level II conditions. Training programs should include specific instructions regarding proper use of selected devices.

\section{Buddy System}

MIOSH and Westinghouse (EPRI) recommend use of the buddy system under certain conditions as a preventive work practice. The committee agreed and recommended that employees be trained and/or responsible for observing fellow workers to detect early signs of heat illness such as weakness, unsteady gait, disorientation, etc. This countermeasure should be optional for Leve? I and mandatory for Level II hot micro-environments.

\section{Contractor Compliance Requirements}

Current Energy Systems' procedures for health protection in hot environinents are in apparent disagreement regarding nonemployee compliance (i.e., Paducah and Porismouth require it, whereas Oak Ridge [ORGDP] does not). NIOSH/OSHA/EPA recommends that a site safety plan, which includes measures for work in hot weather, be developed, reviewed, and approved prior to site activities. Committee members agreed to recommend that other contractors and subcontractors requiring workers to wear semipermeable or impermeable clothing be required to submit a written heat stress control program with documented evidence of proper training and mecical approval for each individual before work proceeds. Ideally, this documentation should be required by the Purchasing Department in each bid offer and submitted to Energy Systems' Health, Safety, and Environmental Affairs Division for review and approval prior to contracting the selected organization. 


\section{APPENDDX K}

\section{EXAMPLE OF QUALTLY ASSURANCE/QUALITY}

CONTROL PLAN

OAK RIDGE NATIONAL LABORATORY

OPERATED BY MARTIN MAAIETTA ENEROY SYSTEMS, INC.

POST OFFICE BOX 2008. OAK RIDGE. TENNESSEE 3783

\section{QUALITY ASSURANCE PROGRAM}

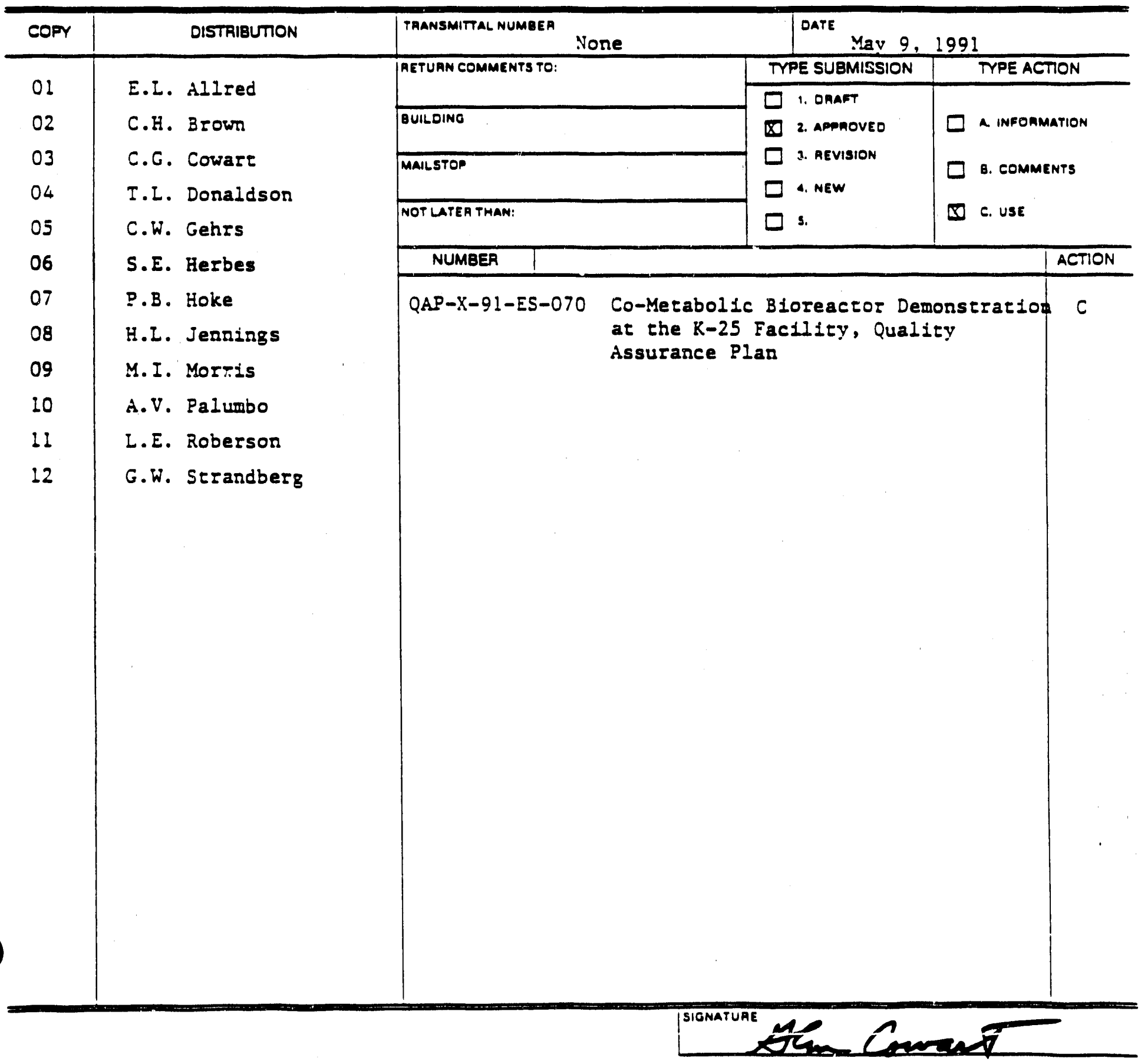


Documerit NO.: QAP-X-91-E8-070

\title{
CO-METABOLIC BIOREACTOR DEYONBTRATION \\ AT THE OAX RIDGE K-25 FACIIITY
}

\author{
QOALITY A88URANCE PLAN
}

REVIBION 0

KAY 8, 1991

S. E lieilis $=/ 3 / i$

S. E. Herbes, Project Manager Co-Metabolic Bioreactor Demonstration

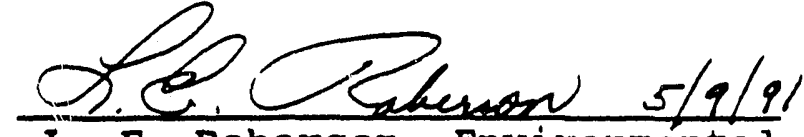

I. E. Roberson, Environmental Sciences Division Quility Assurance Specialist

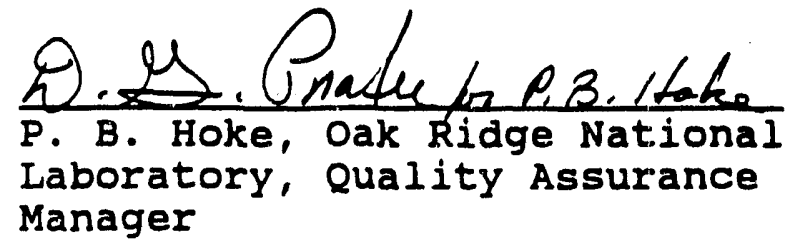

C.A. Couner $5 / 8 / 91$ C. G. Cowart, Waste Research and Development Programs Quality Assurance specialist 


\section{TABLE OF CONTENTS}

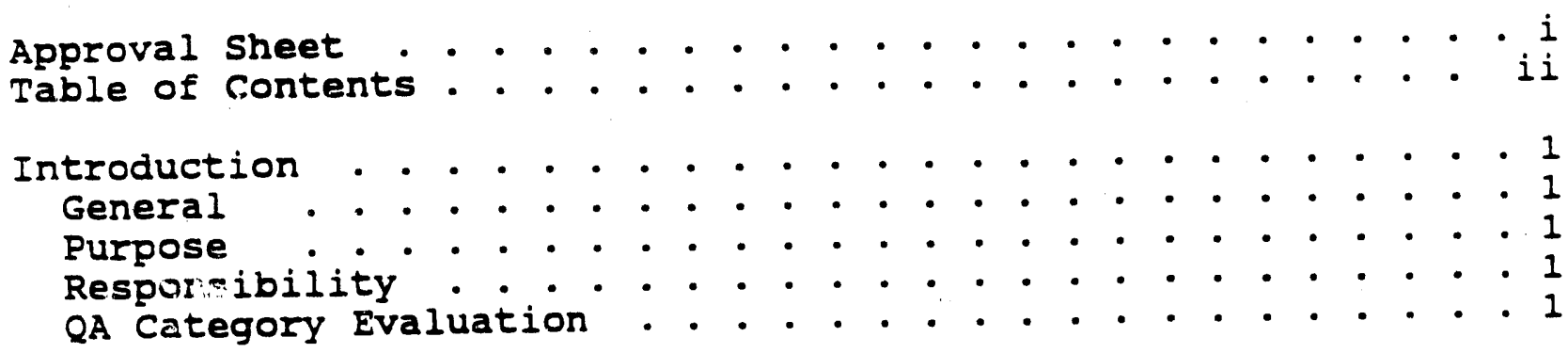

1.0 organization . . . . . . . . . . . . . . . . . . 2

1.1 General .. . . . . . . . . . . . . . . . . . . 2

1.2 Project Manager . . . . . . . . . . . . . . . . . 2

1.3 Principle Investigators . . . . . . . . . . . . . . . 2

1.4 Quality Assurance Staff . . . . . . . . . . . . . . 3

1.5 Support organizations . . . . . . . . . . . . . . 3

2.0 Quality Assurance Program . . . . . . . . . . . . . . . 4

2.1 QA Plans . . . . . . . . . . . . . . . . . . . . . . . 4

2.2 Status Reporting . . . . . . . . . . . . . . . . . . 4

2.3 Indoctrination and Training . . . . . . . . . . . . . . 4

3.0 Design Control . . . . . . . . . . . . . . . . . 5

3.1 Laboratory Studies . . . . . . . . . . . . . . . 5

3.2 Bench-scale Tests . . . . . . . . . . . . . . . 5

3.3 Field Bioreactor Demonstrations . . . . . . . . . . . . 5

3.4 Site Preparation . . . . . . . . . . . . . . . . 6

4.0 Procurement Document Control

5.0 Instructions, Procedures, Plans and Drawings . • . . 6

5.1 Project plan . . . . . . . . . . . . . . . . . . 6

5.2 Instructions and Procedures . . . . . . . . . . . . 6

5.3 Drawings . . . . . . . . . . . . . . . . . . . . 7

5.4 Reviews . . . . . . . . . . . . . . . . . . . . 7

6.0 Document Control . . . . . . . . . . . . . . . . . . . 7

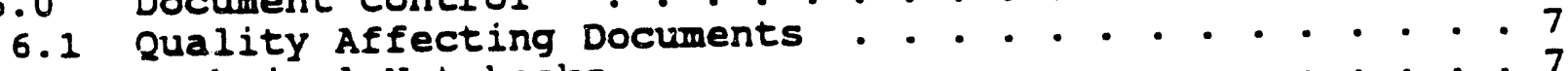

6.2 Technical Notebooks . . . . . . . . . . . . . . . . . 7

7.0 Control of Purchased Items and Services . . . . . . . . 8

8.0 Identification and Control of Materials, . . . . . . . 8

Parts, and Components

8.1 Samples and Items to be Controlled

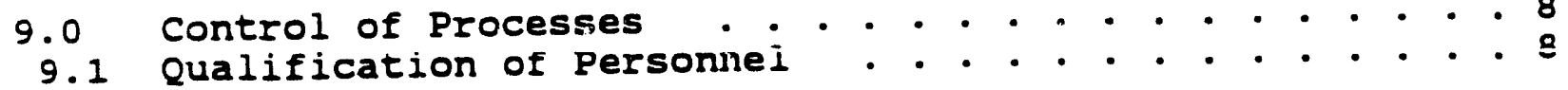


TABLE OF CONTENTS (Continued)

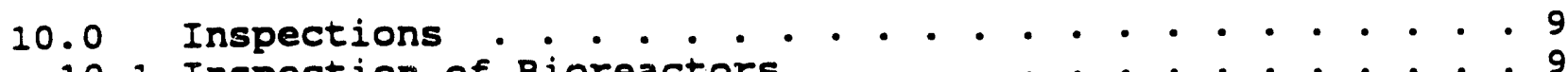

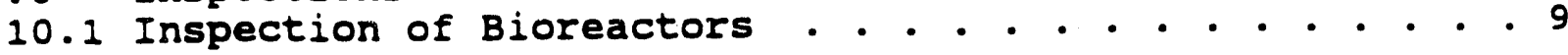

11.0 Test Control . . . . . . . . . . . . . . . . . . 9

11.1 Preoperational Testing . . . . . . . . . . . . . . . 9

12.0 Controi nf Measuring and Test Equipment . . . . . . 10

12.1 ORNL . . . . . . . . . . . . . . . . . . . 10

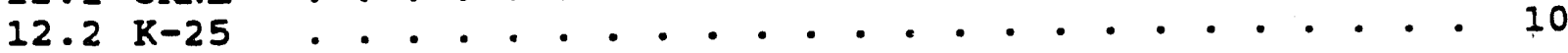

13.0 Handling, Storage, and Shipping . . . . . . . . . . 10

13.1 Sampling . . . . . . . . . . . . . . . . . . 10

13.2 Waste Materials . . . . . . . . . . . . . . . 10

14.0 Inspection, Test, and operating status . . . . . . . 11

15.0 Nonconformances and Corrective Action . . . . . . . . 11

16.0 Quality Assurance Records . . . . . . . . . . . . . 11

17.0 Audits and surveillances . . . . . . . . . . . . . 11

18.0 Software . . . . . . . . . . . . . . . . . . 11

\section{APPENDICES}

Appendix A - Organization Chart

Appendix B - QA Plan Matrix

Appendix C - Functional Reponsibilities Matrix

Appendix D - Training Record Form

Appendix E - QA Records Categories

Appendix F - Document Review Form 
INTRODUCIION

\section{GENERAL}

This demonstration project is to be conducted by Oak Ridge National Laboratory (ORNL) for the U.S. Department of Energy (DOE) Office of Technology Development in accordance with Technical Task Plan OR-369-AB. The project consists of installation and operation of two types of biological treatment systems (i.e. bioreactors), using as influent groundwater contaminated with mixed organic compounds from a seepage flow at the K-25 Plant in Oak Ridge, Tennessee. The demonstration will be conducted by ORNL staff and subcontractors in collaboration with the K-25 Health, Safety and Environmental Affairs (HS\&EA) Division and the Environmental Restoration Division.

The objective of the project is to demonstrate the effectiveness of two innovative bioremediation technologies, based on co-metabolic processes, to remediate groundwater contaminated by mixed organic solvents at DOE sites.

\section{PURPOSE}

The purpose of this QA Plan is to describe the quality assurance program applicable to this project. The Plan details the Environmental Sciences Division (ESD) policies and procedures applicable to the work and the relationship of other organization's QA programs which apply in their areas of responsibility.

\section{RESPONSIBUITY}

The Project Manager is responsible for development and implementation of this QA Plan. Although activities are delegated to others in the project organization, the Project Manager retains responsibility for compliance with the QA Plan. Responsibilities for specific project positions are detailed in section 1.0 "Organization" of the QA Plan.

\section{OA CATEGORY EVALUATION}

Based on evaluation criteria in ESD QA Procedure QA-ES-2-101, this project has been determined to be a QA Category II. 


\subsection{ORGANIZATION}

This section of the QA Plan adopts by reference the guidance in ESD procedure QA-ES-1-100. The project organization operates as a matrix and includes personnel from ORNL and K-25, as well as subcontractors. Appendix A depicts the project organizational relationships and the lines of responsibility and authority which affect the project. The key organizational positions supporting the work are described in the following paragraphs. These positions report vo the Project Manager. Other positions shown on the organization chart in Appendix A are for the purposes of reporting relationships. Subcontractors are considered a part of the project team and are thus subject to the requirements of the QA Plan.

\section{$1.1 \quad$ General}

Each project member has a line organization which is administratively responsible for that person within ORNL or K-25. The project organization, being a temporary entity, utilizes available technical expertise to accomplish the project objectives. Therefore, the project staff operates under this QA program for the life of the project.

\subsection{Project Manager}

This position resides in the Environmental Sciences Division at ORNL and has the following responsibilities.

a) Overall success and quality of the project.

b) Preparation, approval and implementation of the QA Plan.

c) Assurance that all staff are familiar with the QA program.

d) Overall coordination of the task activities and organizational interfaces.

e) Stop work when conditions which pose a hazzard to health, safety or the environment are found.

f) Compliance with Environmental, Safety and Health requirements.

\subsection{Principal Investigators}

These positions report to the Project Manager, are staffed from the Chemical Technology and Environmental Sciences Divisions at ORNL, and have the following responsibilities.
a) Quality of the technical work
b) Review of the QA Plan.
c) Implementation of and compliance with the QA Plan - both for themselves and any staff reporting to them.


d) Reporting conditions adverse to quality to the Project Manager.

e) Timely responses to any corrective actions which may be identified.

f) Assurance that the QA programs and operating procedures of support organizations are adequate for the project.

1.4 Quality Assurance Staff

These positions are represented by the Environmental Sciences Division, the Chemical Technology Division and the Waste Research and Development Programs at ORNL. The QA representatives have the following responsibilities.

a) Review and approval of the QA Plan.

b) Oversight of the QA program through audit, surveillance, review or other verification functions.

Each QA representative has sufficient authority, access to work areas and organizational freedom to:

- identify problems affecting quality

- initiate, recommend or provide solutions to problems affecting quality

- verify implementation of problem solutions

- ensure that further processing, delivery, installation, or use of an item or service is controlled until proper disposition of a nonconformance, deficiency or unsatisfactory condition has occurred.

- stop work when conditions which pose a hazzard to health, safety or the environment are found.

An interface is maintained with the K-25 QA organization to assure that information about activities affecting quality is transmitted to the host site QA representative.

Support Organizations

These organizations may include such functions as Analytical Chemistry, and Hazardous Waste Disposal. These organizations will operate under their own QA programs and their organization's standard operating procedures. They are responsible for assuring the quality of the work they perform. 


\section{QUALTIY ASSURANCE PROGRAM}

The Project Manager reports administratively through the Environmental Sciences Division, therefore a decision was made to use the ESD Quality Assurance Manual as the basic reference document for assigning QA controls to project activities. When necessary and in the best interest of the project. other participant's quality assurance programs will be referenced and used when doing work for the project providing those programs meet with the approval of project management and project $Q A$

This section of the QA Plan adopts by reference the guidance in ESD procedures QA-ES-2-100, QAES-2-101, QA-ES-2-102, and QA-ES-2-103. A modular profile of ORNL and ESD QA procedures. in relation to the NQA-1 elements, is given in procedure QA-ES-2-100 and is not reproduced in this QA Plan.

Significant responsibilities of the organizations involved in the project are presented in matrix form in Appendix C.

QA Plans

Since this is a multiple-organization project, a QA Plan Matrix is presented in Appendix $B$ to show the relationships between the various project tasks and the QA programs controlling those tasks.

2.2 Status Reporting

Status reporting will be done in accordance with procedure QA-ES-2-102. Reporting status to the sponsor is the responsibility of the Project Manager. The WR\&D Programs QAS reports project QA status through the WR\&D Programs monthly status report.

\subsection{Indoctrination and Training}

Indoctrination into the requirements of this QA Plan will be conducted by the ESD QAS (or the Project Manager) for the project staff. Training to specific project procedures. which may be developed during the course of demonstration activities, will be conducted by the Principal Investigator (or a designee) responsible for the activity. Evidence of training will be maintained as separate training records in accordance with Appendix D. Training records become QA records as they are completed. Training records will contain: who was trained, who conducted the training, the date, the subject, and document numbers and titles where appropriate. Training records will be signed by those person conducting and receiving the training.

Training records of personnel operating under separate, approved QA programs - such as Analytical services - will be maintained in their division files. 


\subsection{DESIGN CONTROL}

This section of the QA Plan adopts by reference the guidance in ESD procedure QA-ES-3-100 with specific controls and exceptions identified in the following paragraphs.

The design activities for the project include the laboratory studies, bench scale tests, and the field bioreactor systems. The controls for each of the project are described in this section. Although the laboratory studies and bench scale tests do not require design control, they do produce results which are used in the design of the field bioreactor systems and therefore they require the controls described below.

\subsection{Laboratory Studies}

This phase of the project is intended to rapidly determine optimum cultures and culture conditions for use in the bench-scale bioreactor tests through the use of batch laboratory systems. The controls for and results of this phase are documented in a controlled laboratory notebook. The notebook will include all necessary information to assure reproducibility of the studies and includes the results of the studies; the notebook will be reviewed quarterly and approved by the Project Manager or a qualified, designated alternate and any changes made will be initialed and dated. Reviews are to assure that the information presented in the notebook is understandable, legible, reasonable and is sufficient to allow the work presented to be continued or reproduced by another qualified individual. The Laboratory notebooks will conform to the guidance of QA procedure QAES-6-100 and will be maintained as project QA records.

\subsection{Bench-Scale Tests}

This phase of the project is intended to select the cultures to be utilized in the field bioreactor systems and to identify operating parameters of those systems. The controls for and results of this phase are documented in a controlled laboratory notebook. The notebook will include all necessary information to assure reproducibility of the studies and includes the results of the studies; the notebook will be reviewed quarterly and approved by the Project Manager or a qualified, designated alternate and any changes made will be initialed and dated. Reviews are to assure that the information presented in the notebook is understandable, legible, reasonable and is sufficient to allow the work presented to be continued or reproduced by another qualified individual.. Laboratory notebooks will conform to the guidance of QA procedure QA-ES-6-100 and will be maintained as project QA records.

\subsection{Field Bioreactor Systems}

This phase of the project will yield the results necessary to evaluate the bioreactor systems and make recommendations for their continued development and use. Therefore, control of the configuration of these systems is important to the success and replicability of these demonstrations, and to translation of the design into production systems, if necessary. Existing bioreactor units will be used in the demonstrations, with modifications and additions appropriate to the specific requirements of the processes to be demonstrated and evaluated. The design of these systems will be detailed in drawings and specifications as 
necessary. Requirements for identification and approval of drawings are detailed in section 5.3 of this QA Plan.

It is not expected that the MMES Engineering Division will be used to produce system drawings. However, system schematics, flow charts and other drawings determined to be appropriate for describing the demonstration configurations will be produced within the Chemical Technology Division (CTD) according to CTD procedures.

\subsection{Site Preparation}

Modifications to the site to accommodate the field bioreactor systems and their protective housing, and updates to any K-25 site drawings as a result of site preparation are the responsibility of K-25. The ORNL project manager's responsibility is to assure that requirements adequate to site the field bioreactor systems are transmitted to the K-25 Plant \& Equipment Division, and to assure that the modifications are being performed as required.

\subsection{PROCUREMENT DOCUMENT CONTROL}

This section of the QA Plan adopts by reference the guidance in ESD procedure QA-ES-4-100. Procurement activities will be conducted in accordance with the above procedure. Where procurement responsibility is delegated to the Principal Investigators in the Chemical Technology Division, procurement will be conducted in accordance with ORNL QA procedure QA-L-4-100. The Project Manager retains responsibility for review of all project procurements.

\subsection{INSTRUCTIONS, PROCEDURES AND DRAWINGS}

This section of the QA Plan adopts by reference the guidance in ESD procedure QA-ES-5-100 and ESD administrative procedures concerned with the preparation of procedures. These procedures will be followed to produce any new instructions, procedures or drawings developed for the project. Amplifications and exceptions are described below.

\subsection{Project Plan}

The project plan is the key guidance document for the project and therefore requires a documented technical review to assure that it is adequate for the work and acceptable to all organizations affected by its implementation.

\subsection{Instructions and Procedures}

When instructions or procedures are to be produced by organizations outside of ESD, they may be produced in accordance with that organization's methods providing those methods satisfy the requirements of the referenced ESD procedures. All new instructions and procedures will be subject to review and approval by the Project Manager or a qualified. designated alternate. 
Existing procedures may be adopted for use after review and approval by the Project Manager. Approval for these adopted procedures will consist of the Project Manager signing and dating the title page of the procedure.

5.3 Drawings

System schematics, flow charts and other drawings will be produced within the Chemical Technology Division (CTD) according to CTD procedures. CTD procedures will be reviewed and concurred with by the Project Manager prior to implementation on this project. All schematics, flow charts and other drawings will be identified by: title, document number, revision, and date; and will have an approval block. All drawings are subject to review and approval by the Project Manager.

$5.4 \quad$ Reviews

All instructions, procedures and drawings prepared or adopted for use on this project will be reviewed and approved. Reviews of instructions, procedures, plans and drawings will be documented on the review form shown in Appendix F. The Project Manager is responsible for reviews, and he or a qualified, designated alternate will select reviewers appropriate to the subject matter.

\subsection{DOCUMENT CONTROL}

This section of the QA Plan adopts by reference the guidance in ESD procedures QA-ES-6-100 and QA-ES-6-101. For this project, the Project Manager is the individual resonsible for assuring that documents affecting quality are reviewed, approved and distributed. The Project Manager is also the authority for release of such documents.

Quality affecting documents such as instructions, procedures, drawings and plans are controlled by the Project Manager, or a designated alternate. A controlled documents list will be maintained by the Project Manager or a designated alternate to identify the operating procedures to be used by this project. These will include procedures such as those for preparation, review and approval of drawings and sketches; and sampling procedures. As drawings are produced and approved they will also be included in the controlled documents listing. The controlled document listing will include, as a minimum, the title, revision, date, distribution and responsible individual for each document. Controlled documents will also become a part of the QA Records system.

6.2 Technical Notebooks

Registered technical notebooks will be assigned to individual investigators who are responsible for the protection of the notebooks. The notebooks are controlled during use and become QA records when complete. These notebooks are peer reviewed quarterly and copies are made at that time of all pages completed since the last quarterly review. The copies are transmitted to the project manager for inclusion in the QA records file. 


\subsection{CONTROL OF PURCHASED ITEMS AND SERVICES}

This section of the QA Plan adopts by reference the guidance in ESD procedure QA-ES-7-100. Control of procured items and services will be accomplished in accordance with the above procedure. Where procurement responsibility has been delegated to the Principal Investigators in the Chemical Technology Division, procurement will be conducted in accordance with ORNL QA procedures QAL-7-100, QA-L-7-101 and QA-L-7-102. The Project Manager retains responsibility for the acceptability of all items and services receiv $2 d$.

\subsection{IDENTIFICATION AND CONTROL OF ITEMS}

This section of the QA Plan adopts by reference the guidance in ESD procedure QA-ES-8-100. Procedures detailing specific sampling protocols - including collection, identification, handling, storage and dispossal - will be developed prior to commencement of field bioreactor operations. These procedures will be developed in accordance with Section 5 of this QA Plan. These procedures will be identified and controlled through a controlled documents list as described in Section 6 of this QA Plan.

\subsection{Samples and Items to be Controlled}

Samples and any fabricated or purchased items, determined by the Project Manager or the Principal Investigators to require control, will be identified in the operating procedures and controlled in accordance with the specifics of those procedures. The project Sampling Plan will include these procedures and any requirements for chain-of-custody.

\subsection{CONTROL OF PROCESSES}

This section of the QA Plan adopts by reference the guidance in ESD procedure QA-ES-9-100. For this project, operation of the field bioreactors and the sampling activities, are considered to be special processes since they are specialized techniques which are highly dependent on the skill of those personnel performing the operations. These processes will be controlled through project plans and procedures. The documentation produced to control these processes will be prepared in accordance with Sections 5 and 6 of the QA Plan.

\section{$9.1 \quad$ Qualification of Personnel}

Personnel selected by the Project Manager to perform the processes necessary to collect the information on which to base evaluations of the bioreactor systems will be qualified to perform those processes. Their qualifications will be documented in the project QA records file. Should personnel certifications be required, they will also be documented and maintained in the project QA records file. 


\subsection{INSPECTION}

This section of the QA Plan adopts by reference the guidance in ESD procedure QA-ES-10-100. The Project Manager or a designated alternate is responsible for determining those i:ems, either fabricated or purchased, requiring inspection; and for assuring that inspections are performed by qualified staff. Inspection plans and reports (appropriate to the item inspected) will be prepared and completed in accordance with QA-L-10-100. Inspection plans will identify, as a minimum: what is to be inspected, the inspection criteria, who is to perform the inspection, and when and where the inspection will be conducted. Inspection plans will be approved and dated. Inspection reports will also address each of the areas described in inspection plans.

\subsection{Inspection of Bioreactors}

The field bioreactor systems are existing devices which are being obt/ined from sources outside of ORNL; and modifications, pertinent to these demonstrations, will be made prior to system start-up. Therefore, these systems will be inspected by qualified personnel at ORNL prior to delivery to the K-25 site, and the inspections will be documented.

\subsection{TIEST CONTROL}

This section of the QA Plan adopts by reference the guidance in ESD procedure QA-ES-11-100. The tests to be conducted for this project are the demonstrations of the bioreactor systems. These systems will be tested at K-25 to determine their capabilities to remove the contaminants of interest from the groundwater. The controls governing the tests will be described in test plans. The test plans will be developed in accordance with the above procedure and will receive reviews in accordance with Section 5 of the QA Plan. Test plans and test reports will become QA records. Test plans will identify, as a minimum: what is to be tested, the test criteria, who is to perform the test, and when and where the test will $b$ : conducted. Test plans will be approved and dated. Test reports will also address each of the areas described in test plans.

\subsection{Preoperational Testing}

In addition to the inspections identified in paragraph 10.1 above, the field bioreactor systems will also be subjected to tests appropriate to determine if they can be operated safely and that the modifications made to the units will perform as required. 


\section{CONTROL OF MEASURING AND TEST EOUIPMENT}

This section of the QA Plan adopts by reference the guidance in ESD procedure QA-ES-12-100. The Principal Investigators, using Measuring \& Test Equipment (M\&TE) on this project, are responsible for assuring that each piece of M\&TE is identified and properly labeled, that calibrations occur as planned, and that calibration records are captured for inclusion in the project QA records file.

\section{$\underline{\text { ORNL }}$}

M\&TE used at ORNL will be identified and tagged as either category A, B or C. Category B equipment will be put on the Instrumentation and Controls Division's recall system. Category $A$ and $C$ equipment will be identified in the test plans and procedures requiring that equipment.

\section{$\underline{\mathrm{K}-25}$}

M\&TE used at the $K-25$ bioreactor test site will be identified and tagged as either category A, B or C. Category B equipment will be put on the K-25 recall system. Category $A$ and $C$ equipment will be handled as in 12.1 above.

\subsection{HANDLING, STORAGE AND SHIPPING}

This section of the QA Plan adopts by reference the guidance in ESI procedure QA-ES-13-100. The Project Manager and Principal Investigators will identify those instances which require documented handling, storage or shipping controls. These situations will either be addressed using existing procedures or new procedures will be developed in accordance with Section 5 of the QA Plan. Areas expected to require documented controls are described below.

\subsection{Sampling}

Procedures for sampling, identified under Section 8 of the QA Plan, will include special handling, storage or shipping requirements.

\subsection{Waste Materials}

Procedures for handling, storage and shipping of contaminated influent groundwater which must be disposed after the bioreactor systems demonstrations - will either be addressed using existing procedures or new procedures will be developed in accordance with Section 5 of the QA Plan. A Waste Management Plan will be developed for the project. 


\subsection{INSPECTION, TEST AND OPERATING STATUS}

This section of the QA Plan adopts by reference the guidance in ESD procedure QA-ES-14-100. It is expected that a readiness review will be conducted prior to start-up of the field bioreactor systems at K-25. The readiness review will be palnned and conducted by K-25 personnel in accordance with their readiness review procedures.

\subsection{NONCONFORMANCES AND CORRECTIVE ACTIONS}

This section of the QA Plan adopts by reference the guidance in ESD procedure QA-ES-15-100. The Quality Event Report (QER) and the Quality Investigation Report (QIR) specified in QA-ES14-100 are no longer used at ORNL and are excluded from this project. The Occurrence Reporting System described in QA-L-16-100 will be used. Nonconformance Reports are still applicable and will be prepared in accordance with procedure QA-L-15-100.

\subsection{QA RECORDS}

This section of the QA Plan adopts by referr nce the guidance in ESD procedure QA-ES-16-100. The QA records categories expected for the project are given in Appendix $E$ with the location of the master and duplicate file points.

\subsection{AUDITS AND SURVEULANCES}

This section of the QA Plan adopts by reference the guidance in ESD procedure QA-ES-17-100. Surveillances will be scheduled based on the activities underway but will be conducted at least every six months. Surveillance teams will include both QA and technical representatives. The Project Manager and QA representatives will coordinate scheduling surveillances at appropriate times.

\subsection{SOFTWARE}

This section of the QA Plan adopts by reference the guidance in ESD procedure QA-ES-18-100. No software is expected to be developed for use on this project. Any technical software that is used on the project will be verified with appropriate tests to assure confidence that it is producing results consistent with requirements. Verifications will be documented as directed by the Project Manager but will contain the following as a minimum: 1) what software was verified, 2) what the requirements were, 3) what tests were performed, 4) what the results were, and 5) what corrections were made, if needed. 


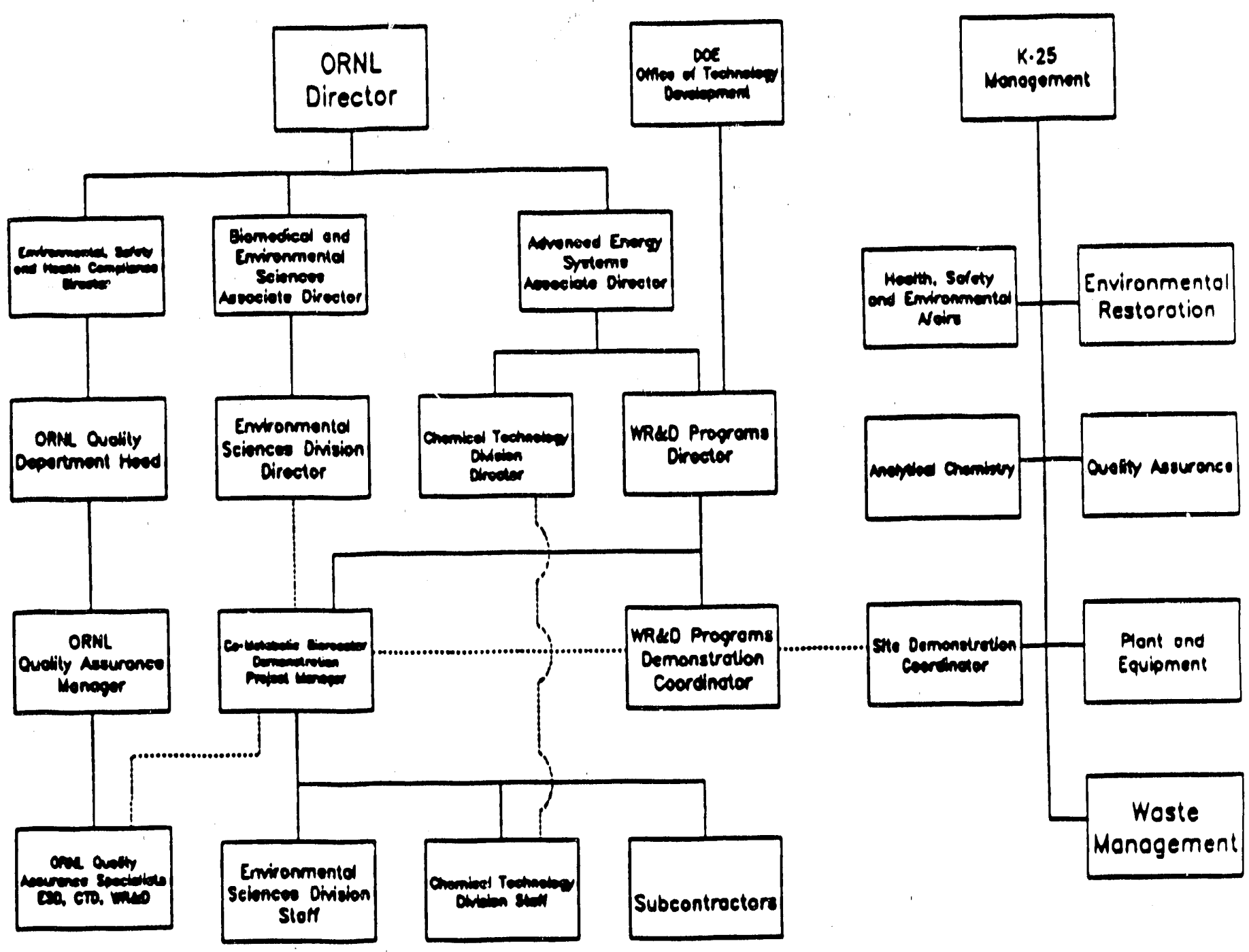

Roperting 


\section{APPENDIX B}

\section{QA PLAN MATRIX}

\begin{tabular}{|c|c|c|}
\hline Task/Activity & $\begin{array}{l}\text { Responsible } \\
\text { Organization }\end{array}$ & $\begin{array}{l}\text { QA Plan } \\
\text { Title/QAP No. }\end{array}$ \\
\hline $\begin{array}{l}\text { Project Management and } \\
\text { Permitting }\end{array}$ & ESD & QAP-X-91-ES-070 \\
\hline $\begin{array}{l}\text { Laboratory and Bench } \\
\text { scale Studies }\end{array}$ & ESD & QAP-X-91-ES-070 \\
\hline Field Bioreactor Design & CTD & QAP-X-91-ES-070 \\
\hline Site Preparation & $\mathrm{K}-25$ & QAP : 07-91-XXX \\
\hline Waste Disposal & $\mathrm{K}-25$ & QAP : 45-91-003 \\
\hline Analyses & $\mathrm{k}-25$ & QAP : $04-91 \cdots X X X$ \\
\hline Utilities & $\mathrm{k}-25$ & QAP : $25-91-X X X$ \\
\hline $\begin{array}{l}\text { Field Bioreactor } \\
\text { operations }\end{array}$ & CTD & QAP-X-91-ES-070 \\
\hline Final Reporting & ESD & QAP-X-91-ES-070 \\
\hline Site Decontamination & CTD & QAP $=X-91-E S-070$ \\
\hline & & \\
\hline
\end{tabular}




\section{APPENDIX C}

FUNCTIONAL RESPONSIBILITIES MATRIX

\begin{tabular}{l}
\hline $\mathrm{P}=$ Prepare/Perform \\
$\mathrm{A}=$ Approve \\
$I=$ Input \\
$\mathrm{R}=$ Review \\
$\mathrm{S}=$ Surveillance \\
$D=$ Distribute
\end{tabular}

Document/Action

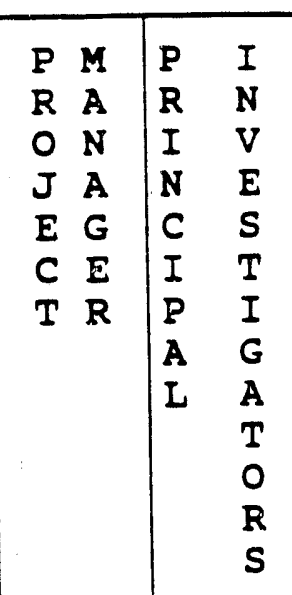

$\begin{array}{ll}S & O \\ U & R \\ P & G \\ P & A \\ O & N \\ R & I \\ T & Z \\ & A \\ T \\ T \\ O \\ N \\ N \\ S\end{array}$

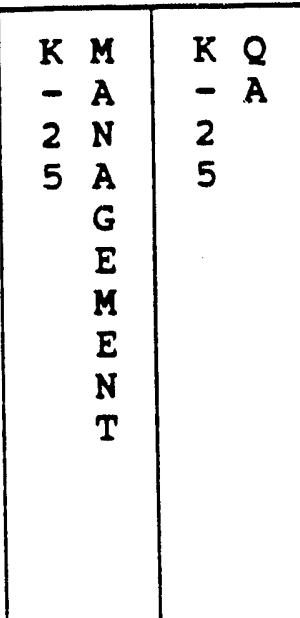

\begin{tabular}{|c|c|c|c|c|c|c|c|c|}
\hline QA Plan & $P / R / A$ & $\mathbf{R}$ & & $\begin{array}{l}P / R / A \\
D\end{array}$ & & $\mathbf{R}$ & t & \\
\hline Drawings/sketches & $R / A$ & $\mathbf{P}$ & & & & & & \\
\hline Purchase Documents & $\mathbf{R} / \mathbf{A}$ & $\mathbf{P}$ & & $\mathbf{R} \star$ & & & & \\
\hline Failure Reports & $\mathbf{P}$ & I & $I$ & $\mathbf{R}$ & & & & \\
\hline Corrective Action & $\mathbf{P} / \mathbf{A}$ & $P / I$ & $I$ & $\mathbf{R} / \mathbf{A}$ & & & & \\
\hline Document Control & $\mathrm{P}$ & $\mathbf{P}$ & $\mathbf{P}$ & $\mathbf{s}$ & & & & \\
\hline QA Records & $\mathbf{P}$ & & & $\mathbf{S}$ & & & & \\
\hline $\begin{array}{l}\text { Bioreactor } \\
\text { operations }\end{array}$ & $\mathbf{R}$ & $\mathbf{p}$ & $\mathbf{P}$ & $\mathbf{S}$ & & & & \\
\hline Document Reviews & $\mathbf{P}$ & $\mathbf{P}$ & & $\mathbf{P}$ & & & & \\
\hline Sampling Control & $\mathbf{R}$ & $\mathbf{P}$ & $\mathbf{P}$ & $\mathbf{s}$ & & & & \\
\hline Chemical Analyses & $\mathbf{R}$ & $\mathbf{R}$ & $\mathbf{P}$ & & & & & \\
\hline $\begin{array}{l}\text { Site Preparation and } \\
\text { Utilities }\end{array}$ & $\mathbf{R}$ & $I$ & & & $\mathbf{P}$ & & & \\
\hline Permitting & I & $I$ & $\mathbf{P}$ & & $\mathbf{P} / \mathbf{A}$ & & & \\
\hline Waste Disposal & I & I & & & $\mathbf{P}$ & & & \\
\hline Audit/Surveillance & $I$ & $P / I$ & & $P / I$ & & I & & \\
\hline
\end{tabular}




\section{APPENDIX D}

\section{TRAINING RECORD FORM}

\begin{tabular}{|c|c|}
\hline & $\begin{array}{l}\text { TRAINING RECORD FORM } \\
\text { Cometabolism of TCE Project }\end{array}$ \\
\hline \multicolumn{2}{|l|}{ Date(s) of Training: } \\
\hline Trainee: & Trainer. \\
\hline \multicolumn{2}{|c|}{ Provess or Procedure (Number or Title): } \\
\hline \multicolumn{2}{|l|}{ Location of Training: } \\
\hline \multicolumn{2}{|l|}{ Comments: } \\
\hline Signature of Traince: & Date: \\
\hline Signature of Trainer. & Date: \\
\hline
\end{tabular}

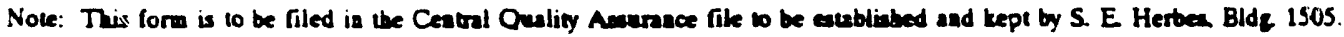




\section{APPENDIX E}

\section{QA RECORDS CATEGORIES}

\begin{tabular}{|c|c|c|c|}
\hline \multicolumn{2}{|l|}{$\begin{array}{l}\text { Retention period (RP) } \\
\text { Master File Point } \\
\text { Duplicate File Point }\end{array}$} & \multicolumn{2}{|c|}{$\begin{array}{l}\text { L (lifetime) or NP (non-permanent), } \\
\text { if NP, state number of years } \\
\text { Location of the project record file } \\
\text { Location of the duplicate record file }\end{array}$} \\
\hline Name of Record & $\mathbf{R P}$ & Master File Point & Duplicate File Point \\
\hline Test Plans & I & Bldg, 1505, Room 386 & Bldg. 3017 , Room 3 \\
\hline Test Reports & L & Bldg. 1505, Room 386 & Bldg. 3017 , Room 3 \\
\hline Calibration Reports & L & Bldg. 1505, Room 386 & Bldg. 3017, Room 3 \\
\hline Inspection Reports & L & Bldg. 1505, Room 386 & Bldg. 3017 , Room 3 \\
\hline $\begin{array}{l}\text { Personnel Qualification } \\
\text { Records }\end{array}$ & I & Bldg. 1505, Room 386 & Bldg. 3017 , Room 3 \\
\hline $\begin{array}{l}\text { Failure Reports - } \\
\text { Occurrence Reports or } \\
\text { Nonconformance Reports }\end{array}$ & L & Bldg. 1505, Room 386 & Bldg. 3017 , Room 3 \\
\hline $\begin{array}{l}\text { Corrective Action } \\
\text { Reports }\end{array}$ & L & Bldg. 1505, Room 386 & Bldg. 3017 , Room 3 \\
\hline $\begin{array}{l}\text { Audit and Surveillance } \\
\text { Plans and Reports }\end{array}$ & I & Bldg. 1505, Room 386 & Bldg, 3017, Room 3 \\
\hline $\begin{array}{l}\text { Readiness Review Plans } \\
\text { and Reports }\end{array}$ & L & Bldg. 1505, Room 386 & Bldg. 3017, Room 3 \\
\hline $\begin{array}{l}\text { Instructions, Drawings } \\
\text { and Procedures }\end{array}$ & I & Bldg. 1505, Room 386 & Bldg. 3017 , Room 3 \\
\hline Document Reviews & $\mathrm{L}$ & Bldg. 1505, Room 386 & Bldg. 3017, Room 3 \\
\hline Procurement Documents & L & Bldg. 1505, Room 386 & Bldg. 3017 , Room 3 \\
\hline QA Plan & L & Bldg. 1505, Room 386 & Bldg. 3017 , Room 3 \\
\hline $\begin{array}{l}\text { Chain-of-Custody } \\
\text { Documentation }\end{array}$ & L & Bldg. 1505, Room 386 & Bldg. 3017, Room 3 \\
\hline Analytical Reports & L & Bldg. 1505, Room 386 & Bldg. 3017 , Room 3 \\
\hline Laboratory Notebooks & L & Bldg. 1505, Room 386 & Bldg. 3017 , Room 3 \\
\hline Waste Disposal Plan & L & Bldg. 1505, Room 386 & Bldg. 3017 , Room 3 \\
\hline Decommisioning Plan & L & Bldg. 1505, Room 386 & Bldg. 3017, Room 3 \\
\hline
\end{tabular}




\section{APPENDIX E (Continued)}

\section{QA RECORDS CATEGORIES}

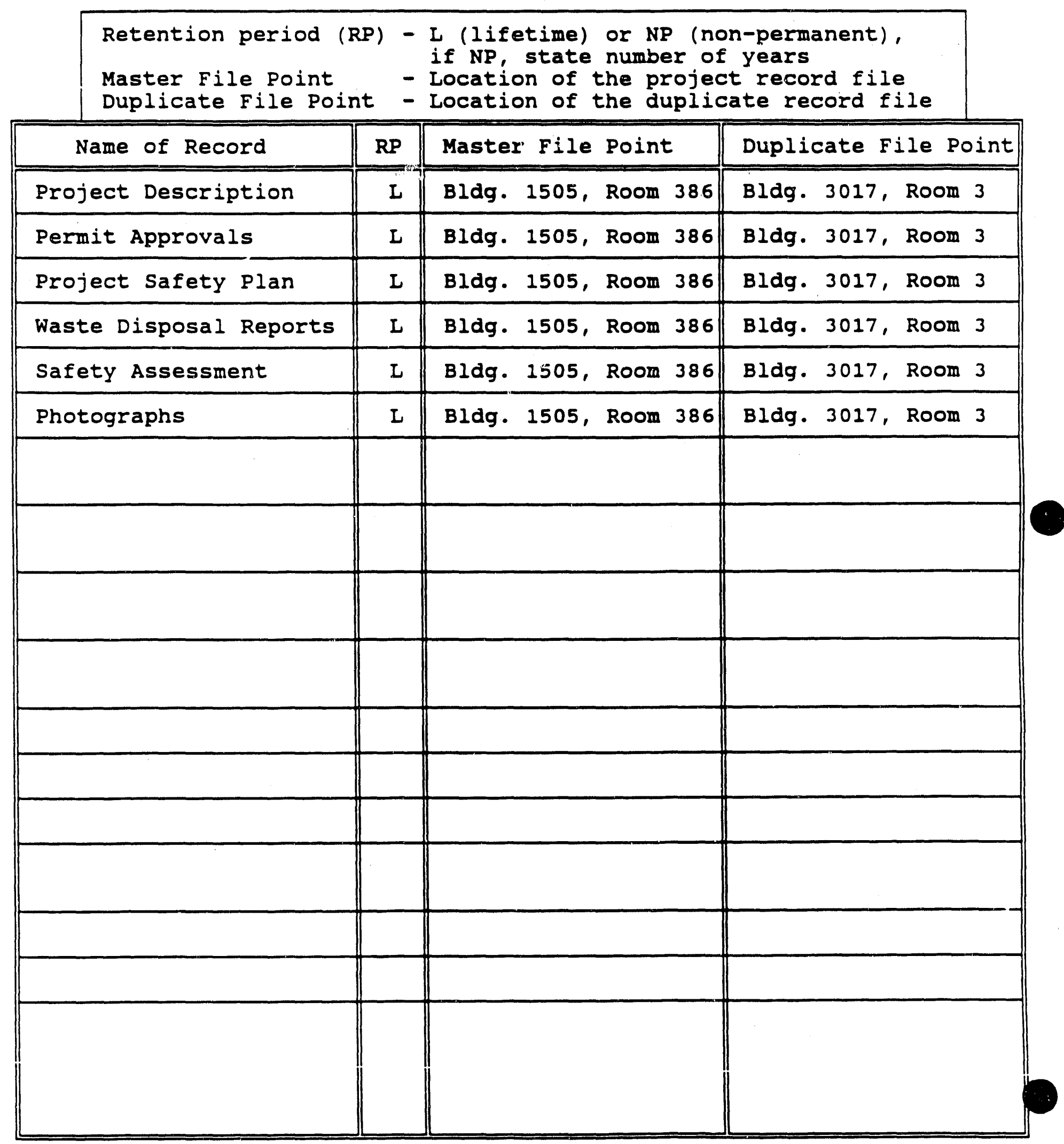




\section{APPENDIX F}

\section{DOCUMENT REVIEW FORM}

\section{DOCUMENT REVIEW FORM \\ Cometabolism of TCE Project}

\section{Route To:}

From:

Subject: Please review the attached document for clarity, technical accuracy, and objectivity based on its class. Feel free to comment on the makeup and mode of presentation. Please return the completed form to me by Thank you.

Title:

Author(s):

CLASS: Memo ORNL/TM External Publication Drawing Other ORNL

COMMENTS: (Use additional pages if necessary.) 


\title{
APPENDIX L \\ EXAMPLE OF READINESS REVIEW PLAN
}

CO-METABOLIC TECHNIQUES FIELD DEMONSTRATION FACILITIES

The Operational Readiness Team

Plan Completed - September 9, 1991

\author{
Prepared for the \\ Readiness Review Boaid \\ for the \\ Co-Metabolic Techniques Field Demonstration Facilities
}

\author{
Prepared by the \\ Operational Readiness Team \\ Co-Metabolic techniques Field Demonstration Facilities \\ Oak Ridge, TN \\ managed by \\ MARTIN MARIETTA ENERGY SYSTEMS,INC. \\ for the \\ U.S. DEPARTMENT OF ENERGY
}




\section{Readiness Review Plan}

for the

Co-Metabolic Techniques Field Demonstration Facilities

Effective Date of Plan:

Approvals:

M. I. Morris, ORT Chairman

W. A. Miller, RRB Chairman 


\section{CONTENTS}

1. INTRODUCTION $\ldots \ldots \ldots \ldots \ldots \ldots \ldots \ldots \ldots \ldots \ldots \ldots \ldots \ldots \ldots \ldots \ldots$

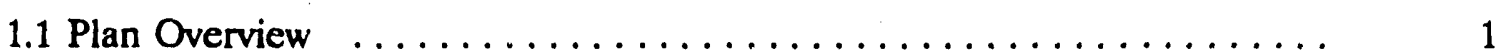

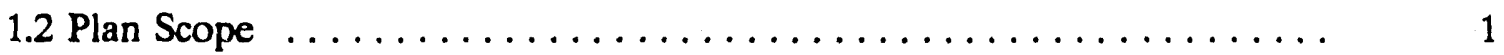

1.3 Overview of the Co-Metabolic Techniques Field Demo .......... 1

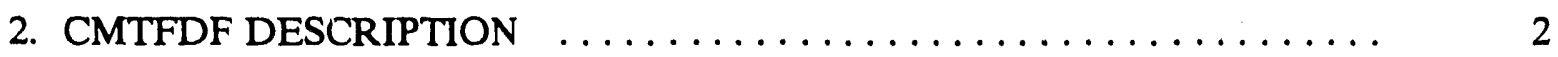

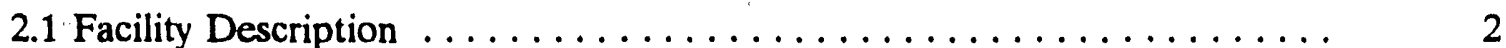

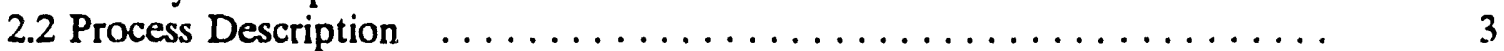

Figure 2.1 Process Flow Sheet $\ldots \ldots \ldots \ldots \ldots \ldots \ldots \ldots \ldots \ldots$

3. PROGRAM MANAGEMENT $\ldots \ldots \ldots \ldots \ldots \ldots \ldots \ldots \ldots \ldots \ldots \ldots$

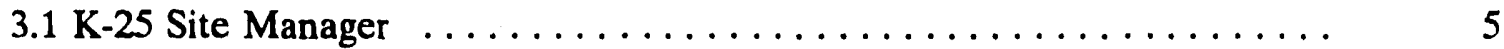

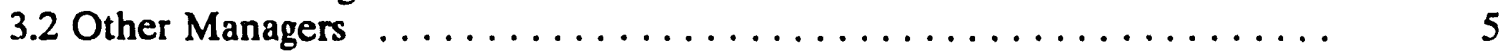

3.3 The Readiness Review Board(RRB) $\ldots \ldots \ldots \ldots \ldots \ldots \ldots \ldots \ldots \ldots$

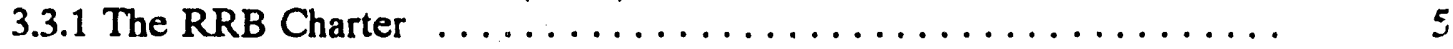

3.3.2 The Board Members $\ldots \ldots \ldots \ldots \ldots \ldots \ldots \ldots \ldots \ldots \ldots$

3.4 The Operational Readiness Team (ORT) $\ldots \ldots \ldots \ldots \ldots \ldots \ldots \ldots$

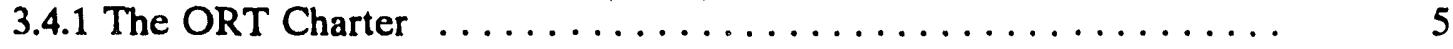

3.4.2 The Team Members $\ldots \ldots \ldots \ldots \ldots \ldots \ldots \ldots \ldots \ldots \ldots$

3.5 The RRB and ORT Interface $\ldots \ldots \ldots \ldots \ldots \ldots \ldots \ldots \ldots \ldots$

4. THE REVIEW METHODOLOGY $\ldots \ldots \ldots \ldots \ldots \ldots \ldots \ldots$

4.1 The Operational Readiness Process $\ldots \ldots \ldots \ldots \ldots \ldots \ldots \ldots \ldots \ldots \ldots$

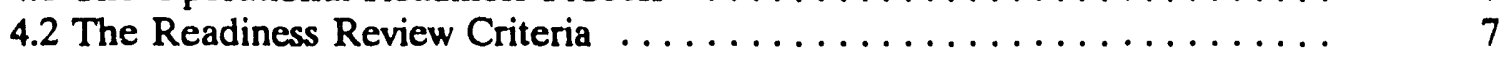

4.2.1 The Operational Readiness Tree for the CMTFDF .......... 7

4.2.2 Readiness Review Criteria to be Evaluated ............. 7

Figure 4.1 CMTFDF Readiness Tree $\ldots \ldots \ldots \ldots \ldots \ldots \ldots \ldots$

Appendix A Readiness Review Criteria for the Facilities and Equipment

Appendix B Readiness Review Criteria for the Managerial/Regulatroy Control Systems and Procedures

Appendix C Readiness Review Criteria for the Personnel 


\subsection{PLAN OVERVIEW}

\section{INTRODUCTION}

Martin Marietta Energy Systems, Inc. Policy GP-24 "Operational Readiness Process" requires activities to follow a formal, focused or comprehensive readiness process to determine an activities readiness to proceed to the next increment of work when management determines that it is necessary. The policy is aimed at reducing the risks associated with mission success and requires a management approved "readiness plan" to be issued which (1) describes the activity under review (2) defines the scope of the process (3) identifies the team members (4) establishes organizational responsibilities (5) defines the methodology and criteria to be used for determining readiness (6) and defines the events which must take place to complete the process.

This Readiness Review Plan for th. Co-Metabolic Techniques Field Demonstration Facilities (CMTFDF) located in the parking lot of building 1098-D complies with GP-24 and the applicable customer requirements. This plan was prepared by the CMTFDF Operational Readiness Team, established by the project team, to provide K-25 Site management and the K-25 Site Readiness Review Board information on the teams plan for ensuring that the CMTFDF will be ready to operate (as defined by the scope of this plan) when the formal readiness review process is completed. This plan together with progress reports that will be prepared by the review team on the CMTFDF readiness status will enable the Readiness (Name of Activity) Review Board to conduct it's independent assessment of the CMTFDF readiness to operate successfully and safely in accordance with the CMTFDF objectives.

This plan provides an overview of the CMTFDF project, the major milestones which must be accomplished for readiness, the methodology used to develop the criceria and the events which must take place as part of the review process to determine readiness for each phase of operation. The Operational Readiness Process schedule will be kept by field demonstration project engineer, $\mathrm{H}$. L. Jennings, and is available for review at trailer facility.

\subsection{PLAN SCOPE}

Before the CMTFDF can begin operation, there has to be documented evidence that DOE, EPA, and TDHE concerns have been addressed; applicable permits and environmental documentation have been issued and procedures are in place specifically addressing the safe operation of these facilities: Safety, Utilities, Industrial Hygiene, Environmental Management, Health Physics, and Quality Assurance personnel have reviewed the facilities and plans; construction materials, used on the facilities, and equipment, used in the facilities, have been tested for their intended use; support personnel have been identified; a records system is in place; safety requirements have been met; and all support documentation has been completed. This plan has been prepared to ensure the safe and successful operation of the CMTFDF after the above requirements have been satisfied.

\subsection{OVERVIEW OF THE CMTFDF PROJECT}

The purpose of the Co-Metabolic bioreactor demonstration project is to demonstrate the effectiveness of bioremediation technologies, based on co-metabolic processes, for treatment of groundwater contaminated by mixed organic solvents. The project consists of installation and 
operation of two types of bioreactors. Groundwater contaminated with mixed organic compounds from the seep located adjacent to the eastern boundary of the building K-1098-D parking lot at the K-25 Site will be used as influent to the bioreactors. Effluent from the bioreactors will then be collected and transported to the K-25 CNF facility for additional treatment and discharge. All the equipment for the CMTFDF excluding tankage will be housed in a van trailer. The effluent collection systems (tankage) will be located in a 90 day accumulation area or a satellite storage area.

\section{CMTFDF DESCRIPTION}

\subsection{FACILITY DESCRIPTION}

The CMTFDF project will consist of the operation of two bioreactor units. During the first phase of the project a single bioreactor unit with methanotrophs will be operated. During the second phase, a bioreactor unit charged with toluene-utilizers or one bioreactor unit of each type will be operated. Each unit will consist of:

- piping from the seep to the bioreactor unit,

- an influent pump and associated valves and controls,

- a pretreatment filter, air oxidation unit (aeration tank), steam stripper, or another pretreatment option if needed,

- the bioreactors,

- up to five standard $300 \mathrm{ft}^{3}$ compressed gas cylinders for the carbon substrate $(3 \%$ methane in air) or a 55-gallon drum containing dilute aqueous toluene solution,

- an off-gas scrubber (if required by the air discharge permit),

- piping and valves for operation in recycle mode,

- piping and containers for the collection of effluent,

- $\quad$ safety monitoring instrumentation and process controls.

Two skid-mounted bioreactor units, each consisting of two columns ( $\approx 12$ inches diameter by 7 feet high) plus associated plumbing, pumps, and control panel will be used. These units will be housed in a van trailer to provide protection from inclement weather. The bioreactor will serve as the primary confinement. A stainless steel drip pan beneath each skid with the trailer will serve as secondary confinement. The drip pans will drain to a sump with a capacity of 55 gallons. Ventilation for the trailer will be provided by an exhaust fan mounted in the back door.

The utilities required are (1) process water for preparation of nutrient solutions and general equipment washing and flushing; (2) an AC electrical supply of 220 volts and 50 amps (3 phase); (3) compressed air at 50 psig; and (4) low pressure process steam for the steam stripper. $\quad \mathrm{T} \mathrm{h} \mathrm{e}$ facilities will be attended daily by project personnel. Weekend coverage will be arranged with K-25 shift personnel. In addition, automatic shutdown is provided if the liquid level rises in the bottom of the bioreactor column, or if liquid accumulates in the drip pans provided beneath each skid unit. 


\section{PROCESS DESCRIPTION}

The bioreactor systems as shown in Figure 2.1, operate on the principle of co-metabolic degradation of TCE and associated contaminants. Microorganisms are grown in the bioreactor in the presence of oxygen and nutrients, with an added carbon source. Methane will be used as the carbon source in one of the bioreactors and toluene will be used in the other. Degradation of TCE occurs fortuitously during utilization of the carbon source. The effluent produced should have lower concentrations of the initial volatile organic contaminants (VOCs). 


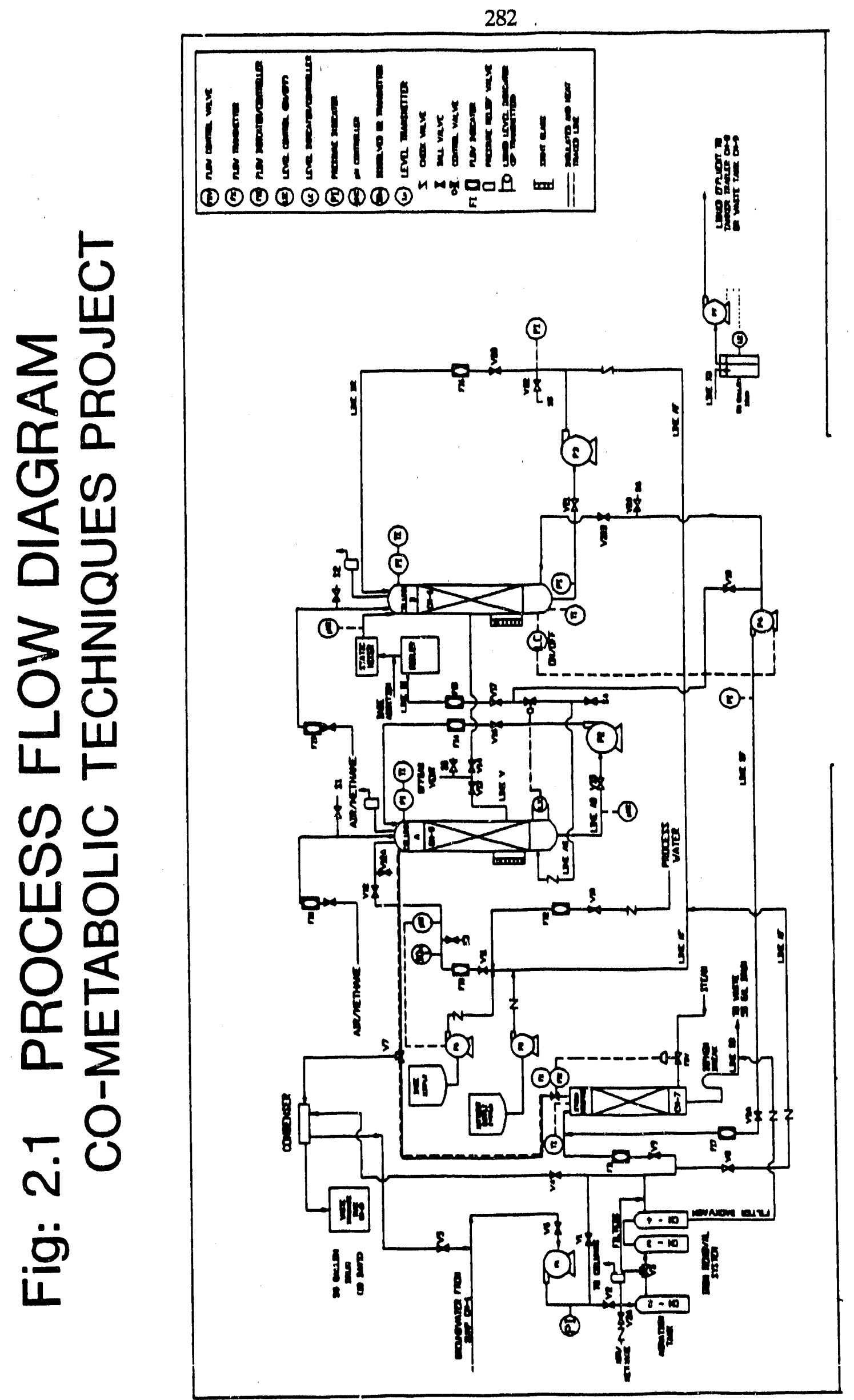




\section{PROGRAM MANAGEMENT}

The readiness review of the CMTFDF is managed by the K-25 Site manager, L. E. Hall; The K-25 Site Quality Assurance Department manager, E. L. Alread; and the CMTFDF project manager S. E. Herbes

\subsection{K-25 SITE MANAGER}

The Energy Systems Senior Representative for the CMTFDF project is L. E. Hall, K-25 Site manager. He will appoint a Readiness Review Board that will monitor the readiness of the CMTFDF and will make recommendations for proceeding to the required operating status.

\subsection{K-25 SITE QA DEPARTMENT MANAGER AND THE CMTFDF PROJECT MANAGER}

The K-25 Site Quality Assurance Department manager, E. L. Alread; and the CMTFDF project manager S. E. Herbes are responsible for determining whether the CMTFDF needs to undergo a formal readiness review, and they have identified the facility as needing this formal readiness review. They have appointed the Operational Readiness Team (ORT), which is directly responsible for monitoring the facility's readiness for operation. The CMTFDF Project Manager is responsible for evaluating the readiness review plan, coordinating the approval of the plan, and requesting that the RRB be convened to verify the CMTFDF readiness to proceed to the required operating status.

\section{THE READINESS REVIEW BOARD}

\subsubsection{The Readiness Review Board Charter}

The Readiness review board (RRB) is an independent management group appointed by upper level management. The group has been established to (1) provide independent oversight of the readiness process, (2) approve the readiness review plan and criteria, (3) verify the readiness process validity, (4) evaluate risk of proceeding to the next work activity and (5) recommend actions regarding proceeding supporter by readiness criteria.

\subsection{The Board Members}

W. A Miller, K-25 Quality Assurance Department, RRB Chairman

L. V. Gibson, K-25 Technical Services Department

C. C. Watson, K-25 Health, Safety and Environmental Division

\subsection{THE OPERATIONAL READINESS TEAM (ORT)}

\subsubsection{The Operational Readiness Team Charter}

The Operational Readiness Team is a management appointed multi-disciplined group that has been established to (1) evaluate the state of readiness of the CMTFDF to operate, (2) identify and validate supportive objective evidence of readiness, and (3) assist the program manager in presenting the evidence of readiness to the Readiness Review Board. Specific responsibiiities inciucic:

* Preparation of the readiness review plan 
- Use of appropriate analytical techniques to ensure full coverage of all activities

* Preparation of the readiness criteria

* Identification and verification of the visible objective evidence

- Monitoring and determining the state of readiness and reporting this information to K-25 Site Manager

* Presentations to the Readiness Review Board on the state of readiness

The milestones of the Team's activities will include the review of the evaluation of the readiness of facilities and equipment, the readiness of materials, the readiness of operating personnel and training, the readiness of plans, permits and procedures, and the readiness of support services.

\subsection{The Team Members}

The ORT members are:
B. R. Bailey
K-25 Site QA Specialist
T. L. Donaldson
CMTFDF Project Task Leader
S. E. Herbes
CMTFDF Project Manager
H. l. Jennings
CMTFDF Project Engineer

M.I. Morris

Demonstration Coordinator and ORT Chairman

\subsection{THE TEAM BOARD INTERFACE}

The ORT has the responsibility to provide the RRB with the verification data necessary to validate the readiness for proceeding to the next increment of work. The ORT will make this information available in progress reports and meetings held to review readiness.

The RRB will be responsible to review the data, evaluate the risks associated with operation, and make recommendations regarding the facility's readiness for operation. 


\section{THE REVIEW METHODOLOGY}

\subsection{THE OPERATIONAL READINESS PROCESS}

The Operational Readiness Process (ORP) is a management tool that establishes and verifies the state of readiness of an activity. The process began with the creation of this plan and the initial readiness criteria. Detailed criteria will be formulated by the team approved by the Board and carried out. The process concludes with the RRB's documented decision on the facility's state of readiness for operation and any accompanying recommendations that need to be addressed by the program management.

\subsection{THE READINESS REVIEW CRITERIA}

The readiness criteria are the standards by which the CMTFDF will be judged ready for operation. The review criteria are being defined according to their specific applicability to the activity, and the generic criteria have been defined for major milestones or events that need to be accomplished to determine readiness. The Operational Readiness Team used the comprehensive operational readiness tree (a positive logic tree), developed by Martin Marietta Energy Systems, Inc. using the basic readiness tree and lessons learned, to identify the readiness criteria.

\subsection{The Operational Readiness Tree for the CMTTDF}

The Operational Readiness Tree is being used by the ORT for identifying everything that needs to be evaluated to determine the facility's readiness for operation. This tree, which is shown in Fig. 4.1, is a tool that will guard against any omission of an item that could affect system performance.

\section{Readiness Review Criteria To Be Evaluated}

Specific review criteria to be evaluated will include an evaluation of the state of readiness of facilities and equipment, materials, manpower and training, plans and procedures, support services, and engineering activities. Included with these criteria are the primary responsible ORT members responsible for ensuring that these criteria/activities are completed.

These specific criteria for evaluation of the CMTFDF are provided in the appendixes as follows:

Appendix A: FACILITIES AND EQUIPMENT

Appendix B: MANAGERIAL/REGULATORY CONTROL SYSTEMS AND PROCEDURES

Appendix C: PERSONNEL 


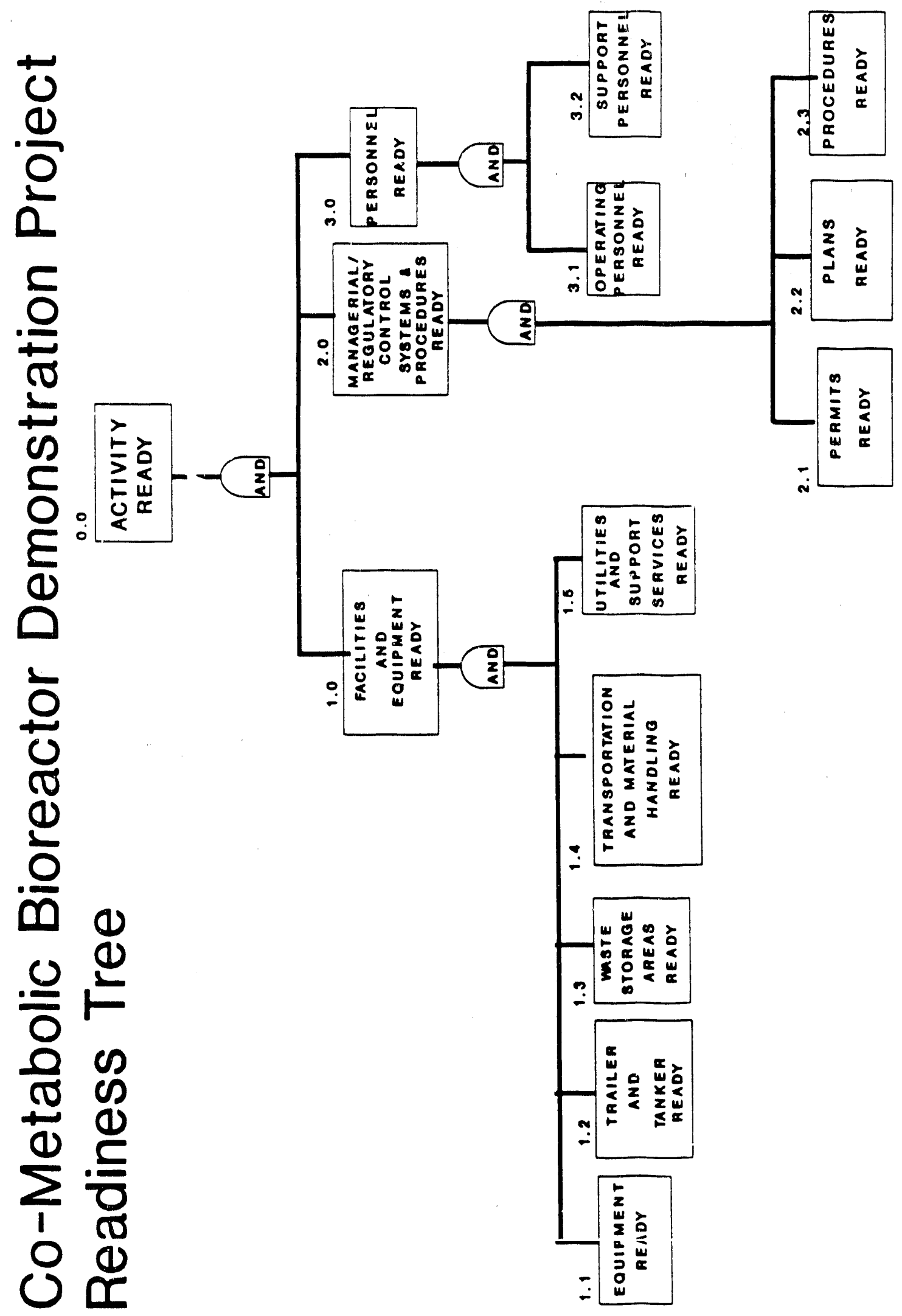




\section{APPENDIX A \\ READINESS REVIEW CRITERIA \\ for the \\ FACILITIES and EQUTPMENT, SECTION 1.0 \\ of the \\ CO-METABOLIC TECHNIQUES FIELD DEMONSTRATION FACIITTIES}

1.1 Is the equipment to be used in these facilities ready for operation based on the remaining criteria in section 1.1 ?

1.1.1 Has the equipment being used in these facilities been evaluated to ensure that OSHA regulations are being met? (K-25 Site Safety Engineer)

1.1.2 Has the applicable equipment being used in these facilities been calibrated and do calibration records exist? (Project Engineer)

1.1.3 Is the equipment being used in these facilities ready for operation based on the remaining criteria in section 1.1.3? (Project Engineer)

\subsubsection{Do drawings exist for the applicable equipment? (Project Engineer)}

1.1.3.2 Has the equipment been taken into consideration in the Safety Study (Safety Assessment)? (System Safety Engineer)

1.1.4 Has the equipment been installed properly based on the remaining criteria located in section 1.1.4?

1.1.4.1 Have the applicable equipment installation inspection reporis been issued? (QA Inspection Team Leader)

1.1.4.2 If applicable, have non-conformances associated with the installation inspections been resolved and are the resolutions documented? (QA Inspection Team Leader)

1.1.5 Have the equipment operational tests been completed based on the remaining criteria in section 1.1.1.5 and is documented evidence available?

1.1.5.1 Have the individual unit tests been completed for the applicable equipment? (Project Engineer)

1.1.5.2 Have the integrated tests been completed? (Project Engineer)

1.1.6 Have the equipment operating procedures been issued; are they available to the end user: and do they include the operational and design limits? (Project Engineer) 
1.1.7 Has all the equipment been marked/labeled and in agreement with the operating procedures? (Project Engineer)

1.2 Are the trailer and tanker ready for operation based on the remaining criteria in section 1.2

1.2.1 Is the trailer ready for operation based on the remaining criteria in section 1.2.1

1.2.1.1 Has the trailer been inspected to ensure that OSHA regulations are being met? (K-25 Site Safety Engineer)

1.2.1.2 Are the electrical systems in compliance with all applicable regulations and site requirements (ORNL Safety Engineer)

1.2.1.3 Does the HVAC systems meet all process requirements? (Project Engineer)

1.2.1.4 Is the trailer blocked and stable? (Project Engineer)

1.2.2 Is the tanker ready for operation based on the remaining criteria in section 1.2 .2

1.2.2.1 Has the tanker been inspected to ensure that DOT regulations are being met? (Transportation Inspection Department)

1.2.1.2 Has the tanker been hydrostaticly tested? (Transportation Inspection Department)

1.2.1.3 Has the tanker been grounded in the storage area? (Project Engineer)

1.3 Are the waste storage areas associated with these facilities ready based on the remaining criteria in section 1.3 ?

1.3.1 Are the applicable waste containers properly identified and stored per the applicable requirements? (Project Engineer)

1.3.2 Are the storage areas in compliance with EPA/MMES/OSHA requirements? (K-25 Site Environmental Compliance Manager)

1.4 Is the Transportation and Material Handling system to be utilized by the facilities ready for operation based on the remaining criteria in section 1.4 ?

1.4.1 Are there truck cabs qualified and available to haul the tanker to the CNF facility? (K-25 Waste Management Transportation Manager)

1.4.2 Are the drivers qualified to haul the tanker? (K-25 Site Waste Management Transportation Manager)

1.5 Are the Utilities and Support services to be utilized by these facilities ready for operation based on the remaining criteria in section 1.5 ? 
1.5.1 Has an adequate supply of electrical power been provided to the facilities and has it been tested to insure it is operational? (Project Engineer)

1.5.2 Does an adequate supply of required emergency equipment exist(fire extinguishers, protective equipment, etc.) at each facility and is this equipment easily accessible to the end user? (QA Inspection Team Leader)

1.5.3 Has an adequate supply of potable water been provided to the system and has it been tested to insure it is operational? (Project Engineer)

1.5.4 Have the applicable air supply systems (i.e., plant air, instrument air, breathing air, etc.) been supplied to these facilities and have the air supply systems been tested to ensure they are functional and operational? (Project Engineer)

1.5.5 Has the methane supply system been tested to ensure it is operational? (Project Engineer)

1.5.6 Has an adequate supply of steam been provided to the system and has it been tested to insure it is operational? (Project Engineer) 


\section{APPENDIX B \\ READINESS REVIEW CRITERIA \\ for the \\ MANAGERIAL/REGULATORY CONTROL SYSTEMS AND PROCEDURES, SECTION 20 of the CO-METABOLIC TECHNIQUES FIELD DEMONSTRATION FACILITIES}

2.1 Are the permits to be used for this project ready for operation based on the remaining criteria in section 2.1 ?

2.1.1 Has a NEPA determination been made and is the documentation in place? (Project Demonstration Coordinator)

2.1.2 Is an air permit required, and, if so, is it in place? (K-25 Site Environmental Compliance)

2.1.3 Has the NPDES permit for the CNF facility been revised to accept CMTFDF waste? (K-25 Site Environmental Compliance)

2.1.4 Have the waste storage areas been permitted? (K-25 Site Environmental Compliance)

2.1.5 Are there other permits required by EPA. TDHE, and/or MMES and are they in place? (K-25 Site Environmental Compliance)

2.1.6 Have Safety requirements been evaluated? (System Safety Engineer)

2.2 Are the Flans to be used for this project ready for operation based on the remaining criteria in section 2.2 ?

2.2.1 Have the Quality Assurance requirements been defined, procedures documented, approved, and made available at their point of use? (QA Specialist)

2.2.2 Have the Application Testing requirements been defined, procedures documented, approved, and made available at their point of use? (Project Demonstration Coordinator)

2.2.3 Have the Health and Safety requirements been defined, procedures documented, approved, and made available at their point of use? (Project Demonstration Coordinator)

2.2.4 Have the Waste Management requirements been defined, procedures documented, approved, and made available at their point of use? (Project Demonstration Coordinator) 
2.2.5 Have the Readiness Review requirements been defined, procedures documented, approved, and made available at their point of use? (Project Demonstration Coordinator)

2.2.6 Have the Contingency requirements been defined, procedures documented, approved, and made available at their point of use? (Project Demonstration Coordinator)

2.2.7 Have the Sampling requirements been defined, procedures documented, approved, and made available at their point of use? (Project Task Leader)

2.3 Are the procedures to be used for the project ready for operation based on the remaining criteria in section 2.3 ?

2.3.1 Have the equipment operating procedures been prepared, issued and available at their point of use? (Project Engineer)

2.3.2 Have the sampling procedures been prepared, issued and available at their point of use? (Project Engineer) 
September 9, 1991

\section{APPENDIX C \\ READINESS REVIEW CRITERIA \\ for the \\ PERSONNEL, SECTION 3.0 \\ of the \\ CO-METABOLIC TECHNIQUES FIELD DEMONSTRATION FACILITIES}

3.1 Are the operating personnel who will operate the equipment in these facilities ready for operation based on the remaining criteria in section 3.1 ?

3.1.1 Are operating personnel identified and available for the project? (Project Manager)

3.2.1 Are the operating personnel trained to operate this equipment based on the remaining criteria in section 3.2 .1 ?

3.2.1.1 Do the operating personnel have 24 hours of OSHA training within the last 12 months; if longer than 12 months then; do the operating personnel have 8 hours of OSHA update training within the last 12 months? (Project Manager)

3.2.1.2 Do the operating personnel have the $\mathrm{K}-25$ site general employee training (GET)? (K-25 Site training)

3.2.1.3 Have the operating personnel had the waste certification officer training? K25 site training)

3.2.1.4 Are there other training requirements, Governmental, MMES and/or site specific? (K-25 site training)

3.2.1.5 Do training records exist for all training received by the operating personnel? (ORNL site training)

3.1.3 Do the operating personnel meet the K-25 site security requirements? (K-25 Site Security)

3.2 Are the personnel who will support the operation of these facilities ready based on the remaining criteria in section 3.2 ?

3.2.1 Have K-25 laboratory services been notified and are they available and trained to support the project? (Project Manager)

3.2.2 Have K-25 Waste Management services been notified and are they available and trained to support the project? (Project Manager) 
3.2.3 Have K-25 Maintenance services been notified and are they available and trained to support the project? (Project Manager) 


\section{INTERNAL DISTRIBUTION}

\begin{tabular}{|c|c|}
\hline 1. & R. E. Adams \\
\hline 2. & R. K. Adkinsson \\
\hline 3. & M. B. Baer \\
\hline 4. & C. L. Baker \\
\hline 5. & L. D. Bates \\
\hline 6 & J. M. Begovich \\
\hline 7 & J. T. Bell \\
\hline 8. & C. E. Benson \\
\hline 9. & J. B. Berry \\
\hline 10. & W. D. Bostick \\
\hline 11. & D. J. Bostock \\
\hline 12. & T. A. Bowers \\
\hline 13 & K. Bracic \\
\hline 14. & J. T. Bradbury \\
\hline 15. & H. M. Braunstein \\
\hline 16. & W. A. Brooke \\
\hline 17. & C. H. Brown, Jr. \\
\hline 18. & V. J. Brumback \\
\hline 19. & R. D. Bundy \\
\hline 20. & G. E. Butterworth, III \\
\hline 21. & T. R. Butz \\
\hline 22. & C. H. Byers \\
\hline 23. & V. B. Campbell \\
\hline 24. & R. M. Canon \\
\hline 25. & H. M. Clancy \\
\hline 26. & O. K. Clotfelter \\
\hline 27. & S. J. Colburn \\
\hline 28. & E. D. Collins \\
\hline 29. & G. D. Conner \\
\hline 30. & K. W. Cook \\
\hline 31. & R. B. Craig \\
\hline 32. & A. G. Croff \\
\hline 33. & N. S. Dailey \\
\hline 34. & F. P. Delozier \\
\hline 35. & T. L. Donaldson \\
\hline 36. & N. W. Durfee \\
\hline 37. & R. S. Eby \\
\hline 38. & J. L. Epler \\
\hline 39. & R. L. Faulkner \\
\hline 40. & C. W. Francis \\
\hline 41. & C. E. Frye \\
\hline 42. & W. Fulkerson \\
\hline 43. & S. B. Garland \\
\hline & R. K. Genung \\
\hline & C. W. Gehrs \\
\hline
\end{tabular}

46. S. M. Gibson

47. L. V. Gibson, Jr.

48. R. W. Glass

49. N. G. Grant

50. R. G. Grubb

51. M. R. Guerin

52. R. Hall

53. W. R. Hamel

54. J. L. Haymore

55. F. K. Heacker

56. J. E. Heiskell, Jr.

57. H. M. Henson

58. S. E. Herbes

59. J. R. Hightowr

60. D. P. Hoffman

61. R. K. Holmes

62. C. L. Johnson

63. E. K. Johnson

64-73. R. L. Jolley

74. L. S. Jones

75. G. E. Kamp

76. J. M. Kennerly

77. B. L. Kimmel

78. R. R. Kimmitt

79. J. W. Koger

80. A. J. Kuhaida, Jr.

81. D. B. Lloyd

82. L. W. Long

83. R. Machanoff

84-93. A. P. Malinauskas

94-99. C. P. McGinnis

100. S. A. Meacham

101. L. J. Mezga

102. R. P. Migun

103. R. E. Millemann

104. T. H. Monk

105-114. M. I. Morris

115. E. B. Munday

116. J. M. Napier

117. B. D. Patton

118. G. A. Person

119. C. H. Peterson

120. K. E. Plummer

121. J. G. Pruett

122. D. R. Reichle 
123. E. J. Roy

124. Don Schaefferkoetter

125. Chuck Scheibly

126-128. R. M. Schilling

129. S. L. Schrock

130. C. D. Scott

131. J. W. Shaw

132. M. J. Shelton

133. R. L. Siegrist

134. D. W. Simmons

135-144. S. P. N. Singh

145 R. L. Snipes

146. B. P. Spalding

147. A. E. Stephens

148. R. E. Swatzell

149-158. D. W. Swindle

159. T. Tamura

160. W. W. Thompson
161. S. D. Van Hoesen

162. R. I. Van Hook

163. T. Vo-Dinh

164. E. A. Wachter

164-174. J. S. Watson

175. H. D. Whitehead, Jr.

176. J. H. Wilson

177. H. R. Yook

178. Central Research Library

179. Document Reference Section

180 - 181. Laboratory Records

182. Laboratory Records - RC

183 ORNL Patent Section - RC

184. EMD Document Management

Center

185-193. ER Document Management

Center

\section{EXTERNAL DISTRIBUTION}

194. W. D. Adams, DOE, FOB, Rm. 2116, Oak Ridge, TN 37830

195. T. D. Anderson, U.S. DOE Headquarters, Trevion Bldg. II, Suite 400, 12800 Middlebrook Road, Germantown, MD 20874

196. W. R. Bibb, DOE, FOB, Rm. 309, Oak Ridge, TN 37830

197. R. E. Blake, Portsmouth Plant, P. O. Box 628, Piketon, OH 45661

198. D. G. Cope, PGDP, P.O. Box 1410, C743-1, MS-105A, Paducah, KY 42001

199. P. H. Edmonds, Radian, 120 S. Jefferson Circle, Oak Ridge, TN 37830

200. Clyde Frank, EG\&G, Tri-County, MS-7606

201. C. S. Gist, DOE, FOB, Rm. 2116, Oak Ridge, TN 37830

202. S. T. Grady, SAIC, 800 Oak Ridge Turnpike, Oak Ridge, TN 37830

203. M. R. Jugan, DOE, FOB, Rm. 2116, Oak Ridge, TN 37830

204. M. Lankford, U.S. DOE Headquarters, Trevion Bldg. II, Suite 400, 12800 Middlebrook Road, Germantown, MD 20874

205. Tom Mayfield, FEDC, MS 8218, Oak Ridge, TN 37830

206. J. P. Moore, DOE-OR, P.O. Box 2001, Oak Ridge, TN 37831

207. T. Myrick, SAIC, 800 Oak Ridge Turnpike, Oak Ridge, TN 37830

208. W. L. Richards, PGDP, P.O. Box 1410, C743-TO1, Paducah, KY 42001

209. R. C. Sleeman, DOE, FOB, Rm. 216, Oak Ridge, TN 37830

210. R. H. Snyder, Portsmouth Plant, P. O. Box 628, Piketon, OH 45661

211. Office of Assistant Manager, Energy Research and Development, DOE-OR, P.O. Box 2001, Oak Ridge, TN 37831

212- Office of Scientific and Technical Information, P.O. Box 62, Oak Ridge, TN 37831 

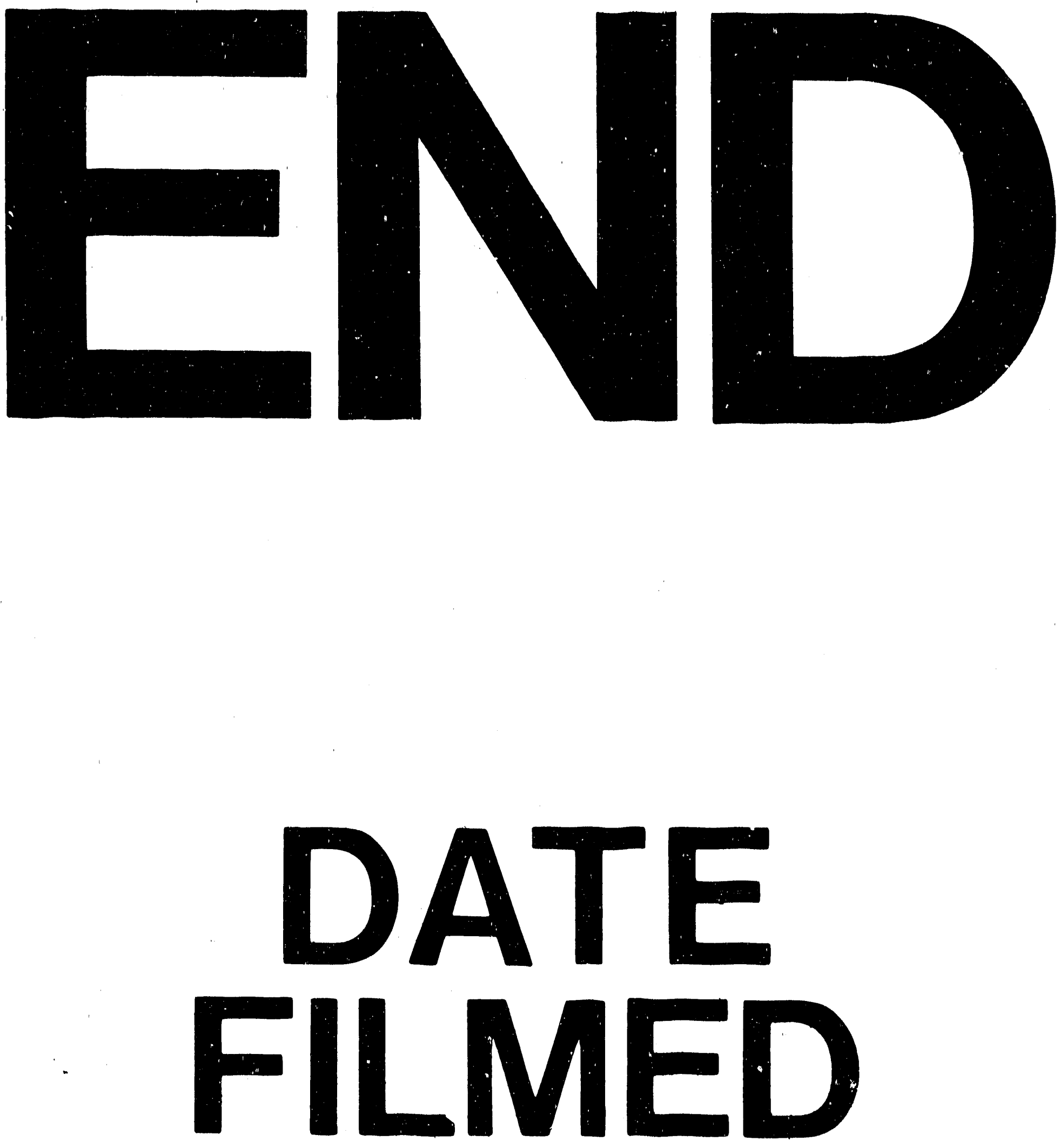

1

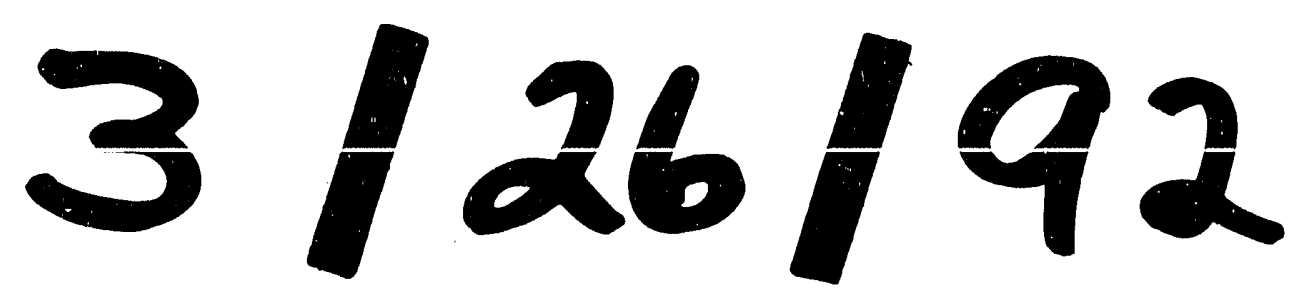

